GENRE GAMES: EDWARD GOREY'S PLAY WITH GENERIC FORM

BY

EDEN LEE LACKNER

\begin{abstract}
A thesis
submitted to the Victoria University of Wellington

in fulfilment of the requirements for the degree of

Doctor of Philosophy
\end{abstract}

Victoria University of Wellington

2015

Page 1 of 216 
Page 2 of 216 


\section{ABSTRACT \\ Genre Games: Edward Gorey's Play with Generic Form}

This thesis examines Edward Gorey's play with form and content across five literary genres, how that play results in the style that has come to be known as the "Goreyesque" and how the Goreyesque has influenced later artists and writers. Gorey consistently places style ahead of thematic and moral considerations, removing the purpose of each genre to reveal what remains in its absence. In doing so, Gorey maps out the boundaries of each form, providing genre- and period-specific details that act as signposts to how his audience should approach each narrative. With these markers in place, Gorey's readers are thus made aware of which genre expectations rule each piece. These expectations, however, are undermined as Gorey removes the audience-understood literary endgame, so that the work appears in all respects to be an accurate representation of the chosen genre, yet is missing the central heart.

Gorey's melodramas present scenarios in which deep familial loss and suffering are at the forefront of each narrative, yet as a result of the distance that Gorey places between the text and his readers, these works ultimately lack sentimentality. His Dickensian narratives, while populated with virtuous orphans and embittered, isolated men, lack moral pronouncements and just rewards, resulting in exceptionally bleak, nihilistic endings that provide little or no social commentary. His children's literature, although full of mnemonic systems, rejects all pedagogical functions in favour of inviting in adult audiences to luxuriate in sound and linguistic form. His mystery and detective fiction, while containing secrets, crimes and criminals, ignores any pretence of decoding the central mysteries. His Gothic horror revels in supernatural excesses, yet engenders no fear. By tracing Gorey's play with genre, we can identify the aesthetic parameters of the Goreyesque, and examine how they manifest in the works of other artists and writers, notably Tim Burton, Neil Gaiman and Roman Dirge.

In manipulating genre expectations, Gorey does more than simply leave readers with the shell of narrative purpose. Instead, he draws attention to the absence and pushes beyond expectation to reinvention. He normalizes the strange and fantastic by removing the very things that make the ordinary extraordinary. He infuses his works with a distance that shifts their purpose from generating high emotion and strong reactions to encouraging minute 
attention to narrative detail. Gorey's fantasies therefore represent odd, underwhelming moments that are otherwise ignored in the search for the uncommon and unique. By underplaying the significance of the events in his stories, Gorey represents and refreshes our concepts of the fantastic, and highlights the strangeness in the overlooked. 


\section{ACKNOWLEDGEMENTS}

I would like to express my heartfelt thanks to my supervisors, Dr. Anna Jackson and Dr. Jane Stafford, who have not only been instrumental in helping me shape my thesis and further develop my research skills, but who also always had an insightful word at the ready, and who helped this Canadian, so far from home, feel a little less alone. My thanks also to my exam committee for their thoughtful and insightful readings of my thesis and an exceptionally pleasant oral exam, and the School of English, Film, Theatre and Media Studies and Victoria University as a whole for their unflagging support, financial and otherwise, throughout my program.

I would also like to thank my friends and colleagues in The International Association for the Fantastic in the Arts. They have been so supportive and warm throughout this entire process, from the moment I began attending the conference as a wide-eyed M.A. student, to my years as a wandering Independent Scholar, to the stress-filled, tear-filled, fear-filled Ph.D. years. Whether they offered a moment of kindness, a long-lasting friendship, or an exceptional academic opportunity, I am grateful for each and every one of them.

No acknowledgment would be complete without thanking my parents, Mr. Conrad Peter Lackner and Dr. Sharron Lee Harper Lackner, for their unflagging support throughout my entire life. They are the ones who instilled the importance of a good education in me, and who have always encouraged me to follow my dreams, sharpen my skills, and keep a level head. My father taught me to plan for the future, all the while stressing the importance of being an outstanding student...even if that meant "out standing in the hall." My mother lead by example, going back to school while I was in elementary, and ultimately becoming the first person on her side of the family to hold a Ph.D. It is because of her that I believed I could attain the same heights, and also why I spent many of my formative years happily banging around the University of Calgary Sociology Department, sitting in on her classes after my own school was done for the day. This thesis is in her honour. I miss you every day, Mum. 
Page 6 of 216 


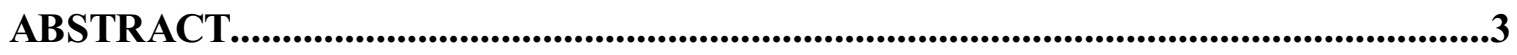

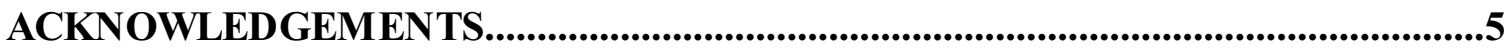

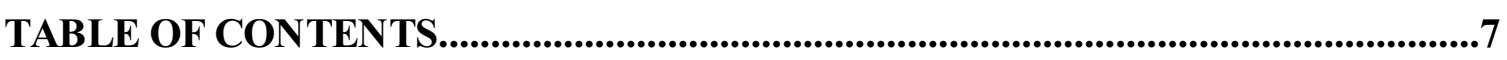

CHAPTER ONE: EDWARD GOREY UNDER REVIEW......................................9

CHAPTER TWO: HEARTLESS MELODRAMA..................................................29

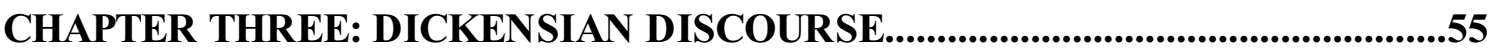

CHAPTER FOUR: PEDAGOGICAL NONSENSE....................................................81

CHAPTER FIVE: CLUELESS DETECTIVES................................................................107

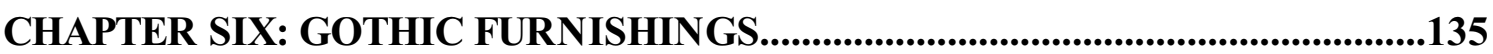

CHAPTER SEVEN: ODDLY INFLUENTIAL_................................................163

CHAPTER EIGHT: STRANGELY OVERLOOKED........................................189

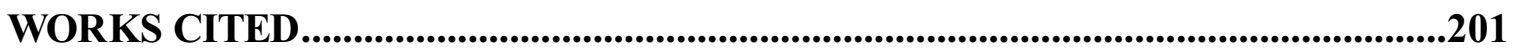


Page 8 of 216 


\section{Chapter 1: Edward Gorey Under Review}

Edward Gorey (1925-2000), twentieth century American illustrator and writer, wrote over one hundred distinct narratives over the course of his career. He also illustrated the works of numerous other authors, including both interior illustrations and covers, and was involved in stage, costume and graphic design. Gorey's work employs obvious and exaggerated genre features, which figure into his consistent placement of style ahead of thematic and moral considerations. Where genres such as melodrama, detective fiction and horror adhere to particular predictable narrative patterns, conventional characters and reassuring moral conclusions, Gorey's texts remove or interrupt these patterns, present aberrant or anarchic characters, and withhold any moral outcomes. In doing so, Gorey maps out the boundaries of each genre, providing genre- and period-specific details that act as signposts to how his audience should approach each narrative. With these markers in place, Gorey's readers are thus made aware of which genre expectations rule each piece. These expectations, however, are undermined as Gorey removes any understood literary endgame the work appears in all respects to be an accurate representation of the chosen genre, yet is missing the central, moral heart present in the nineteenth century genres on which he draws. His Dickensian narratives, while populated with virtuous orphans and embittered, isolated men, lack moral pronouncements or just rewards. His melodramas, despite representations of deep familial loss and suffering, are devoid of emotion and sentimentality. Regardless of the preponderance of supernatural violence, Gorey's Gothic horror tales engender no fear. His mystery and detective fiction, while containing secrets, crimes and criminals, ignore any pretence of decoding the central mysteries. His children's literature, although full of mnemonic systems, rejects all pedagogical functions. Instead, Gorey finds humour in tragedy, surreality and mundanity alike.

This thesis will consider select texts from Gorey's larger collection of works in light of five distinct period-specific genres: melodrama, the Dickensian, children's literature, mystery and detective fiction, and Gothic horror. In each chapter, close examination of representative narratives informed by genre-specific research will delineate what tropes Gorey references and how his treatment of them highlights - and undermines - generic norms. It is this Goreyesque treatment of genre that produces the waning of affect, depthlessness, and the replacement of a sense of "history" with what Fredric Jameson calls a "historicism" closely 
linked with pastiche. Already in the 1950s and 1960s, Gorey's work clearly fits the "cultural logic of late capitalism" first identified by Jameson in 1984. By considering Gorey's play with genre, we can develop a clearer sense of how his influence on other artists and writers manifests in a continuation of the manipulation of genre in particular ways that contribute to a larger aesthetic we know as the Goreyesque. As a result, this thesis will provide a general overview of the pervasiveness of his style and thematics across a significant subsection of twentieth and twenty-first century literature and art, culminating in three detailed close readings of artists whose works owe a large debt to Gorey: Roman Dirge, Neil Gaiman, and Tim Burton.

As Gorey is most concerned with removing meaning in order to play with genre tropes in isolation, his work stresses surfaces and style over all else. This focus is what is meant by the "Goreyesque." It is a particular aesthetic - often with morbid or surreal overtones - in which style takes precedence over content. Most often, it is used as a descriptive touchstone through which to link artists' works to Gorey. For instance, the Empire Magazine's review of Tim Burton's Corpse Bride (2005) points out that "[v]isually, Burton is at his most Edward Gorey-esque in the austere, storybook Victorian land of the living" (EmpireOnline.com.au). Daniel Handler's (aka Lemony Snicket's) A Series of Unfortunate Events, both as a book series (1999) and a movie (2004), are just as often categorized as Goreyesque, as demonstrated by Cleolinda Jones' review of Snicket's first three novels, in which she says, "The world [the Baudelaire orphans] live in--perhaps this perception is aided by Brett Helquist's Gorey-esque illustrations--seems gloriously quaint and old-fashioned, despite occasional references to telephones and fax machines" (DailyDigest.net); and Bob Strauss' Globe and Mail movie review, in which he explains that, "[s]hot entirely on sound stages, $[A$ Series of Unfortunate Events] takes place in an Edward Gorey-esque Otherworld that, while not technically a realm of the supernatural, shares a disquieting/delightful psychic dimension with the Friendly Ghost's haunted house" (TheGlobeandMail.com).

Although the Goreyesque most often denotes a work descending from Gorey's artistic legacy, it can also be used to trace Gorey's artistic antecedents, as in the case of the description of a "Gorey-esque 1880s photo show[ing] wing-collared, frock-coated Peabody assistants grouped sullenly around one of [Othniel Charles] Marsh's boulder-sized thunder beast skulls" (94) in David Rains Wallace's paleontological text, Beasts of Eden: Walking Whales, Dawn Horses, and Other Enigmas of Mammal Evolution (2005). These Goreyesque 
antecedents are strong indicators of Gorey's pronounced usage of nineteenth century aesthetic compositions and tropes which are echoed not only in his own illustrations, but in those of other, later Goreyesque artists.

Regardless of the fact that Gorey is a twentieth century artist and not a Victorian, the genres he most consistently employs are those associated with the nineteenth century. The Dickensian comes from conventions laid down by Charles Dickens; melodrama reached incredible heights of popularity during the same time period; the rise of organized police forces resulted in the development of detective fiction; as notions of what defined a "proper" childhood raged, Victorian children's literature hovered between the punitive teaching texts of previous eras and the pure entertainment of nonsense verse; and Gothic fiction remained a strong, popular literary force, resulting in the development of the Victorian Gothic.

Embedded within Gorey's texts are particular popular notions of the nineteenth century. Indeed, he has been thought of as a Victorian writer. As Alexander Theroux notes, "most newcomers to [Gorey's] work tend to think that he is a long-dead Victorian illustrator" (The Strange Case of Edward Gorey 60), as his illustrations evoke a strong sense of a place and time long past. He uses the style and ambience of the nineteenth century in order to set the stage for his genre play. His children wear formal clothes at all times, from sailor suits and pinafores to bonnets and giant hair bows. Gloves are omnipresent, and ladies and gentlemen dress for dinner. Each room is adorned in ornate furnishings, complex tapestries, wallpapers, and thick, heavy curtains. The Gashlycrumb Tinies (1963) suggests an 1850s setting through the children's various clothes, including a boy in a nightshirt - nightshirts having fallen out of fashion in the 1890s - and the preponderance of Gothic artwork. Likewise, the bell, available for the purpose of ringing for service; the cobblestone streets; and the presence of a steam engine act as markers of historical place within the work. The Retrieved Locket (1994) reflects the fashions of the 1860s, from cardigans and bow ties to turtlenecks and ankle boots, and includes photography, a pasttime that became more accessible to the populace in the 1860s. Additionally, a police officer appears in The Retrieved Locket, marking the rise of organized police forces in England. The Pious Infant (1966) gives us 1870s gentlemen in top hats and spats with heavy facial hair, and women's dresses shockingly without bustles, yet still sporting high collars. The Disrespectful Summons (1973) and The Loathsome Couple (1977) both provide visions of the 1890s, as the characters wear boater hats and bowlers, the fashions turning away from the heavier fabrics of 
earlier decades and into the lighter colours and cloth that characterize the beginning of the twentieth century. The Loathsome Couple even integrates factories, cinemas, cornflakes, grape soda, trams and vans, all of which date back to the $1890 \mathrm{~s}^{1}$.

Yet even in the midst of such period-specificity, Gorey does not cleave to Victorian realities. He often includes anachronistic details, such as the canvas shoes the creature wears in The Doubtful Guest (1957) - a shoe not mass produced until the early twentieth century in the midst of a late nineteenth century setting - subtly signalling the piece's modernity. What is most extraordinary about Gorey's drawings is how carefully they represent modern misconceptions of historic places over cleaving to historical accuracy, mixing era-specific stereotypes with anachronisms. The nineteenth century is Gorey's framework upon which he builds his narratives, but much as he uses the trappings of genres while removing their central narrative purposes, Gorey uses this historical framing as a way to explore popular modern conceptions of the era rather than attempting to faithfully represent nineteenth century life. He constructs settings in which the audience is presented with a simulacrum of the nineteenth century, yet these locations are often so remote and self-contained as to seal themselves off from significant historical touchstones which might otherwise influence or drive the plot. Gorey's narratives, therefore, give the impression of pseudo-nineteenth century bubbles somehow caught outside of time. The town the characters visit in The Headless Bust: A Melancholy Meditation on the False Millennium (1999) lacks any logical layout, a confusing mix of directions that do not truly relate one to the other. The town is also firmly outside of the reach of any other geographic locale, just as most of Gorey's texts take place entirely within a mansion's grounds, the walls of a house, or strangely depopulated nearby streets. There is a strong and disorienting sense of disruption of boundaries - both physical and generic - carried throughout Gorey's oeuvre. His tales are of unnamed countries anchored to sometimes faulty, sometimes idealized memories of the past.

${ }^{1}$ Beginning with the 1900 s and reaching as far into the twentieth century as the 1960 s and 1970s, Gorey does place other texts later in time as well: including The Hapless Child (1961) and The Green Beads (1978), both set in the 1900s; The Beastly Baby (1962), The Other Statue (1968) and The Glorious Nosebleed (1975), set near 1910; The Willowdale Handcar (1962), The Gilded Bat (1967), Serious Life: A Cruise (1992) and The Deadly Blotter (1997) all taking place in the Roaring Twenties; The Blue Aspic (1968) representing the 1930s; and The Curious Sofa (1961) taking place in the 1960s. These twentieth centuryset works, however, are far fewer in number. 
The growth of Neo-Victorian Studies - arising out of the popularity of Neo-Victorian fiction in the 1990s and 2000s - suggests that texts are beginning to reference a "Victorianism" that is less about historical reality and more regarding a set of literary and stylistic conventions. In "What is Neo-Victorian Studies?" (2008), Mark Llewellyn explains that Neo-Victorianism

is not contemporary literature as a substitute for the nineteenth century but as a mediator into the experience of reading the 'real' thing; after all, neo-Victorian texts are, in the main, processes of writing that act out the results of reading the Victorians and their literary productions. (168)

Twenty-first century Neo-Victorianism is thus a movement that seeks to engage with and highlight our recollections of the past as filtered through and referenced by art. It pinpoints those literary markers that are most recognizably "Victorian" - such as orphaned children and pitiless guardians - and explores their resonances in the nineteenth century and the eras that follow. Llewellyn regards this "period fetishism" as

a fact of our contemporary culture; that in bookstores and TV guides all around us what we see is the 'nostalgic tug' that the (quasi-)Victorian exerts on the mainstream identification of our own time as a period in search of its past.

Neo-Victorianism and Gorey share this fascination with nineteenth century tropes outside of their true historical contexts, potentially positioning Gorey as a proto-Neo-Victorian. Yet despite Gorey's exploration of the trappings of the nineteenth century, study of his work is noticeably absent from most Neo-Victorian spaces. Neo-Victorian Studies, the central academic journal for such criticism, features a variety of articles on twentieth and twenty-first century artists, yet Gorey is not within their ranks. In fact, the journal's second volume of 2011 (4.2) carried Kara M. Manning's article, '"That's the Effect of Living Backwards': Technological Change, Lewis Carroll's Alice Books, and Tim Burton's Alice in Wonderland," which considers the ways in which Carroll's Alice has been adapted to film, with specific focus on the Neo-Victorian aspects of Burton's 2010 Alice in Wonderland. This article is significant in that it is about how Burton fits into a Neo-Victorian framework, and Burton is an artist who is strongly associated with and influenced by Gorey. Additionally, NeoVictorian Studies' 2012 special issue The Other Dickens: Neo-Victorian Appropriation and Adaptation (5.2), which is concerned with adaptations of Dickens in the post-nineteenth 
century artistic landscape, does not include Gorey's texts either. Given Gorey's implicit ${ }^{2}$ and explicit references to Dickens throughout the full course of his oeuvre, the dearth of Dickensian criticism referencing Gorey is noticeable.

Gorey's use of Victorian elements to explore a series of tropes rather than historical reality speaks to a proto-Neo-Victorianism, preceding the establishment of Neo-Victorian conventions. These tropes, combined with his own aesthetics and thematic preferences, set an early distinctive Goreyesque standard that is a significant influence on later artists. These Gorey-influenced artists pair text and illustration, deliberately evoking this Goreyesque aesthetic; that is, they employ specific characteristics that echo Gorey's own works: primarily black and white visuals, spot colour for emphasis, human figures drawn to evoke certain characteristics or inner lives rather than realistic representations, a heavy use of shading and shadow, and an interest in archaic or historical details, often anachronistically. They evoke the stylistic markers that Gorey uses to great effect to distance the narrative from its readers. These works often juxtapose innocence with evil in a way that lacks a moral or just impetus. The characters are often children: while Gorey's works are not all about children, his most popular texts are, making child characters a touchstone for Goreyesque artists.

A broad variety of artists have been influenced by Gorey, from writers and illustrators to film and television creators, tabletop and video game makers, fashion designers and musicians. As Gorey's generic manipulation is central to his narratives, it is useful to explore how those artists he has influenced also play with genre. While filmmaker Tim Burton's stopmotion animated films such as The Nightmare Before Christmas (1993), Corpse Bride (2005) and Frankenweenie (2012) are the most prominent examples of Gorey's influence, Gorey's aesthetic spreads far further both within Burton's oeuvre and throughout other artists' endeavours. Burton is not the only filmmaker to be influenced by Gorey. David Lynch, known for such dark and surrealistic fare as Eraserhead (1977), Blue Velvet (1986) and Twin Peaks (1990), frequently employs inexplicable, amoral happenings alongside monstrous children, violent adults and supernatural events. Alongside a wide variety of horrors, Lynch's films often employ a similar style of humour to Gorey's own: simultaneously absurd and

${ }^{2}$ Implicit references include those in such texts as The Hapless Child (1961) and The Green Beads (1978), and explicit references such as the whole of both The Haunted Tea-Cosy (1998) and The Headless Bust (1999), as they directly engage with Dickens' A Christmas Carol (1843). 
tragic, affording significant emotional distance between his characters and audience. His films require decoding by active audiences, resisting the passivity afforded by straightforward, clear narratives, and echoing Gorey's twisting tales which expect readers to work to identify and connect implications with events in order to accurately follow and understand the progress of his stories. Just as Gorey's The Other Statue (1968) must be viewed carefully in order to tease out the full murder mystery, including who the victim, suspects, and perpetrators are, Lynch's television series Twin Peaks leads the audience on a complex, convoluted journey punctuated by obscure scenes and enigmatic characters, and culminating in a supernatural cliffhanger. Like Gorey, Lynch's filmic visions often showcase worlds in which tragedies happen without reason or moral purpose.

For Angus Oblong, however, Gorey's influence manifests in a far more cheerful fashion. His book, Creepy Susie and 13 Other Tragic Tales for Troubled Children (collected 2004) and the subsequent television adaptation The Oblongs (2001) takes much of Gorey's stark, surrealistic style and adapts it to a carefree world in which tragedy still strikes without reason, but at the same time, the perpetrators of extreme violence are often the protagonists who are acting out merely because they are confused, annoyed, or frustrated, their violent acts culminating in a release of and relief from negative emotions. While Creepy Susie is a collection of self-contained short stories and The Oblongs is an episodic television show in which the characters and scenario remain consistent from week to week, each medium showcases stories of physical and sexual violence acted out by shared characters. Creepy Susie's narratives are almost entirely free of morals, many illustrating revenge fantasies - such as Helga's infiltration and eventual murder of a popular but cruel group of girls known as "The Debbies" in a short story of the same name - or random fits of pique by its child characters - such as when Creepy Susie herself, in a tale titled with her name, kills the boy who has a crush on her because she has no idea how to handle her feelings regarding him. The Oblongs instead focusses on the misadventures of Milo Oblong - who is referenced in the Creepy Susie story "Milo's Disorder" - and his friends and family. The violence of The Oblongs is more casual than that of Creepy Susie, manifesting instead from ill-thought-out plans and slapstick scenarios. Throughout both the book and the television series, however, Gorey's aesthetic remains in place, as Oblong makes use of high contrast black and white and surrealistic character design, his thematics concerned with mutations, monsters and mortality. The text which accompanies each short story in Creepy Susie makes use of Gorey's 
techniques of rhyme, brevity and suggestion, pairing short sentences or verses with illustrations which expand on and elucidate the larger tale. Although The Oblongs brings far more colour and dialogue to his characters in their televised form, the basic frame is maintained: clearly defined drawn lines and wilfully oblique statements which work together to create ostensibly human, yet fatally flawed characters who psychologically embody their physical mutations and wreak havoc without the nuisance of long-term consequences.

Oblong is not the only creator to take a similar positive tack in tackling Gorey on television. Long-running animated show The Simpsons (1989) has elicited Gorey's aesthetic on more than one occasion. "Yokel Chords," the fourteenth episode of the eighteenth season, embeds the Goreyesque tale of "Dark Stanley" within the framing narrative of the rest of the episode. In an effort to frighten fellow students, Bart Simpson creates an impromptu urban legend in which cafeteria worker Stanley DeGroot is teased by students for failing to graduate from college: they chant, "Stanley, Stanley, no degree. Two credits short at MIT," as he grows increasingly angry. The tale culminates in Stanley snapping, murdering the children who taunted him, and making "kids' head soup" out of them. Dark Stanley's story is not quite fifty seconds long, but in that time the writers and animators of The Simpsons create a distinctly Gorey world; one which they invoke again five seasons later. "The D'oh-cial Network," the eleventh episode of their twenty-third season, ends with an extra-narrative tale titled "A Simpsons 'Show's Too Short' Story." While it shares the same characters as every episode of The Simpsons, unlike Dark Stanley's nested narrative in "Yokel Chords," "A Simpsons 'Show's Too Short' Story" has no ties to the larger plotline of "The D'oh-cial Network," existing instead as an independent story crafted to fill an excess minute and thirtyfour seconds at the end of the main show. Within that minute and thirty-four seconds, however, is a short which shows an impressive grasp of the qualities that make a story Goreyesque. The backgrounds against which the characters move in both "A Simpsons 'Show's Too Short' Story" and the tale of Dark Stanley are rife with cross-hatching and linework that delineates and darkens each scene, the colours primarily leeched out of the Simpsons' world while the characters themselves are composed in muted tones. Their normally large, bright eyes are narrowed down to small, black spheres, their pupils the single point standing in for the whole eye. Both narratives are morbidly comic: Dark Stanley's story of bullying and cannibalism is framed as a campfire tale, bookended by a beginning in which Bart holds a flashlight under his face and an ending in which the cafeteria lights suddenly shut 
off, inciting mass panic. Conversely, "A Simpsons 'Show's Too Short' Story" uses poetic verse to lighten and distance the viewer from the destruction and mayhem Bart visits on all the people in his life. In this latter narrative, the vocabulary choices and rhythmic structure including Bart's "day at school, engulfed in ennui," a reference to Neville's death from ennui in The Gashlycrumb Tinies (1963) - mimic Gorey's textual choices, and the concluding scene, in which the characters in their more familiar incarnations gather around Principal Skinner, makes the connection tangible, as Skinner reads from a red hardcover book titled Somewhat Gorey Stories.

The Simpsons' Gorey homage also highlights Gorey's link with the musical world. "The D'oh-cial Network" concludes with a version of the ending theme covered by The Tiger Lillies, a cabaret group of whom Gorey himself was fond. Towards the end of his life, Gorey sent the band a package of unpublished material, some of which they selected and adapted into thirteen tracks on their album, The Gorey End (2003), unfortunately completed and released after Gorey's death. The Tiger Lillies are not the only musical group influenced by Gorey, as Nine Inch Nails' video of their single, "The Perfect Drug" (1997), directed by Mark Romanek, heavily incorporates Gorey's aesthetics: the primary colour palette is muted, black the most prominent colour, with washes of blue and green which highlight, rather than define the various scenes; the characters within the video stand in tableaux, movement minimized in favour of rigid, portrait-like poses; and direct references to Gorey's works, including a body lying prone behind a large decorative stone vase, only his or her legs visible, a broken obelisk, and a young child dressed in Edwardian clothing sitting on a bench in front of a large painting. Amanda Palmer, who began in the Dresden Dolls and now operates as an independent musician, collaborated with Neil Gaiman and a selection of photographers on a book called Who Killed Amanda Palmer: A Collection of Photographic Evidence (2009), a companion to her album of the same name. The book consists of a set of short stories paired with staged photographs in which Palmer has died in a variety of ways. This repetition of her death throughout the book's pages paired with the irreverent, anachronistic settings and costuming falls in line with such pieces as Gorey's The Gashlycrumb Tinies, in which every frame presents a new death to the viewer.

Novelist Daniel Handler, better known as Lemony Snicket, captures Gorey's sense of gloom and despair in his children's novels, A Series of Unfortunate Events. In this series, three children, the Baudelaire orphans, must make their way in the world after losing their 
parents in a horrible accident and realizing that their abusive guardian, Count Olaf, is only after their fortune. Handler's writing in these thirteen books contains sly humour that upends the terrible tragedies the children have faced, embeds vocabulary-building pedagogical moments, and acknowledges the metatextual divide between story and audience, hallmarks of Handler's works that can be traced back to Gorey's influences. Handler himself recognizes this link alongside an important observation regarding Gorey's growing visibility as an artist. He says,

When I was first writing "A Series of Unfortunate Events," I was wandering around everywhere saying, "I am a complete rip-off of Edward Gorey," and everyone said, "Who's that?" Now, everyone says, "That's right, you are a complete rip-off of Edward Gorey." (Dery)

Although Handler's stories are more sparsely illustrated than Gorey's heavily visual-oriented narratives, Handler's writing voice is a strong example of Goreyesque writing. He balances fantastical, awe-inspiring events with mundane and depressing observations that, when taken as a whole, evoke such Gorey tales as The Hapless Child, The Evil Garden and The Epileptic Bicycle.

Unsurprisingly, alternative comics have also been influenced by Gorey. Most notably, Jhonen Vasquez, creator of Johnny the Homicidal Maniac (circa 1990), and many of his colleague at Slave Labor Graphics write and draw Goreyesque graphic novels. This publishing house puts out a number of Gothic-themed surrealistic black and white comic books where tragedy and comedy exist side-by-side, realism is subsumed under style and the fourth wall is very thin. Despite not existing within traditional book publishing paradigms, graphic novels such as those put out by Slave Labor are the natural successors to Gorey's work. Although often containing less subtle comedy and more gruesome violence, their format, themes, stylistic choices and overall atmosphere continue Gorey's legacy. This legacy is not tied exclusively to Slave Labor Graphics, either, as demonstrated by other comic properties, including Rob Reiger's Emily the Strange (1991), a line of merchandise and comic books revolving around a young goth girl and her odd adventures. Gorey's influence is not solely restricted to English-language texts, either, as evidenced by works such as El joven 
Lovecraft $t^{3}$ (2008) - a compendium of sequential art illustrating the fictionalized younger years of H.P. Lovecraft, appropriately filled with (comedic) eldritch horrors - by Spanish artists José Oliver and Bartolo Torres, and Billy Brouillard: Le don de trouble vue $e^{4}(2008)-\mathrm{a}$ bestiary, story and poetry collection in which the title character, a young clairvoyant boy, navigates the secret grotesqueries of the world - by French artist Guillaume Bianco. In fact, as he begins the process of translation, Billy Broullard's English-language translator, Edward Gauvin, directly refers to the text as, "Edward Gorey meets Calvin \& Hobbes."

Gorey's literary influence also surfaces in some unconventional places. In marking Gorey's eighty-eighth birthday on February 22, 2013, Google's "Google Doodle feature[d] Gorey-esque cartoons spelling out the search giant's name" (Telegraph.co.uk). The entire premise of the card game Gloom (2004) - in which players each choose a predetermined fictional Edwardian family as their own and then play modifying cards from their hands to make their family as sad and downtrodden as possible while attempting to cheer up and change the bad fortunes of opponents' families - melds the inevitability of mortality with the sly humour of Gorey's works. It also encourages players to participate in collaborative storytelling, as an optional device to explain the tragedies and triumphs visited on each other's characters, and thus facilitates a more active audience. As Gorey's tales often acknowledge the role of the author and therefore peer out at the audience, so too does Gloom invite each player to move past the random, preset risks provided by the pre-printed cards in favour of taking on interpretive roles. Likewise, tabletop and casual video games such as ROBOX Studio's Grimm: Ride of the Perambulator (2007), in which the player pilots a baby and carriage through a sidescrolling Victorian landscape filled with danger, and Playdead's $L I M B O(2010)$, a platformer in which the player guides an unnamed boy through an otherwordly forest in search of his sister, make use of the stark Gorey aesthetic alongside distressing, tragic tales with child protagonists. Fashion designers Anna Sui and Kambriel have drawn inspiration from Gorey for some of their pieces, Sui referencing Gorey's silhouettes in one of her late 1990s evening dress collections, and Kambriel not only

\footnotetext{
${ }^{3}$ Translated into English by Carla Diaz Juhl and Emer Cassidy, and published as Young Lovecraft (2009).

${ }^{4}$ Translated into English by Edward Gauvin, and published as Billy Fog and the Gift of Trouble Sight (2011).
} 
designing Gorey-inspired clothing such as her men's Gorey Coat, but also holding Goreythemed shows, participating in a Goreyesque Halloween charity ball (2007) and designing costumes for the Snappy Dance Theater's production of The Temperamental Wobble (2004), a touring performance composed of short Gorey-inspired pieces.

Outside of original Gorey-inspired texts, there is a strong base of fans who directly interact with Gorey's material in creative ways. Some construct costumes to wear at fan events or during Halloween that replicate characters from the Gorey universe, such as the Gashlycrumb Tinies or the women from Gorey's animated opening to the Public Broadcasting Service's (PBS) Mystery! series. Some fans create Gorey-themed cakes, or get Gorey tattoos, and there are a world of artistic parodies and homages available on the internet that meld Gorey's most famous work with other favourite fandoms, including: a Lord of the Rings mashup, The Khazad-dum Tinies; The Gashlycrumb Hobbit; the video game-inspired The Game Over Tinies; a Doctor Who version, The Gallifreycrumb Tinies; a Harry Potter adaptation, The Hogwarts Tinies or, After the Rowling; and through the medium of Twitter, the Chaucerian Gashelyecrumbe Worthyes. FanFiction.net (www.fanfiction.net) and the Archive of Our Own (archiveofourown.org), popular multi-fandom repositories of fan fiction, house a combined total of forty-five works either referencing or directly engaging with Gorey ${ }^{5}$. Many of these stories are creative riffs on The Gashlycrumb Tinies, expanding the text and exploring the children's fates in more detail, but others meld Goreyesque elements and structures such as vocabulary, rhythm, tone, rhyme scheme and plot points with other media properties. In these cases, Gorey's works serve as touchstones and templates for fanwritten adventures in Les Miserables (1862), various versions of Sherlock Holmes (1887), The Addams Family (1938), The Chronicles of Narnia (1950), Teen Titans (1964), Star Wars (1977), The Cain Saga (1991), Resident Evil (1996), Buffy: The Vampire Slayer (1997), Harry Potter (1997), Angel (1999), Bleach (2001), Fullmetal Alchemist (2001), the Inheritance Cycle (2001), Jonathan Strange \& Mr Norrell (2004), Avatar: The Last Airbender (2005), Supernatural (2005), Metalocalypse (2006), Inception (2010), and The Losers (2010). In one notable instance, there is even a story of a fictionalized conversation

${ }^{5}$ While forty-five Gorey-inspired stories is a small number compared to fandoms such as Supernatural (2005) and the Marvel comic, television and movie universe, which have 72 890 and 76234 stories respectively archived on the Archive of Our Own, it still indicates the presence of a modest but dedicated following in fan fiction circles. 
between Frank O'Hara and Edward Gorey. Taken together, the variety of other texts Gorey fans inject with the Goreyesque reflects his widespread influence.

On learning that Gorey was a Star Trek fan, but had never seen the famous episode, "The Trouble with Tribbles," Shaenon K. Garrity took the opportunity to create a nine panel tale which recreates the episode as if it had been adapted by Gorey himself. Kate Beaton, an artist best known for her webcomic, Hark! A Vagrant, has periodically referenced Goreyillustrated book covers and reimagined their inner narratives based solely on those covers. Francesco Marciuliano, current writer for syndicated newspaper comic strip Sally Forth and sole creator of webcomic Medium Large, references Gorey in a strip in the latter work showcasing a twenty-seventh Gashlycrumb Tiny, positioning this new character as the only one who escaped Death. Multimedia artist Matt Duplessie has animated The Gashlycrumb Tinies, working with the elements of each panel and adding voiceovers and atmospheric sounds to create an online video that builds on Gorey's humour and makes room for Duplessie's own interpretations of the circumstances of each child's death. Even more recently - and certainly a marker of Gorey's growing popularity - online corporate giant Google marked Gorey's eighty-eighth birthday (February 22, 2013) by featuring Goreyinspired art in their Google Doodle, which is a temporary alteration of their logo on their search engine front page (and its regional mirrors) in order to mark notable events, people and holidays.

Regardless of the often small print runs of his first editions and subsequent lack of reprintings that were the hallmark of most of his career, Gorey's audience has grown organically, without substantial or high-profile marketing or promotion. Currently, he is in the process of being discovered by a wider audience, as his texts are being increasingly brought back into print in larger numbers than their initial print runs and as the profiles of those artists he has influenced rises. As Gorey's popularity continues to grow, his influence will continue to spread, and that fact will result in even more literature and artwork being informed by his aesthetics.

Despite the breadth of his influence on other artists, criticism of Gorey does little to establish the distinctiveness and significance of his work. He is woefully underrepresented in anthologies. He does not appear in The Bedford Anthology of American Literature (2008), The Norton Anthology of American Literature (2011), nor The Heath Anthology of American Literature (2013), although this is presumably attributable to these anthologies focussing on 
poetry and prose rather than more visual mediums. Yet neither does Gorey appear in graphic novel anthologies: not either volume of An Anthology of Graphic Fiction, Cartoons, and True Stories $(2006,2008)$, nor any of the volumes of The Best American Comics (2006-2013) ${ }^{6}$. At this point, scholarly study of graphic novels and sequential art is still new, so as academically-focussed graphic fiction anthologies continue to proliferate, there may be far more opportunities to trace the development of such a visual medium. Regardless, Scott McCloud's Understanding Comics: The Invisible Art (1994), one of the first full-length texts to seriously consider the history, development and meaning of sequential art as an art form, does include Gorey as an important part of the medium's development. While the mention is quick, as McCloud moves quickly into theory and methodology and away from an enumeration of illustrators and comic book artists, it is presented in a way that highlights Gorey's prominence and echoes his penchant for embedding meaning in his visuals that fleshes out the accompanying text. McCloud does not explicitly embed Gorey's name in his text, but rather presents his own illustrated avatar, standing in front of a wall filled with the covers of various artists who are best known as illustrators, commercial artists, and cartoonists. Alongside Shel Silverstein, Jules Fieffer and Raymond Briggs is a copy of Amphigorey, the first anthology collecting together a number of Gorey's published works. McCloud's avatar gestures directly at Amphigorey, giving it prominence within the panel.

Alongside the lack of Gorey's representation within academically-focussed anthologies is the small amount of critical work on his texts. A significant amount of this research is primarily biographical. In order to properly pursue a literary review of criticism pertaining to Gorey, the reader must comb through a number of magazine profiles, obituaries and commercial book reviews before unearthing academic commentary. Many critical works mention Gorey in passing, or use him as a contextualizing or comparative figure in larger studies of other artists ${ }^{7}$ rather than providing an in-depth examination of Gorey's works.

${ }^{6}$ Gorey's omission from The Best American Comics may be attributable to the anthology's function as a curated list of notable graphic novels within its year of publication, yet 2006's Amphigorey Again included previously unpublished material that would have been eligible and, in concert with their publishers, the Edward Gorey Estate continues to release Gorey's previously unseen works alongside new editions of familiar texts.

${ }^{7}$ For examples of Gorey's inclusion as a contextualizing or comparative figure, see Brian Dillon's exploration of Samuel Becket's influence: "Stirrings Still" in Modern Painters (04/2006, 68-71) and Steven Heller's article, "Peter Sís, Children's Book Author and 
While such articles lack sustained explication of Gorey's works, they do, however, add to the growing evidence of his influence on twentieth and twenty-first century art.

By far the largest available pool of Gorey discussion is of a biographical nature. Profiles abound, including Donald Weeks' "Portfolio: Edward Gorey" (1979), Carol Stevens' "An American Original" (1988), Robert Wyke's "Dark Star" (2009) and Carol Verburg's Edward Gorey On Stage: Playwright, Director, Designer, Performer: a Multimedia Memoir (2012). Notably, Alexander Theroux, a personal friend of Gorey, published his biographical account, The Strange Case of Edward Gorey (2000), shortly after Gorey's death in 2000. Within the slim volume's pages, Theroux offers an in depth account of a personal side of Gorey which was out of reach of many interviewers, given that Gorey was notoriously solitary. Theroux provides a detailed account of Gorey's life, beginning with his birth and childhood through his education and early life, and into his short service as a Company Clerk for the United States Army near the end of World War II. The bulk of the biography acts as a personal recollection of Gorey's opinions, habits and preferences, peppered with publication histories and brief considerations of Gorey's various texts, both from Theroux's and Gorey's own point of view. The sheer breadth of sources influencing Gorey's own work is on display in The Strange Case, as Theroux recounts which popular movies, television shows and advertisements Gorey was especially fond of, juxtaposing those with Gorey's background in French language and literature, silent film, ballet, nineteenth century English literature, and pre-twentieth century art. While this biography provides an excellent breadth of knowledge of Gorey's life and artistic background, Theroux's personal reminiscences of his friendship with Gorey take centre stage, and it is thus primarily useful in providing contextualizing background details of a very private man's life.

Karen Wilkin is currently the most widely-published Gorey expert, so it is no surprise that her three books, taken together, provide a wider breadth of insight into Gorey's narrative art than any other author's text. As a consequence, with each new publication, Wilkin moves further away from narrating Gorey's life and more towards a full explication of his body of work. Yet there is still much duplication within each of Wilkin's publications, as she devotes a great deal of space to (re)introducing her audience to the man each time. This need for repetition is an interesting mirror of Gorey's subcultural status, as despite his continually

Illustrator" in Print (05/2004, Volume 58, Issue 3, 30-162). 
growing audience, his name has yet to achieve widespread recognition. Additionally, most of Wilkin's texts focus on presenting a wide variety of samples of Gorey's art. With the exception of Ascending Peculiarity: Edward Gorey on Edward Gorey (2001), Wilkin provides a short introduction or discussion of Gorey, while more than half, and oftentimes as much as two thirds of the publication is a carefully curated collection of reproductions and plates. Although this approach does bring Gorey's art to the forefront and allows for side-byside comparisons which bring to light many of his idiosyncrasities and oft-visited themes, it tends to shorten the space for explication or examination of those characteristics with both an eye to larger career-spanning features and smaller single-work-specific details.

Wilkin's first Gorey text, The World of Edward Gorey (original publication 1996), is a collaboration with Clifford Ross, marrying biographical information and critical engagement with his artwork. Ross' interview - later republished in Ascending Peculiarity - begins the text. This interview is primarily devoted to Gorey's artistic influences, and delves into his creative process. It is fairly in-depth in regards to Gorey's artistic knowledge, and does not spend much time lingering on personal details that do not directly impact his art, Ross preferring instead to discuss Surrealism, Gustave Flaubert, pen nibs, the drawing process and television sitcoms with Gorey. As a result, the interview is a treasure-trove of glimpses into Gorey's view of his own art and his ambivalence towards categorization. Directly after this interview is Wilkin's explication of Gorey's stylistics, "Mr. Earbrass Jots Down a Few Visual Notes." Wilkin dedicates the largest portion of text to providing an overview of Gorey's oeuvre, exploring his overall style, themes and atmosphere. She is careful to include his work as an illustrator for other writers and his contributions to the theatrical world alongside his own texts. The World of Edward Gorey is significant in that it is one of the first large-scale book projects to explore Gorey's art in detail with an eye to cataloguing the great number of influences on which he draws.

Wilkin's expertise lie with art rather than text, and her knowledge is on full display here, as she runs the gamut of Gorey's works, delving into each with a weathered eye and broad toolkit of artists. Especially useful is how she mixes biographical information into this essay; in her other texts, there is much more of a divide between Gorey the individual and Gorey the creator, but in "Mr. Earbrass Jots Down a Few Visual Notes," she uses personal details to further deepen her exploration of his art rather than prioritizing the private man over the public artist. The World of Edward Gorey is further enhanced by a great number of 
reproductions of Gorey's illustrations, interspersed in the text to correspond with related discussions and as examples of particular modes or mediums. Yet the explicit dialogue with his creative ventures truncates on page 113, as instead Ross and Wilkins devote the rest of the text to plates of Gorey's various works with no commentary beyond names, dimensions, and publication dates. Although many are mentioned in the main text - and while they make for interesting viewing - there is a palpable dialectic vacancy within this section. The text then closes out with a timeline of Gorey's life, thrusting the biographical impulse back to the forefront. Regardless, The World of Edward Gorey is one of the most in-depth Gorey resources currently available when looking for direct engagement with his stories.

Conversely, Ascending Peculiarity, Wilkin's second Gorey text and the first anthology of interviews, is an excellent resource for quotations directly from the artist himself. It collects twenty-one lengthy interviews with Gorey conducted over twenty-five years, the earliest from 1973, and the latest from 1999, the year before his death. The interviews are organized chronologically, facilitating the natural progression and outgrowth of Gorey's opinions and viewpoints. They illustrate Gorey's sometimes shifting, contradictory approach to his own art, his firm statements as to what he is trying to achieve and for whom he is attempting to write at odds with statements of confusion and ambivalence to intent, audience, and significance. By curating these interviews and collecting them all together, Wilkin constructs a loose autobiographical timeline, stitched out of Gorey's responses to a number of interviewers on a plethora of topics. Wilkin presents these interviews with little outside commentary other than an introduction which touches on a mix of little-known, well-known and oft-repeated biographical details. As well, this introduction concerns itself primarily with Gorey's reactions to interviewers and being interviewed, and only skims the surface of his works. The interviews themselves provide more useful depth. They are for a variety of markets, and while all tackle the topic of Gorey as a writer, there is also room for discussion of his balletomania, his interest in film and television, his views on political, economic and social structures, and his influences, both conscious and unconscious.

Elegant Enigmas: The Art of Edward Gorey (2009), is the one of Wilkin's works that moves the most fully away from a biographical recounting of Gorey's life. The introduction, however, revisits much of the same ground as her other Gorey texts, beginning with a generalized description of his fanbase, and then moving on to a short explication of his life and opinions. Yet there is a quick turn towards the analytic, as Wilkin dedicates most of the 
text in the book to discussion of Gorey's craft, primarily focussing on his artistic style and the minutia of his illustrations over his narratives. Wilkin provides an in-depth overview of Gorey's career, and despite asserting that Gorey cannot be categorized, she very firmly situates his texts in a pseudo-Victorian world. Wilkin's discourse with Gorey's tales then truncates on page 36 , moving over in favour of seventy-nine pages of plates.

Moreso than The World of Edward Gorey or Ascending Peculiarity, Elegant Enigmas is a straightforward presentation of illustrative plates. Wilkin does, however, contextualize Gorey's cult status, highlighting the divide between Gorey's readers and the lack of widespread knowledge of his work outside of his dedicated following. Additionally, where The World of Edward Gorey had no discussion within the plates section, Elegant Enigmas offers more, with quotes from the narratives that accompany each illustration, unfinished pieces and previously unpublished plates; however, these short bursts of text are very sparse, and only engage with a very small number of the reproductions. Nevertheless, what is most remarkable about this book is the previously unpublished series of seven illustrated envelopes towards the end of the plates (104-6). These envelopes are the result of correspondence for his mother during his Harvard attendance. As they are early on in his career, they are most notable in how close they are to his more mature style; a through line between Gorey's early and late artistic career, and evidence of an extraordinary stability of style.

Another significant entry in the recording of Gorey's legacy is Kevin McDermott's Elephant House, or The Home of Edward Gorey (2003). As with Wilkin and Theroux, McDermott has a personal connection to Gorey, as he "met [him] in 1985, on [McDermott's] twenty-first birthday" as he began what would be decades of involvement with staged theatrical productions based on Gorey's texts (5). This association is significant, as all the major Gorey publications are spearheaded by those most invested in maintaining his legacy not only as an artist, but also a man. In this vein, Elephant House is very much a coffee table book that marries large, glossy photos of its subject with personal reminiscences and observations on the house and how its architecture and interior design reflect Gorey's aesthetics. Further, McDermott skilfully chooses Gorey's own elephantine artwork, narrative passages and interview quotes, interspersing them amongst the pages to even more explicitly show these linkages. There is very little overt analysis to Elephant House, however, as it focusses primarily on photographic presentation, the content and layout of Gorey's home, and 
anecdotal tales. It is therefore most useful as a proxy for primary source material, a way into Gorey's physical artistic environment without travelling to Massachusetts.

In addition to these full-length books, there are a handful of critical academic articles on Gorey available. Some, like Kazuya Okada and Shuri Okano's "Rhyme Dictionary of Edward Gorey" (2005) - a guide to the way Gorey uses syllabication and rhyme within the Amphigorey series - are exceptionally focussed on linguistics, and in Okada and Okano's case, their research culminates in a dictionary which lists the frequency with which Gorey uses certain words. Others, like Victor Kennedy's "Mystery! Unraveling Edward Gorey's Tangled Web of Visual Metaphor" (1993) - in which Kennedy considers Gorey's illustrations within the realm of metaphor, and compares his art to other artists - spend more time on close readings of particular texts with an eye to their meanings. Mark T. Rusch's "The Deranged Episode: Ironic Dissimulation in the Domestic Scenes of Edward Gorey's Short Stories" (2004) studies Gorey's use of irony in a selection of texts; Wim Tigges' chapter 'The Limerick: The Sonnet of Nonsense?" in Explorations in the Field of Nonsense (1987) compares Gorey's and Edward Lear's limericks and their relation to studies of Nonsense literature; A. Robin Hoffman's "G is for Gorey Who Kills Children" (2005) looks at his representations of childhood mortality and their relation to the pleasure to be found by readers in horror; and Zofia Kolbuszewska's "A Graphic Story of Writing a Novel: (Pe)R(e)verse Ekphrasis in Edward Gorey's 'The Unstrung Harp'" in The Lives of Texts: Exploring the Metaphor (2012) explores Gorey's medium-blurring rhetorical strategies with reference to Mr. Earbrass' attempts to write a novel. A few academics take a wider view when studying Gorey, considering him in terms of his relation to larger genre- and period-spanning thematics. Katherine R. Bailey's 2012 dissertation, "Appropriations from the 19th Century and the Topic of Death in Modern Gothic Narratives: Edward Gorey, Walt Disney, and Tim Burton" looks at the relationship between humour and death in Victorian texts and the twentieth and twenty-first century Gothic narrative traditions that spring from those roots; Derek Bainton's "Urban Legends" (2011) places Gorey's The Wuggly Ump amongst a group of works which excel at evoking a specificity of place in their pieces, and discusses their relation to the depiction of modern urban life; and Edward Bradford, the Edward Gorey Charitable Trust's official bibliographer, focusses on the specifics of Gorey's postcard and envelope art in "Separate Unity" (2012), exploring his fascination with postal illustration. 
These articles provide a base upon which the study of Gorey can - and continues to - grow as his art becomes more recognized by both academic and popular spaces.

Yet while these studies do essential work of considering textual and theoretical meanings in Gorey's oeuvre, they do not contribute to understanding what is meant by the Goreyesque, how Gorey has forged such an influential aesthetic, nor how his work might be understood in a postmodern context. It is my contention that you cannot understand the Goreyesque without understanding the essential importance of genre to his work. Therefore, this thesis looks at a selection of significant, recurring genres within Gorey's body of work the Dickensian, melodrama, mystery and detective fiction, Gothic horror and children's literature - and how Gorey uses their defining tropes to explore the limits of each form. Gorey focusses on this form over morals or meaning, actively removing these messages from his narratives. When genre is stripped of its meaning, however, what is left? Gorey's play with genre tropes absent of their associated moral messages and purposes has the effect of upending genre expectations entirely. The paranormal becomes normal, and fantasy becomes mundane. Gorey's fantasies aren't spectacular or sublime. They are ordinary moments that are often ignored in the search for extraordinary experiences. They are the underwhelming, the ignored, the odd. Therefore, that distance, the way no stock is put in the strange and horrifying, underlines the tendency for narrative and audience alike to overlook what is truly surprising. By underplaying the significance of the events in his stories, Gorey represents and refreshes our concepts of the fantastic. This is what we mean when we talk of the Goreyesque, and I conclude the thesis by looking at how it operates when other writers and artists put the Goreyesque into play in their own works, focussing on select texts by Roman Dirge, Neil Gaiman and Tim Burton. 


\section{Chapter 2: Heartless Melodrama}

Melodrama is a mainstay of Gorey's texts. His pared-down narrative voice - in which plotlines are reduced to their most significant elements and communicated in short sentences alongside a handful of illustrations depicting the most dramatic moments in each tale - is melodramatic by design. Each tale is organized around a series of climaxes rather than rising and falling actions, which intensifies the narrative tone. By removing all but the most important events and moments from each story, Gorey heightens the emotions involved. His stories include such tropes as tragic orphans, heartless villains, mistaken identities, starcrossed lovers and lost fortunes, yet most do not end with those orphans finding family, love and fortune, the villains being punished, nor the lovers reuniting to live happy lives together.

Although melodrama intersects with a number of distinctive genres - such as mystery, romance, and children's literature - it distinguishes itself with its reliance on excess and sentimentalism. Indeed, melodrama relies on emotional excesses of all kinds. It is "a mode of high emotionalism and stark ethical conflict that is neither comic nor tragic in persons, structure, intent, effect" (Brooks 12). It was on the nineteenth century stage that melodrama first rose to prominence: "[i]t dominated...Western theatre for prolonged periods and throughout the century virtually monopolized the spoken stage of the popular theatre" (Rahill xiii). The grand gestures of theatrical melodrama translate over into melodramatic novels, providing readers with tales of heightened emotion, heroic suffering, tragic loss, and ultimately (morally) rewarding endings. Within melodrama, good and evil are highly personalized: they are assigned to, they inhabit persons who indeed have no psychological complexity but who are strongly characterized. Most notably, evil is villainy; it is a swarthy, cape-enveloped man with a deep voice. Good and evil can be named as persons are named - and melodramas tend in fact to move towards a clear nomination of the moral universe. (Brooks 16-7)

They are deeply connected to the upholding or restoration of morality within their narratives, using high emotion and sensationalism to draw in the audience and raise the stakes for their characters. Indeed, the stark differences between good and evil characters - making them instantly recognizable to the audience - helps to bolster the strict delineation of moral from immoral, and rewards from punishments. 
The nineteenth century melodramatic novel assumes a particular audience who is well-versed in melodramatic tropes. As Anna Jones explains in "A Victim in Search of A Torturer: Reading Masochism in Wilkie Collins's No Name," the ideal Victorian reading public is, among other things, "primed by widespread sensational journalism to expect hidden crimes in the domestic sphere; and...well-conditioned to respond to the affective stimuli of the sensation novel" (197). Nineteenth century melodrama therefore relies on the knowledge of its audience in its excitation of sentiment and emotion. In general, twentieth and twentyfirst century literature, however, expects a jaded audience who will identify with morallyambiguous characters, accept ethically-compromised decisions, and question overly idealized characterizations, shifting melodrama out of the realm of printed fiction. For instance, popular twentieth and twenty-first century novels Lolita (1955) and Life of Pi (2001) both employ melodramatic tropes of emotionalism, sensationalism and ethical conundrums, yet their narratives are entirely suspect. Vladimir Nabokov's Lolita is written entirely from the point of view of unreliable narrator (and child abuser) Humbert Humbert, who paints a version of Dolores Haze which may not be based on any facts whatsoever; and Yann Martel's Life of Pi (2001) undermines the first version of Pi Patel's story of survival after a shipwreck, in which animals fall prey to each other, with a second version in which humans are murdered and cannibalized, refusing to give either version a greater weight of truth over the other. Readers of both of these novels are expected to question their narratives and read against the text rather than accept their sensational plots.

While melodrama is therefore more closely associated with nineteenth century literature and theatre than modern literature, it has not disappeared entirely in later eras. Although it is present across genres and mediums, it most strongly manifests in our popular entertainment. Detective novels, historical fiction, epic fantasy, space and soap operas, and police procedurals provide melodramatic outlets for their audiences. When considering the ebb and flow of genre film and television,

[i]f modern mass entertainment is so dominated by a limited number of fixed sub-genres - police story, western, hospital drama — it is because these offer the clearest possible repertoires of melodramatic conflict. They provide an easy identification of villains and heroes (who can often be recognized simply by uniform), of menace and salvation. They give a set of situations in which virtue can be held prisoner, made supine and helpless, while evil goes on the 
rampage, and they offer highly exteriorized versions of its vindication and triumph. (Brooks 204)

Therefore, while it is tempting to consider all post-nineteenth century melodrama as parody, that viewpoint does not take into account the prevalence of melodrama within popular culture.

Modern English-language melodrama is now most strongly represented by soap operas and other daytime drama television shows, where the focus is on an excitation of feeling through the unspooling of tragic circumstances rather than morality triumphing over immorality. Although soaps like Coronation Street (1960), Days of Our Lives (1965) and Shortland Street (1992) often feature storylines in which good characters face off with evil ones, the nature of such scripted television requires storylines to continue indefinitely (barring actors leaving or being written off the series), leaving little room for satisfactorily definitive endings in which a character who has experienced a great deal of tragedy or personal suffering receives a morally-uplifting reward. Instead, while major characters may experience moments of respite, they will find themselves drawn into a new crisis or beset with a new source of suffering shortly thereafter. The nature of television as a medium also allows for soap operas to make use of the more visual, theatrical elements at melodrama's roots, displaying

melodrama's gradual consolidation of action, its development of everincreasing capabilities for compressive shock and intensive absorptive display, and its increasingly forceful and systematic exploitation of the unsettled emotional states that such techniques produced. (Buckley 182)

Soap opera plots therefore move forward on waves of sensationalism and emotion, enticing their audiences through the promise of ever-increasing stakes, and provide an outlet for melodramatic tales that are otherwise rejected by modern literature.

Texts with strong visual elements, such as Gorey's illustrated narratives, can take advantage of the theatrical nature of melodrama by providing strong tableaux that communicate sensational and climactic moments. Gorey's melodramas make use of the contrasts between great emotion and utter stillnesses, each panel echoing these theatrical tableaux that showcase moments of high emotion, such as the instant before the death of a loved one, the discovery of a body, the escape of an imprisoned orphan, or the search for a lost object. His narratives present these instants of high emotion, which appear on the surface 
to be the precursors to melodramatic resolutions, yet ultimately they lack the genre's expected emotional catharsis, creating a distance between the text and its readers. Gorey's characters are equally as removed from the audience, as he renders them in such quick, short detail that they exist primarily as archetypes rather than strongly characterized individuals with whom the audience can empathize and identify. In Gorey's texts, heightened tragedy and senseless endings invoke melodrama, but the empathetic distance is so great that such high emotion provokes laughter over pity and pathos.

Regardless, even in the face of these missing resolutions and characterization touchstones, Gorey's manipulation of melodramatic characteristics is deft. The Green Beads (1978) plays with the melodrama of downtrodden fictionalized families, wealthy lost relatives, and fortune-changing discoveries that underpin so many theatrical and novelized treatments of this type, including Isaac Pocock's The Miller and his Men (1813), Wilkie Collins' The Woman in White (1859), Ellen Wood's East Lynne (1861), and Mary Elizabeth Braddon's Lady Audley's Secret (1862). Alongside his mother and sister, Little Tancred - the protagonist of this tale - has fallen on hard times through a series of misfortunes that underline the harsh social structure of the nineteenth century. While Gorey does not immediately spell out the cause of Tancred and his family's poverty - distancing his narrative from sympathy and sentimentality by initially denying the audience the sensational details of the family's individual tragedy - he quickly reveals the fracturing events through both textual and visual means. In panel nine ${ }^{8}$, Gorey provides a flashback in which we see mother, sister and brother dressed elegantly, denoting their wealth and status: Tancred's mother is clothed from top to bottom in a neat herringbone outfit, striped stockings, shiny shoes, proper gloves, an impressively (and excessively) large feathered hat and accompanying tasselled purse; his sister, Tiny Clorinda, wears a tidy coat with ornamental half-belt, gloves, stockings, shoes and a wide-brimmed hat with long, trailing accent ribbon; and Tancred himself has on a tweed coat with back vent, a clean white-collared shirt, stockings and shoes, and a boater hat with

${ }^{8}$ Most of Gorey's texts lack page numbers, and the number of panels per page changes depending on whether the text is published singularly or as part of an anthology. Therefore, in the interests of simplicity and clarity, I have chosen to reference panels, not pages, starting from the first panel after the cover, frontispiece, title page and/or introductory materials and counting forward from there. Thus " $1 "$ is the first panel of the narrative, " 2 " the second, and so on, to the end of the tale. 
striped brim. All three of them sport tidily groomed hair, and Tancred's mother holds a spyglass with which she watches the loss of her mother-in-law as the ship she is on, the Moon of Valparaiso, sinks in the bay. While the narration does not explicitly detail the breadth of the fortune they lose, each of these visual details - including the spyglass, an item made of extremely expensive components - suggests a wealthy family.

Although these details allow the reader to draw conclusions regarding all Tancred's family loses, the lack of tangible signposts of their wealth outside of this single illustration omits a key element of the melodrama. The exact height from which the family must fall, and the depth of their suffering are brushed aside as minor concerns in the face of the stark facts of the case. In doing so, Gorey further trivializes the tragedies to which Tancred's family is subject. He treats the details as unimportant; the narrative thus carries an air of detachment that segues into the sudden and amoral ending. There is no reward or punishment in store for the characters; the tale simply ends without a satisfying resolution.

For Gorey, there is no comfortable middle; loss occurs completely, or not at all. As Mark T. Rusch says in "The Deranged Episode: Ironic Dissimulation in the Domestic Scenes of Edward Gorey's Short Stories," Gorey's texts reflect a "fondness for portraying only the dirt poor and the extravagantly wealthy; there is rarely any middle ground in terms of social class" (447), and there is certainly no middle ground for Tancred's family. In panel ten, an illustration of the direct aftermath of the loss of the Baroness von Rettig, the wealth that Gorey hints at is already slipping away. Although Tancred's mother still wears the herringbone skirt, shoes and stockings, she is now missing gloves and lacks any head adornment other than a long, thin scarf. Instead of a full mourning outfit of sombre, stylish black, her sole piece of black clothing is a simple tunic. In fact, the continuance of the skirt from one panel to the next not only underlines the immediacy of her husband's death, but also the sudden turn in fortune, as she is abruptly without the means to purchase new mourning clothing, having to make do with what she has. Tancred himself shows signs of poverty: his smart shirt and jacket have been replaced with a simple shift, and he too is without gloves and hat. Further, the only offering he has to leave at his father's grave is a single flower in an oversized jar, rather than a large bouquet in a suitable vase. It is a very short slide from these initial misfortunes to their living conditions three years later, as in every other panel in which Tancred appears, he is clad in the clothes he wore at his father's graveside. Similarly, his mother still wears her black tunic and scarf, yet even the herringbone skirt has been lost, as 
she is now clad in a modest woven skirt. Not only do the reoccurring items of clothing serve to help identify each character, they underline the depths of their downfall. In the three years that have elapsed from the loss of their grandmother and father, Tancred's family have not been able to afford to replace or expand their wardrobes, and therefore are forced to continue to wear what amounts to the remains of their previous life. To further drive their state home, in her only appearance outside of panel nine, Clorinda reflects these same desperate circumstances in the shapeless shift that has replaced her tidy, wealthy clothes (5). This shift in fortune as reflected in their appearances is consistent with melodramatic tropes. The sudden change and familial downfall precedes many a melodramatic protagonist's progression from privilege to suffering. The audience is then able to empathize with the hardships the protagonist must face, secure in the knowledge that the pleasure afforded by the sensationalist nature of such suffering will be rewarded by another turn of fortune in which good characters - most specifically the protagonist - will be rewarded, and those that have caused their suffering will be punished.

It is not simply the degradation of the family's clothing that reflects their initial change in fortune, as Gorey also makes use of other visual cues. While they watch the Moon of Valparaiso sink, they are in a park setting with a statue of a man in the background. Despite the wildness of the stormy sky, the statue suggests a formal garden which would require landscapers, gardeners and caretakers to keep it in good shape. The crosshatching on the ground is regular and slants in the same direction, evoking a well-maintained carpet of grass. While there is no indication of whether the garden is public or private, the fact that the family has free access to it without challenge places them within an upper class framework; the chaotic event that will change their lives occurs outside of the panel, the panel itself maintaining the societal separation of a perfectly proper upper class world. The thin black border contains this moment, preserving and separating out the family's comfortable lifestyle from the rest of the tale, closing it off from the destitution that awaits them. Only the disintegration of the patterned sky, extending from the left side of the panel and slowly spreading towards the right, hints at the way in which their family unit is breaking down. The forking white lines both suggest the violence of lightning and the destruction of the Moon of Valparaiso, which breaks apart and sinks outside of the view of the reader.

It is notable that the loss of the Baroness occurs outside of the frame. There is a stillness to most of Gorey's panels, in The Green Beads and across his works, where most of 
his figures are drawn at rest. The majority of the time they stand, sit or lie down - all almost artificially posed, some looking out at the viewer - but they are far less likely to be pictured in motion. Gorey's characters are orderly, still creatures, caught in amber or pinned to the scene like butterfly specimens. The sinking of the Moon of Valparaiso, however, is a chaotic act, existing outside of the order the characters live within. It is fitting, therefore, that such a turbulent event occurs outside of the gaze of the text. The characters can look out at the sinking ship, but they cannot directly interact with it as they are bound to their carefully constructed panel.

This separation from direct trauma repeats within The Green Beads. When the Baroness confuses Tancred for his sister, Tancred tells her that Clorinda "died last autumn from a disorder of the spine brought on by a lack of nourishing food" (5). Gorey, however, does not explicitly draw Clorinda's death, preferring instead to narrate it via her absence. She appears in exactly two panels: the flashback to the loss of the Baroness (9), and the flashback to her illness (5). In the latter illustration, even though Clorinda is ill, she too exhibits that stiffness of body that characterises the rest of the individuals, save for the Baroness, within the tale. Arguably, her spinal condition is at fault for her inability to sit properly in her chair, but Gorey uses this reason to good effect: Clorinda does not sit so much as lie across the angles of the chair as a makeshift hypotenuse. She is almost as stiff as a board, her feet oddly twisted out of alignment with the rest of her body. Where the other characters experience a natural motionlessness - in that they never appear twisted or uncomfortable when at rest Clorinda is positioned unnaturally, a signal that she is not long for the natural world.

Where the rest of the characters appear almost exclusively in passive poses or small actions, the Baroness von Rettig exists in a constant state of activity. She is continually throwing her arms about, bending her body at an angle, and stepping from one foot to another. Her appearance matches her active, chaotic state, as she is entirely unkempt. Her hair is a mess, loose and uncombed, lacking the sleekness and propriety that Tancred and his family maintain even in the face of poverty. The Baroness is a tangible reminder that The Green Beads is a melodramatic tale. Her every gesture invokes the grandiosity of emotion and passion inherent in melodrama; after all, "[t]he nineteenth-century novel is full of gesture, full of significant non-verbal signs that carry a great measure of expression" which comes from the practise of integrating tableaux into the most emotional of scenes in the stage drama (Brooks 75). Alongside the grand gestures, the Baroness moves even further into expressive 
space facilitated by her loss of sanity; not only is she homeless and wandering, lacking a fixed point, but on her first appearance within the text, she is so ambiguous as to be ungendered. Tancred sees "a disturbed person whose sex [is] unclear coming towards him while it wave[s] its hands about" (2), and it is five panels before the Baroness identifies herself and affects a pronoun shift within the text (6). Until that moment, she is "it" or "the Disturbed Person," lacking even a name. Gorey's character design also works to mask her gender, as her silhouette is tall and straight, masked by shapeless clothing that does not hint at any particular body shape underneath. Likewise, her clothing is a mixture of feminine, masculine and neutral. She has on ankle boots with large bows and an extremely long necklace, yet she also has bow ties knotted around her forearms. Her high-collared coat falls to her ankles, hiding whether she is wearing a skirt or trousers, and it lacks any detail that would indicate whether it is cut for a man or a woman. Her hair is so unstyled as to not provide any hint of the fashions of the day, and her facial features lack the delicacy associated with a woman's face or the strong lines associated with men's faces. Until she reveals her name and relationship to Tancred, she exists in an unwritten state, constructed of the flotsam and jetsam of homelessness. This lack of a home works even further to rob her of a backdrop upon which to inscribe her personage, as all the trappings which serve to define her are attached to her body, in fluid motion alongside herself. She is a personification of the hidden and mistaken identities that populate melodramatic plotlines, briefly pushed so far into non-identity as to lose every recognizable marker, including her gender and home, and even when her identity is restored, Gorey refuses to allow for this reveal to segue into a release of Tancred's family from its troubles.

Conversely, the flashback to the Baroness before her near-death experience speaks of a highly-gendered, highly-coded person (11). She is the epitome of the proper nineteenth century woman, dressed for a decadent evening entertaining or attending a lavish party, and her silhouette is far more defined than any other character within the piece. She wears a long, flowing dress with a scooped neckline which accents her decolletage, rather than the highnecked dresses in which Gorey usually clothes his female characters. She has a defined waistline, a thin, long neck, and a tidy, fashionable upswept hairstyle. Her gloves are longer than those of any other character, and extend almost all the way up her arms to her shoulders. Her dress sports an impressive bustle and train, the latter of which is so long it extends outside of the frame. In fact, she is the only character who breaks out of the narrative frame, 
both verbally through the textual narration of her insanity and gender-slippage, and visually through the way her dress spills outside of the panel. Further, her loss and recovery give her a power over the text that no other character has; she is able to slip in and out of the narrative, presumed dead when she is outside of it, but in truth, simply lost to sanity and the regulating influence of words. Thus, when she slips back into the text, there is a long moment in which both text and Tancred must grapple, not just with her identity, but also her gender.

In the posed portrait of the Baroness before she is lost, the beads to which the title refers rest around her neck in a orderly strand. These green beads that are the source of all wealth and fortune to be had by Tancred's family are more than a simple strand. They spill down the Baroness' front in excess, and would potentially come near to brushing the floor if she was not holding the strand slightly away from her body. Yet while the Baroness still possesses them after she is lost at sea, the green beads reflect the turmoil of this loss. They no longer drop in one straight line, nor do they settle firmly against the back of her neck. Just like the Baroness, they are always in motion, jumping, moving and sliding around her neck and shoulders as she moves. In her first appearance, the beads twist near the end of the necklace even as they slide off her shoulders (2). They slip further down her back as she twists (3), and end up in the Baroness' mouth as she questions Tancred about his name (4). This last panel is also the first textual mention of the beads, as Gorey explains that "the Disturbed Person [chews] on a string of green beads it [wears] around its neck" (4). Unlike the Baroness in her more fortunate guise, here she is without any anchoring in propriety. The beads, for all they are worth, are treated unceremoniously and without any regard for their importance. Indeed, two panels later, as the Baroness becomes aware of Little Clorinda's death, the fate of the strand becomes part of a larger outward expression of grief. The Baroness' "teeth [rend] the string asunder, the green beads flying in all directions and vanishing into the grimy drifts of snow" (6). Visually, they scatter across the panel, becoming projectiles from which Tancred must protect himself. With the loss of the beads, the final remnants of the family's riches, the Baroness reveals her identity, but does not vocalize any concern for her loss of property. As she is untangled from their length, so too do her gender and name resolve themselves, as if it is only with the loss of absolutely everything - sanity and materiality - that she is able to begin reconstructing her familial bonds.

In a clever moment of visual pathos, Gorey also subtly imitates melodramatic depictions of the genteel poor. Much as nineteenth century melodrama reliably presents the 
viewer with a series of stock characters, in which the rich are either evil and ostentatious or humble and good, those characters who have fallen on hard times do not fully embrace the meanness of poverty, but rather cultivate an air of ruined grace. For instance, towards the end of in The Woman in White, Walter Hartright describes the poverty in which he, Marian Halcombe and Laura Fairlie must live with a mixture of sadness and contained excitement at the intrigues that have brought them low:

The street is in a populous and a poor neighbourhood. The ground floor of one of the houses in it is occupied by a small newsvendor's shop, and the first floor and the second are let as furnished lodgings of the humblest kind.

I have taken those two floors in an assumed name. On the upper floor I live, with a room to work in, a room to sleep in. On the lower floor, under the same assumed name, two women live, who are described as my sisters. I get my bread by drawing and engraving on wood for the cheap periodicals. My sisters are supposed to help me by taking in a little needle-work. Our poor place of abode, our humble calling, our assumed relationship, and our assumed name, are all used alike as a means of hiding us in the house-forest of London. We are numbered no longer with the people whose lives are open and known. I am an obscure, unnoticed man, without patron or friend to help me. Marian Halcombe is nothing now but my eldest sister, who provides for our household wants by the toil of her own hands. We two, in the estimation of others, are at once the dupes and the agents of a daring imposture. We are supposed to be the accomplices of mad Anne Catherick, who claims the name, the place, and the living personality of dead Lady Glyde.

That is our situation. That is the changed aspect in which we three must appear, henceforth, in this narrative, for many and many a page to come...And yet alive! Alive in poverty and in hiding. Alive, with the poor drawing-master to fight her battle, and to win the way back for her to her place in the world of living beings. (Third Epoch, I)

Throughout these passages, Hartright conveys the starkness of their fortunes, a visceral contrast to Limmeridge House. He is "an obscure, unnoticed man, without patron or friend to 
help [him]," and so too are his "sisters" humble seamstresses, in total contrast to their former existence as "people whose lives are open and known." Yet his continual invocation of their assumed names and relationship, their status as people in hiding underlines their previous lives and leaves open the possibility that they will rise again from their poverty-stricken state (which, of course, they do). There is a sense that Walter, Marian and Laura have gracefully accepted their current circumstances, but refuse to fully embrace them, as they look towards a better future.

In a similar manner, Gorey presents the family in The Green Beads as resisting the indignities of poverty even while they encroach upon them. While he does not write the details of Tancred's family's circumstance into the narrative, Gorey's illustrations communicate the pains Tancred's mother takes in retaining some measure of the respectable veneer of a comfortable life. The glimpses of the inside of Tancred's home are small, but the peeling wallpaper and exposed wood quickly demarcate a home in decline. With the exception of two small throw rugs $(5,8)$ and a tiny chair $(5)$, the wood floors are bare, and the windows have blinds, but no decorative curtains. Yet in spite of this lack of luxury, there are definite touches that are meant to superficially mask the extent of their home's degradation. In panel five, a portrait of an unidentified man hangs far below eye-level, only partially covering a large section of bare wall. Even without the visual cue of the worn wall, the odd position of the picture immediately indicates that it is out of place, and is serving a function outside of that of a decorative art object. There is a bit of lace pinned over another bare patch in panel eight, swathed across it in imitation of a piece of swag or curtain with either side fastened so that the ends dangle downwards, and the middle dips. Additionally, there is a small plant on the windowsill (1) and a frame without a photo near the window (12), two more indicators that Tancred's family is trying hard to make a comfortable home for themselves. Even so, these genteel markers are not enough to push back the encroaching dilapidation, as the barren spots on the wall become larger and more prominent with each successive panel illustrating the inside of their house. What begins as three holes in the wallpaper, close to the ground in the first interior illustration (5), becomes three darker, more conspicuous holes much higher and more comprehensively scattered across the surface of the wall (8), and finally metamorphoses into two sizeable holes taking up a large amount of space, one extending from the base of the wall upward, and the other from the ceiling 
downward (12). These blemishes therefore progress from smaller concerns to a visual representation of the infringing, inescapable poverty that threatens to engulf the entire family.

Once Gorey has sketched out the full melodramatic setting and plot trajectory, however, he deliberately subverts the common tropes of this type of narrative. With few exceptions, after facing much suffering and trial, nineteenth century melodramatic protagonists must find vindication and reward: Laura Fairlie has her name restored and finds love with a good man, just as Robert Audley brings a fraud to justice and finds love with a good woman. Yet Gorey's protagonists come within a hair of salvation and then unceremoniously lose that last thread of hope. Tancred and his mother do rediscover one of the family members they thought lost forever, as they are reunited with the Baroness. In this moment, Tancred's mother voices a further hope: "But if you are not lying on the bottom of the sea...can it be possible that your emerald necklace is not there after all either?" (11). Tancred himself inflates the possibility of a happy, rewarding ending further by pointing out that "Grandmother, when [he] met her...was chewing some green beads, but they broke and rolled away" (12). With the solution to their dire straits within their grasp, the three of them go out into the street in the night to search (12). At this point in a proper melodramatic narrative, the protagonists would overcome the final obstacles and find their fortunes, love, or both. In The Green Beads, however, Gorey not only removes the happy ending, but taunts the protagonists with its potential before pulling it away. Tancred, his mother and the Baroness search high and low for the beads, "but in the end [find] only one green bead, and that prove[s] to be a glass marble belonging to a more fortunate little boy named Hugo who live[s] father up the block" (14). Even one bead would present a loosening of the clutches of poverty, and Gorey allows them the momentary joy of finding one, but immediately afterward, even that bead is taken away. Instead of a jewel, it is a toy, and even then, it belongs to someone else. Further, that someone else is a boy just like Tancred. He is almost the same height, and the outline of his features mirrors Tancred's own, yet he is obviously better dressed, having resources which allow him to be clothed warmly in a full-length coat, mittens, boots, scarf and flat cap, in sharp contrast to Tancred's thin, inadequate clothing. Tancred must relinquish the false bead to this wealthier boy, who, having one marble, no doubt has a larger set in his possession. Thus, not only is Tancred stripped of the potential for slipping the noose of poverty, but he is also deprived of possessing even a small toy. 
For Tancred, his downfall comes in the guise of a loss of his grandmother, father, sister, fortune and hope. Charlotte Sophia, the orphan at the centre of The Hapless Child (1961), however, starts out in an environment similar to Tancred's origins, only to lose even more and fall even further as she becomes increasingly mired in her own fate. The Hapless Child - a tale of the downfall of young girl, from the lofty heights of her happy home to the loss of both parents and eventual tragic demise - exemplifies Gorey's play with melodrama, from the lush, full details of Charlotte's pre-orphaned life to the gritty squalor of her downfall .

The very first panel - in which Charlotte appears as a ghostly-white figure set against a heavily detailed backdrop of an extremely embellished room - signifies the height from which she will fall. The scene itself is over-texturized, providing a vision of not simply richness, but overabundance: of pattern, possessions and wealth. Added to this richness of place is a richness of family, represented in the same high level of detail. As with the furnishings, Charlotte's parents are drawn with bold, strong lines, intricate patterns and detailed faces. They match and meld with their background in a way Charlotte does not, as if Gorey is visually priming her for her transition from treasured daughter to lonely orphan. Yet even against this background, Charlotte is slowly separating from her text. In sharp contrast to the riotous patterns and textures that make up her home, Charlotte herself lacks all but the most basic of lines, so lightly sketched and with such thin strokes that her features almost disappear. She is a washed-out figure, nearly transparent, a figure upon which the melodramatic protagonist can be easily overwritten. In fact, while Gorey explains that "[h]er parents were kind and well-to-do" (2), the text never comments on Charlotte's own character: Gorey does not provide any information on Charlotte's temperament, inner thoughts or opinions. For the duration of her story, she does not speak, and with the exception of her escape from her school(14) and later from the alcoholic brute (27), she does not show any agency over her circumstances. She is defined entirely in relation to her possessions and the events which act upon her, drifting through her narrative towards her ultimate demise. The

${ }^{9}$ As melodrama intersects with a variety of genres, in addition to displaying pure melodramatic characteristics, The Hapless Child has much in common with Edwardian children's literature, such as Frances Hodgson Burnett's A Little Princess (1905) and The Secret Garden (1910), in which the young protagonists must overcome tragedy and loss of fortune in order to obtain emotional and financial rewards. 
reader knows that Charlotte has "a doll whom she call[s] Hortense" (3) and a "locket with her parents' pictures inside" (16), but these only hint at Charlotte as an individual, providing few clues. The doll is elaborately dressed, with a large wardrobe of clothes, visually signifying the wealth in which Charlotte lives at the beginning of the tale. Hortense even changes clothes after Charlotte's parents die, as Charlotte outfits her in a full mourning dress, hat and veil (10). The fact that Charlotte possesses a locket containing pictures of her parents, meanwhile, indicates her love for them (17).

Yet even with these small clues, Charlotte remains a blank slate. She is a literal apparition, a ghostly girl marked by her death from the very first panel, unable to integrate with her setting. While she does not lose her sight until late in the narrative, she does not have pupils in any of the panels; her eyes are empty circles which change shape with her expression, but which are already symbolically blind. Likewise, her mouth is rarely more than a minuscule curved line. Further, in eleven of the panels, she is turned away from the viewer so that her features are entirely obscured; in four, her face is half-obscured or observed only in profile, leaving her face fully visible in only thirteen of the twenty-seven panels in which she is featured. With her lightly-sketched outline, her lack of features and her ofthidden face, Gorey inscribes Charlotte's fate on her body from the very beginning; it is only a matter of time before it plays out, inevitable and inescapable.

When this downfall comes, it comes swiftly, and in a series of cascading events. Within five panels, Charlotte's father is "ordered to Africa" (4) and "[s]everal months later he [is] reported killed in a native uprising" (5). While this pattern of events falls fully within the trajectory of the melodramatic waif, it is also an exercise in surfaces. Although the text asserts that it is several months before Charlotte and her mother receive news of her father's death, narratively, it is the space of two sentences. Thus, the reader has no time to absorb more than the surfaces of things: Charlotte's familial situation, her father's army rank, and his swift death. Further, Charlotte does not just lose her father, but her mother, on learning of her husband's death, "[falls] into a decline that prove[s] fatal" (6). Again, this occurrence happens within two sentences and their accompanying panels. The text itself gives us a very straightforward, factual account of surface events, not engaging in emotional editorializing, hinting at rather than fully exploring the depth of suffering at hand, and thus requiring the reader to piece together illustrated details. In panel five, Charlotte's mother stands slightly offcentre, her face grave as a letter flutters from her hand to the ground. She is clearly in shock, 
as this moment is the one directly after she receives news of her husband's death. Unlike her earlier appearances, she completely ignores her daughter, caught up instead in the first wave of grief. The next panel is similarly visually rich, as Charlotte's mother is now very gaunt, her body sinking into the bed. Her silhouette has straightened between the earlier panels and this one, the curves of her breasts no longer in evidence, making her appear to not just waste away, but to flatten out into a two-dimensional figure. Although she looks at Charlotte, it is Charlotte who holds her mother's hand, curling her fingers around her mother's own; there is no reciprocal gesture, her mother's hand stretched out passively underneath Charlotte's. In the background, atop the bedside table, is a portrait of Charlotte's father, set between a bottle of medicine and a half-filled glass with a spoon inside. Just as Charlotte's mother is in the process of fading into and becoming part of the bed, so too does his portrait fade into the background. It is nearly invisible unless the viewer pays close attention to the illustration; the dark, textured wallpaper acts as camouflage against which the portrait blends. As Charlotte's mother leaves the text, so too does her father.

Charlotte's further misfortunes fall on her like a row of dominoes, each one tipping over with no pause in between. While Charlotte has an uncle to rely on, he is fatally "brained by a piece of masonry" (7) in the panel directly succeeding her mother's death, and is thus unable to care for her. In fact, Gorey does not even allow for a glimpse of her uncle's face, leaving him entirely anonymous, his back to the viewer. His death is an unemotional event, notable only in the curious way he is killed and the immediate consequences for Charlotte, as he enters and exits the narrative in the exact same moment. As she has no other family, Charlotte is therefore "left in the hands of the family lawyer [who] at once put[s] her into a boarding school" (8-9), uncaring of her fate. Gorey physically distances Charlotte from the lawyer, mirroring his emotional disconnection as they stand on opposite sides of the panel's midline, almost entirely backed into either corner. Neither do they make eye contact. While the lawyer looks down at Charlotte in panel eight, Charlotte's face is half-obscured by her hat, only her mouth remaining visible. In panel nine, while the physical distance has been eliminated, Charlotte's face is entirely turned away from both the lawyer and the viewer so that only the slightest sliver of her profile is visible past her hair. Additionally, neither the lawyer nor Charlotte touch each other, reinforcing the lack of familial care being demonstrated. 
Naturally, for this would be no melodramatic tale if the boarding school turned out to be a kind and gentle educational institution, Charlotte is "punished by the teachers for things she [hasn't] done" (10). Her punishment is further exacerbated by the other students, who offer her teacher another book to place on her head. Her torture at the school is extensive, as her treasured doll, Hortense, is ripped to pieces (11) by the other students, and she spends her days hiding from them (12) and her nights crying (13) before she is able to escape (14). The escape is the first of only two active moments for Charlotte, where she takes action against her circumstances rather than passively allowing events to happen to her. Yet in neither instance does Charlotte improve her fortunes, as each defiant moment exacerbates an already terrible situation.

The events leading up to this moment of escape would be pathos enough, but Gorey continues to pile on the tragedy as a weakened Charlotte passes out in the street and is robbed of the only memento she has left, the "locket with her parents' pictures inside" (16). She is taken advantage of by not one, but three separate men in rapid succession, as after the theft she is then kidnapped by an anonymous man (17) who brings her "to a low place" (18) and sells her "to a drunken brute" (19). Gorey compounds Charlotte's predicament as the brute "[f]rom time to time...[gets] the horrors" (22), bringing in the potential for visceral terror on top of the desperation and drudgery that comes with being forced to make artificial flowers (20) and having nothing to eat but "scraps and tap-water" (21). She huddles in a corner on a thin blanket, an expression of fright on her face as the man flails and covers his eyes, warding off some invisible vision (22). Where her home was luxurious and the school spartan but tidy and clean, here she is surrounded by tattered drapes, ripped posters, discarded plates and bottles, and cracking walls. Further, the horrible conditions under which Charlotte is forced to work result in her blinding (23), an echo of the real circumstances in nineteenth century workhouses, where long hours and inadequate working conditions contribute to injuries and health hazards. This loss of sight works on a narrative level to strip Charlotte of the one thing she needs in order to ultimately escape her downfall. Yet even the work she leaves behind is frivolous, as she is tasked with making paper flowers, a frippery that lacks practical usage and is easily torn or destroyed. Like Charlotte, the flowers are fragile and ultimately transitive, and while the trajectory of the plot should evoke sentimentality, the brevity of the narrative and the rapid piling up of Charlotte's misfortunes results in a disconnect between the severity of her woes and the presentation of her tale. The sheer number of calamities placed in 
Charlotte's path invite the reader to indulge in disbelief, and encourage amusement where melodrama would have the audience sympathize.

While melodramatic characters are subject to multiple tragedies before they find salvation $^{10}$, Gorey subverts this archetype in the rapid cycling of events. Charlotte's life becomes increasingly worse by the moment, and there is no narrative space which allows the reader to linger over the details of each new calamity. Even as The Hapless Child mimics a melodrama, it is so distant from its characters and treats them so lightly that the melodramatic tone slides directly into humourous parody. Building on that distance between narrative and audience, Gorey deliberately conceals details that would allow for a stronger emotional response. In the space of the five panels directly after her escape, Charlotte is nearly insensible, being unconscious during four and only rousing in the last as she becomes aware of her surroundings. While she is unconscious, her face is seen only in profile or not at all, her eyes completely invisible, and any expression is obscured. Charlotte has become her own Hortense, a doll to be carried about and dressed and redressed in different roles - first that of happy daughter, then orphaned student, then workhouse waif - only valuable in terms of what she can produce. She is valuable to the school only in her role as scapegoat, and to the men who rob her, kidnap, sell and use her as a source of income.

The true tragedy, however, is not the multitude of indignities that Charlotte suffers, but rather how close she comes to escaping them and regaining some semblance of her old life. Charlotte is a victim of a melodramatic vision of the nineteenth century as surely as Collins' Laura Fairlie, yet Charlotte is trapped within her downward trajectory. There is no happy ending for her, even though Gorey briefly offers that possibility. In a late twist to the narrative, Charlotte's father is miraculously alive and returns to England to search for his daughter. While the story does not explain why he was thought dead or how he survived, it is clear that he has returned home (24) and "[e]very day he motor[s] through the streets searching for her" (25). The familial link remains strong: his first appearance on returning home is in a cemetery, suggesting a visit to his late wife, and he spends the rest of the tale in his quest to find his daughter. Gorey's illustrations always have him outdoors, in or near his

${ }^{10}$ For instance, in The Woman in White, Laura Fairlie must marry a man she doesn't love, who then attempts to take all her money. She becomes the victim of mistaken identity, is committed to an asylum, and after she escapes, she lives in poverty, hidden from those who would harm her. 
car, never at rest, as Charlotte herself, in her second - and final - act of defiance, escapes her captor and runs into the street (27). In a true melodramatic narrative, this event would precipitate a happy reunion, but instead, having just escaped from the horrors of the workhouse, Charlotte is immediately run over by a car (28). Just as Gorey compounds Charlotte's violations by piling a series of them on her in rapid succession, here too is Charlotte's tragedy further compounded. The car is driven, shockingly, by her own long-lost father, out looking for her (29). That would be horrifying enough, but Gorey goes one tragic step further and rips away even the most fleeting flares of hope, as Charlotte is blind, and therefore cannot see her father to identify him, and she is "so changed, [her father does] not recognize her" either (30).

In this manner, The Hapless Child carries all the surface hallmarks of a melodramatic tale, yet intentionally omits the moralization that fulfils audience expectations of the genre. For instance, in Lady Audley's Secret, Helen Talboys, the titular Lady Audley, is punished for faking her own death, abandoning her husband and child, creating a new identity, marrying for position and money, and attempting to murder her true husband and his best friend by losing her position, sanity, freedom (as she is committed to an asylum) and ultimately, her life. Conversely, Robert Audley, who investigates Helen's duplicity, is rewarded for his efforts by being reunited with his friend George, who has not been murdered by his wife after all, and meets, falls in love with and eventually marries Clara Talboys. Yet Charlotte's suffering in The Hapless Child - the very thing that is meant to make her potential reward that much sweeter - is never eased, nor rewarded. There is no compensation of any kind, not even in a final, tearful reunion with her father before her death. This unhappy ending is a repetitive theme within Gorey's works, as most of his narratives end in ambiguous or tragic ways, truncating any sentimental or moral reader reaction. What repeats is a lack of reward, moral, or reason for each story to turn out as badly as it does. Charlotte dies not because she has succumbed to the horrors visited upon her, but rather from a sudden and unexpected car accident: unpredictable, unwarranted, and merely bad luck. There is a distance here, between text and audience, that is precisely engineered by Gorey through his compressed narratives The Hapless Child, for instance, is made up of only thirty panels - and sparse, brusque text. Instead of wallowing in the joys of pathos and sentimentality, the reader is invited to laugh at the horrors on the page, to indulge in the very impulse Oscar Wilde spoke of when he said, "one must have a heart of stone to read the death of Little Nell without laughing." 
As with The Hapless Child, Oscar Wilde's reading of Little Nell applies equally well to The Pious Infant (1966). This narrative tracks the spiritual progress of Henry Clump, a very young boy who is extremely dedicated to his faith. At the age of three, he becomes aware of the concept of sin, and begins living his life in lockstep with the precepts of the Bible, positioning religious piety above secularity as he navigates everyday events. Even when he is struck down by illness, he views his own death as a chance for celebration, as he says, "God loves me and has pardoned all my sins! I am happy!" (14). The narrative concludes with an illustration of Henry's grave, and the assertion that while his "little body turned to dust in the grave...his soul went up to God" (15).

The Pious Infant is a profoundly ambiguous work. When one considers the religious themes present in the narrative, the lack of any supernatural occurrences juxtaposed against the text itself - which never undermines Henry's beliefs - reveals an empty, unknowable space behind the story. Although Henry believes fervently in God and redemption, and expresses these beliefs at every turn, Gorey never illustrates any instances that could be classified as miracles, divine intervention, or other acts of God. Henry's belief comes from the faith that these precepts are true, and he does not demand or seek out any proof. While Henry's belief in God is strong, God does not exist as a palpable force within the text. Henry's parents introduce him to scripture and the idea that even at three years old, "his heart [is] wicked, but God love[s] him nevertheless" (1). This pronouncement is presented as a general tenet of faith, rather than an absolute judgement of Henry's worth as an individual, but he internalizes it as a basic truth and acts in concert with its precept. To combat his wicked heart, Henry learns "a great many texts and hymns, and [is] always saying them over to himself" (2), "habitually [goes] without sweet things so that he [may] give pennies to stop the poor heathen from bowing down to idols" (4), and he "never tire[s] of asking what he might do for [his parents]" (5). Certainly, learning scripture and songs has the effect of making Henry more knowledgeable regarding the textual basis for his religion, but it does not have an appreciable effect on the world around him. Similarly, his penny donations are not directed towards tangible causes, such as hunger or poverty, but rather evangelical in purpose. Instead of seeing the results of such evangelism, the reader views a panel in which Henry stands outside of a candy store and looks on as a girl in a patterned dress and hair bow exits holding a large lollipop. Denying himself sweets is a fruitless act, as it does not stop the little girl from indulging herself, nor does it visibly result in the religious conversion of any of the other 
individuals in Henry's world. Where learning hymns and donating to evangelical charities does little but bolster his faith, Henry's desire to help his parents is a tangible example of a "good work." What prevents it from affecting real-world change, however, is that while Gorey presents Henry as continually offering help, he does not show Henry's parents taking advantage of his offer.

Henry's other efforts at living a good life are similarly hollow. He scolds some boys for playing on the Sabbath rather than reading the Bible (8), he worries about the spiritual health of his sister to excess (9), and he painstakingly censors "frivolous mention[s] of the Deity" in individual copies of books he comes across (10). These acts do little but reinforce his deep belief in the corruption of his own heart and speak of an earnest need to do everything in his power to live a pure life. Yet again, these are meaningless acts that serve to do little more than annoy those he scolds, feed his own worries, and deface books. By writing Henry as a three year old when he internalizes his parents' assertions about sin, Gorey undercuts any potential for Henry to be truly wicked. He is nothing like the horrifying child in The Beastly Baby, and appears to be a supremely well-behaved child who adheres to the rules. Gorey never shows Henry acting out, and gives no hint of any substantial misbehaviour which might brand him as a difficult child. He is consumed with being as pious as possible in all areas of his life, and yet most of his actions are misdirected, as they do not stand as examples of Christian charity, where unfortunate souls are helped rather than excoriated for not believing or behaving in a manner Henry deems proper.

Like so much of Gorey's genre play, Henry's piety meets the letter of the law, but not the spirit. He appears to be the epitome of the nineteenth century innocent child, but that appearance ultimately falls short. Gorey visually marks him as an innocent through his drawing choices. As with Charlotte Sophia, Henry literally stands out from his dense, heavily-crosshatched surroundings by virtue of the light linework Gorey uses to depict him. His eyes are small black dots rather than the wide, empty circles Gorey uses for Charlotte, but his clothes are as white as Charlotte's, marking him as pure and unspoiled. Nearly all the other characters are more fully defined, Gorey having added denser linework to denote a higher level of texture and detail to their bodies. This aesthetic choice also has the effect of making these characters blend into their backgrounds while Henry stands out as the focus of each panel. He is a tabula rasa, written upon by faith, and is thus a cleaner, whiter slate than the other individuals in The Pious Infant. 
Henry's devout appearance evokes that of the suffering child of nineteenth century melodrama, especially notable in the form of The Old Curiosity Shop's (1840) Little Nell. Although her grandfather gambles, with the intent of providing her with a reasonable inheritance, Nell's entire life is one of poverty. It is her destitute state, however, that underlines her piety and innocence. She is helpful, compassionate and giving; she offers kind words to all around her, displays a belief that all people are basically good, and gives time and attention to those who need it. She is a perfect example of an unspoiled, godly child, and this quality is especially underlined directly after her death:

She was dead. No sleep so beautiful and calm, so free from trace of pain, so fair to look upon. She seemed a creature fresh from the hand of God, and waiting for the breath of life; not one who had lived and suffered death.

(Chapter 71)

Nell is unspoiled by the world because of her inherent goodness, an unblemished specimen of purity, "fresh from the hand of God." The narrator continues to rhapsodize on her inherent goodness throughout the scenes regarding her death, enumerating her virtues when he says, "[d]ear, gentle, patient, noble Nell was dead" (Chapter 71), and:

Where were the traces of her early cares, her sufferings, and fatigues? All gone. Sorrow was dead indeed in her, but peace and perfect happiness were born; imaged in her tranquil beauty and profound repose.

And still her former self lay there, unaltered in this change. Yes. The old fireside had smiled upon that same sweet face; it had passed, like a dream, through haunts of misery and care; at the door of the poor schoolmaster on the summer evening, before the furnace fire upon the cold wet night, at the still bedside of the dying boy, there had been the same mild lovely look. So shall we know the angels in their majesty, after death.

Alongside the agony the characters experience over her death is a conscious extolling of her goodness and specialness. Not only does she help people in ways Gorey's Henry Clump does not, but she is such a rarified presence that death cannot harm her. Instead, it rewards her in a way her grandfather cannot by taking away the pain life causes. Death is transformative in that it further purifies an already pure child, removing her from the ravages of time and 
adulthood, and elevating her to the rank of angel. In fact, the narrator is not the only person to recognize her Heavenly nature:

'It is not,' said the schoolmaster, as he bent down to kiss her on the cheek, and gave his tears free vent, 'it is not on earth that Heaven's justice ends. Think what earth is, compared with the World to which her young spirit has winged its early flight; and say, if one deliberate wish expressed in solemn terms above this bed could call her back to life, which of us would utter it!' (Chapter 71)

Nell is such a model of goodness and piety that she is better suited to Heaven and the angels than the imperfect earth. Henry exists in stark contrast to Nell and the template she represents, as although he has the appearance of the same religious devotion that drives Nell, he is focussed on punishment and wickedness.

The closest Henry comes to a brush with the divine is in panel six, when the text reflects that he was "sometimes tempted by Satan, but he felt his sins deeply and was truly sorry for them afterwards." The illustration depicts Henry and a tall, dark man with his left hand outstretched towards the boy. At first glance, the man is reminiscent of so many of Gorey's characters, as he is heavily bearded and dressed in a top hat and fur-collared coat, and therefore is a metaphorical representation, rather than a physical one, but further examination reveals that he has a pointed tail snaking out from beneath the hem of his coat, nearly obscured by the background detail and heavy shading. This man is thus a literal devil. In addition to the tail, he is also the only character who sports a completely black outfit from head to toe, a definite contrast to Henry's virginal white. His beard is pointed, mimicking the triangular point of a goat's beard which reoccurs in a variety of representations of Satan and other devils, including popular nineteenth century depictions such as Les Diableries (1860). This series of over one hundred and eighty stereoscopic photographs published between 1860 and 1890 depict visions of Hell created by artists such as Pierre Adolph Hennetier, Louis Alfred Habert, and Louis Edmond Cougny (May 9) ${ }^{11}$. The goat beard is a reoccurring marker of Satan within these tableaux, echoing earlier Christian artworks.

${ }^{11}$ Les Diableries is also notable as each piece is a melding of two mediums: sculpture and photography, just as Gorey's works almost always cross mediums by pairing art with text. 
Gorey also positions the man so that he is on the left, or "sinister" side of the panel, he is reaching for Henry with his left hand, and his left foot is slightly ahead of his right. These clever tiny details subtly indicate that Henry is meeting Satan himself. Yet while Satan arrives to tempt Henry, Gorey gives no indication of what Henry is being tempted by, as there is no visible object in Satan's hand, nor does the text provide dialogue from or motivation by Satan. Whatever it is Satan offers Henry, it is intangible and ultimately lacking in real temptation or threat, as Henry suffers no consequences apart from "[feeling] his sins deeply" and being sorry afterward (6). Satan himself lacks in real power as well, as there is no appreciable repercussions to Henry turning down his offer. He inhabits only one panel of the fifteen that make up The Pious Infant, and the story moves on without him. The accompanying text does indicate that Henry is "sometimes tempted by Satan" (emphasis mine), suggesting that Henry crosses paths with this devil on more than one occasion, but that these meetings are inconsequential.

It is Henry's one tangible charitable deed, however, that results in his demise. After spending his few years engaged in prayer, penance and proselytizing, "[o]n a winter afternoon when he was four years and five months old he went to give his bread-pudding to an unfortunate widow" (11). As he attempts to return home, he is caught in a hailstorm and develops a sore throat; by morning, he is on his deathbed. Rather than being distressed by his imminent demise, however, Henry is overjoyed that "God loves me and has pardoned all my sins" (14). This pardon comes as a result of dying, not through his actions in life. Henry has not had a chance to be significantly evil, and thus prove the purported wickedness in his heart, nor has he been able to live a significantly good life, as at four years old (and due to his inward-focussing piety), he has not had enough time to contribute positively to the world around him. Henry may be thoroughly pious, meeting the criteria of the narrative's title, but his life is an empty one. None of the other characters comment on any of Henry's pronouncements, not even his death. He inhabits a space in which his voice is the only one articulated, the rest relegated to silence, an echo chamber of his own making. Where Nell is surrounded by grieving loved ones after her death, Henry's final panel is of his gravestone, no mourners in evidence. For all that Henry's "soul [goes] up to God," the more tangible result is that his "little body turn[s] to dust in the grave" (15).

Henry forever strives to be better than he is, but never expresses contentment nor happiness until his life comes to an end. His (lack of) suffering disrupts that which is typical 
of a melodrama, as nineteenth century melodramatic texts focus on the suffering as earning the child's reward: The Old Curiosity Shop's Little Nell, after all, is more beautiful and fragile for having been through the very trials that prove her basic goodness. Conversely, Henry earns nothing. He does not suffer at all prior to the sudden storm and rapid illness, and that small space of suffering does not transmute him into a truly tragic figure. He occupies the space set aside in a melodramatic text for the poor waif, but as he has lived a comfortable life and primarily acted as a scold, he has not gone through the trials by fire that would excite an audience's emotions and inspire pity upon his death.

Gorey's treatment of religious faith in The Pious Infant echoes his treatment of genre. The trappings of religion are represented in the text, but the payoff - in this case, in the form of a tangible miracle or definite mark of salvation - is absent. The deeper meaning of faith is missing from Henry's narrative just as Gorey's melodramas deliberately sidestep any invocation of feeling. Instead, the reader views a world in which meaning is discarded in favour of appearances. Henry appears to do good works which ultimately benefit himself over others; his faith appears to provide the tools needed to live a good life, but there is no textual evidence that he is any more pious or worthy than the less faithful individuals he comes into contact with; and God appears to be present in the narrative, but there are no supernatural events which would tangibly indicate the presence of the divine. Likewise, The Pious Infant presents the trappings of a melodramatic plot, where a good, pure child who lives as piously as possible is struck down by a fatal illness which cuts his life short. He is rewarded for his suffering in Heaven, however, as his struggles bring him the benefit of eternal salvation. Yet, even as a major tenet of melodrama is the excitation of emotion in its audience, the text does not provoke such feeling. Gorey's chosen format of illustrations accompanied by short bursts of text is such that the process of reading is quick, giving the reader little space to linger over descriptive passages or long, drawn-out events building to a desperate climax. The narrative is often clinical, presenting the action of the plot in straightforward, unembellished terms, providing the audience with no adjectival clues as to how to read and react to Henry's plight. Gorey's narratives are stories in which things simply are. They do not spare much space for editorialization, preferring instead to imply meanings rather than state them, or sometimes outright ignore meaning in favour of happenstance.

Within The Green Beads, The Hapless Child and The Pious Infant, Gorey plays with nineteenth century excesses and the sentimentality of melodramatic narratives. Each text 
displays Gorey's understanding of the form and style of such tales, from the visual markers of the nineteenth century - fashion, furnishings and architecture - to the archetypal characters orphans, misers, lost relatives, poor families, unfeeling lawyers and vicious brutes - and excessive emotions - grief, insanity, awe and despair. Gorey, however, deals entirely in surfaces, as the moral and sentimental hearts are not present in any of these works. For instance, while he represents the Baroness in The Green Beads as continually in motion and always in the midst of a large gesture that expresses her boundless emotion, the rest of the characters are curiously still. Gorey's characters most often sit or stand, hands at their sides or below their shoulders. Few are in the midst of moving; each illustration presents the viewer with individuals caught at rest or in moments of hesitation. This arrangement is not restricted to The Green Beads, but is rather a larger characteristic across Gorey's works. This stillness undercuts the transmission of expansive feelings; as the illustrations depict still individuals sporting neutral expressions, the high emotion of melodrama is stunted. Likewise, the brevity of each narrative contributes to a further stripping of emotion, as Gorey does not linger on or provide much detail regarding his characters or the events which shape their lives. Without any breathing space to absorb the increasing mass of tragedies that befall them, Gorey prevents the development of character and the possibility of audience empathy. Instead of being invited to partake in his characters' sorrows and celebrate their triumphs, Gorey invites his audience to distance themselves and laugh at the absurdities of each situation. Further, the lack of reward at the end of each tale - Tancred and his family lose their last hope of their fortune being restored, and are now saddled with an insane relative; Charlotte Sophia is blinded and run down in the street by her own father; and Henry Clump leads a devout but ineffective life, brought low as a result of his only truly charitable act - completely undercuts melodrama's penchant for endings rife with moralising. In Gorey's works, events simply happen, and plotlines abruptly come to an end. As a result, Gorey's melodramas are exercises in hollow mimicry: they imitate popular nineteenth century texts, but deliberately undermine the characteristics that make these works meaningful. Like the nonsense verse of Edward 
Lear and Lewis Carroll, Gorey instead creates amphigouris ${ }^{12}$ in place of meaning, delighting in style and form.

${ }^{12}$ Of special note is Gorey's love of wordplay, especially in relation to "amphigouri" (or "amphigory"), as all four volumes of his collected works are titled Amphigorey, inviting the reader to view his works as an extended exercise in form without meaning. 


\section{Chapter 3: Dickensian Discourse}

Gorey derives a great deal of inspiration from the fiction of Charles Dickens, from setting and character to thematic forms. Dickens uses the foundation of melodrama - which most usually marks a plot of high emotion and sensational drama meant to elicit sentimentalism in its audience, and culminating in the relief of upheld moral systems - to explore social issues. It is his engagement with nineteenth century issues such as poverty, the penal system and working conditions that are at the heart of his texts, yet it is his particular versions of melodramatic tropes that have filtered down into modern popular culture. As Boyce and Rousselot have argued, what we understand as "the Dickensian" represents an eminently knowable and assimilable version of the 'Victorian': crucially, even those who are unfamiliar with Dickens's works understand what is meant by the adjective derived from his name...[T]he label 'Dickensian' has become a convenient cultural shorthand through which to signal condemnation of repressive institutions, social injustices, such as child exploitation, and governmental or bureaucratic inertia...[T]he signifier 'Dickensian' is mutable and mobile, capable of supporting contradictory representations. If, on the one hand, it stands in the popular imagination for urban poverty, destitution and suffering, on the other, it is evocative of bountiful Christmases, idealised families and domestic harmony. (Boyce 3)

For the twenty-first century Western reader, reference to Dickens brings to mind such tales as Oliver Twist: The Parish Boy's Progress (1838), A Christmas Carol: A Ghost Story of Christmas (1843), A Tale of Two Cities (1859) and Great Expectations (1861). The characters and themes which populate these works filter into popular culture so that even audiences who have not directly read Dickens' novels are peripherally aware of their content, and have a reasonably high likelihood to have encountered adaptations or references to Dickens' texts across various media.

Television shows and episodes such as Sanford and Son's "Ebenezer Sanford" (1975), Family Ties' "A Keaton Christmas Carol" (1983), Blackadder's Christmas Carol (1988), Saban's Adventures of Oliver Twist (1996), and Doctor Who's "A Christmas Carol" (2010) parody, reinterpret and generically shift Dickens' novels where modern characters live through ghostly hauntings that change their lives: Scrooge never learns his lesson; Oliver is a 
dog, and part of a larger cast of animal characters; and the Christmas Ghosts become a way to convince an old, resentful man to stop the destruction of a futuristic spaceship. Films like The Only Way (1927), Non è mai troppo tardi (1953) ${ }^{13}$, Mickey's Christmas Carol (1983), Oliver \& Company (1988), Scrooged (1988), The Muppet Christmas Carol (1992), Twisted (1996), Twist (2003), Boy Called Twist (2004), and Christmas Cupid (2010) adapt, modernize, and spin Dickens' narratives to appeal to a wide variety of audiences, from children to family, adult and alternative media audiences. Sonic's Christmas Carol (1993), Fagin the Jew (2003) and Batman: Noël (2011) adapt Oliver Twist and A Christmas Carol for graphic novel audiences; The Life and Adventures of Nicholas Nickleby (1980), Dickens' Women (1989), Marley's Ghost (2003), Fellow Passengers (2004), A Klingon Christmas Carol (2007), and 3 Ghosts (2011) bring Dickens' works to the stage; Oliver! (1960), Pickwick (1963), Drood (1985), and Mrs. Bob Cratchit's Wild Christmas Binge (2002) give a musical spin to Dickens' texts; the December 24, 1949 episode of Richard Diamond, Private Detective (1949) and The Six Shooter episode "Britt Ponset's Christmas Carol" (1953) present reinterpreted versions of $A$ Christmas Carol to radio audiences; and God Bless Us Every One (1985), "Whatever Happened to Tiny Tim?" (1992), Timothy Cratchit's Christmas Carol, 1917 (1998), Marley's Ghost (2000), "Scrooge \& Cratchit" (2002), The Last Christmas of Ebenezer Scrooge (2003), Mr. Timothy (2003), and I Am Scrooge: A Zombie Story for Christmas (2009) pick up where Dickens left off with written sequels. The preponderance of Dickens adaptations and reinventions results in this wide-ranging, general knowledge across a variety of audiences, permeating popular culture with recycled and reflected fragments of Dickens' oeuvre.

While the Dickensian is a direct outgrowth of Dickens' works, it is not an identical replication of the author's narrative style. Instead, it is an aesthetic informed by direct knowledge of Dickens' texts and indirect, popularized understandings of the content and themes of his oeuvre. As in any situation of indirect exposure to a text, the nuance and detail of the original source flatten in the process of these retellings and reimaginings. Therefore, the Dickensian, as referenced by popular culture, becomes a series of identifiable tropes. It is most often set in a pseudo-nineteenth century world, populated by characters who "may not be exactly lifelike, but they are only a little larger, and uglier, than life. In other words, they

\footnotetext{
${ }^{13}$ English title: It's Never Too Late.
} 
are caricatures, figures made ridiculous through exaggeration" (Petzold 186). These characters sport fantastical, complicated, or overly descriptive names, such as Bruce Bogtrotter, Julius Rottwinkle, Miss Trunchbull and Miss Honey in Roald Dahl's Matilda (1988), or any number of Gorey's own characters, including Mr. Earbrass, from The Unstrung Harp; or, Mr. Earbrass Writes a Novel (1953), and the Fibleys of The Retrieved Locket (1994). The narrative may have a strong parodic or satiric aim, and coincidences and swift changes in fortune abound. Dickensian texts tend to use these tropes in broader ways than Dickens himself, favouring their use as intertextual touchstones which highlight their link to their antecedents. It is at this point, where Dickens intersects with the Dickensian, that Gorey's engagement begins.

In understanding Gorey's relation to the rest of the literary world, literary critics often start by highlighting the "Dickensian" nature of his texts. Alexander Theroux invokes Gorey's resemblance to Dickens repeatedly over the course of The Strange Case of Edward Gorey (2000), most notably when he explains that Gorey's characters taken all together make up a neo-Dickensian ${ }^{14}$ onamasticon, with a cast of wonderlings such as Mr. Earbrass; Udgeion; Miss Squill; Professor Bedsock; Sarah Hane (Batears) Olafson; Urula Schnittlauch; Snibby; Harold Snedleigh; Mona Gritch; Baron de Zabrus; Plastikoff; the MacFizzets; Mona Skrim-Phaw; Mr. Crague; Millicent Frastley; Miss Marshgrass; Eepie Carpetrod; and the lovely ballerina, Federojenska. (55) Gorey mimics Dickens' descriptive nomenclature in naming his own characters, but where Dickens' characters sport names that are slightly ridiculous - such as Ebenezer Scrooge

\footnotetext{
${ }^{14}$ Theroux's use of the "neo-" prefix here is unclear, as he does not clearly indicate whether appending it to the term "Dickensian" is a function of aligning Gorey's work with the Neo-Dickensian and larger Neo-Victorian movement, or directly referencing Gorey's positioning as a twentieth century artist, in contrast to Dickensian writers of the nineteenth century. Given that the larger context of the quote is an anecdote in which Theroux relates first happening upon Gorey's works and his subsequent surprise that Gorey is a modern author and illustrator; that the paragraph that follows describes one of Gorey's plays as "neoByzantine"; and that Theroux does not discuss Neo-Victorianism or the Neo-Dickensian outside of that one instance, it is far more likely that his use of the "neo-" prefix refers primarily to Gorey as a twentieth century artist referencing nineteenth century tropes rather than the more complex dialectical relationship between the Neo-Dickensian and the nineteenth century.
} 
himself, whose first name conjures up associations with "miser," "miserly" and "misery," and whose last name is one of a series of variations on "scrounge" or "screw" -- they also underline particular defining characteristics that guide the reader in understanding each character's function within the text. Gorey's character names, however, take inspiration from Dickens' imaginative descriptions, but do not act as signposts or guides through which to read his characters' features. They are names which are entertaining to the ear and eye, but rarely carry any particular decodable meaning. Indeed, Gorey's separation of Dickensian character names from one of their most important purposes is a small example of the larger ways in which Gorey manipulates Dickensian tropes, emptying them of their intended purpose as facilitators for social commentary and critique.

As a framework for that social commentary, the Dickensian contains excesses of passion, sentimentality and overflowing wordiness (Bottum 29) that multiple critics Jonathan Loesberg, Marcia Muelder Eaton, Natalie Rose and Dieter Petzold amongst them locate within texts such as A Christmas Carol, The Old Curiosity Shop, David Copperfield, and Oliver Twist. In "Dickensian Deformed Children and the Hegelian Sublime," Loesberg identifies the grotesquerie of the physically deformed child as particularly Dickensian, as "pitiable children frequently exemplify sentimental excess in Dickens" (626). Eaton's "Laughing at the Death of Little Nell: Sentimental Art and Sentimental People" is entirely concerned with evaluating the sentimentality of The Old Curiosity Shop, and Rose tackles the excesses inherent in "Dickensian Discipline" (518) in "Flogging and Fascination: Dickens and the Fragile Will." Bottum provides an even more vivid vision of Dickens' own Dickensian impulses, as

what makes $A$ Christmas Carol a triumph [is] the energy, the madness, the darting from thing to thing, the extravagance invested in every moment...There are perhaps seven thousand named characters in his stories, and every single one has more put in him than necessary...Dickens is like some mad magician, incapable of not transforming each thing that happens to catch his eye. (30) Regardless of the individual characteristics each critic singles out as Dickensian in origin, the unifying feature across considerations is of the Dickensian as an excessive space. It is signified by excesses of energy, words, sentimentality, grotesqueries, emotion and passion.

The Retrieved Locket is an eight panel tale of parents whose child is kidnapped, and the police search that follows. Amelia Emily is born to the Fibleys, who christen her and gift 
her with a locket containing their names and pictures. She disappears a week later, and for months, there is no sign of her. Eventually, a neighbour finds a dog wearing the locket, and the Fibleys accept the dog as their child and live out their lives with the dog's descendants. On the surface, The Retrieved Locket meets the standards of a Dickensian tale: a child, born to a loving home, is beset by challenges and suffering. Yet this narrative is not from the point of view of the Dickensian waif. Instead, it presents the viewpoint of the lost relatives themselves, whom the reading audience most often meets near the end of such stories, where the young protagonist is reunited with her or his fortune, family, or proper societal status. The Fibleys are equivalent to Oliver's Aunt Maylie and Mr. Brownlow, restored to familial and parental roles at the end of Oliver Twist. They are the other Cratchits, neither Tiny Tim nor Bob, who rejoice as Tim's health improves, and who accept Scrooge into their home at the end of A Christmas Carol. Their tales are hidden or fragmentary in Dickens' narratives, as they are relegated to nearly-invisible bookends for the main character. They live in the margins of each story as the happy circumstances that preceded such tragedy and the reward that lies at the end of the protagonist's journey.

Gorey, however, places the Fibleys in limbo, denying them a satisfactory reunion with Amelia Emily. She is never found nor returned to them, blocking any restoration of familial harmony. They are further denied the opportunity to grieve and find some measure of closure, as they are presented with a dog wearing Amelia Emily's locket and take her in as if she was their child (6). Any possibility for the Fibleys to find some peace is truncated with each turn in the plot: the narrative never reveals Amelia Emily's fate while simultaneously dangling a tantalizing clue quite literally around the dog's neck, and the Fibleys willingly enter a bizarre parental relationship with that same dog, never questioning where Amelia Emily has gone, nor challenging their acceptance of the dog as their daughter. For Dickens,

[t] he main narrative structure of [his] novels...is the complexity of the plot, or, rather, the coexistence of multiple plots that intermingle through links and connections made of recurrent figures, images and metaphors. (Chialant 44) Yet Gorey distills most of his stories down to one plot, and streamlines it further so that characterization and setting exist only to serve the narrative through-line. At a slim eight panels and eight sentences, The Retrieved Locket concerns itself solely with the sequence of events between Amelia Emily's kidnapping and the Fibleys' relationship with the succession of dogs with which they replace their child. The reader learns nothing about the Fibleys that 
would explain their motivation in accepting the first dog as a child-substitute and, in fact, their first names are never revealed in the text. They are presented as a unit, neither distinct from the other. In each panel, the Fibleys stand beside each other in identical stances. During Amelia Emily's baptism, each parent uses one arm to hold her aloft, their hands on her shoulders, and their free hands clasped together between the two of them (1). Similarly, they hold the locket they give to their child between the two of them, each holding one end of the chain at chest-height, their opposite arms held stretched down at a slight angle out from their waists, and their heads tilted slightly downward as they view Amelia Emily in her cradle (2). Their reactions to Amelia Emily's disappearance remain exactly the same, as they both lean forward, hands held up, palms facing out as they discover her empty cradle (3), and stand straight, pressed against each other, clasping hands as they face a police officer and child who report no sign of Amelia Emily (4). Once they immortalize Amelia Emily in paint and hang it above their fireplace, they stand in the same pose, their hands crossed, palm over palm, in front of their bodies, faces turned slightly upward to look at the painting (5). The only variation between the two of them is which hand is folded over which, but in this slight difference, it is again a moment of mirroring like so many of their poses in previous illustrations. The Fibleys once again lean forward in exactly the same pose as they first view the dog who will become their surrogate Amelia Emily, arms lax in front of them but slightly forward, as if they are just beginning to reach out for the animal (6), and they hold their arms up, bent at the elbows and palms out in shock as they discover the new puppies (7). Finally, they sit on their couch, turned slightly towards each other, both hands resting on their current pet, fingers curled over her back as they live out their "declining years" never having found the human Amelia Emily (8).

Gorey's positioning of the Fibleys to mirror each other extends outside of their respective physical stances within each panel. Panel seven, where they discover the dog's puppies in Amelia Emily's cradle, is a mirror image of panel three, in which they discover Amelia Emily's disappearance. The Fibleys stand in exactly the same positions in both panels; the only major differences are their clothes, the lack of a small notecard under the cradle, and the shift in panel perspective. In panel three, the Fibleys stand to the right of the cradle; in panel seven, they stand to the left. They exist as part of a series of tableaux, where their purpose is primarily visual: they create a pantomime of love, surprise, sadness and resolution without the narrative doing any heavy characterization work. Indeed, although the 
Fibleys are the central characters in Gorey's story, he never fleshes them out. They remain as one-dimensional as their marginalized counterparts in Dickens' novels, yet because they are central to the narrative, the empty space left by a lack of characterization is extremely obvious. Where Mr. Brownlow, Rose and Harry Maylie, Estella Havisham and Agnes Wickfield stand as rewards for Dickens' main characters, supplying family, love and fortune at the end of each main character's journey, the Fibleys are themselves the main characters, yet they lack all but the most meagre signposts of personality or motivation.

Just as Dickens uses names to suggest character traits, Gorey alludes to the Fibleys' central defining trait with their name. Gorey does not provide either parent's first name, referring to the two of them only in the collective, as "the Fibleys." They physically embody the concept of folie à deux, or shared psychosis, as after Amelia Emily's disappearance, the Fibleys begin to live a lie, as they are "fibbing" to themselves. While there is no evidence of the couple discussing their shared delusion, they both appear to accept it without question. Further, in behaving as if the dog is their lost daughter, they are actively denying that she is still missing, and therefore fibbing to themselves. Narratives such as Dickens' Oliver Twist and Nicholas Nickleby turn on the revelation of truths, whereas The Retrieved Locket hinges on the preservation of a lie. There is no human child to adopt or take Amelia Emily's place; there is no spiritual or legal human successor. Rather, the Fibleys are complicit in a strange new narrative: because they gave Amelia Emily a locket with their pictures inside, the bearer of the locket therefore must be Amelia Emily. The Fibleys ignore the more logical conclusion: that the dog has been in some level of contact with their lost child, and may help them find her. If enacted, this more logical conclusion would also steer the plot's trajectory to a more traditional and straightforward path, likely culminating in the Fibleys reuniting with Amelia Emily. Instead, Gorey chooses to arrest any narrative forward motion, freezing the Fibleys in their state of denial. The story similarly atrophies and truncates, as there are few actions available for the couple.

This stagnation, however, reveals a strange sentimentalism that is at once in line with Dickenian tales, and devoid of the emotionalism required to transmit that sentimental sense to the audience. By replacing Amelia Emily with the dog, the Fibleys signal their need to keep the live presence of their daughter in their lives. They are exceptionally attached to her, and thus unable to let her go or accept her unknown fate. As a result, they use the dog as a surrogate, and go so far as to accept a multigenerational outgrowth of this decision. Not only 
does the dog become Amelia Emily, but her puppies, and those puppies' successive descendants continue to stand in for the Fibleys' lost child. Yet their excessive attachment to the idea of their daughter does not engender similar feelings in the reader. The briefness of The Retrieved Locket alongside the lack of characterization has a distancing effect on the narrative. The Fibleys show their grief indirectly, through their adoption of the dog, but Gorey provides so little evidence of their inner lives that they are almost entirely ciphers. The close association of their name with the word "fib" also serves to reduce the magnitude of the situation to something that can be easily dismissed with a little white lie.

The Fibleys' expressions remain neutral throughout The Retrieved Locket. Both halves of the couple have very small eyes, rendered as dots or lines, limiting the amount of expression available through which to convey emotion. Likewise, Mr. Fibley's moustache completely covers his mouth, and Mrs. Fibley's mouth is no more than a line. Although Mrs. Fibley shows some small amount of pleasure at the beginning of the story, smiling as she and her husband present their baby for baptism (1) and later gift her with the locket (2), she displays little to no range of emotion in the other six panels. Her mouth shrinks down to a dot when Amelia Emily disappears, and remains near that state, never again growing to the size of her (small) smile in the second panel. Gorey turns up the edges of the line of her mouth in panel six very slightly, but it is such a tiny detail that it is barely a ripple in her lack of emotional display.

Similarly, the Fibleys are silent throughout the duration of The Retrieved Locket. There is no dialogue whatsoever in this tale, yet Gorey communicates the intentions of the police and the neighbours. The reader knows that "[n]either the police, nor anyone else for that matter, could find [Amelia Emily]" (4) and that "[a] neighbour brought [the Fibleys] a dog wearing the locket in which he had recognized the snapshots" (6). These are the only two explicitly relayed conversations that appear in the text, as even when "[t]he Fibleys christened their baby Amelia Emily" (1), the illustration places the family at the baptismal font, where the primary speaker would be the religious officiant performing the ceremony. As the Fibleys lack emotion, expression and voice, they are truly passive characters. Their sentimentalism is therefore at a significant remove from the audience, as the text reports on actions that hint at emotion, but does not present it in full view of the reader.

Much of the Fibleys' investigation into Amelia Emily's disappearance is cursory or altogether invisible. There is a small rectangular piece of paper underneath Amelia Emily's 
cradle that neither of the Fibleys appear to notice (3). Although it disappears from the floor the next time Amelia Emily's cradle appears, there is no evidence that her parents have picked it up, viewed it, or passed it on to the authorities. It is a small, subtle detail tucked away in a set of minimalist illustrations, as The Retrieved Locket is missing the heavily textured backgrounds of many of Gorey's other texts. Similarly, the police investigation around Amelia Emily's disappearance appears to lack in substance. The only hint of police presence is the officer in panel four, who holds up his hands, palms out, indicating that he has no idea where she may be. A young girl stands just behind and to the side of the officer, her one visible hand held up and her palm turned towards the Fibleys in a similar gesture. This physical symmetry invokes the Fibleys' own mirroring tendencies, emphasizing the characters' collective inaction. Additionally, the text accompanying this illustration states that "[n]either the police, nor anyone else for that matter, could find her." Until the neighbour arrives with the dog, there is no other evidence of the search for Amelia Emily. While this scarcity of evidence is a function of Gorey's brusque style, it also undercuts the drama of Amelia Emily's disappearance. Narratively speaking, such a tragedy should lead to a dramatic search that does not end until the child is found or the parents have died.

In any Dickens tale, there is an audience expectation that the setting will be welldrawn and will contribute to the overall atmosphere of the story. As Maria Teresa Chialant explains in "Dickensian Resonances in the Contemporary English Novel,"

London, the main setting for most of Dickens's novels, serves additional functions. The capital's labyrinthine structure effectively complements the intricate plots of the novels by providing extensive physical space in which events can take place. Slum streets and alleys in their darkness and vitality also provide a context and social texture for the stories as well as room in which to develop the lights and shadows of a multitude of characters. (45)

Yet in The Retrieved Locket, Gorey very consciously does not provide anything more than a very basic sketch of a setting. Backgrounds are nearly non-existent, Gorey's usual highly detailed and crosshatched scenes set aside in favour of furniture against blank space. While the narrative has many hallmarks of a Dickensian tale, including a missing orphan, a lost but loving family, a mystery around her disappearance, and amusing names that suggest characterization, the story does little more than present these ingredients before moving on. This story sits in a disconnected space where the sense of place is as lightly sketched as the 
plotline (which never comes to fruition). As a result, in stripping away the meaning of the Dickensian tropes it uses, leaving nothing but their empty forms, The Retrieved Locket is an anti-Dickensian tale. It invokes nineteenth century Dickensian touchstones and follows what should be a sensationalist plot, even creating space for a potentially socially-aware criticism of criminal investigations and police involvement in their very clear lack of interest in solving Amelia Emily's disappearance, but while Gorey provides all the correct pieces in the right places, emotionalism, sensationalism and moralism never become part of the narrative.

While Gorey references and plays with excessive moments across his oeuvre, it is $A$ Christmas Carol that he most directly parodies. Gorey's two texts that are most strongly Dickensian are The Haunted Tea-Cosy: A Dispirited and Distasteful Diversion for Christmas (1998) and The Headless Bust: A Melancholy Meditation on the False Millennium (1999). Both parody Ebenezer Scrooge's moral awakening, the former mirroring his experience with the three tense-oriented ghosts (Past, Present and Future), and the latter following on the first and extending the conceit to a critique of truth and falsity. In The Haunted Tea-Cosy, the protagonist, "Edmund Gravel, known as the Recluse of Lower Spigot to everybody there and elsewhere" (1), meets "the Bahhum Bug" (5) and experiences an evening of "affecting," "distressing" and "heart-rending" scenes presented by three ghosts: the Spectre of Christmas That Never Was, the Spectre of Christmas That Isn't, and the Spectre of Christmas That Never Will Be. From the very start, Edmund Gravel occupies Scrooge's placing within the narrative: he is a recluse, a penny-pincher, and because of his encounter with the three "subfuse but transparent personage[s]" $(6,14,21)$, by the end of the tale, he is a changed man.

Yet in condensing A Christmas Carol down to its component parts, Gorey also reduces the scale of Scrooge's transgressions. Gravel's miserly ways extend as far as his writing "by hand several letters to the newspapers anent the price of a typewriter ribbon having risen the day of the winter solstice" (3). This short line delineates that Gravel is cheap: he refuses to use a typewriter and instead writes his complaints out longhand; (in an outspoken act) he writes to a number of newspapers to inform them of this travesty; and he does not show particular interest in the winter solstice, and by extension, the holiday season. $\mathrm{He}$ is guilty of little else but being reclusive, and Gorey suggests that Gravel may also be a hoarder, as he cuts himself "a slice of fruitcake from the last one he had received more than a decade ago" (2). Here, the narrative suggests a number of levels of meaning alongside the fact that Gravel is still holding onto a fruitcake that is more than ten years old. Gorey plays 
with the longevity and heavy preservation of fruitcake, referencing the popular culture conception that fruitcake is inedible and indestructible, and Gravel is "hardly able" to cut himself some. Additionally, as it is the last fruitcake he has received, Gorey neatly summarizes Gravel's own reclusiveness and withdrawal from the greater community. He has not received another fruitcake because he does not socialize with other people.

Conversely, Gravel's companion, the Bahhum Bug, loosely occupies Jacob Marley's position, as he is the first strange creature to appear, and his name not only echoes Scrooge's favourite exclamation, but it is "Humbug, I tell you! Humbug!" (A Christmas Carol, Stave One) that Scrooge shouts at Marley after attempting to brush off his dead partner's presence as, "an undigested bit of beef, a blot of mustard, a crumb of cheese, a fragment of an underdone potato" (Stave One). Thus, the Bug takes on Scrooge's shout in a visceral way, embedded in the text without ever being used as an expletive. Furthermore, the Bahhum Bug appears from underneath the titular tea-cosy, a physical manifestation of Gravel's waiting tea. He is the bit of beef, mustard, cheese or potato determined to disrupt Gravel's trajectory through life. It is telling that he is an insect, as just like the tiny undigested crumb, a bug is of little consequence, being both small and easily dispatched. In this manner, Gorey further reduces the magnitude of Scrooge and Marley's collective sins to a trivial level, disrupting the morality tale at the centre of Dickens' story. Indeed, Gorey is extremely cognizant of the moral heart of $A$ Christmas Carol, and uses that to his advantage. On his first appearance, the Bug explicitly states that he is "here to diffuse the interests of didacticism" (The Haunted Tea-Cosy 5), acknowledging A Christmas Carol's pedagogical purpose, yet for the duration of the tale, the Bug does nothing but observe alongside Gravel and close each spectral scene. While he is dismissive and uninterested in any of the pedagogical moments highlighted by the spirits, any active moments of diffusion are lost in the Bug's passivity. After each ghost reveals things that never were, are, or will be, the Bug concludes the section with variations on, "That is enough of that" (20). The tense of the verb shifts to fit each scenario - past, present and future - neatly referencing what Gravel and the Bug have just witnessed, and which ghost has shown it to them.

These scenes are just as trivial as Gravel's transgressions and the Bahhum Bug's diffused didacticism. From the outset, the spirits are delineated as representations not of possible, but impossible outcomes, removing their potential for impact upon Gravel and the larger world. These are Christmases that never were, aren't now, and never will be, and as a 
result, they can only illustrate by absence. The "small orphan called Nub and a large stray dog" did not "[huddle] against a tombstone whose inscription was worn away" (9). Alberta Stipple's drawing room wallpaper never disappeared (10). The Edward Boggles' clock was never out of time (11). Reverend Flannel never lost his tuning fork, and Alma Crumble never broke her wrist while baking (12-3). These small tragedies are nonexistent, and the present and future that extends from them are necessarily as inconsequential, fragile and fictional as the past on which they are built. Gorey lines up the strikingly tragic - an orphan abandoned in a graveyard - alongside far lesser disasters - lost tuning forks, stolen wallpaper, and inaccurate clocks - giving each equal space and severity. He elevates petty losses and problematic timepieces to the loss of home and family. There are no shades of tragedy in this tale; everything is the same level of disaster, a satire of melodramatic tragedy. As a result, the Scrooge figure that stands witness to these scenes is not viewing a morally moving tale. Gorey removes the pedagogical heart of $A$ Christmas Carol, which should result in the narrative collapsing in on itself. Without the moral message, the instruction in becoming a better person by eschewing greed and selfishness, what is the tale's purpose? Gravel's trajectory is nonsensical in that his experiences with the spectres are disjointed and without ethical guidance. He observes people he does not know - and who may not even exist - take part in events that never happened, and yet he still exits the narrative with a change of heart. Gravel appears to experience change merely through the act of observing humanity. $\mathrm{He}$ becomes a different man through proximity to the past, present and future, and interaction with the Bahhum Bug and the spectres. Unlike Scrooge, who cannot change without direct intervention, Gorey presents a surprisingly more realistic version of $A$ Christmas Carol as his Scrooge experiences growth simply by being in contact with the world.

Very early on in Gravel's travels with the Spectre of Christmas That Never Was, Gravel, the Bahhum Bug and the Spectre come across

[a] small orphan called Nub and a large stray dog named Bruno hudded against a tombstone whose inscription [is] worn away. (9) Nub, the perfect picture of a Victorian waif, clings to Bruno, represented here as not only without a home or family, but residing in the place of the dead, exposed to the elements, made witness to the finality of death. While there is no indication that Nub is huddled against 
one of his parents' gravestones, the fact that the inscription is unreadable indicates that, along with the rest of the witnessed events within the narrative, the nature of Nub's familial loss is undefined and unimportant. It is beyond the scope of the tale, creating a distance and lack of background detail that is the complete antithesis of the lush detail and sentimentality within $A$ Christmas Carol.

Within The Haunted Tea-Cosy, Nub is the closest analogue to Dickens' Tiny Tim. Although Nub is not physically crippled and Tim has an intact family, both are children beset by tragedy, their well-being in peril. Nub is metaphorically crippled by his circumstances, his homelessness standing in for his vulnerability and implicitly invoking the potential of a disastrous, tragic end. Where the possibility of Tiny Tim's death in Scrooge's vision of the future and in the spectre of his own frailty overshadows A Christmas Carol, Nub's parents' deaths overshadow him. Both Tim and Nub suffer from poverty: Bob Cratchet's income is not enough to properly support his family or get Tim the medical support he needs, and Nub is without shelter or family. His protector is a dog, nothing more, and unable to provide for him in any meaningful way. Yet perhaps because the resonances between the two are tenuous at best - indeed, their primary similarities are that they are the weakened, endangered children in both tales - Tim is far more active and articulate within Dickens' novel than Gorey allows Nub to be. Nub does not speak in either The Haunted Tea-Cosy or The Headless Bust, and in his introductory panel, Gorey does not even draw his mouth ${ }^{15}$. Without his mouth, he lacks the physical ability to speak, and without a home, family or any prospects outside of the graveyard, he is unable to fully articulate the sentimentalism inherent in the struggles of the orphaned child. Where Tim is the heart of A Christmas Carol, Nub lacks the agency that would result in positive action or any affect on the larger storyline.

Despite the fact that a figure resembling Nub appears twice more in The Haunted TeaCosy and twice in The Headless Bust, this first panel is the only one in which he is named or referred to by the narration (9). He experiences this one brief moment of time, and when he appears again, he is merely an appendage to the larger narrative, his name stripped away alongside all but the most visual of markers. Nub stands to the side in a cemetery - possibly the same one he began in, but due to the disjointed events that make up The Haunted Tea-

\footnotetext{
${ }^{15}$ Just as Gorey does not draw Charlotte Sophia's eyes in The Hapless Child, a foreshadowing of her eventual blindness.
} 
Cosy, potentially a new one all together - offering three small, scraggly picked flowers to a different gravestone than the one he originally huddled against. He is ignored by the other characters who are the focus of the panel, and while the drawn details echo those of his initial appearance and thus silently continue his plotline, the text itself does not acknowledge him.

It is his third appearance that is especially interesting, in that Nub's trajectory displaces him from his own narrative. Again, the text does not acknowledge his presence, and this time, he is without the illustrated details that would further his tale. While it remains unstated, Nub appears as one of the guests at Gravel's party, and without the graveyard, dog, tombstones or flowers, he is reduced to simple mimicry of Gravel and the Bahhum Bug. He is the smallest figure in this makeshift triptych, all three with arms outstretched ${ }^{16}$ as they admire "a cake taller than anything else in the room" (29). As he is reduced to simple mimicry, Nub has become entirely dislocated from his life, exiting the events Gravel and the Bahhum Bug witness and entering their shared space as a third observer. Without parents or other caretakers to anchor him, Nub the orphan floats progressively freer of his own narrative. It is in this dislocation that Gorey subverts his Tiny Tim analogue. Tiny Tim acts as an anchor around which the sentimentality and morality of Cratchett, Cratchett's family and Scrooge revolve. Tim's health is a lynchpin: although it is both a cause and effect of his family's poverty, when Tim dies in the Ghost of Christmas Future's visitation, the emotional health of the Cratchett family disintegrates. In sharp contrast, Nub does not have the power to influence Gravel - and indeed, Gravel's change of heart does not appear to be at all related to any of the events he witnesses within The Haunted Tea-Cosy - and thus becomes increasingly detached from his narrative, losing his name, his relevance to the events in Lower Spigot, and eventually his place within the central narrative.

The nonexistent events that Gravel and the Bahhum Bug view, and which so alter Gravel, exist in layers on top one another, as evidenced by Gorey's very Dickensian play with names. Edward Gravel not only shares his initials and first name with his creator, but his surname provides the reader with clues to his character as an anti-social loner. Just as gravel is rough, uncomfortable and unpleasant under one's feet, so too is Gravel, who does not fit smoothly and comfortably in more gregarious society. The rest of the characters have

${ }^{16}$ This triptych also evokes the large, expressive gestures native to melodramatic theatre and nineteenth century tableaux. 
similarly playful names which twine together over the course of the narrative into ever increasing spirals of rhyme and letter arrangement. Where the past provides us with Nub, Bruno, Alberta Stipple, the Edward Boggles, Reverend Flannel and Alma Crumble, the present supplies Nero, Edo Haggle, the Edgar Grapples, Albina Fennel and Alfreda Scumble, and the future introduces us to Fido, Edwin Stopple, Lady Snaggle, Alethea Funnel and Alicia Grumble. As each spectre presents scenes that did not, cannot and will not exist, each tense permutation differs significantly enough from the previous one so that the shift between scrambles these names, reorders these characters, and represents unfulfilled possibilities.

On a simple level, the dog character shifts through three different names: Bruno, Nero and Fido. Each name is typical for a pet, and each holds the same cadence of two syllables, trochaic in intonation and ending in a long ' $\mathrm{o}$ '. Further, there is a definite progression to the dog's trajectory. Bruno, the past incarnation, is a large black stray dog who huddles with Nub, his orphaned boy, lost and abandoned in a cemetery. They are the perfect picture of Dickensian waifs. Bruno is able to provide warmth and comfort, and a modicum of passive protection for the young child. Nero, the present version, is similarly paired with a child, and moves from passive to aggressive, as he barks as "Alfreda Scumble [is] abstracted from the veranda by gypsies" (17). As the cemetery is a perfect place to find a parentless child, so too are gypsies the perfect stereotypical abductors, as they fit directly into popular fables about child-stealing nomads. They are the archetypal villains, cast in the role in order to teach behavioural lessons and scare children. Alfreda takes Nub's place, as she is a young girl whom Nero protects; however, she is dressed much better than Nub, and she is abducted from a veranda: clues which indicate that she is not an orphan, and that Nero has moved up in the world and is no longer a stray. Additionally, the shift from "Bruno" to "Nero" indicates a shift in fortune as well. Where Bruno references a type of bloodhound, the Bruno Jura Hound, Nero most obviously refers to the Roman Emperor of the same name. Where popular conception and urban myth suggest that Nero "fiddled while Rome burned," so too does the canine Nero uselessly make noise as tragedy - in the form of Alfreda's kidnapping - occurs. Transitioning into the future, Nero becomes Fido, a large white dog with the most stereotypical of canine names, belonging to an unnamed young boy bearing a startling resemblance to Nub. Unlike Nub, Gorey depicts this boy as part of a prosperous household, able to employ a maid: the very person who returns Fido to the arms of his child. The dog's young companion has moved up in the world from an abandoned orphan to a kidnapped child 
and, further still, to a safe and privileged boy. Yet the dog's fortunes have plummeted. Although he is a stray in the past, he remains with his child, and continues to provide a measure of protection. In the present, however, he loses his companion as he is unable to protect her. Even worse, once he moves forward into the future, he not only loses his colour - taking on a deathly pallor - but also his life. Fido is "returned from the taxidermist and set down by the fireplace" (24), removing all agency and life altogether.

Another thread which winds its way through the text is the mystery behind the missing wallpaper. As Gravel looks on in the past, "Alberta Stipple return[s] home to find the wallpaper in the drawing room gone" (10). This panel is the only one which does not sport a wash of colour across the background, emphasizing the paper's absence. The whiteness thus acts as a visual hole, lacking even the smallest stipple of paint. Indeed, Alberta's surname is a Dickensian one, as it is playfully melodic and suggests Alberta's place within the narrative. Stipple, after all, is the act of painting through application of small dots of paint as well as the resultant textured surface. Alberta Stipple is thus indivisible from her wallpaper, missing though it may be; and although the starts and stops of the line pattern of her high-necked, ankle-length, puff-sleeved dress are common features of Gorey's artistic style, they also work here to mimic a stippling effect.

This literal hole in the text - the missing wallpaper - carries through into the present. It does turn up, but without an appearance from Stipple or her present tense analogue. In fact, with the exception of the final two panels, which describe Gravel's party, it is the only panel that lacks reference to a character. The text underlines the lack of an active subject by indicating that "a wrong coffin in a newly dug grave was found to contain rolls of used wallpaper" (19). Gorey's use of the passive voice removes the agency from the two men pictured retrieving the wallpaper from the grave, as they are relegated to positions of unimportance, merely facilitators for discovery; as a result, the wallpaper takes centre stage. Indeed, by occupying the coffin and grave, it takes up the space set aside for a body. Thus, by being named, and with no Alberta Stipple to mourn its loss, it takes on the position of a character, superceding its own owner(ship).

While there is a strong sense of disconnection from reality in The Haunted Tea-Cosy engendered by fantastical elements such as the magical realism of the Bahhum Bug, the paranormality of the spectres, and travel across time and space, Gorey also grounds the narrative in his suggestion of location. He immediately identifies Gravel as "the Recluse of 
Lower Spigot" (1), providing readers with a setting that, while fictionalized, suggests the English countryside. Gravel does not simply live in Spigot; he is a resident of Lower Spigot, a locational detail reminiscent of hamlets and villages such as the Bedfordshire County's Upper and Lower Shelton, and Upper and Lower Caldecote; and West Yorkshire's Upper and Lower Cumberworth, and Upper and Lower Denby. If there is a Lower Spigot, it logically follows that there is also an Upper Spigot not far away. Gorey is particularly careful to provide further locational clues that allow the audience to mentally sketch out the boundaries of Gravel's world. When he and the Bahhum Bug are whisked away by the Spectre of Christmas that Never Was, they find "themselves at a great distance somewhere to the north" of Gravel's home (8). Once they observe Nub and Bruno in the cemetery, they are directed "[a]cross the road from the churchyard" to Alberta Stipple's home (10). Directly after, they move "[t]hree doors to the east" to the Edward Boggles' house (11), and immediately following that observation, they find themselves in "the high street of the village" (12). They then conclude their visit to the past "[i]n the cottage next to the post office" (13) before returning to Gravel's rooms. Each of these details, when pulled together, provide an almostcomplete map of Gravel's route. These navigational points continue throughout the present and future excursions. The present revisits the cemetery, which is now to the south of much of the other present-tense events, and while it is the only location that remains the same, it does allow for an overlay between tenses and an extrapolated loose outline of the village in which these happenings take place.

Gorey's geography mimics Dickens' "living cityscape[s] which [yield] complex vicarious emotions" (Baumgarten 219). Dickens' settings are integral to his plots, as they replicate London in the midst of the increasing industrialized turmoil of the mid- and late nineteenth century. For instance, A Christmas Carol contains especially vivid descriptions of London streets in the face of the descending cold of winter, in which

the fog and darkness thickened so, that people ran about with flaring links, proffering their services to go before horses in carriages, and conduct them on their way. The ancient tower of a church, whose gruff old bell was always peeping slily down at Scrooge out of a Gothic window in the wall, became invisible, and struck the hours and quarters in the clouds, with tremulous vibrations afterwards as if its teeth were chattering in its frozen head up there. The cold became intense. In the main street, at the corner of the court, some 
labourers were repairing the gas-pipes, and had lighted a great fire in a brazier, round which a party of ragged men and boys were gathered: warming their hands and winking their eyes before the blaze in rapture. The water-plug being left in solitude, its overflowings sullenly congealed, and turned to misanthropic ice. The brightness of the shops where holly sprigs and berries crackled in the lamp heat of the windows, made pale faces ruddy as they passed. Poulterers' and grocers' trades became a splendid joke: a glorious pageant, with which it was next to impossible to believe that such dull principles as bargain and sale had anything to do. The Lord Mayor, in the stronghold of the mighty Mansion House, gave orders to his fifty cooks and butlers to keep Christmas as a Lord Mayor's household should; and even the little tailor, whom he had fined five shillings on the previous Monday for being drunk and bloodthirsty in the streets, stirred up to-morrow's pudding in his garret, while his lean wife and the baby sallied out to buy the beef. (Stave One)

This passage leads the reader from Scrooge's counting-house to the world outside, sketching out the surrounding streets and buildings and communicating the flurry of activity of a variety of individuals in their quests to combat the coming cold and prepare for Christmas festivities. Dickens' settings are alive with detail and movement. Gorey's settings, however, give the appearance of a similar level of detail, but presented as they are through illustrated tableaux and short bursts of text, they lack the movement and life inherent in true Dickensian landscapes. These Goreyesque landscapes are static; each scene takes place in a room empty of all but the barest of essentials, or outside in panels that depict frozen moments rather than lengthy sequential pieces which would portray character progress. This removal of life and activity from the Dickensian setting is a reflection of Gorey's larger removal of the social conscience of the Dickensian tale. Once again, Gorey's narratives present the surfaces of the genres he engages with while stripping away their underlying purposes.

As Gorey provides this village sketch, there is also a built-in disconnect between Gravel and the events he witnesses. After all, the spectres transport him "a great distance somewhere to the north" (8). Even if Lower Spigot is very large, the scenes he witnesses take place in a village (12), and often occur across a street or within a space of two or three neighbouring houses. Given that villages consist of small populations to begin with, the 
likelihood that Lower Spigot encompasses the locations Gravel views so far to the north is extremely slim. Further, when Gravel and the Bug return to Lower Spigot at the end of the tale, Gravel declares that he "shall give a party and ask everyone in Lower Spigot and others from elsewhere" (28). While this sudden gregariousness is in line with Scrooge's own change of heart, there is no need for Gravel to include "others from elsewhere" if, indeed, his enlightenment comes from encounters exclusively within his own village. Gorey is thus distancing Gravel further from the Christmases That Never Were, Are or Will Be past the simple impossibility of their occurrences, adding a geographical distance. Thus, they exist in a negative time and space.

Although this text utilizes colour - unlike most of Gorey's other works - The Haunted Tea-Cosy is comparatively spartan in terms of the riotous patterns and rich details found in the majority of Gorey's oeuvre. Gorey continues to make use of cross-hatching, patterned floors and accoutrements, but the walls and skylines of this tale are filled only by muted colour. Outside of the boundaries of the Goreyesque, an examination of these panels would lead to their consideration as highly detailed representations, yet within a Gorey framework, they are far more austere. The colours suggest rather than outright represent what is normally present in other texts: with the exception of one panel, in which the wall is all white as a consequence of missing wallpaper, and which holds the only painting or wall hanging in the entire piece (10), the figures in each panel, regardless of setting, stand against plain, muted washes of pink, grey, green or orange. Further, with the loss of the starkness afforded by all black and white illustrations, the patterns are not as distinctive as they are partially lost amongst the colours. The human and animal figures, however, remain entirely black and white, which gives them a special prominence amongst their settings. Yet with few exceptions, the colours help the audience to properly place each shift in location. Pink backgrounds are (almost) always Gravel's home (panel number 25 being the only divergence), grey ones are always the outdoors, and orange and green backgrounds are neighbours, villas, and other people's residences. These washes lend the story a gravity and depressive atmosphere akin to the claustrophobia Gorey most often represents through heavy draperies and detailed wallpaper.

This starkness continues into Gorey's followup work, The Headless Bust: A Melancholy Meditation on the False Millennium. It picks up immediately after the end of The Haunted Tea-Cosy, and where The Haunted Tea-Cosy directly parodies A Christmas 
Carol, The Headless Bust takes the conceit further. After Gravel's guests have gone and his Scrooge redemption moment has passed, Gravel and the Bahhum Bug - now referred to as the "Bahhumbug" - find themselves propelled into another adventure. Where The Haunted Tea-Cosy asks them to consider pasts, presents and futures that never happened, their guide in The Headless Bust asserts that

'Initial, dash cannot conceal

The fact that everything is real,

But whether it is also true

Is left entirely up to you.' (6)

Where The Haunted Tea-Cosy concerns itself with the nonexistent past, present and future, The Headless Bust questions the nature of reality itself. From these opening lines, Gorey points towards a fictionalized realm, as these concealing initials and dashes are a direct reference to one of the conventions of roman à clef writing, originating in the seventeenth century, and popular through the nineteenth. Using the first letters of a real person's first and last names followed by a dash allows for semi-realistic writing which sidesteps direct references to living people, as well as providing an authorial level of plausible deniability which still leaves room for scandalous gossip in fictional form (Boyde 155). The Headless Bust is not the only one of Gorey's works to employ this form; however, it is the most direct acknowledgement of the artifice in operation. Gravel's guide, the small, bug-like creature named very late in the text as the "Whatsit" (26), invites both Gravel and the Bahhumbug to consider whether the real scenes that they witness are true or false, and in doing so, strips away the fictional layer that protects roman à clef nomenclature. Yet at the same time, Gorey's characters are entirely fictional, and appear to reference his love of alphabetical play rather than real world individuals. Not one of the names relegated to the initial and dash form repeats previously used letters. With the exception of "Pf " (22), and excluding titles and honorifics, each name is exactly one letter long, followed by the requisite dashes. Collectively, these thirteen names, employing fourteen letters, cover more than half the alphabet, and utilise some of the least-used letters in the English language, including Q, V, X and $\mathrm{Y}$. This alphabetical play brings a complexity to the presentation of reality within The Headless Bust. Gorey uses these initial and dash pairings to lend the text an air of historical legitimacy, yet undermines that legitimacy through the lack of letter replication and an implicit connection with his myriad of abecedariums. Read within Gorey's larger set of 
works strengthens the alphabetical ties, as many of his tales, including The Glorious Nosebleed (1975), use the initial and dash form to place characters within an alphabetical narrative.

Gorey acknowledges the artifice of The Headless Bust in the very first stanza of the narrative:

'Twas hours and hours after dawn

Ere the last guest was fin'lly gone.

Ça va, hélas, from bad to worse:

Adieu to prose, allô to verse.

The shift from The Haunted Tea-Cosy's prose to The Headless Bust's poetry also signifies a shift in narrative tone. The rhythm, metre and form of poetry allow for a level of artifice that, in this case, separates the action further from the reality the Whatsit presents. Each stanza throughout the tale is made up of rhyming couplets arranged in iambic tetrametre. When read aloud, the rhythmic structure coaxes the speaker into a litting, sing-song pattern, divorcing the text even further from regular speech and realistic conversational tones. As a result of the poetic form, the narrative steps further away from the heavy moral tale at the core of $A$ Christmas Carol, as The Headless Bust is far more concerned with form than morality. The regulation and reformulation of prose into poetry reshapes the text's relationship with the audience so that the reader is explicitly aware of the artifice of the narrative. This technique paves the way for the concerns at the heart of the tale: while the Whatsit asserts that all the visions Gravel and the Bahhumbug witness are real, those realities come under extreme scrutiny as the viewers - Gravel, the Bahhumbug and readers - are exhorted to extract truth from falsities.

Much like the scenes in The Haunted Tea-Cosy, The Headless Bust is filled with events of varying levels of tragedy, all presented with the same degree of seriousness. The Whatsit reveals that the writer $\mathrm{V}$ has an extra toe (7) with as much gravity as a pair of ruined shoes (18), a ripped dress (20), the conviction of a badly-dressed woman (14), and the disappearance of a family member (22). Not only does this equalization of tone result in an undercutting of any sense of urgency or ominousness, but the overwhelming question of whether or not these scenes are true or false further removes any authentic weight. Gravel and the Bahhumbug are once again in a position in which what they see does not directly affect either themselves or the world at large. While there is a possibility that some of the 
scenes are, indeed, true and factual accounts, they all take place at a large remove, in "some remote provincial town" (5), even further away than the village they visit in The Haunted Tea-Cosy. They are so distanced from any real action that whether these visions are true or false is a non-issue. In fact, the Bahhumbug vocalizes this dissonance, as he says,

'Much ado...

What does it matter if they're true?'

The Whatsit hissed, dissolved in air,

And was no longer anywhere. (26)

In light of the Bahhumbug's question, the Whatsit is unable to retain a physical presence and disappears; the question is a destabilizing one that undercuts the supposed thrust of the narrative: the nature of reality. By declaring the irrelevance of truth, the Bug undermines the philosophical heart of the tale and removes any moral lesson. Unlike The Haunted Tea-Cosy, once Gravel and the Bug are transported back to Gravel's abode, there is no further change to their behaviours. The excursion is completely negated as they simply continue to clean up after the party that ends The Haunted Tea-Cosy, and they relegate the events of the evening to the realm of mystery:

'Who were those people? Why did they

Appear to us along the way?'

'But then again, why should we care?

It's quelque chose d'un grand mystère.' (28)

The Headless Bust expresses a profound sense of ambivalence for the Whatsit's scenes, the truth, and on a larger level, the turning of the century. Over and over, Gravel and the Bug are tasked to consider the truth of any one event, yet they ultimately reject the worth of such judgements. This rejection of the larger importance of the end of the year and the beginning of the twenty-first century is especially explicit in panel 23. At this point, a giant eggplant appears "[o]n which were limned for all to see/The mystic letters Q.R.V." "Q.R.V." is one of a series of Q-Signals used by wireless telegraph operators, and later amateur radio enthusiasts, to transmit short standardized messages. This code was created and popularized at the beginning of the twentieth century, in 1909, by the British Postmaster General. Depending on whether or not an interrogative symbol appears at the end, Q.R.V. means "All right now, everything is in order," or "Is everything in order?" (McEwen Appendix III). The strange and sudden appearance of this sequence on the eggplant - in a tale which carries no 
other paranormal elements - suggests a question that speaks to the larger issue outside of the immediate viewpoint of Gravel and the Bug. Are they ready for what is to come? Given the continual rejection of the questions asked by the text and the fact that their response to the end of the millennium is to do nothing more but sit on the carpet and drink tea (30), one must conclude that, as with their refusal to discern what is truth and what is falsehood, neither Gravel nor the Bug particularly care to prepare for the new century. In essence, The Headless Bust communicates a deep ambivalence on every level, and outright rejects Dickensian moralization and sentimentalism.

Dickens' narratives move beyond simple sentimental versions of the nineteenth century, using excess emotion as a vehicle for underlining the sources of social strife: these Dickensian passions allow for polarization of good and evil, innocent and experienced, and thus provide stronger delineation between Victorian reformist visions and the status quo. The Haunted Tea-Cosy and The Headless Bust, however, are exercises in removing these motivating messages for social change, leaving the reader with A Christmas Carol stripped of its strong morality and sentimentality. The Retrieved Locket operates in a similar manner, presenting the barest bones of a Dickensian tale, then refusing to fill in any details or allow the characters to move forward. Dickens' world oscillates between a harsh vision of a London caught in the midst of social, political and industrial change, where the gap between rich and poor is wide and bridgeable only through blood or inheritance, and the softness and sentimentality of happy families united in celebration and joy. These strong moral and emotional stances are completely missing from Gorey's Dickensian visions, bringing about a curious result: not only are Gorey's texts less emotionally affecting than Dickens' sentimental narratives, but they are also harsher than his social commentaries. Gorey's dispassionate narratives do not provide the reader with characters to empathize with, nor do they allow for any satisfactory punishments or rewards. Unlike A Christmas Carol, where Scrooge learns from a lifetime of miserly behaviour, Gravel comes away from both The Haunted Tea-Cosy and The Headless Bust completely unchanged. His visions are of events that did not happen and people he does not know; they are completely irrelevant, making his entire excursion pointless. Gorey's Christmas and New Year are utterly ambivalent and lacking in the sentiments associated with these holidays in popular culture: there is little cheer, hope, love, kindness and charity presented here. Gorey's Dickensian texts are bleak; if the moral heart of Dickens' stories is removed, what is left is not just the surface trappings of the genre, but an 
exceedingly desolate physical and emotional landscape. It is not just that Gravel does not learn and change, it is that he cannot learn or change. The narrative remains frozen in place, its characters doomed to remain within the very social fabric that Dickens' own narratives disrupt, overturn and criticize.

Gorey's use of Dickensian tropes is therefore anti-Dickensian in that it is completely devoid, not only of the sentimentalism and emotional excess that Dickens shares with melodrama, but also the social commentary that marks Dickens' texts. For all that Gorey provides signposts that these three texts are Dickensian, none of them follow through and fulfill their genre promises. While to a certain extent it is possible to label all of Gorey's texts "anti-" the genres with which they play, most of his genre work is exploratory. By stripping away meaning and morality in melodrama, he reveals the structural foundation on which the genre rests. Yet his hollowing out of Dickensian tropes is more aggressive for lacking the gravity that underlies texts such as A Christmas Carol and Oliver Twist. The Retrieved Locket, The Haunted Tea-Cosy and The Headless Bust are more sharply devoid of meaning for their refusal to do more than present the basic ingredients of a Dickensian tale. The Retrieved Locket consciously refuses to move the plot forward in an active way, allowing the Fibleys to stagnate in an unresolved state: Amelia Emily is missing, yet none of the characters use the clues directly in front of them to resolve her fate. Instead, they deliberately choose to live out their lives in service to an awkward lie, one whose unbelievability is evident every time they look at the new "Amelia Emily." Gorey refuses to represent the excess emotionality associated with a story of a child in peril, and further refuses to provide any commentary whatsoever on what such a loss means, how it affects the parents involved, and how the authorities and community react. Despite the police's lack of investigatory effort in this narrative, none of the characters, nor the text itself comments on the ramifications of such inattention. In The Haunted Tea-Cosy and The Headless Bust, Gravel does not experience any revelatory events that might otherwise improve his character. These characters, the Fibleys and Gravel, live in a world in stasis, and through passivity and inaction, they become frozen in place as well.

In this manner, they cut across not one, but two genres: Dickens and the Dickensian. As Gorey's Dickensian texts display a direct awareness of Dickens' narratives, his stories sit at the intersection between direct interaction with Dickens and indirect referencing via popular culture. These works present the basic framework shared by Dickens and the 
Dickensian, but go on to fulfill none of either genre's promises. Alongside the lack of social commentary and strong sense of place is a deficiency of emotion. There are no happy families in these texts, nor suffering orphans or put-upon heroes who will be rewarded at the end of the day. They are tableaux, frozen in time, unable to move forward or backward, caught at the moment of Dickensian genesis. Without a moral ending to strive for, and without excessive emotionalism and atmospheric landscaping, these texts reveal an utter hopelessness at their hearts. These main characters drift through their lives, without purpose. Of all of Gorey's genre play, his Dickensian texts are some of the bleakest precisely because they do not allow for forward movement of any kind. Although Gravel journeys through the past, present, and future, and is invited to consider the nature of reality, at the end of each sojourn with the Bahumbug and his guides nothing has changed. He has no appreciable effect on the lives of the people he views, and they have no effect on him. The Fibleys' lives are even more bleak, as they wilfully choose to remain in an unknowing state, passively selecting what is directly in front of them and blatantly ignoring the evidence in front of their eyes.

With few exceptions, much of Gorey's genre play deals with fictional texts that exist primarily for entertainment. When social commentary is a major component of the genre under manipulation, however, Gorey's customary stripping away of meaning results in harsher, bleaker works as a result of the excised real-world link. In doing so, Gorey underlines the importance of Dickens' engagement with nineteenth century social and political issues. Past the excess of emotion, Dickens engages with his London in an intrinsically important way. His representations and critiques of society lead to critical thinking and forward movement outside of the fictional realm of the novel. By removing that critique, Gorey's Dickensian characters forestall any development or transformation while their plot lines stagnate, frozen in tableaux. The inherent link between Dickens' fiction and the real world charges his works with weightier metatextual discourse than the melodramas that exist alongside his novels, and therefore any removal of the meaning behind his texts results in an even more explicitly hollow and distressing lack. Perhaps it is in his excising of purpose in these Dickensian Gorey works, rather than in his ghoulish play with Gothic horror and pedagogical texts, that the horror truly lies. Like so many of his other texts, these works do not promise rewards, morality, reunions or revelations, but they also go one step further: The Retrieved Locket, The Haunted Tea-Cosy and The Headless Bust are studies in existential 
inertia. They cannot move forward precisely because the characters within each work refuse to move forward, adopting a nihilistic attitude to the world around them. 


\section{Chapter 4: Pedagogical Nonsense}

As Gorey's works consist primarily of short pieces of text paired with illustrations, on the surface, they appear to be principally aimed at a young audience. This reader expectation is one connected directly to the status of illustrated and graphic novels in twentieth and twentieth-century literature. As "adult" literature is primarily text-only, and "children's" literature is often heavily illustrated, illustrated works, regardless of narrative content, tend to be considered the province of young readers. Furthermore, by virtue of form only, such sequential art narratives become associated with the comic format, which has been disregarded as "crude, poorly-drawn, semiliterate, cheap, disposable kiddie fare" (McCloud 3). As a result, Gorey's preferred medium is at odds with his narrative content. On a superficial level, works such as The Haunted Tea-Cosy, The Headless Bust, The Green Beads, and The Hapless Child send signals that they fit into the larger category of children's literature, but after engagement with their content and thematics, it becomes rapidly clear that Gorey is not, in fact, explicitly writing for children ${ }^{17}$. As Karen Wilkin observes,

Gorey himself was equivocal about his relationship to children. He occasionally said that he intended some of his work for young readers, while at other times he declared that he was perplexed when told that children liked his books, claiming to know few children and insisting that he hadn't thought about anyone but adult readers. The subtle references to literary and visual

${ }^{17}$ When submitting a paper proposal for the 2013 International Conference on the Fantastic in the Arts titled, '"Do You Dream of Heaven? Have You Wanted to Die?': The Perils of Childhood in Tim Burton's and Edward Gorey's Texts," I experienced this disconnect first-hand. Despite having submitted my proposal to the Visual \& Performing Arts and Audiences (VPAA) Division, which "accepts papers on visual arts such as comic books, paintings, architecture, sculpture, photographs and illustrations...and audience/reception studies concerning audiences for any medium or genre of the fantastic," I received an acceptance letter from the Children's \& Young Adult Literature \& Art (CYA) Division, which "accepts critical scholarship papers that focus on literature aimed at younger readers" (fantastic-arts.org/). As became clear when I questioned this shift in Divisions, since my proposal concerned child protagonists and representations of childhood in Gorey's and Burton's texts, the VPAA Division Head felt it would fit in with CYA better than the Division to which I had submitted. It required a number of emails and explanations of both my paper and Gorey's and Burton's positioning as genre authors before I was switched back to the correct Division. 
precedents with which his books are laced bear out the accuracy of this last statement...Gorey recalled urging one of his publishers to market his books to children and being told that they were unsuitable for young audiences.

(Elegant Enigmas 28)

Yet many of his texts conform to picture book standards. Kuskin observes that [1]ike poetry, a picture book has to be written in two ways. It must work when read aloud, and also when read silently to oneself. Every syllable counts. Most important, the well-chosen words need to be simple but never simplistic, clear and strong enough to interest a child and hold her attention. Style alone is not sufficient...Short, interesting stories are the structural steel that supports the illustrations in picture books... The reader follows, drawn by the pictures into the story, by the story into the pictures. It is this always-changing relationship of words and picture that makes and shapes picture books. (160-

Gorey's works are, indeed, economical pieces in which each word carries the weight of poetry; each line is highly crafted for both spoken and silent reading; and the illustrations are as vital to the plot as each sentence. His illustrations invite second looks and detailed viewing, adding layers to the brief, compressed sentences and verses that accompany them. These images cannot be removed from the accompanying text without removing narrative coherence. As with an exceptionally high number of picture books, Gorey's protagonists are most often children. It is through these children that Gorey is able to exploit adult sentimentality regarding childhood. As with his melodrama and Dickensian works, he cultivates the generic cues that encourage emotionalism and sentimentalism only to forcefully distance the reader from the narrative. This distance results in a space in which the expected emotion transforms into amusement, as Gorey invites his audience to laugh at both the text and their own emotional expectations. The audience therefore expresses any remaining sentimentality by rejecting such feelings: an action that runs parallel to Gorey's push to separate narrative from reader.

According to child psychologist Bruno Bettelheim, children's fairy stories suggest "that a struggle against severe difficulties in life is unavoidable, is an intrinsic part of human existence-but that if one does not shy away, but steadfastly meets unexpected and often unjust hardships, one masters all obstacles and at the end emerges victorious" (Bettelheim 4). 
Many children's texts therefore present child protagonists faced with adversity, which they are able to overcome through cleverness, their own fortitude, outside help, or even simple circumstance. In contrast, Gorey's children are subject to extreme trials that frequently end in death without moral teachings, nor otherworldly rewards. His tales go beyond the depiction of miserable fates to revel in such hideous endings: his children are at the mercy of their circumstances, which are most often the results of random chance and coincidence, entirely outside of the scope of controllable actions. Accidental death is frequent, the equivalent of anvils or pianos falling from the sky, and the difference between a happy ending and a tragedy is oftentimes no more than a simple missed connection or opportunity. Gorey exploits sentimentality in these narratives, cultivating readers' responses to children and childhood, where

a rewarding, good life is within one's reach despite adversity-but only if one does not shy away from the hazardous struggles without which one can never achieve true identity. [The stories Gorey evokes] promise that if a child dares to engage in this fearsome and taxing search, benevolent powers will come to his aid, and he will succeed. The stories also warn that those who are too timorous and narrow-minded to risk themselves in finding themselves must settle down to a humdrum existence-if an even worse fate does not befall them. (Bettelheim 14)

Gorey, however, revokes such notions of reward and punishment, as his children are unable to effect change on their world, regardless of whether they strive for better circumstances or remain utterly passive. The evil of the fairy story is not ambiguous; there are no ambiguities in such tales (Bettelheim 5). In stark contrast, Gorey's texts are all ambiguous. Pure evil and good are superfluous terms when applied to his oeuvre, as they would imply a moral system underlies his narratives. For Gorey's child protagonists, events happen for no reason other than they simply $d o$; there is little point in engaging in the struggle to better themselves as their world is chaotic and their lives miserably short.

Gorey's tales take the form of narrative poetry, limericks, abecedaria, and picture books, all formats that lend themselves to comedic expressions and child-friendly works, making their content all the more delightfully grisly. His "vision is a modern comic Gothic one, full of tongue-twister names and neurotically minimalist plots" (Bodmer 116), all in service to a macabre version of childhood. Even as such gruesome fates appear in most of 
Gorey's texts, it is in his stories that explicitly engage with children's literature that Gorey most plays with ethics and expectation. As Karen Coats observes in "Conventions of Children's Literature: Then and Now," "[n]o other literature is quite as implicated in the ethics of readership as books written for and marketed to children" (390). Children's literature comes with an implicit motivation to teach, whether that lesson is identifying letters, numbers, objects, or socially acceptable standards of behaviour; and as with his texts that play with other genre characteristics, Gorey's parodies of children's literature consciously undermine such pedagogical purposes. Additionally, while most of Gorey's texts play with the genre as a whole, his work with pedagogical narratives stands out as a deliberate exploitation of the sentimentality of children's literature, populating such stories with Dickensian child protagonists as he manipulates the tropes and structures found in these works.

Abecedaries are the most formal and pedagogical type of children's literature, and they have a long history. Early abecedaria, such as the Etruscan Marsiliana d'Albegna tablet (700 $\mathrm{BCE}$ ), took the form of basic listings of alphabetical characters without accompanying explanatory text (lila.sns.it/mnamon), but as the abecedarium form developed, these ABCs were often embellished with narratives that created associations with each letter, such as "A is for Apple." As time went on, they became a platform for both tangible and esoteric teachings, from tools to create links between language and physical objects to delivery systems for religious and ethical teachings. Pre-nineteenth century pedagogical texts, such as The New England Primer (c. 1690), included abecedaria focussed on imparting religious teachings, integrating sacred texts such as the Bible. These didactic works aimed to instill moral lessons in their readers, promising fire and brimstone for children who did not learn the boundaries of their faith alongside their letters.

As the nineteenth century approached, however, religion-based teachings were overtaken by more secular practices, and abecedaria moved towards more generally ethical teachings. In the case of writers such as Edward Lear and Lewis Carroll ${ }^{18}$, a cheerful anti-

${ }^{18}$ Although best known for his nonsense poetry and Alice books, in 1868, Lewis Carroll published The Alphabet-Cipher, a Vigenère cipher intended for encoding messages through alphabetical substitution. This polyalphabetic cipher highlights at least a passing interest on Carroll's part for alphabetical forms. 
didacticism arose, manifesting in more secularized fantasy and nonsense verse. Even as abecedaria remain

one of the most rigid forms of children's literature, the alphabet book is ripe for innovation and exploration. The alphabet book looks like a teaching tool for children, but its entertainment value has always lain in the stretching of its borders. Modern writers undermine its capacity for teaching and the expectations of its assumed young audience; like much in contemporary literature it reflects our distrust of "safe" borders in art and life. Even our ability to learn and to teach is questioned. (Bodmer 115)

For writers such as Lear and Carroll, the goal was not education, but rather entertainment alongside enthusiasm for language in and of itself. The sounds of syllables and rhythms thus trumped any teaching impulse. The mid-to-late twentieth century brought another turn, in which abecedarial didacticism came back into force. Authors such as Dr. Seuss and Richard Scarry preserved the cheerful tone characteristic of nineteenth century $\mathrm{ABCs}$, but restored the pedagogical heart of such teaching texts by focussing on educational instruction rather than moral. Although a strong thread of nonsense words and sounds continued to run through these texts, at their centre, they strove to teach children and other new readers letter identification, formation and pronunciation alongside recognition and naming conventions of real-world objects. Though they were written within the same timeframe, rather than following along in a similar fashion with his twentieth century peers, Gorey's abecedaria create something new out of the full historical gamut of this form.

Where traditional teaching abecedaria consist of instructive or child-friendly illustrations, Gorey's The Gashlycrumb Tinies (1963) flouts such conventions. The work is composed of twenty-six illustrated panels in which twenty-six Edwardian children die in twenty-six different ways. Each panel is accompanied by one couplet from the larger poem that makes up the text of the work, detailing each child's death in alphabetical order. The poem is bookended by a frontispiece depicting the children watched over by a tall personification of Death dressed in undertaker's clothing and holding an open umbrella aloft, and an outro illustration of twenty-six shaded headstones. Instead of alphabetically arranged animals, plants or toys positioned as objects to which children are drawn, this text is full of children themselves. They are the instructive objects, yet the shift is not solely an exercise in changing the locus of attention, but rather a larger parodic project. In place of the large, 
colourful, friendly drawings reminiscent of artists such as Dr. Seuss are small black and white illustrations filled with tiny, hard-to-see details; rather than entertaining verses that end happily like Edward Lear's "The Owl and the Pussycat" and "The Jumblies" are rhythmic rhyming lines that drive the reader onward to each child's death. Gorey himself illustrated both "The Jumblies" and "The Dong with the Luminous Nose" and his own antididacticism is reminiscent of Lear's nonsense poetry. Yet in contrast with the cheerful optimism of Lear's verses, Gorey's Gashlycrumb Tinies can be described as "a revenge against those who would take an alphabet book seriously, a sarcastic rebellion against a view of childhood that is sunny, idyllic, and instructive" (Bodmer 117).

As with his melodramatic and Dickensian tales, Gorey's strengths lie in his knowledge of and ability to manipulate the very form he parodies. Gorey uses the tools at the very heart of children's literature and picture books in his deconstructive narrative, including play with language. Wordplay is important not only in Gorey's abecedarian, but across Gorey's oeuvre, evident in his extensive use of pseudonyms ${ }^{19}$. Amphigorey Again (2007), the fourth volume of Gorey's collected works ${ }^{20}$, lists thirty-one pseudonyms Gorey used over his lifetime, including "D. Awdrey-Gore," "Dreary Wodge," "Edgar E. Wordy," "Eduard Blutig," "Ogdred Weary," "Roy Grewdead," and "Ydora Wredge." Most of these pseudonyms are anagrams of "Edward Gorey" interlaced with plays on words and meanings, but a few are also deliberate translations chosen for humourous affect, such as "Eduard Blutig," as "blutig" is a German synonym for "gory." Gorey does not use a pseudonymic attribution for Gashlycrumb, but the wordplay is very similar in the way apparently inconsequential word choices suggest macabre (or gory) meanings. In The Gashlycrumb Tinies, the spectre of death appears before the text even begins, with the title alone giving full evidence of Gorey's love of wordplay. While at first glance, "Gashlycrumb" appears to be nothing more than a formal surname or title, the syllables contain significant clues to the rest of the narrative. "Gashly" is extremely close to "ghastly"; a matter of one missing and one moved letter: adding a ' $t$ ' before the ' $y$ ' and moving

${ }^{19}$ Here again we see the stripping out of purpose: a pseudonym is usually used to disguise an author's identity, or to offer more than one authorial identity to distinguish different strands of an author's work; in contrast, Gorey's use of pseudonyms has the opposite effect of emphasising the Goreyesque.

${ }^{20}$ Preceded by Amphigorey (1972), Amphigorey Too (1975), and Amphigorey Also (1983), all of which are a play on "amphigory," a work of nonsense. 
the ' $h$ ' between the ' $\mathrm{g}$ ' and 'a' completes the switch. Even without manipulating its spelling, "gashly" is a near-homophone for "ghastly," and often appears as a slang or dialectic version of the word. For instance, in Mark Twain's The Adventures of Huckleberry Finn (1884), on the discovery of a corpse, Jim says to Huck, "It's a dead man. Yes, indeedy; naked, too. He's ben shot in de back. I reck'n he's ben dead two er three days. Come in, Huck, but doan' look at his face-it's too gashly" (Chapter IX). As Gorey uses it here, it conjures up the same associations: as a linguistically corrupted version of "ghastly," it foregrounds the horrifying deaths of each child within the narrative, yet it simultaneously provides distance through this language shift. Unless the reader is already familiar with "gashly" as slang, she or he must take a moment to recognize it. "Gashly" thus carries less of a linguistic charge, which also defuses some of the horror inherent in a "ghastly" spectacle. "Crumb" does the rest of the work, as it is also a diminutive word. Gorey is providing a small tidbit, a piece that is inherently understood to be part of a larger whole. By proffering a crumb of the ghastly, Gorey offers limited, controlled contact with the macabre. Everything about The Gashlycrumb Tinies is diminutive: this small piece of the ghastly is further underscored by the fact that it deals with "tinies." As much as the narrative is about small children, "tiny" also functions as an intensifier. The phrase "The Gashlycrumb Tinies" therefore points out its inconsequential smallness three successive times, in the distancing from "ghastly," the crumb it offers, and the tininess of both the subject and the narrative itself.

Yet in sharp contrast to the assertion of diminutiveness is the scale of threat against Gorey's children. Death looms large in this narrative, appearing before the tale even begins. The personification of Death is present on the cover, and often the frontispiece of various editions, a tall figure clad in a long black coat, matching gloves and top hat adorned with a lengthy funereal veil. The only bare part of its body is its face (a skull), a clear marker of its otherworldly function, and it holds an open umbrella above its head, casting a shadow that engulfs all the tiny figures below. In this tableau is a strong suggestion of possession: the long shadow of death encompasses the children in a physical reminder of their shared fate, and the inescapable inevitability of it. These children both figuratively and literally live in the shadow of their own mortality, separate from the rest of the world; their location within the shadow articulates their association with Death and marks them as belonging to it.

Just as Death appears at the beginning of the tale, so too does it appear at the end. This time, however, Gorey does not draw the personified form, but rather allows lingering 
echoes to stand in for it: twenty-six headstones, devoid of any inscriptions, cluster close together within the boundaries of a shadow that echoes the first cast by Death's umbrella. Gorey arranges the headstones in the same formation as the children, each one a marker of a child's passing; the shadow is the same oval shape, and the only missing piece is the lack of Death's human-like analogue. Regardless of this missing figure, the personification of Death is still present in the illustration. In the cover piece, the Death figure is required in order to signal the children's demise; without it, there is no overt, ominous indication that the children are about to die. Conversely, in the closing piece, the children's deaths are telegraphed succinctly by the headstones themselves. There is no need to redraw the Death figure as it is present through the existence of this cluster of graves; the final illustration, which lies outside of the narrative just as the frontispiece does, therefore creates a bookending effect; Death is the beginning and ending of this tale. Yet despite Death's physical manifestation outside the boundaries of the narrative, with very few exceptions, within the tale, each child is caught in a moment before her or his death. Kate and Winnie are the only children whom Gorey represents post-death: Kate has already been "struck with an axe" (11), and lies in the middle of a clearing at night, axe head embedded in her chest, a significant amount of blood pooled around her body; Winnie, meanwhile, is "embedded in ice" (23), the water she has fallen into having already frozen around her. The other twenty-four illustrations, however, are of Gashlycrumb children en route to their deaths. Amy is in the midst of falling downstairs (1), Basil has only just encountered the bears that will maul him (2), and Clara continues to languish in her sickbed (3). Death is an assumed, but not illustrated end, and stands just outside of the narrative, ready to take the child.

Much like Charlotte Sophia's empty eyes in The Hapless Child, the faces of Gorey's Gashlycrumb children display only a minimal amount of detail. They do not have fully realized eyes, noses or mouths, these features either reduced to dots and lines or completely obscured. Six of the children - Fanny, George, Prue, Rhoda, Victor and Winnie - are turned away from the viewer or completely covered, making their expressions invisible and unreadable. Fanny's head is entirely engulfed in a large sun hat (6), and George is only visible from the waist down, as he is otherwise covered by a rug (7). Prue and Victor are viewed from the back, Prue about to enter a "Saloon Bar" (11), and Victor stands on train tracks, looking down the railway line, body immersed in deep shadow (22). Rhoda is covering her face with her arms as she is on fire (13), and Winnie's face is obscured by the ice 
in which she is entombed (23). The other nineteen children are turned towards the viewer, or present enough of a profile that their expressions are visible. Yet Gorey renders each face with very few lines; they are minuscule figures whose eyes are all pupil, their noses only barely in evidence, and their mouths, when present at all, reduced to tiny down-turned lines or spots. With the exception of Ernest, every child's expression is either neutral or dismayed; Ernest, however, sports a very small smile as he looks at the peach on a plate in front of him, unaware he is about to choke on it (5). His scenario is the only one that proceeds directly from a moment of joy; all the others - such as Basil's bear attack, Clara's infirmity, Titus' exploding package, and Zillah's alcohol poisoning - are neutral or dangerous situations that go badly wrong. In each panel of The Gashlycrumb Tinies, the child figure is a small focal point engulfed by a far larger backdrop; while each one is the only individual in their respective scenes, each child takes up a fraction of her or his panel. Each scene is heavily crosshatched and textured, darkening the surroundings and making the less detailed portions of each child stand out in stark relief. Such extreme contrast directly affects the tone and atmosphere of the narrative. The children's bare white faces telegraph innocence in the face of overwhelming darkness. Death is not just the inevitable consequence of their individual situations, but is also present in their surroundings. The oppressive blackness stands in for the personification of Death, all but obliterating each figure before she or he dies.

Alongside each illustration is a line of dactylic trimeter which emphasizes the alphabetical underpinnings of the abecedarium format. The rhythm and rhyme works to make each line memorable, which is a useful strategy in pedagogical situations. In a traditional child's abecedarium, this form would promote memorization of the letters of the alphabet, helping to cement written language in a new reader's mind. Here, it stems from parodic intentions, as The Gashlycrumb Tinies deliberately flouts "acceptable" teaching material. Instead of attractive, family-friendly subjects such as the fantastical and colourful creatures in Dr. Seuss's ABC: An Amazing Alphabet Book! (1963) or the friendly animals in Richard Scarry's Find Your ABC's (1973), Gorey's narrative is a stark, hopeless black and white tale. Although his illustrations share unrealistic, cartoonesque characteristics with Seuss' and Scarry's works - none of which attempt to present a realistic world in either art style or narrative content - Gorey's are tailored for an audience primed for nuance. Instead of large, clean lines and bold, solid colours, the viewer must contend with dark, detailed panels in which the slightest difference in the curve of a line affects the interpretation of an expression, 
and pertinent details threaten to disappear amongst the dense linework and texturized backgrounds. Instead of entertaining poetic lines introducing readers to new vocabulary, Gorey's alphabet is comprised of a series of names. As much as a name is a signifier for a sign, a series of twenty-six names depends on abstract concepts of identity rather than common and corporeal examples of items or actions that more easily guide early-readers in forming a connection between written words and the physical world around them.

In addition to deliberately flouting the form and content of twentieth century childfriendly abecedaria, Gorey parodies earlier instructive versions that are more concerned with pedagogical lessons of morality, religion and punishment than gentle reading guides. The New-England Primer, one of the first educational texts aimed at an American audience, is especially intertextually important in Gorey's case, as it was first published by Benjamin Harris in Boston, Massachusetts, the capital of the very same State that Gorey made his home in the latter half of his life: the Edward Gorey House, as it is now called, is Gorey's Cape Cod, Massachusetts residence, which was converted into a museum after his passing with the express purpose of celebrating his life and work. The New-England Primer includes abecedaria in its various editions, each version's text altered to fit popular political and Puritanical viewpoints of the time. "A" is the only letter to escape alteration, as it remains, "In Adam's Fall/We sinned all" across all editions. Additionally, this abecedarium consists of twenty-four letters instead of twenty-six, missing "I" (or in some cases, "J") and "V," a marker of its relationship to older, Latin teaching texts, in which "I" and "J," and "U" and "V" were not orthographically distinct from one another. In this primer

was no easy road to knowledge and to salvation; but with prose as bare of beauty as the whitewash of their [Puritan] churches, with poetry as rough and stern as their storm-torn coast, with pictures as crude and unfinished as their own glacial-smoothed boulders, between stiff oak covers, which symbolized the contents, the children were tutored...No earthly or heavenly rewards were offered to its readers. (Ford 1-2)

While the text changed periodically, the central educational narrative remained. The first verse, "In Adam's Fal/We sinned all" (1) ${ }^{21}$ sets the religious tone for many of the successive

${ }^{21}$ As The New-England Primer has both gone through many changes throughout its lifetime, with the earliest surviving copies often suffering from damage, and its abecedarium 
verses. Although there is some variation in the accompanying woodcuts between editions, they share common characteristics and general layout. Thus, the first panel is of Adam and Eve standing on either side of the Tree of Life, each of them with one arm outstretched towards the tree, Eve holding an apple. The snake coils around the trunk, mouth open and fangs extended, reaching for the apple. The next verse exhorts the reader to follow the teachings of the Bible (2), and the ninth reminds all Christian readers that Jesus died for them. Each of these, as well as many of the other panels and verses pair learning letters with religious piety. Some of the verses impart more secular morals, such as "An idle Fool/s whipt at School'22 (6) (appropriately accompanied by a woodcut of a court jester), impressing the importance of hard work and study on the audience, and still others emphasize the transitory nature of mortality, leaving only a few to impart knowledge of the mechanical workings of the world.

In the panels most concerned with death is the blueprint on which The Gashlycrumb Tinies is built. The primer reminds the reader that "[a]s runs the Glass,/Man's life doth pass" (7), "Time cuts down all/both great and small" (19), "Xerxes the Great did dye,/And so must you and I" (22), and "Youths forward slips/Death soonest nips" (23). Each of these verses serves a particular function past imparting scenes of mortality; in tandem with the religious focus of the rest of the panels, the abecedarium creates a text which underscores the transitory nature of life while simultaneously extending the offer of salvation if the reader accepts God and follows the precepts of the Bible.

The Gashlycrumb Tinies, however, present scenes of death lacking any potential for salvation, immortality, or even a simple mortal happy ending. This thematic choice is present across all of Gorey's works, as most end ambiguously or fatally for the characters involved, but it carries an even heavier significance here, as Gashlycrumb specifically lacks the moral underpinning present in its literary ancestors. There is no salvation for the Gashlycrumb children, and no hope of avoiding their deaths. As an abecedarium, The Gashlycrumb Tinies therefore deliberately removes the underpinnings of the form. The work is not child-friendly,

takes up very little space on the page (four pages total), I am opting to adopt the same strategy I am using for Gorey's works and citing the alphabetical panels in order, one through twentyfour, rather than cite page numbers for ease and accuracy of identification.

${ }^{22}$ This version is dated somewhere between 1702 and 1714; later versions made minor changes, including switching "The" for "An." 
it does not link letters with familiar concepts or objects, and it does not provide moral, religious, or educational structure. As a result, The Gashlycrumb Tinies draws attention to these functions, inviting scrutiny and engagement beyond the acquisition of reading skills. The way the text pushes against its own form results in a narrative that, while morbid, is also highly entertaining. By distancing itself from other abecedaria, it also provides distance between the audience and the text; the form sets up expectations of audience participation through the repetition and study inherent in learning the alphabet, and also of audience age and reading level. Yet the content undermines these characteristics, as the dark, detailed artwork and morbid narrative is one more suited to a literate adult audience familiar with, but well-past reading abecedaria for individual educational benefit. Together, form and narrative combine to invite cognitive dissonance: a traditional child's text repopulated by death: not just the deaths of so many child characters, but also the death of form and content. Gorey successfully upends the abecedarium form, using it to create a narrative that is completely opposite to the format's own literary purpose.

The Eclectic Abecedarium (1985) is even more conscious of its pedagogical roots than The Gashlycrumb Tinies. It consists of twenty-seven tiny panels: the title illustration and twenty-six rhyming alphabetical verses and pictures. These illustrations are far smaller than Gorey's usual drawings, much closer to the size of The New-England Primer woodcuts, each enclosed in formal double borders. The formatting of the text is very consciously the opposite of that in The New-England Primer, which capitalizes and italicizes the word in each verse that highlights the particular letter of the alphabet under examination. The Eclectic Abecedarium, on the other hand, while it still maintains the same type of capitalization, italicizes every word except the one highlighting the correct letter of the alphabet. Additionally, where the primer has multiple panels dedicated to religious instruction, this abecedarium has only two: "E" and "W." "E" depicts a lone figure on a hill, hands clasped behind his or her back, face upturned to the cloudy sky. The verse itself reads, "There is an Eye/Up in the sky" (5), referring obliquely to the presence of a God or Godlike figure. The verse presents this information factually, and does not use it as a moment of spiritual teaching. There is no follow-up exhortation to read and use the Bible as a blueprint for behaviour, nor any effort to convert the reader to a religious path. The same holds for "W": "The way to Hell/Is down a Well" (23). In this case, the illustration is of a male with his hands on the edge of a stone well, looking down into its mouth. There are no demons nor 
hellfire in evidence; instead, the scene is ordinary, lacking in any fantastical characteristics that would mark it as containing evidence of the Divine. As a result, this scene invokes the religious teachings present in many classic abecedaria and then discards them. The verse does not link the metaphorical path to Hell with ruination of the soul, but rather presents it as a literal route through a particular well that can be physically traversed with or without spiritual mistakes. By making the route literal, Gorey strips it of spiritual power, as it can be easily avoided simply by avoiding the well.

The pressing concerns of mortality also appear in The Eclectic Abecedarium, yet they are far lesser than the similar concerns expressed in The New-England Primer. In "G", Gorey writes that "[b] eyond the Glass/We see life pass" (7), and pairs it with a boy kneeling on a windowsill, peering out at the world outside his room. Instead of a direct reference to the transient nature of humanity, this verse instead focusses on how life passes by the observer. Distinctly different from Gorey's literary antecedents, any deeper moral meaning to the text is left up to the reader. The audience can interpret it as an exhortation to be involved with life before it slips away, or a subtle allusion to the ever-looming spectre of death, or, indeed, simply an observation on how people go about their business on the other side of the window. "Y" presents the same scenario, as "[w] ith every Yawn/A moment's gone" (25). The illustrated child stands with his back to a small toy boat in a stream as he yawns. While there is room for an esoteric interpretation of boredom eating up the small moments of life, this panel is as straightforward in its presentation as the rest. By yawning, the child is inattentive to his toy, which is about to sail past the border of the panel, and will miss the chance to retrieve it. Additionally, just as with breathing, sleeping, eating, blinking, or any other human activity, a moment spent yawning is, of course, a moment that slips away, simply because of the inexorable march of time.

This practical outlook extends into the rest of the text, as when not parodying mortality and religious teachings, Gorey's Eclectic Abecedarium provides its own form of secular instruction, much like The New-England Primer's zoological and historical panels ${ }^{23}$.

${ }^{23}$ These include text identifying the characteristics and functions of particular animals, such as "A Dog will Bite/A Thief at Night" (4) and verses regarding royalty which would be rewritten to conform to popular viewpoints at the time of publication, such as the early eighteenth century version, "K. William's Dead and left the Throne/To Ann our Queen of great Renown" (10). 
These make up the bulk of the text, ranging from facts about animals, such as, "A hidden Bird/Is often heard" (2) and "Don't try to cram/The dog with Jam" (10), to observations and practical advice, including, "Forbear to taste/Library Paste" (12) and "The kitchen sink/Is made of Zinc" (26). As a result, The Eclectic Abecedarium presents a pragmatic educational vision far less concerned with salvation and religious piety than in stripping away this deeper meaning in favour of straightforward engagement with the world.

Beyond playing with the pedagogical roots of abecedaria, Gorey also uses the form to explore alphabetical texts for the amusement of children. He does not only satirize the abecedaria of the seventeenth century and earlier, but also nineteenth and twentieth century works. While such texts still involve teaching children to read, the moral and spiritual guidance is removed in favour of collections of animals, plants, or technology designed to be easily associated with objects and concepts in the real world. Gorey's The Utter Zoo (1967) works within this framework. The narrative conforms to abecedarium format: twenty-six illustrations of animals accompanied by explanatory rhyming text. Much as The Gashlycrumb Tinies chooses abstract concepts in the form of names to stand in for each letter, however, The Utter Zoo similarly eschews recognizable animals, presenting instead a cryptozoological menagerie. In the style of Lewis Carroll, Edward Lear, and Dr. Seuss, Gorey populates his alphabetical zoo with creatures that do not exist. Further, they are not mythological creatures either; he does not catalogue dragons, gryphons, unicorns or vampires, but rather his own creations, awkward hybrids and entirely new animals with strange new names. Gorey thus invokes the rejection of the real that occurs in works such as Dr. Seuss' If I Ran the Zoo (1950), where the young protagonist, Gerald McGrew, disapproves of normal, realistic zoo animals, and instead favours fantastical creations of his own as he says,

The lions and tigers and that kind of stuff

They have up here now are not quite good enough.

You see things like these in just any old zoo.

They're awfully old-fashioned. I want something new!

So I'd open each cage. I'd unlock every pen,

Let the animals go, and start over again.

And, somehow or other, I think I could find

Some beasts of a much more un-usual kind (3-4) 
Gerald's animals range from strangely proportioned hybrids of real animals - like the lion with ten feet (6) or the Elephant-Cat (10) - and far-fetched creatures with little relation to nature, such as the "family of Lunks" (21) or "a scraggle-foot Mulligatawny" (26).

The Utter Zoo shares such fantastical visions, as the abecedary begins, "The Ampoo is intensely neat;/Its head is small, likewise its feet" (1). Gorey's drawing is of a creature that fits the sparse narrative description, sporting both a tiny head and feet against a clean, white backdrop. In line with its proclivity for tidiness, Gorey refrains from high contrast, densely detailed textures in this panel; even the Ampoo itself is rendered in thin black lines, a minimal delineation of its outline with no excess detail. The illustration adds to the fantastical nature of the Ampoo, as the verse provides little more than the broadest of outlines regarding its nature. While its feet and head are tiny, its body is not. Its proportions are not natural, lending it a strangeness that Gorey intensifies by precariously balancing the Ampoo on top a small decorative post with a rounded head. The positioning emphasizes the Ampoo's strange proportions, as it perches there against logic; its feet and legs should not be enough to hold up its body weight, nor should it be able to balance on such a small area with ease. Oddity and awkwardness are features of the creatures in The Utter Zoo; they are burdened with overlong limbs, stretched torsos or bulky bodies; some lack the ability to navigate the world, and others are surprisingly nimble despite their strangeness. Each verse reveals a little of the animal's personality and physical characteristics, which the illustration then expands. As with the faces and expressions of some of The Gashlycrumb Tinies, some of the creatures are obscured. The Boggerslosh hides behind bottles so that it is nothing but a dark outline (2); the Dawbis is so shy, it hides behind blinds, only its feet exposed (4); the Ippagoggy, while not fearful or actively attempting to conceal itself, is obscured by a fall of paper (9); and the Jelbislup is enclosed in a jar (10). Each of these techniques, from unreal physical proportions to deliberately obscured bodies, feeds into the larger unreality of this zoo.

In this work, Gorey's naming conventions invoke Carroll and Seuss. Although Dr. Seuss's $A B C$ mixes fantasy creatures with real animals, his trademark nonsense words and illustrations are present throughout Seuss' abecedarium. The text begins with "Aunt Allie's alligator" (4); but quickly progresses to including a duck-dog (12); a Fiffer-feffer-fef, a fuzzy orange and yellow bipedal creature that features four giant feathers on its head (16); and ends with a huge individual with a snout, yellow fangs, shaggy pink hair and a pink and white checkerboard pattern all over its fur which calls itself a Zizzer-Zazzer-Zuz (63). Although the 
illustration for the duck-dog makes its hybridized roots clear - it has a bill, webbed feet, fur, four legs and a collar - the more fantastical the name, the less guidance the illustrations provide. The Fiffer-feffer-fef and Zizzer-Zazzer-Zuz are colourful and visually appealing, but Seuss allows their biological origins to remain a mystery. The Zizzer-Zazzer-Zuz is especially oblique, as it speaks directly to the reader and sets up the false assumption that the audience will be able to identify it, as it says, "I am a Zizzer-Zazzer-Zuz as you can plainly see" (63). Here, Seuss plays with assumptions, as since the Zizzer-Zazzer-Zuz does not exist outside of the pages of Dr. Seuss's $A B C$, not even as a common mythological creature, the assertion that the reader "can plainly see" what it is turns the educational purpose, that of learning letters by identifying familiar objects, on its head.

In the same vein, the creatures in The Utter Zoo sport nonsense names that, at most, hint at their genesis without explicitly explaining. For instance, as the Boggerslosh can be found behind bottles (2), the syllables of its name are a fitting onomatopoeic. "Boggerslosh" links the animal with liquid; a bog is a wet, marshy, still area, and the Boggerslosh is a murky creature that likes to be still and hidden; just as liquid sloshes around inside containers, so does the Boggerslosh's name. It is indivisible from its environment; by choosing to conceal itself behind bottles, it becomes inextricably associated with watery, contained environments. A similar situation holds for the Humglum, an animal that "crawls along the ground/And never makes the slightest sound" (8). The verse implies that the Humglum does not have much mobility, but the illustration significantly adds to the text's meaning. Gorey draws the Humglum with four limbs, which erase the possibility of it having to crawl for physiological reasons. Instead, the creature is stretched out across the ground, arms and legs straight in front of and behind its body, its one visible eye wide and beseeching. Rather than seeming incapable of travelling quickly, the illustration communicates an unwillingness to move. The Humglum is therefore both a humdrum individual, incapable of excitement (both in its internal emotions and in its capability to inspire excitement in others) and obviously sad, or "glum." The Limpflig (12) suffers from a similar ailment, as it drags its legs along the ground. It is so tired all the time that it "finds it hard to keep/From spending all its life asleep" (12), and as such, has difficulty holding itself up. Gorey's Limpflig possesses sagging skin that falls in waves of wrinkles, drawing down its expression and body, communicating extreme exhaustion; it is a limp creature. Additionally, in the panel for "I," the second syllable of the Ippagoggy (9) is very much like a childlike corruption of "doggy," and while 
its head is obscured, the illustration of a dog-like torso and a raft of paper tossed in the air and scattered across the ground further upholds this association. In fact, as "[t]he Ippagoggy has a taste/For every kind of glue and paste" (9), Gorey is invoking the stereotypical children's excuse for schoolwork that is incomplete, namely, "the dog ate my homework."

The rhythm, rhyme and nonsense words at work in these abecedaria become even more prominent in Gorey's texts that specifically play with children's verse. The Wuggly Ump (1963) exemplifies such play in its mix of bright colours, rhyming couplets and imaginative word choice. It is one of the few Gorey works that appear in colour; in this case, while the colour is sparse and muted when held up against children's books by other authors such as Dr. Seuss, when compared to Gorey's own works, the cool blue and yellow washes and highlights are a shocking contrast to his usual stark black and whites. The spot colour and delicate, spare line work create a text filled with friendly, light, happy images reminiscent of Dr. Seuss and Edward Lear. Likewise, the narrative consists of fourteen iambic tetrameter rhyming couplets, all conforming very strictly to the parameters of the form. These couplets give the narrative a sing-song quality when spoken aloud, as the rhyme and rhythm skip through the iambs, helped along by word choice. For instance, the opening verse, "Sing tirraloo, sing tirralay,/The Wuggly Ump lives far away" (1) contains words in the first line which, when pronounced, are spoken at the front of the mouth, and require the speaker to draw back his or her lips, resulting in lighter, sharper sounds from the tip of the tongue, encouraging trilling. "Tirraloo" and "tirralay," while not wholly Gorey's creations, are onomatopoeic expressions of joy and carefreeness that are in direct contrast to the heavier "Wuggly Ump" in the second line. When pronounced, "the Wuggly Ump" resides closer to the back of the throat, near the glottis, its component consonants and vowels producing weightier, thicker sounds which suggest a darker, more depressing tone. "The Wuggly Ump" draws down each couplet in which it appears $(1,4,6,8,10,14)$, subtly disrupting the rhythmic flow enough to inject a note of dissonance that singles out the Wuggly Ump itself as a creature that does not belong in an orderly, safe world. Indeed, the word "Wuggly" contains an echo of "ugly" - just as the Ippagoggy of The Utter Zoo contains a childlike version of "doggy" - it is, after all, only two letters more. The text also supports the notion of the Wuggly Ump as visually displeasing, as the children note that its habits are unpleasing (3), it makes "an unholy fuss" when it appears (11), it possesses the most "nasty little wilful eyes/For anything of such a size" (12), and, of course, "[h]ow uninviting are its claws!/How even moreso are its jaws" (13). Although these 
assertions appear to be side-notes to the children's lives, as they run, play and sing, "pass[ing] [their] happy childhood hours/In weaving endless chains of flowers" (5), the spectre of the Wuggly Ump lies at the centre of many of their decisions.

Despite The Wuggly Ump appearing to be a gentle childhood tale, filled with pleasing rhyme, bright pictures, and lighthearted children, in true Gorey fashion, danger lurks around the corner. The text hints at the dangers of the Ump throughout the narrative, as while the children appear to be carefree, they continually reference their own safety in comparison to the relative proximity of the Ump. The tale begin with the children singing, not just because they are happy, but because "[t]he Wuggly Ump lives far away" (1). As night falls and they prepare for bed, their singing turns from trilling exclamations of joy to quieter, reflective sounds, as they now sing "hushaboo...hushaby" as "[t]he Wuggly Ump is drawing nigh" (8). There is a note of fear within this couplet; both "hushaboo" and "hushaby" are multi-syllabic words arranged around the word "hush," suggesting a need to be quiet and still. Although this need is easily associated with bedtime and relaxation in order to facilitate sleep, it is explicitly linked with the Ump coming closer. The children must be quiet in order to avoid attracting the Ump's attention. Yet it is the next morning, in the assumed safety of daylight and their own home that they finally encounter the Ump. Unlike the night before, the children display cautious curiosity, first standing in the hallway, well away from the closed door, which is between them and the Ump (10), then observing it from an open upstairs window, just out of reach of its arms and tail (11), and finally from a balcony well over its head (12). Such lengthy exposure, however, results in a loss of caution that results in their downfall. They come down from the safety of the upper level and leave their house, but instead of meeting a strange but harmless Seussian creature, they meet a Goreyesque fate: the Ump devours the three children whole (14).

The threat of danger in The Wuggly Ump echoes that in one of Lewis Carroll's most famous nonsense poems, "Jabberwocky." Just as the Ump has frightening jaws, claws and eyes, so too does the Jabberwock have "jaws that bite...claws that catch" and "eyes of flame" (Through the Looking Glass 8). Where the Ump stalks the children, however, the Jabberwock is stalked by the speaker's son. In Carroll's poem, the Jabberwock may be a figure of fear, but that fear is short-lived, as it is sought out and defeated. Conversely, in The Wuggly Ump, the Ump pursues the children and ultimately consumes them. As with the 
senseless deaths in The Gashlycrumb Tinies, The Wuggly Ump reverses heroic monsterslaying narratives in favour of a hopeless, sad end in which the monster triumphs.

Regardless, Gorey stays true to the nonsense verse form itself. In parallel to the son's utterance, "O frabjous day! Callooh! Callay!" (9) in "The Jabberwocky," most of the nonsense phrases in this text occur in the children's dialogue. Here, the spoken word allows for a greater freedom of expression that breaks out of the boundaries of normative linguistic rules. Onomatopoetic sounds supercede clarity and regularity of meaning, as the children sing virtually meaningless compound words that communicate their emotions regardless of the words' absences from the dictionary. For instance, as the Ump leaves its den, the children "[s]ing jigglepen, sing jogglepen" (4). Both "jigglepen" and "jogglepen" function as rhythmic nonsense words that rhyme with "den," and the second syllable, "pen," hints at the Ump's den as a place of containment. These words also communicate the sound of the Ump moving, as it jiggles and joggles as it leaves its home and begins its progress towards the children. As it picks up speed, it is described as "hurtling on, kerbash, kerblump" (6). The shift from jiggling and joggling to hurtling itself ahead is reflected in the harshness of "kerbash" and "kerblump," which, in tandem with the illustration of the Ump running so quickly up a hilltop its feet do not touch the ground, conjure up a sense of haste and movement lacking care, as it bashes and bumps its way forward.

Even more evocative are the final lines of the story, where the children "[s]ing glogalimp, sing glogalump,/From deep inside the Wuggly Ump" (14). They have been swallowed, and are pictured floating upside down inside the Ump's body. Essentially, they have become limp lumps within the Ump, having lost all autonomy; and just as the sound of the Wuggly Ump's name contains auditory cues that create a more depressing atmosphere, so too does the first syllable of both "glogalimp" and "glogalump." The sounds that make up "glog" are spoken almost exclusively in the back of the throat, and draw the jaw and tongue downwards. Despite neither "glogalimp" or "glogalump" being legitimate formal words, they still manage to communicate the children's emotions and predicament. As a result, Gorey uses traditional nonsense verse to his advantage: like Carroll, these utterances move beyond denotative meanings and become appealing, aurally-stimulating onomatopoeia that articulate action and emotion.

Especially and disturbingly, when engaging directly with literature aimed at a young audience, Gorey's texts continue to present narratives in which all moral and pedagogical 
purpose is stripped away. In The Gashlycrumb Tinies, the children at the centre of the narrative do not just die in novel ways, but also do so in service to a poetic abecedarium, subverting a safe space for childhood learning, and removing child-friendly verses and illustrations in favour of the spectre of death, the most frightening monster of all. Wilkin has observed how, throughout all of Gorey's works,

the Awful Consequences [of life and death] are seen not as warnings, but as more or less normal and not particularly tragic. Children are the most frequent victims- the obvious ones, Gorey says-but adults are not exempt. (The World of Edward Gorey 61)

The Gashlycrumb Tinies does not offer any particular reason behind these children's deaths; they simply meet bad ends, without any explanation, compensation or reward. The Eclectic Abecedarium acts in a similar manner as, instead of providing moral instruction or religious guidance that would open the way to salvation, it merely offers secular observations and advice such as "[b] e loathe to drink/Indian Ink" (9). Although it is not concerned with ethics, The Utter Zoo rejects its function as a teaching tool, presenting the audience with a menagerie of fictional animals with nonsense names, undercutting the basic purpose of the abecedarium as a tool through which children can learn the written alphabet by associating words with their real-world counterparts. Just as these abecedaria lack in pedagogy, Gorey strips away any hope of safety in The Wuggly Ump, repeating the amoral thematics that manifest so strongly in The Gashlycrumb Tinies. The unnamed children in The Wuggly Ump die not because they are not careful enough, nor due to any trespass, but simply because they encounter the Ump. There is no moral message, no warning nor reward; the narrative does not provide any potential exit, and does not implicate the children in their own fate. The Ump simply consumes them, the act "normal and not particularly tragic" (The World of Edward Gorey 61). Just as Gorey removes the moral and emotional underpinnings of melodrama, so too does he remove the happy, safe, triumphant endings inherent in much of children's literature. Yet the basic form itself remains: illustrated poetic verses and wordplay working together to create the surface appearance of the teaching tale. As Gorey himself prevaricates regarding his relation to an audience of children, so too do his narratives simultaneously embrace and reject narratives geared towards such young readers.

Gorey states in interviews (and by way of third-party anecdotes) his profound ambivalence regarding the meaning of his texts. According to Theroux, 
[a]s to deeper meanings, well, Gorey said, "I generally feel that what you see is what you get, but all those who want to read something into it, poor bunnies, then they can. Half the time, I think, Oh dear, this drawing doesn't mean much. You know, what's it all in aid of? Occasionally, someone will come up to me and say, 'I figured out what your book was about,' and I ask, 'Oh, what?' Then they tell me something completely bizarre. And I'll think," he shrugged, "if that's what you want to see, it's okay by me."' (4)

It is tempting to take this tendency as a reason to either overlook Gorey's oeuvre as frivolous and meaningless or to immediately invoke Roland Barthes' "The Death of the Author," but just as Gorey's stories require more than one reading to fully appreciate their depth, there is more to Gorey's ambivalence than it at first appears. As much as Gorey dismisses these "poor bunnies" in their search for meaning, his texts repeatedly tackle such questions. It is not a larger meaning, however, that his narratives search for. Instead, they examine form and content divorced from purpose. His stated ambivalence thus mirrors the placements of his texts; it is no surprise that he is baffled by his readers' search for meaning, when each narrative searches for an experience outside of meaning. Gorey's abecedaria celebrate the bridge between purpose and fantasy for the sake of itself, and his nonsense verse is the natural outgrowth of that impulse. They resist directed, discoverable meaning in favour of a surreality where purpose is pushed aside in favour of strange, fantastical worlds. Even as his narratives remove moral and educational rewards, they invite the reader to explore a transformational moment in which reality bends to fantasy and the point is not to find a larger meaning, but to revel in the pleasure of sound.

This is not to say that Gorey's texts are not for children, but rather, that their audience is not exclusively children. The rise of popularity of young adult and children's literature amongst an adult audience speaks to an increasing blurriness of the divide between children's and adult literature. In "The Post-Modern Alphabet: Extending the Limits of the Contemporary Alphabet Book, from Seuss to Gorey," George R. Bodmer explains that the alphabet book for all readers shares in our changing sense of fiction and our fictional place in our world. As a picture book, the illustrated alphabet in our times has reflected the ambivalence of those who write children's books. The definition of this genre and its audience is blurring, a limitation, like the 26 letters, to be played with, strained, and stretched. (117) 
As publishers and merchants continue to look for new ways to market stories across audiences, genre categories become increasingly flexible, making children's literature a permeable boundary.

Although academics such as Kevin Shortsleeve and Jackie E. Stallcup argue that Gorey fits neatly within the umbrella of children's literature ${ }^{24}$, this approach radically truncates the ambiguity at the heart of Gorey's oeuvre. Just as his melodramas and Dickensian texts lack sentiment and morals, his children's literature lacks pedagogical purpose; these missing elements appear, at first, to propose a shallow, entertainment-focussed intent to each story. Yet such cursory readings ignore a more deconstructionist approach in which Gorey's narratives peel away a genre's expected tropes to reveal what is left behind. The kind of repeated reading patterns any Gorey narrative requires mimic both the repeated readings children request of favoured books, and the more detailed, in depth readings an adult engaged in critical engagement with a text requires. In Gorey's abecedaria and nonsense verse lies a playfulness and joy in language, rhythm and rhyme that come to the fore once the pedagogical purpose is stripped away. Absent of that purpose, these narratives set aside the concept of an ideal or age-specific audience. Just as Gorey repeatedly expresses ambivalence for or outright rejects meaning in his texts, these same works use ambiguity as a way to clear space for expanded, non-traditional interactions with each genre.

Even without the direct aim of engaging child readers, Gorey's abecedaria create a discourse between themselves and their literary ancestors. These works invoke the extreme piety of The New England Primer and restore the morbidity absent from twentieth century works, yet at the same time reject their function as useable teaching tools. Although abecedaria and nonsense verse are opposite in intent - nonsense verse functioning as an outlet for a joy of sound and language with less emphasis on meaning - Gorey's texts unite the two. Works such as The Utter Zoo act as a bridge between the forms, melding a laundry list of letters with meaningless syllables and phrases. The Wuggly Ump and other specimens of Gorey's nonsense poetry continue in this project, reflecting the verse structures of Lear and Carroll in their play with language and the elements of children's literature. Additionally,

${ }^{24}$ See: Shortsleeve, Kevin. "Edward Gorey, Children's Literature, and Nonsense Verse." Children's Literature Association Quarterly. 27.1 (Spring 2002): 27-39. and Stallcup, Jackie E. "Power, Fear, and Children's Picture Books." Children's Literature. Volume 30 (2002): 125-158. 
$[\mathrm{m}]$ onsters, violence, and anti-social behavior are among the most common themes in nonsense; from Carroll's slain Jabberwock, to Lear's numerous tortured ladies and gentlemen, and to Gorey's carnivorous Wuggly Ump, nonsense has always presented a boldly confrontational spirit, both dark and pessimistic in appearance. (Shortsleeve 32-33)

Where The Gashlycrumb Tinies, The Eclectic Abecedarium and The Utter Zoo deliberately flout their generic purposes, the morbidity of Gorey's The Wuggly Ump reflects the inherent darkness of nonsense verse.

As with his melodramatic and Dickensian texts, Gorey displays extensive familiarity with each genre he undertakes. By stripping away the pedagogical function of his abecedaria, Gorey removes the formalized structure of educational narratives. His abecedaria explore a freer sense of the worth of engagement with language, as they are not rigidly tied to teaching concrete concepts. Instead, they revel in the joys of sound and order for the sake of themselves. This prioritization of pleasure over education starkly contrasts early abecedaria such as The New-England Primer as

[i]n Puritan times and places, however, mere fun always connoted sin; the Quakers warned that you must 'gather the flowers of pleasure in the fields of duty'. Men of equally Puritan mind could permit play only because they believed that to find 'relief from moral activity is in itself a moral necessity'. (Erikson 191)

There is little room in The New-England Primer for amusement; in Gorey's texts, there is little room for education.

On the surface, the violence of The Gashlycrumb Tinies echoes the Puritan imperative to harshly punish transgressions and moral failings. Children are the objects of punishment within the seemingly educational framework of the text, which creates a shallow simulacrum of a morality tale. Yet almost immediately, the pedagogical promises inherent in the abecedaria form fall away as the utter bleakness, pointlessness and hopelessness of the Tinies is revealed. As punitive as the narrative appears at first glance, the children themselves have done little to invite punishment, and there are no moralizing messages interspersed throughout the text. Instead, each child is subject to cruel, unfeeling, indiscriminate fate. The Gashlycrumb Tinies therefore refuses to instruct its audience morally or linguistically. 
The Eclectic Abecedarium, conversely, embraces its pedagogical roots, even using concrete objects in its instructional $\mathrm{ABCs}$, but trades any substantial educational material for observations on life in general. Even as Gorey acknowledges The New-England Primer (and other similar woodcut texts) as this abecedarium's antecedent, he consciously rejects the heavy burden of religious instruction, and prefers instead to offer practical advice about engaging with the secular world.

The Utter Zoo presents itself as an organized zoological list, invoking a pedagogical order, yet immediately casting that educational positioning off in the delight of pleasing sounds. In a sense, The Utter Zoo positions itself both before and after the traditional place of the abecedaria. Its reliance on nonsense words and strange creatures is associated with childlike wonder and pre-literate creativity. In the absence of formalized education, younger children first experience language as a collection of sounds that have not yet coalesced into communicable syllables and words. As the American National Research Council and Institute of Medicine explains in From Neurons to Neighborhoods: The Science of Early Childhood Development,

[a]lmost all children learn to talk without explicit instruction, suggesting that language acquisition is a relatively resilient process, although they do not all learn to talk well, suggesting that language acquisition includes some more fragile elements. In contrast, reading as a component of literacy is a much more fragile process. Not everyone achieves fluent reading, and instruction seems to be essential. (Shonkoff 126)

The primary purpose of abecedaria is to provide this early instruction, yet The Utter Zoo consciously steps back from such work in favour of revelling in nonsense words that mimic more independent language acquisition such as that which would originate from a child. Children's early attempts at replication of objects and individuals around them facilitates imaginative play with language that may not yet fall into recognizable patterns of speech, and also provides room for the creation of fantastical creatures that are half-memory and halffantasy. Where The Gashlycrumb Tinies fully rejects the purpose of the abecedarium and The Eclectic Abecedarium trivializes its pedagogy, The Utter Zoo celebrates children's pre-literate phase with a collection of these nonsensical names and fantastic creatures that charm and entertain children still in the process of learning how to communicate. 
At the same time, Gorey's narratives consciously wink at the reader, their complexities and hidden layers inviting in a more adult audience. By stripping any serious pedagogical intent from his abecedaria, he positions these works so that they act as a bookending force, representing the states that occur before and after formal education, rather than the act of disciplined, formalized learning in which society places children. He continues to consciously evoke and twist the nostalgia of childhood alongside an adult world by melding the most foundational of children's literature with adult concepts. Just as his abecedaria evoke pre-literate linguistic play, they also remove the educational imperative associated with such texts, inviting adult readers into the narrative. The deliberate lack of concrete concepts linked to the alphabet is a signal that these works are not for the children with whom the form is usually associated.

Gorey's prioritization of abstract concepts, such as names, in his abecedaria speaks of linguistic complexities intended for an audience already past the stage in which they would be learning to match the written word to concrete objects. The dark and sometimes perverse thematics invite in adult viewers. The distance between viewer and subject inherent in The Gashlycrumb Tinies and The Wuggly Ump facilitates a disconnect between audience and text that is especially evident during sudden, violent textual moments; these moments encourages laughter through their absurdities, shock value, and emotional distance. Kevin Shortsleeve is especially explicit about this disconnect, as he situates Gorey amongst other nonsense verse writers in his article, "Children's Literature, and Nonsense Verse." Shortsleeve explains that "[1]ike Lear, Hoffman, and Carroll, there is in Gorey's work an emotional detachment from violence" (33), and it is that detachment that The Wuggly Ump takes full advantage of as he stalks and ultimately swallows the children of his tale. The Wuggly Ump fully inhabits the space between children's and adult literature, embracing nonsense verse, fantasy creatures, and pleasing rhythm and rhyme which thinly cloak a predatory tale that ends in death.

Jack Zipes, in "Why Fantasy Matters Too Much," explains that the fantastic in picture books fails when it is merely descriptive, complimentary, decorative, or titillating. It succeeds best when it provokes the reader to stand back, take a second look, doubt, and reflect. Often image and text resist one another. The resistance to convey direct meaning and draw literal parallels with reality is at the heart of the design in picture books that 
make effective use of the fantastic to provide resistance to reality and that show how reality can be transformed. (6)

Gorey's illustrations shine when his audience takes the time to view, question and review the narrative. Where casual, quick reading supports the illusion that his texts are quirky, light fare, repeated and close readings reveal incisive, layered narratives that resist the traditional seats of meaning for pedagogical texts. Just as his abecedaria bookend formalized education, they resist their purpose only to create new purpose. His nonsense verse luxuriates in its own form, inviting in a wide audience to indulge in the impulse to laugh at the misfortune of others and revel in dark themes that have been made more palatable by the removal of any possibility of emotional excesses and a bolstering of the distance between reader and text. This resistance to clear meaning permeates Gorey's oeuvre, and reflects how he thinks and speaks about his works. For Gorey, meaning is malleable, multiple, and often missing entirely.

As previously evidenced by Gorey's melodrama and Dickensian narratives, he removes the meaning of each genre he manipulates in order to examine what remains; and it is those remains that Gorey's "poor bunnies" must excavate, examine and reexamine in order to comprehend the full scope of each of his narratives. Despite Gorey's own textual ambivalence - or perhaps because of it - meaning is a slippery, complex thing. His texts are constructed in order to resist reality and provide a transformative space in which the form becomes as important as any moral or pedagogical core. They require active reading and detailed, repetitive viewing in order to tease out each narrative layer. Even as his stories push the reader away from emotional attachment, they invite in children and adults alike with the promise of depth that goes beyond the formalized and expected tropes of pedagogical and nonsense literature. 


\section{Chapter 5: Clueless Detectives}

Just as Gorey visits and revisits the tropes of melodrama and children's literature in his works, so too does he play with the tropes of detective fiction. His mystery narratives reference the tropes of Golden Age detective fiction, primarily evoking "genteel class" stories in which the participants are middle- to upper-class figures, and the action occurs in a small village or isolated estate far enough away from nearby cities to engender a sense of disconnect between the characters and urban life. Isolation is a built-in characteristic, whether it manifests in village life, societal circles, or one-room locked-door mysteries. On the surface, like so many of Gorey's genre parodies, his detective narratives appear to possess characteristics which mark them as fully of that genre. Yet much of this appearance is a surface-blind, as when the reader delves past the initial viewing, it becomes rapidly clear that Gorey is engaged in exploring what happens when surface identifiers are preserved and significant thematic characteristics are removed. His is a genre dissection project: what remains of the body when the heart is taken away? This is not to say that Gorey's work lacks nuance, thought or aesthetic and textual detail, but rather that the science of detecting - the clues, the lengthy explanations, alibis, and investigatory procedures - is stripped down to bare essentials or completely removed.

At the centre of detective fiction lies an obsession with detail. Each mystery is carefully taken apart, examined, reenacted and reconstructed until it is worked out, puzzlelike, and a solution is found. There is a true answer, one which can be found out and held up above all others, and even in the face of doubt, that answer will be discovered. Detective stories distill the process of uncovering criminality down to a singular, law-abiding character possessing a key. Whether that key is training, tools or intelligence depends on the narrative, but that individual will always exist as the point of representative rationality through which the crime can be decoded ${ }^{25}$. As Cavallaro explains, this paean to logic is embodied most firmly in twentieth and twenty-first century audiences as

${ }^{25}$ Similarly, the criminal will possess a complimentary skillset which works against the goals of the detective by endeavouring to disrupt or outright block any attempts to decode the crime. 
the 'scientific' fact-finding of the paradigmatic detective of fiction, Sherlock Holmes, the super-rational analyst of clues that, if viewed properly, have only one significance...The fact-finder as scientist, exemplified by Holmes, is consonant with the emergence in late Victorian culture of a growing acceptance of science as a path to objective truth. It coincides, too, with the increased professionalization of the police and a perception of investigation and forensics as being properly within the academy. In this period, this articulation of objectivity as the goal of the learned person transcended 'pure' science, reaching into interpretive disciplines like history and law as well.

The detecting figure is thus the scientist of the tale, collecting data for analysis, and inexorably marching towards the truth of the crime. In order for this analysis to proceed, there must be significant details to be observed, and it is these details, and further, a detective's deep attention to them that Gorey removes from his mysteries. While a clear understanding of Gorey's narratives depend on the depth of detail inherent in his illustrations, his detective stories remove any visible deduction process within the narrative. As a result, the science of detection is conspicuously absent from his mysteries.

Instead, Gorey presents the reader with a skeletal framework that is recognizable as a mystery, but does not engender the satisfaction of a mystery narrative. As there is an inherent intellectual payoff in detective fiction - in that the detective solves the crime, the criminal is found out, and the law metes out an appropriate punishment (or there is an implication that justice will prevail after the close of the narrative) - Gorey's mysteries actively block the audience's psychological satisfaction through aborted puzzle-solving and thwarted sentimentality.

Visible clues rise to prominence in mystery fiction in the nineteenth and twentieth centuries. Franco Moretti, in "The Slaughterhouse of Literature," tracks the emergence of the clue as a major component of the detective story to Sir Arthur Conan Doyle:

Conan Doyle stumbled upon clues while he was working at something completely different, which was the myth of Sherlock Holmes. Think of the opening scenes of the Adventures, when Holmes "reads" a whole life from the signs on the body of his client: this is what Conan Doyle wants from clues: a support for Holmes's omniscience. They are a function of Holmes, an 
attribute, like coke and the violin. Then Conan Doyle starts "playing" with clues and eventually turns them from a mere ornament into a puzzle-solving mechanism. (215)

It is at this point that clues become an integral aspect of the detective tale. The detective's ability to seek out and recognize clues sets him or her apart from the other participants in the narrative as the intellectual authority who unearths the crime and interprets the motivations behind it for the other characters and the audience. These deductions are an inherent part of the story, and while they are not always laid out by the author for the reader to spot and trace to their logical conclusion, they exist to be gathered together and explained by the detective figure. Clues, therefore,

begin as attributes of the omniscient detective....and then turn into details open to the rational scrutiny of all. But if they are the former, they cannot be the latter: Holmes as Superman needs unintelligible clues to prove his superiority; decodable clues create a potential parity between him and the reader. The two uses are incompatible: they may coexist for a while, but in the long run they exclude each other. (Moretti216)

For a detective story in which the detective character is presented as an exceptionally intelligent or talented individual (such as Doyle's Sherlock Holmes, or Agatha Christie's Hercule Poirot) to be truly successful, the detecting process needs to hint at clue decoding that reveals the criminal without undermining the detective's perceived intelligence. If the reader is able to decode the mystery before the detective, it weakens the detective's omniscience. Conversely, if the clues are not present in some measure for the reader to recognize within the text, the solution runs the risk of appearing to materialize out of thin air. The existence of clues in late nineteenth century (and following) literature allows for audience investment through puzzle recognition and decoding. The appearance of logic legitimizes the intellectual superiority of the detective character, even if that logic must eventually be obscured in order to allow the detective to act as the ultimate textual decoder.

Gorey's mysteries, however, provide clues that lack the specificity of detail necessary for decoding to take place. Where Holmes can extrapolate the life of a client from a hair on his shirt and the dirt under his nails, Gorey refuses to provide clear, identifiable details within his plotlines that would facilitate such deductions. As with so many of Gorey's other narratives, his mysteries enforce a distance between reader and text that shifts the audience's 
gaze from the microscopic details that render narrative clues to a macroscopic viewpoint that underlines the larger form of the detective tale at the expense of more intimate knowledge of the specifics of the crime.

Instead, Gorey's narratives encourage the reader to decode the larger tale from a metatextual standpoint. Instead of identifying the particulars of the crime alongside the detecting figure, Gorey's readers must step back from the text and puzzle out the plot itself. Gorey's dense illustrations and sparse text therefore work together to obscure the narrative, making it the audience's responsibility to take on the detective role and use the sparse narrative clues to puzzle out the progression of the plot. Where Gorey's in-text mysteries rest on vague clues, the exceptional detail of his illustrations allows for metatextual clues that the reader can use to decode the story's trajectory. In Gorey's detective stories, the detective is the reader rather than a character in the text. The detective figure is a red herring, as he or she does not exist to demonstrate his or her omniscience; Gorey's audience already exists in an omniscient position, and Gorey therefore encourages the reader to take on the detective mantle and participate in solving the narrative mystery. His detective stories relocate the mystery so that it is no longer positioned within the text, but is rather extratextual. The details of the crime are vague precisely because they are not the main mystery of the narrative; the main mystery instead exists in the space between the reader and the text. The reader's ability to decode the action of the text is thus a measure of her or his abilities as a detective. The successful reader takes her or his place alongside fictionalized omniscient detectives when she or he solves the narrative, as it is at that point that she or he is able to understand the progression of the plot, the scope of the crime, and the identity of the criminal.

The Deadly Blotter: Thoughtful Alphabet XVII (1997) is one such work that uses form to parody the conventions of detective fiction. The Deadly Blotter is a fifteen panel work which follows a murder from the discovery of the corpse through to the reveal and capture of the murderer; the entire text is twenty-six words in length, each word beginning with a sequential letter of the alphabet. Much of The Deadly Blotter invokes the broadest strokes of detective fiction. The title indicates what should be the central theme or pivotal object: a dangerous desk blotter. The blotter is visible in the first panel: an unnamed individual sits at a desk, dip pen in hand, the paper of the desk blotter obvious in front of him, a large white space across the surface of the desk. In the style of tales such as Doyle's "The Five Orange Pips" (1891), in which orange seeds are sent as warnings, Sayers' Strong Poison (1930), in 
which the central question is who administered arsenic to the victim and when, and Christie's The ABC Murders (1936), in which the killer murders victims in alphabetical order by name, The Deadly Blotter works with genre expectations, indicating the murder weapon via the title. Yet outside of the title panel, the blotter does not appear in any successive illustrations, nor is it referred to in the text, nor is there any indication that it is the murder weapon. In addition to a blotter being an ineffective weapon of any kind (given it is made primarily out of paper, and therefore would only be useful wadded up and thrust down the victim's throat, or as a delivery method for "death by a thousand paper cuts"), the true murder weapon in this narrative is never identified.

Despite the ineffectiveness of a blotter as weapon, however, the presence of the blotter harks back to earlier detective fiction in which mirror image ink transfer left on the paper post-use becomes an important clue in determining key points in a case. In Doyle's "The Adventure of the Missing Three-Quarter" (1904), Sherlock Holmes finds evidence of danger to a missing man through his blotter:

"I rejoice, however, to perceive that he wrote with a broad-pointed quill pen, and I can hardly doubt that we will find some impression upon this blottingpad. Ah, yes, surely this is the very thing!" [Holmes] tore off a strip of the blotting-paper and turned towards us the...hieroglyphic.

Cyril Overton was much excited. "Hold it to the glass!" he cried. "That is unnecessary," said Holmes. "The paper is thin, and the reverse will give the message." (625-6)

This ink transfer again becomes a method of information retrieval, as in "The Adventure of the Creeping Man" (1923), one of Holmes' clients, Trevor Bennett, reveals, "I have the address of the man in London to whom the professor writes. He seems to have written this morning, and I got it from his blotting-paper" (1078). In both texts, simple retrieval and reading of these discarded blotters is as revealing as if Holmes had read the original documents for which they were used. Christie also uses blotting pads as a plot device, as in "The Tuesday Night Club" (1932), Miss Marple's debut short story, Sir Henry Clithering tells a tale of poisoning in which

[i]t happened that the blotting paper in the blotting book had been put in fresh that day, and the chambermaid, having apparently nothing better to do, amused herself by studying the blotter in the mirror just after Mr Jones had been 
writing a letter there. A few days later there was a report in the papers of the death of Mrs Jones as the result of eating tinned lobster, and the chambermaid then imparted to her fellow servants the words that she had deciphered on the blotting pad. (713)

As with Holmes' cases, the remnants left on the paper provide essential clues that allow Miss Marple to solve the murder and deduce the identity of the killer; and also as with Doyle's detective stories, Christie reuses blotting paper in "Murder in the Mews" (1937). This time, Hercule Poirot is the detective on the case, and it is the fact that the blotter is missing that allows him to solve the case. He explains that it is

"[a] curious little problem. I looked everywhere, in the waste-paper baskets, in the dustbin, but I could not find a sheet of used blotting-paper - and that seemed to me very important. It looked as though someone had deliberately taken that sheet of blotting-paper away. Why? Because there was writing on it that could easily have been read by holding it up to a mirror." (1361)

Unlike Holmes' blotter deductions, which rely mainly on acquisition of key information, Poirot's clarity comes from the very lack of a used sheet. Regardless, for Holmes, Marple and Poirot, the blotter is a significant, illuminating piece in their larger investigations.

Yet where the blotters in these tales are revelatory, The Deadly Blotter is entirely about concealment. The plotline is completely vague, revealing little but the broadest of strokes through general thematic statements. None of the characters have names, and some shuffle on and off-stage without explanation. The frontspiece is the only illustration that carries any hint of menace, and even it is muted. While most of the panel is taken up by the figure at the desk (who is absorbed in his thoughts), and the giant architectural detail in front of him (an absurdly oversized vase adorned with vines and leaves), almost unnoticeable near the top of the doorway behind him are four fingers, curving around the doorframe, as if someone is standing in the darkened hallway, watching him. This panel is the only one that carries the threat of imminent danger; the fingers remain unremarked upon, unidentified, and what threat they pose remains nebulous, as while the individual sitting at the desk is later discovered as the corpse, the precise cause of his death remains undefined.

The narrative itself is comprised of twenty-six words spread out over fifteen panels, no panel accompanied by more than three words. The last panel, in fact, is the only one that has three words, nine others having declarative statements of two words each, and the 
remaining five one word each. With the exception of the final panel (15), in which the 'ex' of "Extenuation" stands in as a homophone for the letter ' $x$ ', each successive word, from "[a]larming" (1) through "zero" (15), moves the alphabet forward sequentially. The abecedaria format works with the text to create distance between the reader and the plotline, as the content is subsumed under the form. Gorey's narrative is a series of metatextual statements commenting on the thematic progression of detective and cozy mysteries rather than an individualized plot. The tale begins with "[a]larming behaviour" (1), but it is only through the illustration that any details are specified. A figure who appears to be a maid runs into a sitting room, hand to forehead, obviously distressed. Her appearance startles the three other individuals in the room, who are otherwise casually lounging and standing around. Whether she is the one exhibiting distressing behaviour, or someone else is unclear, as there are no textual clues to guide the reader. In fact, without the visual cues of the illustration, there is no specificity to The Deadly Blotter at all. There are merely "[f]earful glances" (4), "[1]ikely motives" (8) and "[p]ointed questions" (10). The narrative catalogues the full progression of a detective story, beginning with the discovery of the crime - in this case, murder - the arrival of the detective, the behaviour of the suspects - including red herrings, reluctant participation in the case and discussions of motives - through to a plan to catch the criminal, who then confesses and is arrested and removed from the scene.

Even the corpse in The Deadly Blotter lacks specificity and definition. Although he is discovered in the second panel, most of his body, from head to waist, is obscured by a large decorative vase. His tweed trousers, white gloves and dress shoes with spats are the only visible details, and merely mark him as not in the employ of the owners of the house in which he has died. Whether he is the owner of the home, related to the other characters, or a person of note or status is not apparent and never revealed. How he has been murdered is also obscured, as the positioning of his body does not reveal any wounds, weapons or any hint of evidence that would pinpoint the cause of his demise. Yet the reactions on the three individuals viewing his body communicates their shock; all three have wide eyes, the gentleman in front holds up his hands in a shielding motion, and the woman and man behind him shield themselves with a cushion and a book respectively. The horror of the scene is self-evident, but the details themselves are utterly obscured.

The same vagaries apply to all characters in this text. Gorey's detective adheres to the visual stereotypes of the genre, as he first appears in a trenchcoat and tweed cap with a pipe in 
his mouth (3), and once he removes his coat (4), his suit is revealed. There is a maid (1), identifiable by her white apron, headdress, long black dress and her giant feather duster; a flapper with a fashionably short haircut and hemline, no sleeves, long gloves, and a large floral detail on her dress (4); two respectable society ladies, dressed in long dresses with long sleeves and high necklines (3); a mature suited gentleman with prominent Edwardian moustache (1); the young writer from the frontspiece, in bowtie and herringbone suit (1); and an eccentric older bearded man in turtleneck sweater, short pants and long stockings (5). These are character types familiar to a plethora of cozy mysteries: middle and upper class, possessing enough money to employ servants, outwardly reputable, with only a hint of eccentricity (the bearded man) or scandal (the flapper). They are the people who populate Miss Marple mysteries, visiting country homes for the weekend and finding themselves trapped by circumstance in lonely estates ${ }^{26}$. None of these individuals have names, nor do they speak within the narrative. These silent witnesses exist in sharp contrast to the traditional form of the cozy, in which "the detective often seems to solve the mystery through conversation-based information gathering and observing" (Bean 27). The detective in The Deadly Blotter still spends a significant portion of the tale interviewing the other characters, considering the evidence, and even laying a "[s]ubtle trap" (12), a direct reference to one of the features of Sherlock Holmes' methodology, but the reader is not privy to any detailed information whatsoever.

Gorey continues to signal the conventions of a detective story and then promptly subverts them. The murderer, when he or she is caught (15), is not identified. As with the corpse, this character is almost entirely obscured, this time by a significant amount of knitted cloth one of the ladies is in the midst of producing earlier in the narrative (7). In fact, the knitting is so voluminous that the murderer is even less identifiable than the corpse, as even his or her gender is indeterminate. He or she is taken away by nearly identical men (presumably standing in for police officers) while completely wrapped in the knitting, only his or her bare ankles and feet sticking out. Applying a logical process of elimination to the characters that appear in the illustrations is similarly thwarted. Characters appear and

${ }^{26}$ As Susan M. Stabile explains in Still(ed) Lives, these cozy mysteries are "mannerly fictions set in benign social settings with civilized characters and amateur detectives" (410). As with all other aspects of his genre play, Gorey suggests these tropes without providing extensive details. 
disappear between panels without explanation, making it difficult for the viewer to pinpoint potential suspects; and in the end, there is no point in attempting to choose one of the nameless individuals as the culprit, as the detective points to an "[u]nmasked villain" (13) outside of the boundary of the revelatory panel. As five of the characters stand around a pile of pillows, wide eyes expressing bafflement, the detective looks to his left, his arm extended so that his hand disappears at the edge of the illustration. Whomever the killer is, he or she is not one of the individuals to whom Gorey has introduced the audience; even though only five of the characters are present when the murderer is revealed, the two missing people appear in the following illustration, in which Gorey undercuts any remaining narrative weight. All seven of the characters are innocent, and as this tale is not patterned on Christie's The Mousetrap (1952), the detective is above suspicion as well. In this follow-up panel (14), five of the characters - the bearded older man, the flapper, the two more conservative ladies and the moustached gentleman - express confusion at the identity of the killer, as the caption reads, "Who?" The great revelation, the central core of any murder mystery, is completely absent in The Deadly Blotter. The killer lies outside of the narrative, is not introduced until the reveal, and is immediately regarded as no one important. Although the final panel, in which "[e]xtenuation yields zero" (15) falls back within archetypal mystery endings - as the murderer always communicates his or her motivation, only to have the law-abiding characters pointing out that there is no justification reasonable enough for his or her deeds - Gorey's undermining of the villain's identity and relation to the other characters removes even the potential for emotional impact or intellectual satisfaction through his or her confession.

In her article, "Myth and Ritual in Women's Detective Fiction," Christine A. Jackson sets particular standards for the mystery story:

The myriad types of mysteries on the market today represent a substantial investment of writer creativity and reader interest. As literature, the works warrant sustained critical consideration. The best-written mystery novels, some of which are best sellers, include in-depth character development, complex narrative lines, and polished, distinctive styles. They present complexities of experience by exploring the moral ambiguities implicit in violence and justice. (2)

Gorey's mysteries, however, eschew in-depth character development and complex plotlines. This rejection of what would appear to be important aspects of the genre does not make them 
any less worthy of study, as Gorey's focus is on the metatextual shape of the mystery tale. His style remains exceptionally stable across the body of his work, creating a polished, distinctive aesthetic that facilitates the exploration of those qualities that Jackson singles out as essential to the genre.

Despite the indication in its full title that The Deadly Blotter: Thoughtful Alphabet $X V I I$ is the seventeenth installation in a series, there are no other similarly-titled texts in Gorey's oeuvre. Although Gorey uses the abecedaria form extensively, the form encompasses a number of different genres and topics, from children's and nonsense verse to murder mysteries, textless illustrations, poems and unconnected vignettes. While The Deadly Blotter can be grouped into the larger category of abecedaria by Gorey, rather than linking it to a specific Gorey-authored series, the intimation that The Deadly Blotter is one of a set of "Thoughtful Alphabets" instead acts as a metatextual link between it and the preponderance of mysteries and detective fiction which span a significant number of works ${ }^{27}$. By marking The Deadly Blotter as number seventeen, Gorey contextualizes it as belonging to the detective fiction genre. Even though the other sixteen-plus Thoughtful Alphabets do not exist, the suggestion that they do acknowledges one of the basic tenets of the genre. It is de rigueur within the detective genre for an author to create one or more protagonists, most often trained in police work or other observational and criminological fields, and to write numerous stories in which those protagonists take centre stage. For instance, Arthur Conan Doyle's Sherlock Holmes appears in fifty-six short stories and four novels; Agatha Christie's Hercule Poirot is in over fifty short stories, thirty-three novels, and one play; likewise, her Jane Marple appears in twenty short stories and twelve novels; and Dorothy L. Sayers' Peter Wimsey is in two short story collections and eleven novels.

Where detective stories are deeply invested in the shifting game of cat and mouse that culminates in the revelatory moment, in which the detective bests the criminal and all the mysteries and motivations come to light, The Deadly Blotter removes the very heart of such

\footnotetext{
${ }^{27}$ Sue Grafton's Kinsey Millhone series is an excellent example of a long-running mystery series that also contains a link to the abecedaria form. Beginning in 1982, Grafton has published twenty-three of a projected twenty-six detective stories, all of which have titles and themes that correspond to letters of the alphabet. The first, " $A$ " is for Alibi, introduces Detective Kinsey Millhone, and sets up a pattern in which each title references an element of the crime Millhone must solve. Grafton plans to publish the final novel of the series, " $Z$ " is for Zero, in 2019.
} 
tales. Just as Gorey's melodramas remove the elements of reconciliation and reward, and his abecedaria remove all pedagogical motives, so too does The Deadly Blotter remove the revelatory moment. It is a mystery without the mysterious, as Gorey scrubs all the details from the narrative, leaving nothing but the broadest of strokes; instead of revealing, the entire tale conceals. By writing metatextually, Gorey throws the various steps in a classic cosy mystery into stark relief, but his tale is so consumed by form that it distances the reader and obscures all details of the crime, criminal, witnesses, detective and circumstances.

As The Deadly Blotter engages metatextually with the general structure of detective stories, The Awdrey-Gore Legacy (1972) playfully examines authorship and the process of writing a mystery novel. This work is epistolary in nature, as it takes the form of a foreword to a collection of loose notes depicting the planning stages of a detective novel penned by the ninety-seven year old Miss D. Awdrey Gore who, the introduction explains, has been found murdered. The contents of this work comprise the legacy the murdered author has left, and expose the bare bones of her in progress novel. By situating the author herself as the primary corpse, Gorey, however, moves the locus of the mystery away from her voluminous notes and unfinished story to her life. The incomplete narrative does not have a title independent of the overarching text, and the most important details - including the identity of the murdered character, the name of his or her killer, the method and motivation for his or her death - are not yet determined. They are therefore mere curiosities that pale in the shadow of the author's own death. In this manner, Gorey holds to the principles of the mystery story, where death is at the core. This is true even in the so-called "cozy" mystery, a mystery subgenre that could also be called "death go lightly." It often includes a murder reported off the page or a murder scene where the narrative glosses over details. Death is hardly ignored, however. References to the murdered person are numerous. As the sleuth advances in solving the murder, we see the recently departed as a person among others with a home, family, profession. A tea cozy keeps the pot warm. A mystery cozy keeps the body warm. (Jackson 3-4)

Unusually for Gorey, The Awdrey-Gore Legacy opens with a foreword explaining the (fictional) genesis of the text. This explanation further feeds into the structure of the detective story, as it lays the foundations upon which the framing narrative of Miss AwdreyGore's disappearance builds. As E.G. Deadworry's foreword explains, before Awdrey Gore is 
found murdered, she "was one of the most prolific (vide our Two-Shilling Reprint Library) and celebrated writers of detective stories at the time of her unexpected disappearance on $\mathrm{St}$ Spasmus's eve in 1927" (2). Her disappearance stretches over more than four decades, in which time

she has been reported (among a number of other possibilities) in a private lunatic asylum, living in Taormina dressed as a man, married to a Salubrian nobleman in Slobgut, or alternately, a garage mechanic in Idle-on-Sea, in a religious retreat on the slopes of Kanchenjunga. But alway falsely: her whereabouts for the past forty-four years remain unknown (2).

This disappearance deepens the mystery around her murder, but also serves as an exaggerated reference to Agatha Christie's own disappearance in 1926. While Christie was missing for only eleven days, as with Awdrey-Gore, she did not account for her whereabouts during that time, nor did she explain the reasons behind it. The list of sightings of Awdrey-Gore are another level of sensationalism, similar to the questions surrounding Christie's disappearance; yet again, Awdrey-Gore's sightings are far more fantastical in origin. Rumours during Christie's disappearance tended towards accusations of murder, suicide, amnesia, or an attempt to garner publicity.

Although the main narrative is the framing tale of Awdrey-Gore's disappearance and murder, the materials that make up the middle section of inserted, fragmentary notes explore similar mystery tropes to those of The Deadly Blotter. Just as The Deadly Blotter's title hints at its potential narrative contents, so too does The Awdrey-Gore Legacy open with a frontspiece of six book covers for novels penned by Awdrey-Gore: The Toastrack Enigma, The Blancmange Tragedy, The Postcard Mystery, The Pincushion Affair, The Toothpaste Murder and The Dustwrapper Secret (i-ii). Each of these titles focusses on an innocuous object, giving no hint how it fits into the larger tale. Given audience expectations of the genre, each one would be a significant item relating to a crime, but in true Goreyesque style, only one of the six book covers has any hint that a real crime has been committed. The Pincushion Affair depicts a gentleman in long coat, gloves, hat and scarf holding a flashlight and exploring a room. His flashlight illuminates a tomato-shaped pincushion on a small table in front of him, and just below of the beam of light on the floor is a body. Although the body is only visible from the torso down, and there is no evidence of foul play, the positioning and limpness of it suggests murder. Yet the focus of the man with the flashlight is displaced from 
the body onto the pincushion, dislocating the traditional locus of attention from the crime to an item that is merely near the body, betraying no obvious link to the crime. Likewise, while The Dustwrapper Secret does not have any overt indications of criminal activity, it is the only other cover that betrays any hint of foreboding. A man sits in a train carriage, his head tipped slightly forward, his eyes closed as if in sleep, and on his lap is an open book, laid there as if he fell asleep while in the process of reading. Outside of the carriage is a woman whose face is obscured by her headscarf, peering into the compartment and pressing a gloved hand against the glass. Alongside the title and her obscured expression, her positioning communicates urgency, as if she is about to slip into the carriage and take the book's dustwrapper. There is a measure of pathetic fallacy in the illustration as well, as it is raining heavily outside the train, creating a sense of darkness and a heavy, oppressive tone which transmits the seriousness of the dustwrapper's secret.

Unlike most crime fiction book covers, which often depict objects, characters or scenes which are significant to the commission of the crime, the rest of the Awdrey-Gore Legacy covers lack any indication of serious criminality or mystery in any manner past their titles. While it is odd for a toastrack to be found sitting outside on a banister, there is no reason for the man in the fur coat on The Toastrack Enigma's cover to suspect it is anything more than misplaced. The postcard that floats down with the falling leaves in The Postcard Mystery does not appear to distress the woman watching at all; there is no indication if the mystery concerns the message on the postcard or simply a question of where it came from. As no one on the cover of The Blancmange Tragedy appears to be upset, it is just as likely that the tragedy is a failed dessert as a poisoning. The Toothpaste Murder is perhaps the most innocuous of all of the covers, as it merely depicts a man getting ready to brush his teeth. Perhaps the toothpaste is poisoned; perhaps not. As with the other titles, there is no indication of the level of threat, nor of the narrative contents beneath the cover.

The same ambivalence exists in the oiled-silk packet [found] beneath the false bottom of an elephant's foot umbrella stand. Done up with mauve string and indigo blue sealing wax, it was addressed to [E.G. Deadworry's] late grandfather, G.E. Deadworry, then (in 1927) head of Deadworry and Silt, [Awdrey-Gore's] publishers. (3) 
As mysterious as its discovery and presentation make it sound, the package does not provide any answers to either the death of the framing narrative or the detective story Awdrey-Gore was working on.

What it does provide is a deconstruction of the steps involved in writing a mystery novel. The first pages concern the evolution of the detective figure. Twelve sketches illustrate Awdrey-Gore's progress from her detective's first genesis to his final form. Each illustration changes a small detail that moves the detective from an average late nineteenth- or early twentieth-century gentleman to an eccentric, unique individual sporting an eyepatch, wooden leg, and removable artificial hand. He has an impressive selection of facial scars, and dresses in exaggerated patterns, from his argyle socks and tweed suits to his lengthy striped scarf, decorative bowtie, and massive layered fur coat, the latter reminiscent of Gorey's own extensive collection of fur coats, which often appears as an identifying feature in his illustrated self-portraits. His textual description serves to heighten his quirkiness, as the detective Waredo Dyrge gives

[h] is deductions concerning each case...in the form of a linked series of haiku in Gaelic of his own composition; each is presented to the reader as it is made in a literal English translation that, while strange and vague in the extreme, turns out to have been perfectly fair and even obvious. (5)

On the surface, Dyrge's methodology appears more about form than content; by crafting a linked haiku series through which to transmit his deductions, he is prioritizing their textual appearance and artistic merit over clearly communicating important information about the crime. Yet it is in his "literal English translation" that the very structure of a mystery novel comes to the fore. Dyrge's haiku are a literal manifestation of the narrative trajectory of a cozy mystery from beginning to end. Much as Dyrge's haiku are written in Gaelic, and therefore only accessible to a small community of people versed in the language, the mystery begins as an opaque artifact, in which the crime lacks an ascribed criminal or motive. As language is only understandable to individuals educated in it, the reasoning behind the mystery is apparent only to the individuals involved in creating it. As the crime is unravelled, the various clues and contextual components begin to come clear without snapping into full focus right away. These clues act in a manner similar to Dyrge's English translations. They are vague, confusing, and often literal in ways that obscure any figurative meaning. Yet just as Dyrge's haiku become more comprehensive via extended study, by the end of the narrative, 
these clues coalesce into an understandable whole which communicates the mystery's solution and can make the trajectory of the plotline seem obvious in retrospect.

The Awdrey-Gore Legacy is an excellent example of Gorey's play with aliases and anagrams. Fittingly, the author embedded within the narrative, D. Awdrey-Gore, is an anagram for Edward Gorey. In many of Gorey's works, such as The Glorious Nosebleed (1975) and The Chinese Obelisks: Fourth Alphabet (1970), many fictional authorial characters embedded within the text sport the same style and appearance as Gorey himself. While Awdrey-Gore does not look like Gorey, she is nevertheless an authorial presence, and her anagramatic name strengthens the link between her character and Gorey's status as author. Additionally, despite the physical dissimilarity, Gorey writes that during her disappearance, she was rumoured to be "living in Taormina dressed as a man" (2); he therefore provides an avenue through which Awdrey-Gore is able to assume a masculine mantle alongside her status as author, further reflecting Gorey's presence within the text. She is not the only character with Gorey's name, however. The introductory note is penned by E.G. Deadworry, who also refers to his grandfather G.E. Deadworry, "head of Deadworry and Silt" (3), Awdrey-Gore's publishers. As a result, there is a quadrupling of authorship within this tale. Gorey himself is the overarching "true" author; D. Awdrey-Gore is the embedded narrative author; E.G. Deadworry is the faux-biographical framing tale author; and G.E. Deadworry is the ultimate publishing authority at Deadworry and Silt, which gives him a level of authorial control as a gatekeeper between novelist and publication.

The multiplying of authorship, however, does not end there. Embedded within Awdrey-Gore's notes are three more instances of Gorey's overt presence. The detective himself, Waredo Dyrge, not only sports a last name evoking the funeral dirge, but is also, of course, another anagram of Gorey. Gorey therefore places himself within the secondary fictionalized layer as a controlling figure: he is one of the only named characters in AwdreyGore's notes, and he is also the detective, the individual who is traditionally in control of the trajectory of the narrative, as the mystery is solved on the detective's timeline. Further, Dyrge is himself a creative force, as his deductions come via his own Gaelic haiku (5). He also has a dog,

Deary, his inseparable and ferocious companion, [who] is named for his master's favourite reading-the Deary Rewdgo Series for Intrepid Young Ladies 
(D.R. on the Great Divide, D.R. in the Yukon, D.R. at Baffin Bay, etc.) by

Dewda Yorger. (5)

Here again we have more anagrammatic play. In the space of one line, Gorey situates himself as both inside the tale (as Deary Rewdgo, dog and series protagonist) and outside of it, as its author (Dewda Yorger).

Alongside this authorial play lies Awdrey-Gore's incomplete mystery. As The Deadly Blotter represents the detective tale through a thematic outline that stands in for a more detailed text, The Awdrey-Gore Legacy's mystery is fragmented and incomplete. Its discovery in "an oiled silk packet...beneath the false bottom of an elephant's foot umbrella stand" (3) places it in the role of a cipher, which should, after careful examination and decoding, reveal secrets to both detective and reader. Instead, it is a collection of ideas and options, tracing the genesis of a story without providing a particular puzzle or solution. It complicates the trajectory of the detective narrative by remaining incomplete. The fragmentary pages provide a list of seventeen characters, none of whom have been chosen as the murderer, and most of whom do not yet have their basic details finalized. Awdrey-Gore provides fully-realized sketches of these characters, but then writes notes alongside them, such as, "Curate/Vicar/Dean/Bishop Escaped lunatic Cousin from Tasmania" and "Heroine (if she turns out to be the murderer, have a second with different hair colour)" (6). Not only are these notes indicative of the shifting status of events in Awdrey-Gore's outlined narrative, but they also illustrate increasingly wild and unusual possibilities for these otherwise stereotypical characters. Each illustration presents a standard character, from the young, slim heroine in fashionable but modest clothing to the wealthy hostess, tactfully bedecked in jewels (6), to the wealthy American, overdressed in formal suit, top hat and fur-trimmed coat, to the flamboyant, sultry artist in a risque, fashion-forward backless dress and kohl-rimmed eyes (8). The accompanying notes, however, show how easily these stock characters can be moulded into whatever the narrative requires. An eminently practically attired woman in a herringbone suit and culottes, sporting a gentleman's shirt, tie and hat is described as a "Lady novelist Lady with passion for flowers/dogs/other ladies Scottish cousin" (7). Each of these attributes are a separate identity, although not necessarily at odds with one another, yet each can be easily ascribed to the illustration. There is a fluidity here that clashes with the singular through-line characteristic of mystery narratives. 
The same can be said for the rest of the notes and fragments that make up AwdreyGore's unfinished work. The characters are followed by a variety of illustrations of settings in which to find a corpse, and in each one, much like The Deadly Blotter, all that is visible of the victim is his or her feet. Each panel presents a new place in which to commit a murder, and in one notable panel, that place is a "ha-ha" (9), or partially concealed trench, in which the label itself is a double-entendre. The trench is appropriately and specifically named, as a ha-ha is a particular architectural feature found in many gardens and grounds, but at the same time, its name also denotes laughter. The scenario is thus at once a believable locale, and points out the absurdity of the tale. As "trench" or "ditch" are more common terms, Gorey's use of "ha-ha" elicits an association with laughter before the architectural significance comes to the fore.

The rest of the various fragmentary notes similarly range from sensible to ridiculous: the potential murder weapons are categorized by type, including sharp, poisonous, limp, gradual, inexplicable, instantaneous and infernal machine methods (12-15) - the most interesting of which would be death by confetti (14) and by telephone doll (15) - and there are a significant number of context-less cross sections $(16,19)$, maps $(16)$, changing labyrinths (17), layouts (18) and objects (20-21). A series of small notecards, each meant as a writing prompt exercise, are displayed filled out with very specific facts that elucidate nothing, the formulaic blanks repeated more than once in an array of differing variations on "What the murderer failed to realize was..." (23). All hint at a variety of influences and directions Awdrey-Gore's novel may have taken, but none are finalized, few are contextualized, and all remain incomplete.

Awdrey-Gore's notes conclude with a set of potential endings for her novel. As with all the other fragments, these too perpetuate the multiplicity of possibilities for her characters. Six panels present six different endings, each one an illustration of an individual in silhouette, acting out a short caption. These endings range from disastrous to positive: four portray tragic, fatal ends, two definitively by the characters' own hands - hanging and the cyanide pill (25) - and two more ambiguously - over a cliff (26), which may or may not be a suicide, and an unsuccessful escape (27), in which the individual escaping is laid low by a car accident (28). The other two endings offer options in which the characters continue to live, but one is a descent into madness (26). The other, a successful escape (28), is the only positive ending, yet it depicts a man sitting at an outdoor table, enjoying a drink in a position 
similar to that which Awdrey-Gore was found in when her body was discovered (1). Indeed, many of the fragmentary notes echo Awdrey-Gore's life and death, but do not offer up any great elucidation. In addition to the quadrupling of authorship and those traits her detective has in common with Awdrey-Gore herself, her outline contains a cross-section of the very fountain she's found in (16). All through her notes are scattered quotes from another fictional work, The Ipsiad, which take on a metatextual positioning, commenting on her unfinished narrative and her murder. When put together, they read:

They dazzle us, but can we trust

These pictures drawn upon the dust? (ii.)

One moment she was sitting there;

The next, she'd vanished into air (2)

To catch and keep the public's gaze

One must have lots of little ways. (4)

Of all the people on the scene

Some are betwixt and some between (6)

It's most unlikely that his bed

Is where the victim's lying dead. (9)

He was, it's said, somehow done in

With nothing but a safety pin. (12)

The crucial information can

Be hidden in a simple plan. (15)

The smallest clue may be (or not)

The one to give away the plot. (19)

Perhaps it might be even subtler 
The guilty found, there's little wait

Before they're overcome by fate. (24)

And what if then we don't find out

What all of this has been about? (27)

Although when quoted within the narrative, these cantos are presented as out of order - for instance, the first couplet is from canto five of The Ipsiad, and it is directly followed by a couplet from canto six, then four, two, three, six again, eight, one, nine, thirteen, and finally eleven - each provides commentary on the page it is attached to, and fits together in a larger continuous narrative. It begins by commenting on the nature of writing itself, the idea that these fictional, imagined scenarios are at once seductive and untrustworthy, as the first couplet is attached to the covers of Awdrey-Gore's published works. The next couplet refers to Awdrey-Gore's disappearance, yet also on a higher metatexual level, reinvokes Agatha Christie's real life disappearance. Even as the following couplet remarks on Awdrey-Gore's detailed creation of her detective, when read in unbroken sequence with the other quoted parts of The Ipsiad, it touches on one of the historical theories as to why Christie disappeared: essentially, as a way to invite publicity through controversy. After all, the hunt for Christie was one of the largest for a single individual in Britain's history to that point, and while the publicity angle was never proven, it certainly was a small way "[t]o catch and keep the public's gaze." The middle couplets most strongly provide commentary on the building of a mystery narrative, but as the tale widens back to the framing narrative of Awdrey-Gore's murder, they too widen their focus and revisit the question of her killer. In the final couplet, "And what if then we don't find out/What all of this has been about?" (27), is the question at the heart of all of Gorey's mysteries. In The Awdrey-Gore Legacy, the fragmentary novel does not have a solution, because its puzzle is incomplete.

Similarly, there is an implication through Awdrey-Gore's notes that there is a mystery to be solved behind her murder, but, in a surprising and almost nonsensical move, as the collection of notes is concluded, E.G. Deadworry includes some found postcards that "recently fell out of a discarded lending-library copy of The Teacosy Crime, perhaps Miss Awdrey-Gore's most popular work. It will be noticed they were never sent, or, for that 
matter, even addressed" (28). They are not identified as by Awdrey-Gore, nor do they provide any clarity or context for the previous note collection. The captions on all are partially censored, obscuring their specific locales, and the final one, a picture of a rocky coastline and lighthouse, has a hastily scrawled message on the back. In shaky, blotted hand, the postcard reads, "I d- I did it. E.G. Deadworry" (29). What he has done, he does not specify, but as he is the character who acts as the bridge between the note collection and Awdrey-Gore - as he is the authorial voice introducing the notes, commenting on AwdreyGore's disappearance and death, and acting as the framing, contextualizing source - his confession bookends the notes, and acts as a connector to the beginning of the collection. As a result, while there is ambiguity present, the only open question to which a confession can be applied within the context of this tale is who murdered Awdrey-Gore; and as the final quoted canto of The Ipsiad notes, a further crime is that there is no explanation provided, and no way to find out what her murder was all about, given that E.G. Deadworry abandons his contextualizing project just as he confesses to her murder.

Yet the incomplete nature of the narrative and E.G. Deadworry's positioning within the tale ensure that his words cannot be reliably associated with Awdrey-Gore's death. His confession is a possible solution, but as he does not specify what it is he has done, it occupies a fragmentary space alongside all the other incomplete Awdrey-Gore notes. As much as the postcard provides a potential solution to the crime, it merely suggests a possible answer rather than furnishing a complete and satisfying ending.

In The Neglected Murderesses (1980), Gorey plays with historical record-keeping, souvenir postcard books and captioned portraits within a criminological framework. The Neglected Murderesses shares The Awdrey-Gore Legacy's fragmentary narrative strategy, providing small hints of larger stories which invite the reader to extrapolate beyond what each page presents. Each page pairs an illustration of an individual - usually a woman - posing in what appears at first to be an innocuous position, against an equally inoffensive setting, with a brief caption detailing the extent of her crime. At first glance, the juxtaposition is shocking, as each illustration presents a formalized portrait suitable for a family album or hallway gallery, yet the text depicts a salacious act of violence. However, a closer look reveals that each illustration is not, in fact, as innocent as it seems, but rather depicts the moment after the murder or other evidence of the crime. For instance, in panel four, Madame Galoche stands beside a stove, stirring a giant pot with a spoon in one hand and a large container in the other. 
She looks out from the illustration at the viewer as if posing, her face neutral, the pose characteristic of mid-nineteenth century photography, before the advent of shorter exposures and "snapshots" late in the century (Carville 196). Although this scene is extremely domestic in origin, the lines underneath bring a sinister element that explicates the true nature of the picture:

Madame Galoche in May 1911 added a tin of insecticide to a potage purée

Crécy aux perles at the soup kitchen she operated for the indigent of BerchemSainte-Agathe, Belgium.

As Gorey presents the reader with Galoche at the stove, tin in hand, the illustration therefore implies that we are viewing her in the moments around the poisoning. The audience is invited to be both titillated and lulled into a sense of normalcy, as both impulses can be evoked by the picture.

Many of the other panels present similar slices of time directly before or after a crime, when the means to commit the act is still present. The frozen tableau of each panel mimics "the moment when the sleuth discovers or reveals the murderer, [and] time stands still. It is forever high noon...For an instant, time stops, and the face of Insoluble Death is revealed" (Jackson 24). These murderesses are forever caught in the act, without the possibility of "the clock resum[ing] its ticking, [so that] death falls into the background as the unsolvable reality of our experience" (Jackson 24). Miss Elspeth Lipsleigh, a young woman posing beside an ottoman at the top of a tower keep, is surrounded by small cannonballs, which indicate that she "eventually succeeded in causing the death of Arthur Glumm at Towage Regis, 1892" (5). Once again, this illustration shows an ordinary moment in a sightseeing jaunt, but the scattered cannonballs, the ottoman and the adjective "eventually" imply that Lipsleigh has spent quite some time standing on the ottoman, peering over the tower wall, and dropping the cannonballs on Glumm, and has only paused to pose once she has successfully caused his demise. Likewise, Nurse J. Rosebeetle stands on a windswept cliff holding onto an empty wheelchair, and the reader is informed that she "tilted her employer out of a Bath chair and over a cliff at Sludge-Mouth in 1898" (9). This pairing of picture and text strongly suggests that Rosebeetle has just completed the grisly act.

As the youngest murderer represented, Angelica Transome poses with her baby brother in front of a well, surrounded by forest. Gorey tells us that she "so disposed of her infant brother that he was not found until many years later" (6); the audience can thus surmise 
that post-picture, Angelica pushes her brother into the well and walks away, leaving him there without a word as to his whereabouts until he is found a great deal of time later. This scene is perhaps the most shocking of all twelve, as it concerns young children. Both Angelica and her brother pose as if directed, the baby perched on the lip of the well as if placed there by a parent or caregiver. The infant, not entirely aware of the process of picture-taking, looks to the side, his attention wandering, whereas Angelica gazes directly out of the panel, at their audience. Rather than a scene of unsupervised children slipping off into the forest to play before tragedy strikes, the picture heavily implies the presence of minders, whether a professional photographer, parent, or other adult who is able to operate an early camera.

There is an artificiality to these illustrations, each one mimicking posed family photos, but all taking place at moments in which the photographer should intervene. Gorey sets up an interplay of reality and fiction through this technique, as each panel must be hand-drawn from memory or pure fiction, so it therefore cannot be an authentic slice-of-life, yet all the presented figures stand as if posed for capturing through camera, paint or pen. Reality is thus at war with fiction, as suspension of disbelief would indicate that the viewer must believe that each murderess can commit her crime with momentary, if not entirely virtual impunity in the moment that follow each scene, yet the composition of each piece requires the acknowledgement and existence of a viewer. Therefore, while the "neglected" murderesses of the work's title suggest a collection of little-known criminals, at the same time there is an implicit neglect between viewed and viewer; these women are able to commit each murder by virtue of a lack of attention by their audience.

Unlike The Deadly Blotter and The Awdrey-Gore Legacy, The Neglected Murderesses does not have a detective character. On a textual level, this lack feeds into the conceit behind the work, in that these criminals are neglected, not only through a dearth of notoriety, but a lack of interest in the crimes themselves. Without representation of the law present within the text, these murders lose significance; there is no one to occupy an authoritative position from which to witness, display interest in and puzzle out their crimes. Yet each murderess' positioning, looking out from their panels directly at the viewer, prioritizes the audience and places it into the role of detective. Metatextually, readers are invited into a decoding project, restoring the detective figure to a detective-less text.

As the crime in Gorey's mystery narratives moves into the foreground, the detecting process shifts outside of the text. The in-text focus moves from the methodology and mystery 
of detection to criminality itself, the lawmakers fading into the background, becoming footnotes to the action just as the mystery shifts from determining the identity of the culprits to why these criminals are not found out. The Loathsome Couple (1977) is a story inspired by the true story of the Moors Murders, in which five children between ten and seventeen were sexually assaulted and killed by Myra Hindley and Ian Brady in Greater Manchester, England in the early 1960s. It is one of the only Gorey texts to draw from real events, and notably one of the few to result in punishment for the characters who transgress. This narrative follows a similar trajectory to the Moors Murders: After some delineation of their tragic childhood backgrounds, Harold Snedleigh and Mona Gritch meet "at a Self-Help Institute lecture on the Evils of the Decimal System" (7). From there, they begin to explore their mutual interest in criminality, and after a number of years, they decide "to embark on their life's work" (13), the murders of four children. Eventually, through an act of carelessness, "some snapshots [of their crimes] fell out of Harold's pocket on a tram" (22), and as a result they are caught, charged, and found guilty. Although Gorey diverges from Hindley and Brady's story in some of the finer details - Snedleigh and Gritch kill four children, not five; they are both sent to an asylum, when only Brady was, years after the publication of The Loathsome Couple; both Snedleigh and Gritch die in the asylum, where only Hindley has died, and Brady continues to serve out his life sentence - the primary framework remains in place. Gorey's couple is dedicated to murdering children together: they plot their crimes out over a long period of time; the female half of the couple is responsible for luring the children in; they document their crimes in photographs which they then place in an album for perusal later; and they are not revealed to be using guns or other more impersonal methods of killing.

Although at first it appears counter-intuitive to classify this text as one of Gorey's mysteries, as the identities of the criminals and their crimes are never in doubt, nevertheless, there is a mystery embedded within the narrative. The twenty-first panel explains it best, as it says, "For no very good reason their activities remained unsuspected." This lack of reason is the major mystery embedded in the text, and manifests not only in the question of their continued freedom, but also their own motivations. The narrative opens with Snedleigh "beating a sick small animal to death with a rock when he was five years old" (1). The illustration is heavily textured to the point of all but Snedleigh's and his caretaker's faces blending into the background, rendering their surroundings and the act itself secondary. The animal is both obscured by Snedleigh's body and the foliage he kneels in. While killing small 
animals is generally considered a warning signal for children at risk for psychopathic tendencies, the fact that the animal is sick provides an excuse through which to label the act compassionate rather than cruel.

That same potential for misinterpretation enters Gritch's storyline alongside her first appearance. She is "born to a pair of drunkards" (2) who lie around a dilapidated room, senseless and heedless of their baby daughter. Just as with the first panel, little other than naked skin stands out against the multitude of pen strokes that make up the densely textured backdrop, highlighting her mother's debauchery in her state of undress, and her own vulnerability as a half-naked infant. By situating her as a child of alcoholics, Gorey again provides a reason to pity her rather than anticipate her metamorphosis into a murderer. In fact, as he traces both Snedleigh's and Gritch's trajectories through their lives, towards their first meeting, he adds more pathetic characteristics, including the cold Snedleigh caught at twelve and was afterwards never able to shake (3), and Gritch's "thick ankles and thin hair" (4). Yet as they age, they begin to engage in minor criminal actions. Snedleigh steals "curiosa from booksellers whenever he [gets] the chance" (5), and Gritch, "employed behind the jewelry counter in a five-and-ten, [amuses] herself by loosening settings with a nailfile so the stones [will] fall out soon after purchase" (6). Both panels show expressions of sly amusement on their faces, indicating a lack of remorse or fear of discovery. Throughout the narrative, each criminal act is presented in brief, downplaying its severity. Even as the acts escalate, they still receive the same short treatment

Most interestingly, however, is that while the narrative underplays their violent acts, the illustrations hint at a larger moral awareness. Although both Gritch and Snedleigh revel in their crimes, large and small, there is a slight change in the staging of the setting of their murders that indicates that one or both of them acknowledge on some level that they are committing brutal acts of violence. When Gorey shows the viewer where Gritch and Snedleigh plan to contain and torture their kidnapping victims, he draws in two framed silhouettes on either side of the doorframe (14). They are both obviously female, given their hairstyles are in line with women's fashions and do not depict the shorter styles of men of the nineteenth and early twentieth centuries, and both face away from the door. Their positioning, facing away from the doorframe, already implies a subtle disapproval of the planned usage for the room they flank, and the fact that they are silhouettes displayed prominently in Gritch and Snedleigh's "remote and undesirable villa" (11), to the exclusion of 
all other artwork or decorations indicates familial primacy; these are women of importance in Gritch and Snedleigh's lives. It is therefore significant that, when Gritch promises young Eepie Carpetrod a doll in order to lure her to their villa so that she and Snedleigh can spend "the better part of the night murdering the child in various ways" (15-16), these silhouettes are turned on their hooks to face the wall. Either Gritch or Snedleigh have deliberately turned these pictures around so that the women they represent are symbolically unable to see the murder taking place. This disapproval in proxy form indicates some level of moral consciousness at work in one or both of the murderers. While this consciousness never manifests outside of this small action, it is notable in that The Loathsome Couple deviates from Gorey's typical narrative style in preserving a moral heart. Although Gritch and Snedleigh are still subject to the same fateful whims as Gorey's other characters, their accident of fate leads directly to their arrests and convictions. Despite the (dwindling) pleasure they show in their serial murders (18-20), they are punished for their crimes (26), and while "[t]hey [are] taken to the asylum in the same van...after that they never [see] each other again" (27). Snedleigh dies at forty-three as the cold he has had all his life intensifies into pneumonia (28), and Gritch descends further into insanity in a manner reminiscent of Charlotte Perkins Gilman's "The Yellow Wallpaper" (1892), where, instead of wearing a groove into the walls of her prison, Gritch does "nothing but lick spots on the walls" (29) before dying "at the age of eighty-two or eighty-four" (30). For Gritch and Snedleigh, while their punishment comes at the hands of the law, it is further intensified by the ways in which they both waste away: Snedleigh, by being laid low by what began as a persistent sniffle, and Gritch by being forgotten as she grows older, to the point that her age is not particularly relevant or remembered when she finally passes.

As with Gorey's melodramas and children's narratives, his mysteries display all the trappings of the genre while removing the central heart. In the case of detective fiction, he divorces it from the procedural formula, stripping away the intricate, detailed journey from the discovery of the crime through to the solution. While The Deadly Blotter follows this route, it is only at a distance, divorcing the narrative from the intellectual pleasure afforded by extensive detail and puzzle-solving. The Awdrey-Gore Legacy continues this work, as it is an exercise in deconstructing the mystery narrative and examining it as an authorial project. Its mystery lies outside of its fictionalization, lacking an intricate, decodable plot and instead offering little more than a murder and a confession without context. The Neglected 
Murderesses places the audience in the role of detective, but the crimes he presents are already solved, the murderers already caught. The detective becomes the viewing eye rather than the decrypting force, and the murderers themselves lack the notoriety usually afforded fictionalized criminals. Even within The Neglected Murderesses, there is no punishment for their crimes. If there are consequences, they lie outside of the text, unspecified and not carried out. In fact, the postcard format ensures that the murderesses are frozen in time, as their narratives exist only within the space of one panel, almost all of their murders complete. They exist entirely within the moment after they have committed their crimes, and before any punishment can be carried out.

It is only within The Loathsome Couple that Gorey allows justice to prevail. Its connection to a non-fictional case allows for Goreyesque laws to be broken; as Gritch and Snedleigh are based on real people, they follow a similar trajectory to their real world counterparts, yet Gorey goes one step further, and intensifies their punishments in the process of fictionalizing them. The Loathsome Couple is therefore an exception to the rule: morality exists within its narrative, and the guilty do not get away scot free. In all other ways, however, this story conforms to Gorey's larger play with mystery fiction. Just as he removes or distorts the logical puzzles that delineate the trajectory of the traditional detective story from his entirely fictionalized narratives, so too does he remove them from The Loathsome Couple.

By shifting the reader's focus from the expected puzzle within the mystery story to a more distant metatextual level, Gorey draws attention to the form of the detective narrative: the clues are missing and the puzzle unsolvable, and as a result, the plot loses clarity. The reader must therefore actively engage with the text in order to decode the events of the narrative and achieve clarity as to the trajectory of the story. Often, this act is the key that unlocks the identity of the criminal and the details of the crime.

The audience is not the only entity unable to access any in-text decodable clues; regardless of whether the detective figure solves the crime, there is no explicit evidence of deduction or other intellectual exercise which would result in a solution to the mystery. Any solution occurs outside of the text, either silently between the lines of the narrative or in the audience's act of decoding the plot itself. As Viktor Shklovsky explains in Theory of Prose, [i]n the mystery novel, the solution is as important as the riddle itself. The riddle makes it possible for the writer to manipulate the exposition, to 
enstrange it, to capture the reader's attention. The main thing is not to allow the reader to find out what is in fact going on, because, once recognized, such a situation loses its horror. (140)

In contrast to his work with melodrama, the Dickensian, and children's literature, Gorey remains more faithful to the detective genre. Although he continues his project of removing the central purpose of the genre, instead of entirely discarding it, he shifts it outside of the narrative. He violates the tenet of detective fiction which requires actively hiding clues from the reader, providing enough to hold her or his attention, but not revealing enough to expose the solution to the mystery before the end of the tale. Not only does Gorey take this power away from the detective, but he makes the reader over into an extra-textual investigator and the only character who is fully able to decode the plot.

Within his texts, Gorey's mysteries have secrets for the sake of those secrets. They are not meant to be completely understood or deconstructed, thwarting the purpose of the detective narrative even as he rebuilds their structure outside of the text, placing the audience in the detective's position. Regardless, even once the reader becomes the detective and successfully decodes the mystery, because of the divide between reader and text, there is no possibility to mete out punishment to his criminals. As a result, even as his more innocent characters in other genres often find themselves subject to the whims of fate, with very few exceptions, Gorey's criminals slip the noose, avoiding the very fates that punish his innocents. 
Page 134 of 216 


\section{Chapter 6: Gothic Furnishings}

Gorey's Gothic horror is the culmination of his genre play. In all of Gorey's genres is an element of the horrific; it is this element that Gorey retains and exaggerates while removing other emotional elements from the genres with which he works. Although Gorey's narratives are constructed to maintain emotional and empathetic distance between characters and audience, his texts cultivate an excess of tragedy: children die en masse, families are torn asunder by events outside their control, and rampantly verdant gardens swallow all visitors whole. Gorey's works delight in their own horrors, stacking death upon death and loss upon loss, until the sheer mass of catastrophe reaches such heights as to become unbelievable and unaffecting, having become so excessive as to no longer evoke real feeling in the reader. Kelly Hurley, in "Abject and Grotesque," categorizes this overindulgence in tragedy as the gleeful excessiveness of Gothic horror [which] unfolds its uncontrollable and prolonged metamorphoses without apology or restraint, and unconcernedly piles its bloody, eviscerated, suppurating bodies one atop another. (142)

Much of Gorey's work incorporates shocking acts of violence, tragedy, and inescapable death, the foundation upon which he can pile both literal and figurative bodies. The briefness of his narratives and Gorey's enforced distance between his characters and audience works in tandem with this excessive glee to flout the emotionality and spirituality that is otherwise a part of the Gothic aesthetic. Instead, Gorey's tragedies become comedies as the sheer overabundance of horror reaches ridiculous heights.

In "Gothic Pedagogy and Victorian Reform Treatises," Grace Kehler explains the importance of emotion to Gothic narratives, where

figures in the [gothic] literary genre typically show themselves to be receptive to external stimuli and expressive of the impact left on them by culture and nature...The visible, exterior aspects of existence, from social relationships to the state of one's dwelling, provoke reactions in the guts and the gaze, and, though neither uniform nor prescriptive, these reactions epitomize the promise and the terror of the gothic: there is no way to keep the world at a distance or one's sensate involvement with it private and singular. If the individual acts on the world, the world (place, people, things organic and inorganic) pre-exists 
and continuously informs the emotional and physical senses; the senses, in turn, present their own challenges to identity construction, for they may operate either in tandem with the mind or involuntarily...The gothic, then, achieves its unsettling effects by highlighting both the vulnerability of the self to the world and the obstreperousness of the sensations at work in the individual. (438)

The characters in Gothic horror undergo extreme emotion as a result of their narrative experiences. Their fear is elicited from tragedy, that external stimuli of the physical and supernatural worlds which cannot be avoided. These characters' reactions elicit the audience's own reactions to the text and, by extension, the world around them. They are invited to empathise with the work's protagonists, whether through terror, sympathy or pity ${ }^{28}$. Gorey, however, uses the building blocks of the Gothic to elicit the expectation of emotion, as he writes for an informed audience that is well-aware of the conventions of Gothic horror. $\mathrm{He}$ peppers his texts with monsters and supernatural beings who encroach on various characters' psychological well-being, their bodily health, and their peace of mind and sets these creatures against backgrounds populated with Gothic signposts, including crumbling ruins, lonely manors, windswept moors and shadowed rooms. His characters are often distant, isolated and beset by circumstances outside his control. Yet despite the presence of fearful protagonists in his works, his audience is not invited to empathize with their positioning, nor share their fears.

Gothic horror predicates much of its power on the fear of destabilization. Its spectres and hauntings destabilize the social order, unsettling those who are haunted and displacing them within their own spaces. This displacement is a threat to bodily integrity and psychological health; at any moment, the individual may be undermined, whether by supernatural or monstrous means. Horace Walpole's The Castle of Otranto (1764) begins with an explicit physical threat, as a giant helmet crushes Manfred's son Conrad, setting off the supernaturally-driven destruction of Manfred's home and title. Similarly, Ann Radcliffe's The Mysteries of Udolpho (1794) is filled with (generally explainable) hauntings and terrors, such as the figure behind the black veil, that unsettle Emily St. Aubert and eventually displace

\footnotetext{
${ }^{28}$ See David Punter's "Pity: Reflections on Algernon Blackwood's Gothic" in English Language Notes, 48.1 (2010).
} 
her by forcing her out of Udolpho. Mary Shelley's Frankenstein; or, The Modern Prometheus (1818) concerns a larger undermining of humanity and the human form through the Creature's existence and experiences, as on a primal level, the Creature is a corruption of the body and a disruption of social order.

Jonathan Harker in Bram Stoker's Dracula (1897), experiences this threat as a physical danger to his health, originating from a supernaturally monstrous source. While he is held prisoner by Count Dracula, Harker observes the Count's inhumanity:

$[\mathrm{M}] \mathrm{y}$ very feelings changed to repulsion and terror when I saw the whole man slowly emerge from the window and begin to crawl down the castle wall over the dreadful abyss, face down with his cloak spreading out around him like great wings. At first I could not believe my eyes. I thought it was some trick of the moonlight, some weird effect of shadow, but I kept looking, and it could be no delusion. I saw the fingers and toes grasp the corners of the stones, worn clear of the mortar by the stress of years, and by thus using every projection and inequality move downwards with considerable speed, just as a lizard moves along a wall.

What manner of man is this, or what manner of creature, is it in the semblance of man? I feel the dread of this horrible place overpowering me. I am in fear, in awful fear, and there is no escape for me. I am encompassed about with terrors that I dare not think of. (Stoker 77)

For Harker, viewing the unnatural physicality of Dracula unsettles and overwhelms him. Harker's understanding of the Count is fragmentary at best, and in these moments, Dracula is an unknowable creature; that inability to understand and categorize Dracula in rational terms disrupts Harker so much that he is overpowered by fear.

Gorey's monsters exist in this space as unknowable, unnatural creatures, but instead of engendering repulsion or terror, most - such as those in The Doubtful Guest and The Disrespectful Summons - cause irritation and inconvenience. They occupy the space shared by Udolpho's ghosts, Frankenstein's Creature and Dracula and evoke the expectation of fear, but Gorey's penchant for terse text and distancing the audience from the narrative work to defang his own horrors. There is the potential for a disruption to bodily integrity and psychological health in Gorey's texts, but it happens through the build-up of small obstacles and frustrations rather than severe paranormal threats. 
Although the earliest examples of Gothic horror focus on supernatural and otherworldly hauntings, later instances begin to incorporate mundane threats to characters' well-being. The horror in Oscar Wilde's The Picture of Dorian Gray (1890) stems from an otherwise unremarkable object, as Dorian's portrait becomes a receptacle for Dorian's own hedonism, ravaged by time as his excesses are projected upon it. In Charlotte Perkins Gilman's "The Yellow Wallpaper" (1892), the odd yellow wallpaper is described as a kind of sub-pattern in a different shade, a particularly irritating one, for you can only see it in certain lights, and not clearly then. But in the places where it isn't faded and where the sun is just so-[you] can see a strange, provoking, formless sort of figure, that seems to skulk about behind that silly and conspicuous front design. (12)

While the threats in each of these works are psychologically terrifying, they stem directly from mundane objects and occurrences: a portrait, and fading wallpaper. Both of these narrators experiences a physical and psychological erosion of their health by the very objects that surround them. As Robert Miles says in Gothic Writing, 1750-1820: A Genealogy,

[t]he Gothic may evince no single dialectic, but there is broad agreement that the Gothic represents the subject in a state of deracination, of the self finding itself dispossessed in its own house, in a condition of rupture, disjunction, fragmentation. (3)

For Dorian and Gilman's narrator, the very furnishings of their houses become othering forces, warping any sense of peace or safety to their homes and minds.

As Bradford Morrow and Patrick McGrath explain in their introduction to The Picador Book of The New Gothic:

It's not until the 1830s and '40s, with Edgar Allan Poe, that the gothic begins to shift the emphasis away from all this gloomy hardware and becomes increasingly fascinated with the psyche of the gothic personality. With this shift a fresh vein of gothic ore is opened, and in Poe's work we encounter minds and souls haunted by the urge to transgress and do evil, crippled with distortions of perception and moral sense, and obsessed with death and morbidity. With Poe the gothic turns inward, and starts rigorously to explore the extreme states of psychological disturbance. (McGrath xi) 
For instance, in Edgar Allan Poe's "The Tell-Tale Heart" (1843), the narrator plots his murder because of his hatred of the old man's clouded eye, and later betrays his actions by fantasizing he can hear the old man's heart, the "low, dull, quick sound, such as a watch makes when enveloped in cotton" (501), still beating under the floorboards. The heart beats not because it is still capable of physicality, but because the narrator projects his own anxieties onto it:

$[\mathrm{I}] \mathrm{t}$ is Poe who stands central to the [gothic] tradition, reaching backward into the eighteenth century for his crumbling fungoid castles and clammy vaults, and forward into the twentieth with his demented drunks, his paranoids and neurotics, blazing a trail through the darkness. (McGrath xiii)

It is out of Poe's shadow, using the tropes of the Gothic (past and present) that best suit him, that Gorey builds his own Gothic horror narratives. He plucks those characteristics that signal Gothic horror and help build larger-than-life monsters and landscapes while mining twentieth- and twenty-first century audiences for distanced and humorous readings and reactions. As Poe reaches back and forward for his tools, so does Gorey straddle the gap between the emotionality of the Gothic literature of the past and the more cynical world views inherent in more modern audiences.

Just as Gorey plays on monstrous tropes, he furnishes his narratives with mundane objects that should be the building blocks of psychologically-focussed Gothic horror. Works such as The West Wing and The Evil Garden are rife with unremarkable items that become imbued with paranormal phenomena, manifesting both the physical atmosphere and the psychological anxiety inherent in the genre. In this manner, Gorey uses melodramatic and Dickensian conventions heavily and couples them with supernatural and earthly horrors which he places against backdrops filled with the trappings of Gothic art and architecture. As Patrick McGrath and Bradford Morrow write:

in its earliest days, [it] was known by the props and settings it employed, by its furniture. Dark forests and dripping cellars, ruined abbeys riddled with secret passages, clanking chains, skeletons, thunderstorms, and moonlight-from such materials did the first gothicists frame their tales (xi).

Gorey's narratives are rife with dark, brooding mansions, moonlight and darkness, abandoned and ruined spaces, and unforgiving stone walls and iron fences. In each text, Gorey lays out a dark, gloomy world overrun by high-contrast black and white crosshatching which helps to conceal fine lines and minutiae through sheer abundance of detail. His characters melt into 
their backgrounds, as much a part of their settings as their surroundings set the tone of each work. He makes use of the creeping horror of landscape to great effect in The West Wing (1963) and The Evil Garden (1966), filling the former with a pervasive yet unfocussed sense of doom, and the latter with rising terror as the foliage progressively becomes more aggressive and dangerous. Conversely, he strips these Gothic conventions of any sting of fear in The Doubtful Guest (1957) and The Disrespectful Summons (1973), as in the former, the strange guest is nothing more than a nuisance, and in the latter, the main character's experience of demonic possession manifests as an outlet for all her pettiest desires and revenges. In each text, he constructs a template of Gothic horror: supernatural threats to mental and bodily integrity abound; deep shadows, dark rooms and heavily textured backgrounds visually pull characters from the foreground into the background, cultivating dread and paranoia; and unexplained happenings remain unexplained, maintaining a barrier between what is known and unknown in each narrative.

Yet just as he removes the central purposes of other genres and examines both the spaces created by their absence and what remains, Gorey delights in the trappings that create the excessive fear and emotion central to Gothic horror, but removes the empathic connections between his audience and his characters, arresting any growing sense of terror. There is no eruption of repressed emotion leading to supernatural or otherworldly happenings, because Gorey effectively neuters any desire present in the text. Although his characters desire ideas and things, such as a familial stability and success, a quiet day at home, or a happy afternoon out, they are small, reasonable goals, unfettered by excessive emotion. The supernatural still exists within these narratives, but without the extremes and general excesses that lies at the heart of Gothic horror.

A prime example of this disconnect between supernatural horrors and emotionality is The West Wing (1963). Unlike the majority of Gorey's stories, The West Wing is almost entirely without text, the only exceptions being numbered notations below the bottom right corner of every panel. As the title indicates, the work focusses on one wing of a larger mansion, each panel a view of a different room within the western half of an estate. These room illustrations exist as vignettes rather than component parts in a fuller narrative, presenting a collection of happenings that are not necessarily related to each other. In essence, Gorey's Gothic furnishings take prominence in this tale, as the house itself acts as the narrative through-line; rather than movement through story events, Gorey takes the reader on 
a tour of the rooms. These rooms exist as an artistic gallery, each scene a frozen tableau which collectively gives literal meaning to the story's title. The West Wing thus becomes a catalogue of the westernmost collection of a larger multi-wing institution, subtly acknowledging the physical book form the reader holds in his or her hands. The numbered notations at the bottom of each panel also help to translate this paranormal museum into textual form, following a convention in use with bound and published collections of plates and reproductions of artistic works such as paintings, photography and sculpture. In fact, more than one of the illustrations directly reference specific artistic works. Alongside the lush, patterned carpet (1), ornately framed forest and stream landscape (5), Romanesque bust (14), ancient mummy (19), and Ming vase (24) are panels such as number twenty-eight, where a pale young girl kneels on the floor, face turned from the viewer and toward a point outside the panel, her white, lightly drawn and detailed body standing out from the dark, heavily detailed background. Her positioning echoes that of Christina Olson, the subject of Andrew Wyeth's 1948 painting, Christina's World, as Christina faces away from the viewer, reaching and crawling towards the buildings in the far background of the painting.

Through the catalogue structure of its illustrations and text, The West Wing predates and predicts the ways in which Gorey's works are reproduced in survey collections, each panel meticulously reproduced and numbered for ease of reference in accompanying discursive text. In terms of the narrative thrust of the text, however, the rooms take the place of story-driving events, and progression through the tale is not through character actions and reactions, but rather the movement between panels and rooms. In this manner, Gorey creates the trappings of a narrative without the underlying unified story, parallelling his use of Gothic horror tropes divorced from fear.

There is a level of disorientation that goes along with lack of clear narrative in The West Wing. The strangeness begins in the frontispiece, as the facade of the building clearly shows that one of the windows has been bricked up. There is no explanation for this architectural alteration either in the piece, or within the text itself, as there are no interior views of the blocked window. In addition, Gorey produces views of stairs that rise upward, out of frame $(1,16)$, their final destination only knowable through reader assumption that they lead to various parts of the west wing, as there is no orienting text or visual markers to indicate from where staircases are viewed. There are a multitude of doors that remain closed $(6,8,11,19)$, or are ajar $(2,4,24,25,26)$ without any indication of what lies beyond them. 
The entire wing is a study in suspense. As the rooms stand in for narrative movement, so too do the limited views act as obfuscation and misdirection as the text progresses. They are the equivalent of embedded plot twists, literally blocking the audience from seeing what is coming around the corner.

In this manner, The West Wing is a study in atmosphere: each panel is a glimpse into a dark, brooding black and white world consumed by texture. Most panels are empty save for a few lone objects; when people appear, they are always alone. Of the thirty presented scenes, only nine have human figures in them, and of those nine, three are distinctly paranormal. The first panel acts as a visual invite into the text and the wing itself, as it presents a view of an ascending staircase. The staircase is bare, without runner or carpet, and leads away from a lush, heavily patterned carpet on the lower floor. The illustration is aligned slightly below eye-level, as if the viewer is either looking down, sitting, or crouching rather than approaching the staircase directly from a standing position. This angle adds to the disorientation that intensifies as the text progresses. The next panel (2), is of a woman entering a bare room: the floor and walls are undecorated, the floor wood and the walls without wallpaper, mirrors, artwork or shelving. The woman is dressed in a dark, plain dress that covers her from her neck to the floor, with full sleeves that come down to her wrists. Her face is half-turned away from the viewer, and her gaze is forward, without a visible object or person within the boundaries of the panel as focus.

Yet this character does not appear again. She and all other characters exist in their individual tableaux without interacting with or crossing into other illustrations. Indeed, their physical presences are even more separated from each other as every character has at least one panel - usually more - depicting an empty room between them and the next human appearance. The illustrations following the woman in panel one are of a room empty of everything except three abandoned shoes, a hallway opening into another hallway, and a large landscape painting. There is no explanation for the shoes, just the emptiness of a darkened room and the strangeness of an odd number of shoes, the third left without a mate. Although the shoes are ultimately ordinary objects, the setting - a dark, empty room and an undressed, utilitarian window with no view to speak of - is inherently unsettling, by virtue of being uninhabited. Gorey uses the lack of text and emptiness of most of these rooms as a visualization of silence that is full of the weight of the unspoken and unknowable. 
This pregnant silence is especially apparent in the two panels which depict doors opening upon other doors between multiple hallways and rooms. As with most of the other areas in the west wing, these doorways are lacking in adornment, and do not appear to lead anywhere significant. The first scene, in panel four, is well-lit, but does not provide any clues as to its placement within either the wing or a larger narrative. The wainscotting on the walls mimics the doorway panelling, and this panelling is echoed in the hallway the first door opens onto, and the room across the hall. Both doors are open, yet there is no evidence of anyone who opened them. They offer a tacit invitation, however, as they are ajar rather than fully open or closed; the intimation is that these doors are not in their standard positions, either closing off rooms or left perpetually open. Rather, they are evidence of intentional entrance, and beckon the viewer forward. What these doors lead to, however, is completely unknown. The duplication of panelling provides a sense of disorientation, as just like an infinite series of reflections, there is a distinct possibility that the doors will lead to an unending string of identical hallways. Such a layout hints at a larger mystery, especially in light of the paranormal activities in some of the other rooms in The West Wing, yet without a textual or explicit narrative through-line, the viewer is left without the clues to thoroughly decode the halls' meaning.

The repeating door motif appears again in panel twenty-five, yet this time, the two doors are not in rooms with matching wainscotting. The lighting is considerably lower, with the details of the floors and walls almost entirely lost in darkness. Unlike panel four, only the first door in the forefront is ajar, the second firmly closed. The perspective in this panel echoes panel four to such an extent that given the lack of wainscotting, the scene appears to be from the perspective of an individual who has passed through the duplicate rooms and is looking back at them. This time, however, the way back is blocked. As the lighting of the room has shifted from bright to dark, the duplication of doors and the rooms themselves take on a menacing air.

Other than a maid who looks directly out of her illustration (9), all the people who appear in The West Wing avoid looking towards the viewer, and have their expressions obscured. Even the gentleman in panel six, who is the closest to having his expression entirely exposed, sits facing the audience with his eyes closed. His expression is thus closed off from the viewer, as it is at rest and does not give away any particular emotion. Along with the first human figure in the text, the conservatively dressed woman with her face half- 
turned away from the panel foreground (2), and the gentleman whose eyes are closed (6) are a man naked except for a pair of slippers (12), a man collapsed on the floor of a heavilypatterned room (15), and a young girl kneeling in another room (28). Each of these figures have their faces turned away from the reader, observed by the audience, but not observing. Through this placement as viewed but not viewing, Gorey underscores each panel's positioning as a piece of art, passively receptive to a reader's interpretation rather than narratively active. Additionally, the collapsed man is motionless, stretched out on his front on the carpet, and while there are no visual markers of injury, his placement echoes the many other dead bodies that litter Gorey's works. His face is entirely hidden from the reader, concealing all identifying details alongside the nature of his malady. While the child in the twenty-eighth panel is not injured or in distress, she too is close to the floor, crouching rather than lying down. Her face is half turned, her gaze aimed towards the right side of the panel, looking at something outside of its boundaries. Like Charlotte Sophia in The Hapless Child, this girl is devoid of the heavy texturization of her surroundings; almost entirely white, she stands out from the rest of the room. Given the paranormality inherent in The West Wing, this complete whiteness marks her both as innocent and ghostly. She is unaccompanied and unsupervised, and the rest of the narrative does not point to any distress on the parts of the other characters regarding her whereabouts. As with all the other strange tableaux in this work, her appearance is confined exclusively to this room without any extension of affect outside of her singular illustrative sphere. Rather than a fearful protagonist with whom the reader can identify and empathize, The West Wing is filled with faceless, nameless characters whom the viewer encounters in frozen moments. There is no room in these moments for anticipation or reaction, as the viewer is not witness to any action. Events have either happened already, or are about to happen, but given the lack of connection between scenes, there is no way to view any narrative progression. The viewer is thus not invited to take up the subject positioning of the protagonists, even when Gorey places these characters in otherwise vulnerable positions.

Curiously out of place amongst the clothed people populating the rest of The West Wing, a naked man stands in front of a balustrade, hands modestly folded at the small of his back, covering his buttocks, his body turned away from the foreground (12). His face is turned to the side enough so that his extensive facial hair is visible, and while the logical assumption is that a balustrade indicates that he is outdoors on a veranda, porch or balcony, 
Gorey's use of texturing that is identical to many of the inner walls of the west wing removes that certainty. As the balustrade is a marker of an outdoor space, the man appears to be incongruously attired and in the midst of exposing himself in a public sphere, yet the lack of any cues beyond the balustrade to allude to the placement of this panel in relation to the larger estate allows for an even stranger interpretation. All of the other illustrations depict the insides of the wing; without any visual context beyond the balustrade and with the texture of the background matching that of many of the walls of the rooms, this man may be doing nothing more than staring at a wall in an inappropriately designed room. Additionally, the incongruity of his position and nakedness is further intensified by the fact that he has taken the time to put on slippers, while eschewing all other clothing. His facial hair is thick, as he sports bushy eyebrows, a dense moustache and a long beard, effectively cloaking his face while the rest of his body remains hairless. The human figures in The West Wing are as peculiar as the supernatural occurrences, given such incongruity as the man's nakedness in a room that exists somewhere between private and public, and their collective positioning in which their expressions are obscured, and thus unknowable.

Gorey maintains this lack of knowledge and explanation over into the illustrations that most explicitly contain paranormal phenomena. Two sheets float in mid-air (13), no visible means of staying aloft, and no individual in the room who might have tossed them in the air. An entire corridor is filled with water with no particular origin point (11), and no discernable damage to the surrounding rooms. A ghostly figure peers into an empty room that contains nothing except a small, discarded card (17). A mummy roams the hallways (19), and the silhouette of a reclining person is superimposed over highly detailed wallpaper halfway up a wall (21). A cavernous crack reminiscent of popular depictions of an opening of Hell tears through a floor (22), and a small lizard-like creature sporting thick, dark stripes along the length of its body wanders alone across a room (26). Yet none of these phenomena are witnessed by anyone outside of the viewer. They exhibit no threat simply because there is no one present to be threatened. While displaying the trappings of terror in their twisting of the familiar, Gorey effectively removes the essential ingredient to a horrifying story: the fearful protagonist, an individual within the narrative to witness such events and react in fear.

Most of Gorey's works, whether published singly or in anthologies, lack pagination. The West Wing, however, numbers each panel, from the first to the last. Given the lack of text, this choice feeds into the metatextual connectivity that stands in for the narrative line. 
Just as the rooms are collected together in the wing, the numbers link the panels together and provide an artificial connectivity. Yet even as Gorey supplies unity, he disrupts it. Panels one through twenty-nine are properly numbered, but panel thirty is, instead, demarcated with a 'U'. What this ' $U$ ' stands for is entirely unclear, as it is not a proper Roman numeral - unless it is treated as a Latinate stylistic variation on ' $\mathrm{V}$ ', which represents five measured units, and therefore does not correctly indicate the thirtieth panel in the series - and is the twenty-first letter of the alphabet, and thus cannot be an alphanumeric analogue. The only clue to its significance - outside of a deliberate disrupting force - is the illustration itself. Panel thirty is another dark room with no ornamentation, yet it has a small spot of illumination emanating from a floating candle moving towards the right side of the room. The flame bends slightly to the left, indicating movement, and as it is not suspended in a chandelier or carried by a visible person, it appears to be held aloft by supernatural means. The 'U' can therefore be inferred to indicate the presence of the uncanny; in this case, the presence of the lighted candle, which is at once a familiar object, yet presents itself as unfamiliar and disorienting by virtue of moving without human intervention. In fact, the entirety of The West Wing is a study in the uncanny, as every room, from the most innocuous to those most rife with paranormal activity, provides an unsettling tableau of otherwise mundane surroundings. This shift from the familiar to the unfamiliar works in tandem with the silences inherent in the text, unseating the potential for easily divined meaning.

The West Wing is a strong example of exactly how the furnishings of Gothic horror work to distort and disorient an ordered world. Gorey takes much from predecessors such as Edgar Allan Poe, as:

Poe recognized how the furniture of the genre could be spliced together with the sensibility...In such a tale climate, landscape, architecture, genealogy, and psychology seem to bleed into one another until it is impossible to distinguish a figure from its metaphors. The coalescence of all these elements sets in motion a process of regression, decay, a collapsing back into a state of primal unity-a death, in other words; and this, finally, is what the gothic has always addressed. (McGrath xi-xii)

Without text to guide the reader through The West Wing, the climate, landscape and architecture become the core elements of the work. Alongside unexplained paranormal happenings, these characteristics suggest rather than outright tell a tale. Yet as there are no 
definitive signposts or linear clues to reveal a cohesive narrative, the reader is left to project her or his own narrative upon the work, allowing for a bleed between author and audience and further encouraging multiple interpretations and possible meanings. The trappings of Gothic horror become the most important ingredients of the work. Gorey, however, goes one step further in not providing any metaphorical key, so the potential to distinguish metaphor from literal, narrative from tableaux, or meaning from meaninglessness collapses in on itself on a metatexual level. Gorey's death is not an exploration of decay or ceasing to exist, but rather imposing a type of death upon the Gothic horror form. Without the emotional impetus to engage with the horror inherent in the text, the audience does not experience the narrative through the lense of Gothic horror. While Gorey uses generic signposts, the atmosphere and architecture is not imbued with the fear of the unknown that allows for examination of our own temporal states.

Where The West Wing focusses on atmospheric horror in the home, The Evil Garden transfers the supernatural threat to a more public sphere. In this tale, a large group of people visit a ornamental garden which is advertised as having "Eintritt Frei!" (1), or "Free Entry." As the group explores the garden, they experience progressively stranger and stranger phenomena that culminate in each one of them being consumed by nature. Gorey presents this tale, like The Awdrey-Gore Legacy, as the product of a fictional writer arranged by a second fictional writer. Where The Awdrey-Gore Legacy is Awdrey-Gore's unfinished work collected, introduced and edited by E.G. Deadworry, The Evil Garden is Mrs. Regera Dowdy's English translation of Der Böse Garten, a German text by Eduard Blutig; and just as with The Awdrey-Gore Legacy, Gorey is indulging in a tripling of authorship. To begin with, he is, of course, the true author of the piece. He is, however, also both the translator and the fictional writer. As with D. Awdrey-Gore and E.G. Deadworry, "Regera Dowdy" is an anagram of Edward Gorey. As the translating figure, Regera Dowdy exerts authorial control over the exact words and phrases used to transform Der Böse Garten from English to German, yet this also situates her at a slight distance from the original text. Gorey, however, remains the true authorial heart, but in this case, instead of an anagram, he uses German as his disguise. Der Böse Garten is by Eduard Blutig, where "Eduard" is a fairly straightforward German version of "Edward," but "Blutig" is not as easily or directly portable from one language to the other. Instead, Gorey uses the meaning of his name, rather than the individual letters, as the key. Working with his reputation for the macabre, Gorey plays off the idea of 
his last name as an alternate version of "gory," and translates that into a synonym. "Blutig," therefore, is the German word for "bloody," and Eduard Blutig, when translated, becomes Edward Bloody. Gorey thus embeds his authorship at every level of The Evil Garden, and indeed goes one step further as he folds his author-owned publisher, The Fantod Press, into Der Böse Garten's fictional history.

"Fantod" is itself a rare singular form of "fantods," a restless, unsettled state characterized by extreme emotion or movement ${ }^{29}$. As "fantods" originates in the nineteenth century, The Fantod Press name is one more link back to this time period, and helps to subtly underline the unsettling nature of Gorey's works. Yet at the same time - and in his inimitable style - Gorey defuses the full impact of such extreme, unsettled emotion by singularizing it. While fantods are almost always experienced in the multiple, Gorey's press provides a singular shudder. His terrors are muted and viewed at a remove, so that there is distance between the audience and the text. He does not craft his tales to elicit strong reader-character identification, as the details of their lives are nearly always sparse and their fates quick and impersonal. The Fantod Press therefore stands as a real world institution that manifests this Goreyesque remove. Just as Gorey folds himself into his fictions, he does the same with The Fantod Press in The Evil Garden. Where The Awdrey-Gore Legacy is published by Deadworry and Silt, an entirely fictional press, Gorey links the English translation of Der

${ }^{29}$ One of its earliest recorded uses is in the multi-volume story, The Adventures of Harry Franco: A Tale of the Great Panic (1839) by Charles Biggs. During a scene in which several sailors tease the main character, Tom Sweeny, the ship's "captain of the after guard" (248) opines that the ship's doctor will not certify Harry Franco, as Franco has "got strong symptoms of the fantods; [his] skin is so tight [he] can't shut [his] eyes without opening [his] mouth" (249). Mark Twain is fond of the word as well, as it shows up repeatedly in his works, such as when Huckleberry Finn first discovers a strange man lying by a campfire and says,

[B]y and by, sure enough, I catched a glimpse of fire away through the trees. I went for it, cautious and slow. By and by I was close enough to have a look, and there laid a man on the ground. It most give me the fan-tods. He had a blanket around his head, and his head was nearly in the fire. I set there behind a clump of bushes, in about six foot of him, and kept my eyes on him steady.

While the man turns out to be Jim, who is not a threat, Finn recovers quickly from his fantods, but the feeling reoccurs once more as he views a set of unsettling pictures further on in the text, and he notes, "These was all nice pictures, I reckon, but I didn't somehow seem to take to them, because if ever I was down a little they always give me the fan-tods" (206). 
Böse Garten to a real publisher, giving it the same place and date of publication as the real work itself: New York, 1966.

Further in this collapse of real and fictional authorship and publication, Gorey give the translator commentary space in which to denote the literary significance of the translation. Just as books are translated from their native languages into other languages on the basis of popularity, publisher and audience interest or subjective notions of literary significance, Der Böse Garten comes with an epigraph indicating the grave event which the English publication marks. As Mrs. Regera Dowdy says,

Alas, my translation of perhaps Herr Blutig's most famous work appears on the melancholy occasion of the seventy- fifth anniversary of the next to the next to the last time he threw himself out of a window. (i)

This epigraph serves two purposes: it both undermines the seriousness of a translation project, and allows the tragedy that befalls the visitors to the Evil Garden to bleed out of the central text, into the framing narrative, and on into real life. Gorey places what should be the tragic death of the author, Eduard Blutig, at a distinct remove from the text, as although he heavily implies that Blutig committed suicide, he also frames this event with built-in ridicule. As horrifying and sad as Blutig's death should be, the translation of Der Böse Garten is published not on the anniversary of his death, but rather marks one in a series of failed attempts at ending his life through self-defenestration. Such an event is only notable in its relation to the final, successful suicide attempt, and as a demonstration of Blutig's baffling repetition of the same act of jumping out of a window over and over again. Gorey thus transforms an otherwise tragic event by over-complicating the anniversary date - there is no reason to mark the seventy-fifth anniversary of Blutig's third to last jump out a window - and undercuts the inherent gravity of such an epigraph. However, just as in The Awdrey-Gore Legacy, by placing himself within the text as Eduard Blutig, Gorey kills off his avatar-self, not even allowing his unseen authorial embodiment to escape the macabre pull of his narratives.

The true horror of The Evil Garden lies in the transformation of a welcoming space into an inescapable instrument of death. The Gothic is born out of "a long-standing appetite for the gentle melancholy of ruins, an appetite that now acquired rather sinister undertones" (McGrath xii). While The Evil Garden does not take place in the crumbling ruins of old and aging buildings, the rampant fecundity of the garden evokes the ways in which nature, when 
left to its own devices, will overrun mansions and monuments alike. The garden, while beautiful to its visitors at first, quickly becomes a chaotic, dangerous place. In the first panel, the people entering the garden are all smiling, and the accompanying text expresses their pleasure at finding out admission is free: "How elegant! how choice! how gay! To think one doesn't have to pay." Yet the very next panel moves directly into creeping dread, as "[t]here is a sound of falling tears; [i]t comes from nowhere to the ears" (2). The individuals in this illustration have already lost their pleased expressions, and are engaged instead in trying to ascertain the source of the sound. The next few panels present incrementally stranger happenings, such as a tiny, angry creature who approaches the visitors (3), the discovery of a "foot inside a striped sock [protruding] from underneath a rock" (4) in a visual reminiscent of the Wicked Witch of the East's demise in the 1939 filmed version of The Wizard of $\mathrm{Oz}$, flowers whose scent makes people nauseous (5), and a giant moth that nibbles at the Reverend's jacket (6). It is not until the seventh panel, however, that the full horror of the situation becomes apparent. Where the earlier happenings indicate that the garden possesses supernatural qualities, these events merely allow for the slow - for Gorey - unfurling of the visitors' collective fate. Isabelle, one of the attending children, disappears, leaving nothing but her sash. Her disappearance is visually intensified by the fact that this is the only panel in the narrative in which there are no other characters. The sash lies crumpled on the ground, surrounded by strange plants, all of which sport dark leaves. Just as Gorey often uses absence of shading as a characterization technique, here the sash is far more delicate than the surrounding plants, as Gorey depicts it entirely through thin outlines, leaving the fabric textureless and white. Conversely, by filling in all the plants with black ink, the plants appear menacing, and even without Isabelle present, the contrast between her discarded sash and the looming plants communicates her fate.

From this point on, the remaining seven panels depict a variety of deaths for the various visitors to the garden. Great-Uncle Franz, looking slightly apprehensive, is strangled to death by a snake (8); large, fierce bears menace the group as they approach fruit growing in the garden (9); another young girl, Alexa, watches as her aunt is devoured by a plant (10); the baby is carried off by giant bugs (11); and the nurse is swallowed up by an ominous-looking bubbling pond (12). Although they are not at first aware of the danger they are in, the group does not passively accept their own deaths. Alexa's aunt reaches out, trying to escape the plant, and while the nurse stretches her arms beseechingly up above the surface of the pond, 
one of the other adult women, her hair in disarray, flees the scene. It is at this point that Gorey takes full advantage of the black and white art style, as the final two illustrations have entirely black backgrounds, the plants themselves blending into the darkness (13-14). The characters who are still alive, however, stand starkly out against the background, as Gorey chooses not to depict them in heavy detail. Their whiteness underlines their naivete and innocence, as well as intensifying their inability to escape: they are so noticeable against the garden's backdrop that they cannot hide from their fates, and "[f]all down, or scream, or rush about-[t]here is no way of getting out" (14). Yet this epigraph still does not invite the reader to take an empathetic stance. The distance between text and audience remains, the characters' predicament something by which to be amused rather than horrified.

The Doubtful Guest combines the irreverence of Gorey with the hallmarks of Gothic horror. The tale concerns a family in a cavernous estate who find themselves unwilling hosts to a strange creature who appears one "wild winter night" (3). The creature proceeds to frustrate and annoy the residents, and ultimately refuses to leave the premises, instead becoming a permanent fixture in their lives. At the outset of the narrative, the weather itself sets the scene; reminiscent of the rainy, windswept moors of Emily Bronte's Wuthering Heights (1847) or the violent thunderstorms of Mary Wollstonecraft Shelley's Frankenstein (1818), the family opens their door to nature in uproar. Not only is their bell rung by a mysterious and unseen hand (3), but the wind whips across their porch hard enough that the hems of their clothes are caught up in it and drawn away from their bodies, enough so that one of the women must place a hand on her dress to keep it from flying upwards. The wind also threatens hair, as the same woman must clamp a hand firmly on her head to keep her Gibson Girl hairstyle from being destroyed. While she and two men search for the source of their disturbance, another woman and a child peek out from behind the front door, the woman wrapping her hands around her chest against the cold. In the distance, the trees and bushes bend alarmingly to the side, pushed that way by the storm. Gorey's angled hatching darkens the outer walls of the house and the sky, mimicking rainfall, although the hatching does not cross over any of the foregrounded figures. These details work in concert to illustrate "that wild winter night" (3), setting the scene for disturbing happenings in an isolated location cut off from immediate assistance by extreme weather.

Yet the discovery of their visitor, while surprising, is underwhelming. They find their guest "standing on top of an urn, [where its] peculiar appearance [gives] them quite a turn" 
(4). It is a small, penguin-shaped creature clad in a striped scarf and laced canvas shoes, approximately the same size as the young boy, and entirely unthreatening. Whereas banshees, vampires, werewolves, ghosts and other Gothic paranormal forces present an immediate threat - even when they are as socially-astute and polite as Stoker's Dracula - this guest is merely an oddity. Its threat is not that of violence, assault or personal safety; instead, it is a minor annoyance that disrupts the smooth running of the household. Its first act is to run into the hallway and press its nose to the wall (5), where it stays all evening, even after the family tires of yelling at it and goes to bed (6). It continues its disruption by joining the family for breakfast and proceeding to eat "[a]ll the syrup and toast, and part of a plate" (7); then moving on to rend "the horn from the new gramophone" (8), which it refuses to relinquish. It also spends time staring up fireplace flues while "peeling the soles of its white canvas shoes" (9), tearing up books and pushing hung pictures out of alignment (10), spending Sundays lying on the floor blocking doors (11), lounging inside serving dishes (12), hiding bath towels (13), sleepwalking (14), and stealing other people's possessions for the sole purpose of throwing them into a pond (15). None of these actions threaten bodily harm, engender terror nor ascend to the level of full-blown horror narrative, although each carries a seed of the genre within it. As with ghostly visitors attached to a particular Gothic property, the guest "came seventeen years ago - and to this day [i]t has show no intention of going away" (16). The family appears powerless to remove it, as their "exorcism" the evening it appears - where extensive screaming takes the place of formalized rituals and chants - completely fails, and at no point afterward do they explicitly ask it to leave. The guest is "[n]o more than a fact of life, [as] monsters are no longer an issue, their appearance as routine as operations performed daily in hospitals around the world to bring the dead back to life" (Botting 362). In this manner, the guest becomes a permanent part of the property, figuratively haunting the family through its continual presence.

Despite their unwillingness to have it in their home, they do not turn the guest away from breakfast, as it occupies a chair without unseating anyone else, and it is its own place setting that it consumes (7), indicating that someone, be it a member of the family or an unseen servant, has taken the time to make a space for the extra individual before the meal has begun. While obviously finding the guest distasteful, the family begrudgingly accepts its presence and begins to accommodate the destruction it brings to their lives. In fact, while its destructive tendencies are confined to fairly minor objects such as plates, books, the 
gramophone, pocket watches and its own shoes, such actions are in line with stereotypical poltergeist activity, in which a spirit plagues a person or household by tearing up, breaking and throwing around items, or exhibiting bizarre behaviour through odd noises, rearranging furniture or fixtures, and moving and hiding objects. The guest's demeanour is certainly strange, and other than its lack of sound, it engages in all of these behaviours. Although it is physically present, it mimics ghostly apparitions by pointlessly blocking doorways and wandering down hallways in the middle of the night, irritating the family by making their lives incrementally more difficult. It fails to frighten the other characters, but it does successfully annoy, frustrate and distress them. During its first appearance, the young boy and one of the women wear expressions that convey their distress (4), which carries over to late evening, when they ascend the stairs to go to bed (6). In both illustrations, the young boy looks uncertain, his hands raised to his chest, clasped together in the first illustration, and rising to touch his face in the second. Likewise, in each, one woman turns from the guest: during their first encounter, she turns her back on the creature and raises a hand protectively across her chest; in the second, she - or the other woman, as they appear nearly identical hides her face in her hands, back fully turned on the guest, while the other woman looks at it with a furrowed brow, a hand raised to her forehead, and frustration evident in her expression. The men, on the other hand, appear curious to begin with, the man in the striped suit holding his chin as he studies the guest (4), and the heavily-bearded gentleman in the dressing gown looking on with a detached, neutral expression. Yet as the narrative progresses, the women's and child's trepidation vanishes, as does the men's curiosity. Instead, they all begin to wear exasperated expressions, frowning and glaring at the guest as it moves through the house ( 7 , $8,10,11,12,15)$.

The guest is a mixture of the surreal and real, breaching the boundaries between the fantastic and realism. As with Frankenstein's creature, it has no name - although neither do the occupants of the house - yet it is not the result of human creation or hubris. There is no story of its creation; it appears one day without any explanation of its origins, an entirely inhuman monster lacking in any particular threat. As much as it resembles a penguin, the comparison ends with its general shape; it does not share similar markings or behaviours, does not exhibit an affinity for water, and does not appear to require a cold environment. On the contrary, the guest is at least partially dressed against the weather: it has shoes on its feet and a long scarf wrapped around its neck when it first appears, the scarf caught up in the same 
wind that tears at the people's clothes (3). These clothing items contrast the creature's odd appearance, as they are familiar, mundane items worn by a fantastical monster. Yet even within these familiar pieces is a marker of the strange. Despite the fact that the narrative carries hallmarks of nineteenth century life - from the high-necked and long-sleeved dresses, high-collared suits and elaborate dressing gowns to the Gibson Girl hairstyles, elaborate moustaches, heavy draperies, detailed wallpaper and wainscotting - the guest's canvas shoes are distinctly twentieth- and twenty-first century in origin. Although the plimsoll dates back to 1830 , making the existence of canvas sneakers reasonable within the narrative's time period, the guest's shoes resemble commercial high-tops. Their shape is in line with commercial products such as Converse Athletic Shoes, and they sport round patches in the same locations as Converse. As this particular style dates back to 1923, the shoes are therefore anachronistic, undercutting any textual pretence of historical accuracy, and making it difficult for the reader to take the work seriously.

Where The West Wing concerns itself with atmosphere, The Evil Garden with a natural world in revolt and The Doubtful Guest with the irritations of hosting a strange, fantastical creature, The Disrespectful Summons portrays one of the most fearsome supernatural entities in Western culture, the Devil. In this work, a woman named Miss Squill is attacked by the Devil while she is out walking, and subsequently finds herself enjoying the fruits of a Faustian deal. Unlike the traditional Faustian contract, in which an individual calls upon the Devil or takes advantage of his presence to request special favours in exchange for that individual's soul, Miss Squill is surprised by the Devil from out of nowhere, as he "[gives] a sudden leap [a]nd [strikes] Miss Squill all of a heap" (1). Where most deals with the Devil require a ritual summoning by the individual looking for a favour, the summons in this tale comes from the Devil himself. In the very first panel, he appears from above, jumping on Miss Squall's back and pushing her to the ground in an abrupt and undignified manner. Immediately afterward, he "swoop[s] her up from off the ground [a]nd twirl[s] her madly round and round" (2) in mimicry of the dancing frenzies purportedly exhibited by popular Christian perceptions of witches in thrall to demons. Miss Squall's expression, however, deftly communicates her unwillingness in this venture: she is frowning, her brows are drawn together, and her eyes look upwards, towards the sky. Her arms are above her head, and her body bends away from the Devil, who holds her by the waist. Her feet do not touch the ground, and as a result, she has no purchase or control over the dance. In these two 
opening illustrations, Miss Squall's body language, expression and tidy, conservative dress works together to indicate that she does not wish to be in this situation. She is appropriately attired for a late Victorian or Edwardian woman in a long dress, ankle boots, stockings, a long-sleeved blouse and high collar, and she carries a small tasselled purse. Her straw boater is affixed to her arm by a thin cord, indicating forethought and conscientiousness in direct contrast to the recklessness required to willingly dance with the Devil.

Miss Squall's name, however, contains a disruptive feature: she has a type of inclement weather concealed in her last name. Just as a squall is a short, violently disruptive storm, so too does the Devil disrupt Miss Squall's life. Her association with demons is short in duration, brings turmoil to others, and ends in a violent manner (13). In fact, this short association results in her 'miss'ing out on the opportunity to live a longer life, free of demonic influence. Yet, Miss Squall's name also has a built-in ward against the Devil. Miss Squall is extremely close in sound to "missal," a Roman Catholic liturgical text that contains the instructions needed to carry out Mass throughout the year or, more generally, a prayer book. At the beginning of The Disrespectful Summons, she is therefore an embodiment of a holy text, and the Devil's visitation is even more disrespectful than it appears at first glance. The Devil's appearance and subsequent marking violate traditional notions of Devil worship, as there must be an explicit invitation from the individual. Further, by abusing Miss Squall, the Devil is figuratively defiling the liturgy.

Regardless of this non-consensual beginning, when Miss Squall is preparing for bed that evening, she finds herself marked by the Devil (3). Yet, rather than denoting a stream of terrors to come, the next day a "creature named Beëlphazoar" (4) flies into her home, bringing with it "a recipe for fudge [o]f pounded pencil-stubs and sludge. Also a book called Ninetytwo Entirely Evil Things To Do" (5-6). In sharp contrast to The Doubtful Guest, the strange creature of The Disrespectful Summons brings entertaining diversions with it and rapidly becomes a welcome companion. Miss Squall's expression is one of disbelief at its first appearance (5), but within one panel, her opinion changes and she smiles at it as it licks one of the spoons they are using to make fudge (6). As with the guest, there is no overt threat in this first appearance: Beëlphazoar is a small, dark, flying monster with dragon-like features. It also exhibits characteristics associated with demons, including its horns, forked tongue, and tail. Its small size and the tag around its neck belie any menace, however, as the tag and gifts - the fudge recipe and book - indicate that it is a present from the Devil rather than a 
tormentor. Not only does Miss Squall proceed to treat Beëlphazoar as a familiar with whom she performs domestic activities such as cooking (5), but she also treats it as a pet. While she reads Ninety-two Entirely Evil Things To Do (6), Beëlphazoar reclines at the end of the bed, stretched out asleep over her feet. Throughout the rest of the narrative, Beëlphazoar watches her perform witchcraft, its stance indicating approval. As she "cinder[s] toast and rot[s] silk, [corrodes] tin and curdl[es] milk," it sits upright on a stool, face tilted upwards towards her with its hands clasped in front of it (7); and as she does "her neighbours' forms in wax [a]nd [sticks] them full of pins and tacks" (8), Beëlphazoar lies on a table facing Miss Squall, its attention focussed solely on her.

Miss Squall's brush with the Devil turns almost immediately from the miserable experience illustrated in the first two panels to an enjoyable experience. She falls quickly into "evil" ways, but with the exception of causing the deaths of her neighbours (9), all her actions are petty and inconsequential. She makes inedible fudge (5); burns toast, turns milk and destroys silk and tin (7); makes insects faint from the sound of her laughter and causes cows and geese to fall down and flip onto their backs when she frowns (8); and finds "stones with eyes [a]nd plants that [give] out screams and sighs" (10). Her only real act of horror is when she makes voodoo dolls of her neighbours, causing them to "then [expire] with frightful pains [i]nside their bowels, lungs, and brains (9). Although this act is exceptionally violent and horrific, as Gorey places it amongst far lesser sins, it appears instead to be nothing more than one more item in a list of tiny inconveniences. Every other action is on the same level of terror as the creature in The Doubtful Guest. Miss Squall is a short storm of nuisance and activity rather than a more dangerous long-term thunderstorm. It is ironic, therefore, that the Devil returns "one Sunday afternoon" (12) to claim Miss Squall and consign her to Hell, the results of a deal she neither asked for nor explicitly agreed to. This Faustian bargain is curious in that there is no bargain between the Devil and Miss Squall; she receives supernatural benefits as if she has agreed to give up her soul, but then wastes them in minor, frivolous ways. In the end, the scope of her crimes does not matter; the Devil arrives on the Sabbath - a strange choice, as the holiest day of the week according to Christian ritual - and metes out the harshest of consequences. Even in a story involving a pact with the Devil, Gorey restricts the characters to mundane ambitions. He takes the High Gothic of Goethe's Faust and transforms it into a moment of fin de siècle, marking the generic shift representative of the late nineteenth century Gothic. Miss Squall's morals deteriorate at the 
urging of the Devil which, at the end of the narrative, results in a threat to her physical wellbeing. As the Devil comes to take her, Miss Squall has thus moved beyond "the Victorian impulse toward scientific classification and a subsequent normalization of the possibilities bodily, subjective, sexual - of human identity" (Hurley 8). From the first moments of her slide into mischief and sin, she transgresses the boundaries of human. Her voice takes on (minorly) unearthly characteristics, she is suddenly able to find natural objects that behave unnaturally, and she makes voodoo dolls that, when poked, are exceptionally effective. She is no longer merely human; she has become "abhuman," which marks

the ambivalent status of a human subject, who, on the one hand, labors to maintain (the illusion of) an autonomous and discrete self-identity...and who on the other hand welcomes the event of confrontation that breaches the boundaries of the ego and cast the self down into the vertiginous pleasures of indifferentiation...The fin-de-siècle Gothic is convulsed by nostalgia for the "fully human" subject whose undoing it accomplishes so resolutely, and yet aroused by the prospect of a monstrous becoming. (Hurley 4)

Yet even in Miss Squall's becoming, there is a lack of the anxiety associated with the fin de siècle Gothic. Miss Squall finds pleasure in her decadence and decline, and when the Devil comes to take her away, it happens so quickly that there is no time for regret or fear. When the Devil arrives on Sunday, she does not seem distressed at all (11), and when he abducts her (12) and throws her "in the Flaming Pit" (13), her expression is one of disappointment rather than horror. In this movement between High Gothic and the fin de siècle, Gorey explores the limits of Gothic horror. As Teresa A. Goddu says in Vampire Gothic,

[b]y exploring instead of collapsing the boundaries between different locations and traditions of the gothic and by seeing the gothic as a constantly moving form with no fixed abode, we begin to trace its web of monstrous relations.

No matter the Gothic tropes Gorey uses, however, he strictly enforces an emotional distance.

As McGrath and Morrow explain in their discussion of the evolution of the Gothic, "[t]hough no longer shackled to the conventional props of the genre, the themes that fuel these pieces-horror, madness, monstrosity, death, disease, terror, evil, and weird sexuality-strongly manifest the gothic sensibility" (xiv). The Disrespectful Summons, however, conjures up these ingredients, and then flies in the face of such sensibilities. Miss 
Squall's story is one in which the spectre of the Devil should bring the horror of monstrosity, terror, death and evil with it. In fact, her initial reaction to the Devil is fear and disgust. Yet the expected madness and weird sexuality are instead subverted by Miss Squall's happiness at the domesticity she finds when accompanied by her familiar, Beëlphazoar. She finds contentment in what should be Gothic horror: rather than torment, her new status as an acolyte brings her delight, and rather than inducting her into the weird sexual practises associated with historical accounts of witch covens, Miss Squall retains her bodily autonomy for most of the tale. Only during her dance with the Devil before she accepts him and once he comes to claim her soul is she ever put in an uncomfortable position. During her tenure as a marked servant of the Devil, she lives a surprisingly upstanding life. By using the atmosphere and signposts of Gothic horror, Gorey primes the audience to expect themes that uphold the sensibility of the Gothic. Yet it is this sensibility, the examination and experience of the themes and emotions associated with Gothic horror that he removes from these works.

Given the preponderance of death, despair, and the supernatural in Gorey's works, it is no surprise that he frequently references Gothic horror tropes. His illustrations are rife with the furnishings of Gothic horror, delighting in sprawling mansions; lonely, isolated settings; forgotten spaces and secrets; gruesome murders; and unexplained paranormal activities. His mansions sport formal, nineteenth century furnishings, including heavy draperies, highbacked chairs, wood panelling, and highly-detailed wallpaper, all of which are overlayed by stark shadows and darkness. Many of his characters are turned away from the viewer, their faces covered or hidden. Monsters lurk alongside monstrous acts, yet those acts are more often committed by ordinary human beings than twisted creatures. Even Gorey's art style lends itself to Gothic horror, as he works almost exclusively in black and white with only occasional washes of pale colour. Yet despite the presence of such furnishings, Gorey's narratives do not evoke the emotional, fear-based responses of traditional Gothic horror.

As with all of Gorey's genre play, he is most concerned with the trappings of Gothic horror divorced from the fear that drives its excesses of emotion. While "[i]t is in its concern with paranoia, with barbarism and with taboo that the vital effort of Gothic fiction resides; these are the aspects of the terrifying to which the Gothic constantly, and hauntedly, returns" (The Literature of Terror 184), it is the concern itself that Gorey removes. His characters experience supernatural events which should engender extreme terror, both in their reactions and those of the audience, but instead they result in a flat effect: the emotion that should 
accompany such excesses of the supernatural is absent, and the form of the narrative conspires to distance the reader further. The Evil Garden, The Doubtful Guest and The Disrespectful Summons are all written in rhyming verse, the poetic form drawing attention to the rhythm of the lines and away from the content. In addition, the pace of each tale is quick, in line with the shortness of each work, which precludes any length of time dedicated to any particular individual, and therefore cuts out any potential for the audience to identify with or care about the characters. The West Wing, The Evil Garden and The Doubtful Guest do not even name their characters, thus lacking an empathetic touchstone through which to experience these stories. As with Gorey's melodramas, his horror divorces itself from engendering fear and instead focusses on form. He continually presents familiar scenes, and complicates them by introducing elements that transform and defamiliarize the commonplace: a mansion becomes a silent collection of seemingly-unrelated tableaux; an outing to a public garden turns deadly; an unwelcome, inhuman visitor appears from nowhere; and an ordinary woman is targeted by an otherwordly demon, and uses her powers in frivolous ways. Even as "rather than on fertility, the Gothic focuses upon withering; rather than on growth, it focuses on morbid deterioration; rather than on an intrepid human vitality, it focuses upon the human body eminently assailable" (Morgan 65), Gorey explores the essential decomposition of mental and bodily autonomy inherent in Gothic horror, but his narratives exist at such a remove from the audience that their tragedies do not carry much weight.

For Gorey, his Gothic horror is an exploration of the intersection between excess and deprivation. The West Wing and The Evil Garden present otherworldly scenarios in which supernatural and monstrous events lack any emotional connection. The supernatural of The West Wing exists as a collection of images that do not intersect with one another; they are frozen pieces of art, contained by their panels. Despite the visceral danger of The Evil Garden, Gorey seals the fates of his characters so thoroughly that instead of engendering fear, there is a creeping sense of inevitability to their deaths. While there is a potential for terror, it is muted under the distance between audience and characters. In both of these works, the supernatural is uncoupled from fear. It becomes a mundane occurrence to be accepted passively and viewed dispassionately. The Doubtful Guest and The Disrespectful Summons reduce supernatural occurrences to minor inconveniences. The guest of The Doubtful Guest resists the transient nature of a Gothic haunting, as it is ever-present amongst the family, a fixture designed to impose on the other characters without meaning or sense. Despite Miss 
Squall's abduction at the end of the tale, the exceptionally frightening manifestation of demonic possession in The Disrespectful Summons is largely an exercise in indulging petty revenge. Gorey's Gothic horror texts remove the spectre of fear, dislocating the supernatural by removing its purpose. Yet in doing so, the supernatural becomes mundane and the mundane becomes strange. Peculiar, haunting occurrences are transmuted into artistic tableaux; the horror of flesh-eating plants is subsumed under a flatness of emotion; a monstrous guest becomes little more than an irritation; and demonic powers manifest as tools to complete trivial, everyday chores. In upending the purpose of Gothic horror, Gorey redirects the reader to examine those moments that are generally overlooked. He uses the excesses of Gothic horror, such as the dark, cloying settings, the large, haunted mansions, the very furnishings that set the stage for an excess of emotion and deprives his narratives of such expression. Thus, the overlooked and underwhelming narrative moments are pushed to the fore, where they are subject to more attention by the reader. As a result, Gorey's Gothic horror does not inspire fear, but rather points out the basic strangeness inherent in the mundane and familiar.

Perhaps surprisingly, while Gorey's deprivations subvert the purpose of Gothic horror, this subversion is in line with one of the basic purposes of the Gothic: "Then, as now, the Gothic clearly delighted in moving to the dark term of any opposition it encountered. Inversion was its basic structural principle" (McGrath xiii). Rife with

[s]ubterranean passages, vaults, dungeons, cellars-these are all staples of the early gothicists. Such chthonic, claustrophobic spaces they were! Each was a vivid analogue of the tomb, and each provided a site of inversion, where terror and unreason subverted consensus and rationality, where passion was transformed into disgust, love turned to hatred and good engendered evil. (McGrath xiii)

The Gothic hinges on this process of subversion, making the familiar unfamiliar, and the comforting frightening. Just as Gorey's play with Detective fiction involves shifting the locus of clues and detecting to the metatextual level, his Gothic horror dissolves the emotion these darknesses provoke and shifts the focus to more measured responses. Gorey takes what Gothic horror presents as frightening and divorces it from those qualities that engender such fears. Although Gorey's narratives are often quite morbid, and exist within elaborately furnished Gothic landscapes, they do not invite the reader to consider her or his own 
mortality, but rather to divorce her or himself from such distressing contemplation. Gorey's Gothic horror invites its audiences to find amusement rather than terror in death, as the deaths that he presents happen to other people. Those people lack much past the lightest of character sketches, and as such, there are few points of entry through which a viewer can experience empathy. As a result, their deaths are the punchline to Gorey's monstrous humour. There is no reason to fear death, as Gorey places it at such a distance from his readers, removes its emotional power, and makes it over into amusing and ridiculous scenarios. Death is something that happens to other people in Gorey's works. As the Gothic inverts, Gorey subverts. Where the Gothic makes strange, Gorey makes mundane. Furnished with all the claustrophobic, crumbling, creepy spaces that make up Gothic landscapes, Gorey transforms Gothic horror into Gothic humour. 
Page 162 of 216 


\section{Chapter 7: Oddly Influential $^{30}$}

Gorey's play with genre, coupled with his visual techniques and tendency to highlight morbidity in his narratives constructs the aesthetic known as the "Goreyesque." Goreyesque illustrations are usually black and white, using colour sparingly: either as sharp points of contrast or cool, subtle washes. The drawings themselves are often surrealistic depictions of characters or surroundings, with detailed line work, crosshatching, and an eye for contrasting sections of busy and empty space. Their storylines involve questions of mortality and morbidity - often expressed violently - undercutting the seriousness of such topics with frivolity, lightheartedness, surreality and a general twisted sensibility. Weighty topics and material are treated as humourous, and the audience is invited to find amusement in narratives that should otherwise be horrific, shocking, distressing or thought-provoking. These texts also continue to explore the ways in which various genres work, manipulating generic conventions in order to examine their makeup more closely. Those texts that most consciously evoke the Goreyesque include similar types of pseudo-nineteenth century markers to those that Gorey himself incorporates. Their settings contain furnishing and draperies reminiscent of the nineteenth century (if not always historically accurate), and their characters will dress in clothes that conjure up nostalgic associations of this same historical period.

The Goreyesque manifests itself in the works of many twentieth and twenty-first century artists and writers. Foremost amongst those are Tim Burton, Neil Gaiman and Roman Dirge, all of whom have been influenced by Gorey. The Goreyesque most strongly and directly appears across Burton's works, whereas it more subtly influences Gaiman's texts, coming to full fruition in specific narratives. In contrast, Dirge, who did not specifically encounter Gorey's work until later in his career, is an example of how the Goreyesque permeates art and literature so that even those creators unfamiliar with Gorey's texts can be heavily influenced by his aesthetic. As those authors and artists who are aware of Gorey are inspired and influenced by his aesthetic, their works help to spread the Goreyesque to creators

${ }^{30}$ Sections of this chapter appear in the article "A Monstrous Childhood: Edward Gorey's Influence on Tim Burton's The Melancholy Death of Oyster Boy" in The Works of Tim Burton: Margins to Mainstream, edited by Jeffrey Andrew Weinstock and published by Palgrave Macmillan (2013). 
who are not directly aware of Gorey, thus bridging the gap between conscious and unconscious influence. In this manner, Gorey ceases to simply be an author to be encountered, and becomes a style with widespread influence.

Gorey's influence is an ever-present ingredient in Tim Burton's monstrous creations. From Burton's preference for thin lines and a certain sparseness of detail in his illustrations often suggesting rather than fully delineating each characteristic - to his playfully macabre plotlines and themes, Gorey is always there. Burton builds on Gorey's framework, moving beyond notions of solely external monstrosity acting upon innocent souls by doubling the locus of monstrosity. He preserves Gorey's notion of a cruel, heartless world, and intensifies the pathos of his child protagonists by saddling them with grotesque appearances that estrange them from "normal" people. Yet repeatedly throughout Burton's body of work, this monstrous façade belies the protagonist's kindness and basic goodness. It is society, with its sterile lack of imagination and insistence on conformity, that is the true monster seemingly demanding in exchange for adulthood the sacrifice of childish wonder, sympathy, and creativity.

The Melancholy Death of Oyster Boy \& Other Stories (1997) - a poetry collection recounting the often tragic lives of a variety of unfortunate, monstrously deformed children stands out as a particularly Gorey-inspired work, as it is not only contains exclusively black and white line drawings, but also relies on cross-hatching and heavily-textured surfaces that obscure as much as they define. The title poem of this collection, "The Melancholy Death of Oyster Boy," follows a trajectory shared with such Gorey works such as The Hapless Child and The Green Beads; as in both of these texts, Oyster Boy comes to a tragic end through no fault of his own - he is a passive victim of circumstance carried along primarily by the consequences of other people's actions. Indeed, it is in Burton's connection to Gorey and his play with childhood innocence that the grotesque flourishes, coming startlingly to vivid fruition in this collection. There is a viscerality to these intersections of "pieced, stitched...self-abused creatures" (Magliozzi 11) with adulterated childhoods that relies on an understanding of the ways in which children are marginalized and how that marginalization manifests itself within literature in order to be appreciated fully.

To grasp Burton and Gorey's shared cynicism embodied in the recurring motif of the innocent child or child-like protagonist beset by a cruel world, it is therefore necessary to take a step back and to consider its roots in the works of prominent nineteenth-century authors 
such as Charles Dickens, Charles Kingsley, Hesba Stretton, and Frances Hodgson Burnett, which frequently feature child protagonists contending with strife and tragedy. Embedded within such narratives is a fascination with "children on the margins: orphans, waifs and strays, the victims of child abuse, juvenile criminals, and the inmates of workhouses, industrial and reformative schools" (Cunningham 91). Dickens' Oliver Twist, for example, finds himself orphaned and at the mercy of the workhouse and the streets (1838); Tom's life and death reveal the high price of child labor in Kingsley's The Water-Babies (1863); Jessica finds salvation from poverty in faith in Stretton's Jessica's First Prayer (1866); and Sara must overcome the trials of losing her family and fortune as she is put to work in her boarding school in Burnett's A Little Princess (1905). These are the tragic circumstances that make victims out of young characters, subjecting them to the monstrosities of life.

In addition to the melodramas of beset childhood featured in Dickens, Kingsley, Stretton, and Burnett, Gorey and Burton also draw inspiration from traditional children's verse and fairy tales such as the extensive fairy-tale works of Hans Christian Andersen, Robert Louis Stevenson's A Child's Garden of Verses (1885), and the Grimm Brothers' Children's and Household Tales (1812). In works by these authors, childish wonder is the necessary prerequisite to accessing fantastical worlds. Stevenson's poems provide windows into other realms filled with such delights as animated toys ("The Land of Counterpane"), talking animals ("Time to Rise"), pirates ("Pirate Story"), royalty ("Young Night Thought"), and sentient stars ("Escape at Bedtime"); in Andersen and the Grimm Brothers, children must contend with both the promise of strange new sights and supernatural antagonists such as evil queens (The Snow Queen and Cinderella), witches (The Wild Swans, Rapunzel, and Hansel and Gretel), and otherworldly creatures (The Little Mermaid, The Frog Prince, and Iron John). For all these young protagonists, the world holds challenges and visions that are not accessible to adults. What they see is not the normal workaday world, but a world of enchantment that leaves them vulnerable to spells, curses, quests, and challenges.

Gorey's and Burtons' written texts appropriate and fuse these traditions of the suffering child and the fairy tale as their child protagonists contend both with tragedy and the fantastic - and then turn these texts back upon themselves by repeatedly allowing the monsters to win. What therefore links Gorey with Burton most immediately is their shared parody of sentimental or saccharine children's literature and verse that satirically deflates the hopeful messages of such works. Gorey's and Burtons' works mimic "safer" narratives in 
which children overcome obstacles and are rewarded, either in life or in the afterlife, but instead of reward their children are met with misery and suffering at the hands of an unfeeling world. Rather than a joyful reunion or a beautiful death (leading to a joyful reunion in heaven), for the child protagonists of Gorey and Burton, regardless of character or social class, life sucks and then you die (often in blackly comic ways).

Burton's vision in Oyster Boy is as dark as Gorey's, but more socially aware. It is not death that menaces Burton's monstrous children, but social forces that insist on conformity and "monsterize" deformity and difference. For Burton's children, monstrosity is an outward, physical manifestation that reflects the world around the individual rather than marking inner psychological turmoil. Many of his monstrous children - such as Stick Boy, Match Girl, Staring Girl, the Boy with Nails in His Eyes, the Girl with Many Eyes, the Girl Who Turned into a Bed, and Sue - are content with or utterly oblivious to their monstrous characteristics, carrying on otherwise normal lives. For instance, the title of "Stick Boy and Match Girl in Love" tells the whole story: Stick Boy and Match Girl are engaged in a courtship in which the major problem is not inner demons, but rather the unintentional and unfortunate side-effects of their physical bodies. While Stick Boy thinks of Match Girl in colloquial language connoting her attractiveness - "[h]e liked her cute figure, he thought she was hot" (1) - it is the double entendre inherent in the line that communicates the very physicality that makes them monstrous and causes their romantic doom. Predictably, a match and a stick create flames not of passion, but of consumption. Oblivious to the disadvantages of their monstrous bodies, Stick Boy and Match Girl are caught off guard by this development. As with Gorey's illustrations, Burton's accompanying artwork does not just provide a visual representation of the lovers, but also adds to the narrative. Match Girl's expressions are the most evocative of the two, as her pleasure is obvious in her smile and inclined head in the first illustration and her horror is vivid in the second: her eyes are wide, her mouth open, and even the flames around her head stand straight up as an indicator of the depths of her shock as she watches Stick Boy burn (2).

"Staring Girl" continues this theme, as the poem starts out by framing Staring Girl as an oddity. As her name telegraphs, she stares at everything, including the reader, and the narrator warns, "[she'1l] stare at you for hours and [you'll] never know why" (17). Yet for all she makes others uncomfortable with her continual staring, "she seem[s] not to care" (11). Her strangeness is not a major impediment to her life and, in fact, enhances it. She enters and 
wins the local staring contest (19), indicating her community displays some level of acceptance or tolerance of her behavior, and she is not alone: at least two other people enter the contest, as the accompanying illustration of the winners' podium shows (18). While the poem predicates her monstrosity on her large eyes - which Burton features prominently in each illustration - and her penchant for unnerving staring, the true strangeness comes in the final illustration, but even then, the potential for revulsion is muted. The poem concludes with Staring Girl giving her eyes a vacation (21), and it is here, having disturbed the narrator - and by extension, the reader - through her behavior, that she reveals the full extent of her monstrosity. Her optic nerves are far longer than average, and she is able to pop out her eyes and allow them to relax in and by a pool as if they are independent entities. Yet there is no attendant horror in this scene; instead, her eyes deserve this rest, and as grotesque as loose eyeballs and empty sockets are, the poem presents this event as far less unnerving than her habit of staring.

This acceptance of strangeness continues into other poems such as "The Girl with Many Eyes." Once again, Burton writes of a girl with peculiar eyes. This time, however, she has so many eyes that the narrator finds her both surprising and shocking. Yet once he or she surmounts that surprise, the Girl's appearance becomes a point of wonder, as the narrator explains

[s]he was really quite pretty

(and also quite shocking!)

and I noticed she had a mouth

so we ended up talking. (25)

While they become a conversational touchstone, the Girl's eyes rapidly lose the ability to distress the viewer. In fact, while the eyes are what draw the narrator to her in the first place, they also lead him (or her) to notice the Girl's mouth and, from there, open a dialogue. The two of them talk

about flowers, and her poetry classes, and the problems she'd have if she ever wore glasses. (25)

Their conversation integrates the mundane with the monstrous, defusing the potential for horror and creating a comfortable space in which to cultivate friendship. In this manner, her 
unnatural appearance gives way to a process of naturalization: the very features that act as literary stand-ins for dark, disturbing inner lives and antagonistic monsters are instead windows into moments of beauty and insight. The Girl's eyes are thus reduced from something to fear to a minor inconvenience. She would certainly have difficulties if she needed corrective lenses, and the narrator also notes that the only drawback of their friendship is that "you really get wet when she breaks down and cries" (25), but in the end, her eyes are a reason to be attracted to her rather than repulsed.

There is an undercurrent in Oyster Boy of normalization of the grotesque, from the innocence of the highlighted characters and the harmlessness of their deformities to the acceptance of the monstrous in many of the poems or the expression of pity rather than fear. One of Burton's shorter offerings, "The Boy with Nails in His Eyes," exemplifies this prioritization of pity over fear. The Boy is caught in the act of putting up his Christmas tree, the scene a complete mess, as it "look[s] pretty strange because he [can't] really see" (23). The tree itself is upside down, the tip secured in the stand, and the trunk sticking up above (22). As it is made of aluminum, the basic structure of the tree is twisted not from natural causes, but rather from the Boy's inability to see and straighten it out; indeed, it is an inverted echo of Charlie Brown's tiny, pathetic live tree in A Charlie Brown Christmas (1965), a tangible symbol of the daily struggle the nails in the Boy's eyes presents. The decorations are in a similar mess, only two able to cling to the tree, and even then, both of those ornamental balls perch precariously, their hooks hanging onto needles rather than solid branch. The rest lie on the floor, discarded or misplaced alongside the tangled garland of lights which loops, just once, over the Boy's arm. The star topper in the Boy's hand is ragged and misshapen, and while he holds it up towards the tree, the gesture lacks purpose, a reflection of his inability to locate a proper place for it. Indeed, there is a raggedness to the illustration itself that reflects the Boy's violent sightlessness.

It is within "The Boy with Nails in His Eyes" that Burton most clearly delineates the multiple instances of notable eye imagery within Oyster Boy. In "Staring Girl," the Girl's eyes are the main feature of her monstrosity, and yet she is entirely unconcerned by their potential to disturb viewers. For her, her eyes are not markers of the grotesque, but instead the main interface through which she experiences a rewarding world. Likewise, in "The Girl with Many Eyes," the Girl's eyes are a representation of(shocking) monstrosity to the narrator, yet they also contribute to her attractiveness and her ability to express emotion. They are a focal 
point of her conversation with the narrator, but they are as much a portal to her inner life and worthiness as a friend as they are reflectors of grotesquerie. Yet for the Boy in "The Boy with Nails in His Eyes," the state of his eyes is one of the strongest reflectors of the pathos inherent in his physical predicament. As his nails obscure his sight, they close off the potentiality for physical monstrosity to act as a conduit to inner beauty. Instead of obtaining the confidence of the girls in "Staring Girl" and "The Girl with Many Eyes," the Boy is unable to perceive himself or his surroundings, and is therefore unable to convert the grotesque from a liability to an asset.

While many of Oyster Boy's illustrations exude a studied air of inattention, as if Burton has taken pains to draw artlessly, "The Boy with Nails in His Eyes" exaggerates this stylistic quality. The ornaments are nowhere near spherical, their hooks bent into uselessness; the light bulbs on the garland are misshapen to the point of suggesting their utility through the viewer's expectation of tree decorations rather than much similarity to realistic bulbs; there is no consistency to the thickness of drawn lines, and many simply do not connect. In this manner, Burton presents the viewer with an illustration that suggests the impreciseness of the Boy's navigation within his own space and the extent of his physical challenges.

Additionally, Burton does not shy away from graphic representation of the Boy's nails. They're exceptionally long flathead nails, one of the most common types used in construction, and they have been driven directly into the Boy's eye sockets, causing bleeding that spreads down his face in thin rivulets, errant drops dotting his forehead and the spaces around his nose and mouth. The Boy holds a hammer in his right hand, but there is no indication whether he drove the nails into his own eyes, if the hammer is meant to help in the construction of his tree, or if the nails are a recent acquisition or old physical impediment. The expectancy of bodily horror therefore loses its impact, as the illustration and poem focus not on the nails, but instead on the imperfections in his tree. Burton thus indicates that the reader should view the Boy with empathy rather than revulsion.

Where "Stick Boy and Match Girl in Love," "Staring Girl," "The Girl with Many Eyes," and "The Boy with Nails in His Eyes" present the reader with already monstrous children, "The Girl Who Turned into a Bed" is instead a tale of metamorphoses. As a result, there is a stronger sense of loss and distress within this poem, yet ultimately it ends on a positive note. Just as the other children's monstrousness manifests outside of themselves and in their physicality only, the Girl's transformation from an ordinary individual into a bed is 
triggered by an outside source. She picks "some strange pussy willow" (59) which immediately causes her head to change color and swell up to the size and consistency of a pillow, and from there transitions into a full bed set. Even her dress is affected by the pussy willow, as it becomes the duvet; and her arms and feet take the place of head and footboards. As shocking as this mutation is, there is beauty in it as well. The narrator observes that

[t]hrough her organs and torso

she sprouted like wings,

a beautiful set

of mattress and springs. (60)

The transformation itself contains awe and wonder rather than terror. Although the narrator finds it "so terribly strange that [the narrator] started to weep," the irony of the situation is that "at least after that [she or he] had a nice place to sleep" (61). Indeed, it is worthwhile to note that the Girl's monstrosity comes in the form of the very item that is popularly held to be a safe haven against monsters. While childhood monsters typically manifest from closets and underneath the bed, the bed itself acts as a protective talisman, its edges and sheets boundaries across which monsters cannot traverse. Additionally, the way in which the Girl's shoes peek out from the end of the bed in place of a footboard conjures up a similarity with the iconic image of the Wicked Witch of the East's feet, clad in ruby slippers, sticking out from underneath Dorothy's house near the beginning of the 1939 film version of The Wizard of $\mathrm{Oz}$. In that image is the promise of evil destroyed and defeated; thus, rather than becoming a monster, the Girl becomes a charm against them.

There is some ambiguity, however, regarding the Girl's original state before the transformation. The first illustration is of an individual who, while stylized, falls within a realistic physical representation: she has the proper number of limbs, the right number of eyes and a mouth, all of which work together to provide the viewer with a cartoon that is still recognizable as a "normal" human being. Yet the poem undercuts this first glance, as while she is transforming, the narrator notes that "[h]er skin, which had turned all flaky and rotten, was now replaced with $100 \%$ cotton" (59). There is no indication as to whether the "flaky and rotten" skin is merely a stage in her metamorphoses, or a transitory state between human and bed. This poem, therefore, encompasses a significant number of ambiguous monsters. The Girl may or may not begin in a grotesque state, and her transformation, while sad, is beautiful, comforting and protective. The psychological characteristics that would make her 
monstrous are entirely lacking, replaced instead by a physical slide that is both strange and mundane, as she turns, not into a fantastic being, but a household object.

In tandem with Burton's children for whom the monstrous is a safe, secure, or neutral state of being are his children who manifest the monstrosity of others. Nowhere is this more visible than in the title poem itself, "The Melancholy Death of Oyster Boy." Reminiscent of Gorey's The Beastly Baby (1962), Oyster Boy is summarily rejected by his parents at his birth. His mother articulates this rejection in exceedingly blunt language, as she explains to the delivering doctor, "He cannot be mine. He smells of the ocean, of seaweed and brine" (35). This assertion is an especially powerful one, as she is rejecting him on a genetic level; as she must necessarily be present to give birth to him, there is much less room for questions of maternal parentage than paternal. Unlike Gorey's Beastly Baby, however, Oyster Boy is quiet, unassuming, and passive. Although his appearance causes alarm in his parents and invites mockery from others - he is often referred to as "that thing that looks like a clam," rather than by his given name, "Sam"; and the Thompson quadruplets tease him by calling him a "bivalve" before they run away (37) - he does not manifest any violent tendencies, nor does he actively attempt to offend anyone. His tragedy is his physical monstrosity, which is entirely a reflection of the cruelty that he experiences at the hands of others.

Alongside the unkind nicknames bestowed upon Oyster Boy, "one spring afternoon" his parents pull to the side of the freeway and almost abandon him "[a]t the southwest corner of Seaview and Main" (39). Although they do not carry out this abandonment, it highlights a larger concern: Oyster Boy's father has become impotent, and is blaming his son for his inability to copulate. As Oyster Boy is the result of their coupling during their seaside honeymoon, the narrative comes full circle, beginning with their son's creation, and ending with his death. While his father tries

salves, he trie[s] ointments that [turn] everything red. He trie[s] potions and lotions and tincture of lead (41)

These efforts do not restore his sex drive, as instead "he ache[s] and he itche[s] and he twitche[s] and he [bleeds]" (41). As a result, in an effort to solve the couple's problems, the doctor suggests murdering Oyster Boy, as

the cause of the problem may also be the cure. 
They say oysters improve your sexual powers.

Perhaps eating your son

would help you do it for hours! (43)

Just as Oyster Boy is a manifestation of his parents' marriage, he also reflects the narrative of their relationship: his father proposes on the beach, the two of them marry in a church by the ocean, they vacation on an island, eat oysters on their honeymoon and conceive a child that personifies all of these events. He is the product of a fertile encounter, and his physicality externalizes that fertility: after all, he is shaped like an oyster, widely considered to be an aphrodisiac, the very dish they ate before he was conceived. The narrative comes full circle at the end, as it is in consuming his son that his father is able to regain his sexual stamina.

As Oyster Boy is the result of his mother's wish for a child, he explicitly echoes the genesis of Andersen's Thumbelina (1835). All of these tales concern the birth and subsequent adventures of strange children, yet where Thumbelina is a blessing, Oyster Boy is a curse. Indeed, Oyster Boy is ugly where Thumbelina is beautiful, and passive where she is active, as he does not act upon his surroundings, but rather allows them to act upon him. When his parents leave him on the side of the road, his only response is to watch "the rain water as it swirl[s] down the drain" (39). Likewise, when his father approaches him with a knife, he "blink[s] his eyes twice, but [makes] no reply" (45). Even in the face of his own demise, he is utterly inactive, and there is an inevitability to his death.

This theme repeats in "Robot Boy" and "Anchor Baby," poems that follow similar trajectories. In both, characters manifest a desire for a child: in "Robot Boy," the child is a blessing to a happy couple, and in "Anchor Baby," it is meant to be the "anchor" through which the girl from the sea is able to cement her relationship with her musician lover. Just as in "Oyster Boy," these children, through no fault of their own, become the catalysts that destroy their parents' relationships. For Robot Boy, he is the physical manifestation of his mother's infidelity, and his biological father is, instead, "a microwave blender" (7). He is even more passive than Oyster Boy, as

[h]e just [lies] there and stare[s],

not living or dead.

The only time he seem[s] alive at all

[is] with a long extension cord

plugged into the wall (5-7). 
Robot Boy spends most of his time inert, somewhere between life and death. Unable to accept him, his parents actively reject Robot Boy, and he ends up effectively alone, "often mistaken for a garbage can" (9). Echoing the black and white illustrations of "Oyster Boy," Burton draws Robot Boy in a similar manner, the misshaped lines, well-placed rivets and down-turned seam between tin plates on his face effectively communicating Robot Boy's passivity and unhappiness. This passivity is intensified in "Anchor Baby," as the baby is little more than a large, metallic hulk that literally drags down his mother and keeps her from being able to join his father on land. The very thing that is to bring them together becomes a manifestation of this inability to make a life together. He is thus a physical representation of their thwarted hopes, and his mother is entirely unable to disconnect herself from him, as "[t]he umbilical cord [is] in the form of a chain" (109).

The Melancholy Death of Oyster Boy is a playful, parodic study of the manifestation of monstrosity. Taking significant inspiration from Gorey, Burton continues a tradition of adulterating literary representations of children, undermining notions of victimizer and victimhood by reinterpreting them through the lens of the grotesque. In "Mainstream Outsider: Burton Adapts Burton," Jeffrey Weinstock underlines Burton's preferred themes:

Burton's oeuvre is characterized by a handful of repeating themes and motifs: among them, the collision of worlds that restores a sense of wonder to the "real" world, the disavowal of the finality of death, a privileging of the imaginative child or artist, a drive toward the restoration of the family (sometimes nuclear, sometimes newly constituted), a tendency to foreground the film qua film, and a penchant for mingling his monsters - that is, for staging scenarios that bring together panoplies of colorful and bizarre creatures

In his poems, the monster may manifest as the child, but these markings are reflections not of inner turmoil, but of the indignities of the world around him or her. Physical monstrosity thus becomes a neutral state, informed by the circumstances and consequences that manifest around it rather than a site of horror itself. Where they are figures to be grappled with in nineteenth century children's literature, and unavoidable bearers of Fate in Gorey, Burton remakes physical monstrosity into a beautiful state, and transfers the site of horror to the mundane world. Burton's monstrous children are as innocent as Dickens' and Andersen's protagonists, and as slyly comic and subversive as Gorey's tragically fated children. 
Yet while Burton draws significant influence from Gorey's works, his is not simple mimicry. Burton moves beyond Gorey's macabre vision, using it as a touchstone from which to begin, yet extending past Gorey's depressing, despairing vision of a cruel, unfeeling world to one in which outsiders like Staring Girl, the Girl Who Turned into a Bed, Stick Boy, Match Girl, the Boy with Nails in His Eyes, and the Girl with Many Eyes have hope. Even as Oyster Boy, Robot Boy and Anchor Baby are swept away by tragedies not of their own making, their fates are neither inevitable, nor ubiquitous. The Melancholy Death of Oyster Boy \& Other Stories instead offers the possibility of redemption and happiness even when an individual is deemed a grotesque outcast. In the face of a society that rejects difference, Burton's characters have opportunities to find kindred spirits. While Match Girl and Stick Boy literally consume one another, their figurative consumption represents a moment of joy, hope and love; although the Boy with Nails in His Eyes and the Girl with Many Eyes seem pathetic to the viewer, their obliviousness to their own monstrous appearances undercuts any sense of alienation - instead they proceed forward in their lives without shame or self-consciousness and, in fact, the Girl with Many Eyes gains the friendship of the narrator; Staring Girl finds reward and relaxation in the body horror that is a natural extension of her habit of staring; and the Girl Who Turned into a Bed achieves an important modern goal: she has a purpose and is useful to others. Where Gorey's vision is uniformly pessimistic, Burton's proffers hope, even in the darkest of circumstances. This theme reoccurs across his narratives-be they poems, illustrations, films, or sculpture-a key to his significance and overwhelming popularity in twenty-first century art and film. Burton balances the cynicism characteristic of late twentieth and early twenty-first century art with the central wish at the heart of so many fantastical narratives: hope. Within his stories, Burton's characters-strange, monstrous, alienated and othered-navigate the harshness of society and are rewarded with the opportunity to belong. Even in his more tragic tales, the main characters have access to moments of happiness, hope and joy, transcending an unfeeling world, if only just for an instant.

Neil Gaiman has clearly and explicitly articulated his awareness of Gorey's influence on his body of work in ways Burton and Dirge have not. In an interview with online entertainment magazine Collider.com, Silas Lesnick brought up Gaiman's past assertion that his novel Coraline was to be his "Edward Gorey book." Confirming this fact, Gaimain said, I had actually had plans. We had just sort of opened up very, very preliminary negotiations to find out if Gorey would be interested in illustrating it. And the 
day I finished it, he died. I mean literally. I finished it and the news was that Edward Gorey died.

According to the New York Times, "Mr. Gaiman has an original Gorey drawing of 'children gathered around a sickbed' hanging on his bedroom wall" (NYTimes.com). One of his multiple collaborations with Amanda Palmer, Who Killed Amanda Palmer: A Collection of Photographic Evidence (2009) is a book of song lyrics, photography and short stories in which, much like the ever-popular Gashlycrumb Tinies, Palmer dies again and again. Unsurprisingly, while Who Killed Amanda Palmer is thoroughly macabre, it makes use of dark humour to lighten the overall tone.

Even more Goreyesque in tone, however, is Neil Gaiman and Gris Grimly's The Dangerous Alphabet (2008), an illustrated abecedarium in which two unnamed children and their pet gazelle go on a high adventure in the sewers of London. During their adventure, they come across sinister adults, monsters, pirates, murderers, and the author himself. In a playful pedagogical twist, the preface warns the reader that The Dangerous Alphabet's ABCs are devious in an unspecified way, and that the audience should pay close attention and look out for the deception (1). This "eighty-seven word, single-sentence introduction offers a wry glance back at nineteenth century subtitles, but it also pokes fun at the idea of defining ageappropriate readership" ( $\mathrm{Nel} 50)$.

Although Gris Grimly's artwork for The Dangerous Alphabet utilises a fuller colour palette than Gorey's coloured illustrations, there is a similarity in the use of muted tones. These tones, while lending depth and aesthetic pleasure to the larger illustrations, also communicate a sense of aging, as if the book itself is far older than its 2008 publication date otherwise indicates. Rather than sporting vibrant primary and secondary colours, The Dangerous Alphabet's colours all appear to have faded with time. For instance, the giant set of children's wooden blocks depicted on the cover would traditionally be painted in fresh, bright colours designed to attract a child's attention, in line with teaching them primary colours alongside the alphabet. The blocks, however, are faded, softened shades of yellow, blue, red and green, blending into the background rather than standing out. Indeed, most of the objects and figures in the text are against a soft wash of yellow and beige which - much as sepia often signifies aging ink - works to artificially age the illustrations and contribute to the work's conscious placement in a fantastical Edwardian England.

This period-placement is evident in both the text and accompanying illustrations. All 
the little girls, from the main character to the background characters, wear late nineteenth century dresses, with drop-waists, frills, ornamental collars and sashes. Many wear large hair bows and have short sleeves on their dresses, a fashion that became more prevalent in the Edwardian era, as concessions were made to make movement during play easier for children. Their dresses are soft colours, and in more than one case, are decorated with gentle pastel stripes, reflecting the shifting attitudes towards lighter colours and fabrics. The boys are similarly attired, the main character in a white collared shirt, black tie and tweed herringbone suit with matching shorts, the pattern being one whose popularity rose in the Edwardian era, spreading from the upper classes to wider use amongst the middle classes. The other boys who appear in the narrative wear sweater vests, sailor suits and newsboy caps, the latter rising to prominence in the Edwardian period. One boy also wears a baseball cap (14), another clear historical marker, as the precursor to the modern baseball hat dates from the late $1800 \mathrm{~s}$ and begins to enjoy popularity in the early 1900 s.

Just as with the little girls in The Dangerous Alphabet, the little boys are dressed formally in smaller versions of adult fashions. While their clothes are one of the more obvious indicators of period, as they are moving through a primarily fantastical underground world, there are other clues that bolster the narrative's connection to the Edwardian era. Their journey takes them through a sewer system built of stone and rusting, leaking pipes, filled with barbed wire, dynamite, a bathtub with attached plumbing, and milk cartons, all inventions from the late nineteenth century that would be progressively more ubiquitous as the century turned. Like many of Gorey's texts, however, The Dangerous Alphabet moves beyond strict period adherence, as it includes anachronistic details that become progressively more prominent as the narrative advances. Entering the sewer through which they will traverse, the nameless girl and boy protagonists sail past a break in the wall that reveals a nineteenth century landscape that hints at Big Ben and the Palace of Westminster (3). In the foreground of this scene is a set of three gas street lamps, an enclosed horse-drawn carriage, and a small boy wearing a flat cap peering over the wall, all of which provide general nineteenth century cues. The children's fashions, barbed wire, milk carton, dynamite, bathtub piping and the sewer itself further narrow the historical window to the late nineteenth century and into the twentieth, but towards the end of their journey, as the fourth wall between reader, author and audience breaks down, the narrative's historical placement breaks down as well.

Although The Dangerous Alphabet announces its metatexual intentions early on - the 
preface advises the reader that "[t]he alphabet, as given in this publication, is not to be relied upon and has a dangerous flaw that an eagle-eyed reader may be able to discern" (1), thus inviting the audience to actively engage with and decode the narrative - it is not until the child protagonists directly encounter the authorial figure that the story begins to incorporate post-Edwardian features. In a move mirroring Gorey's own penchant for representing himself in his stories, on page eleven, the author first appears in the tale, announcing himself directly with: "I am the author who scratches these rhymes" (11), words which are paired with an illustration of a pale, older man with a flowing white beard and small hat sitting at a drafting table, writing with quill and ink. Scattered around him and tacked to the walls are sketched scenes from the rest of the narrative - including the previous and following pages - and two sketches of the main child characters. His connection to the story is further deepened by the chains that extend from a mooring buoy and the edges of the book to the shackles on his arms and legs and the vines that have grown around him. Both the shackles and foliage hint at the length of time he has spent writing this narrative, and the chains specifically evoke the image of the writer who is quite literally "chained to his desk." There is an element of captivity and external compulsion to write as well, as the chains visibly indicate that the writer sits at the drawing table against his will. In this respect, the mooring buoy acts as a device to keep him literally and metaphorically afloat, while simultaneously keeping him tethered in one spot. Yet at this early stage, his contact with the children is negligible. The girl appears on the previous facing page in the midst of being abducted by monsters, but she is turned away from the author. Additionally, unlike many of the other facing pages, page ten and eleven are not part of the same illustration; the page break acts as a hard barrier between the two scenes, effectively blocking any interaction between the two of them.

When the writer reappears, however, the narrative addresses the fourth wall even more directly as it acknowledges the audience. The writer speaks to both the children he holds captive and the external reader when he says, " $U$ are the reader who shivers with dread; W's warnings went over your head" (25-26). He holds a copy of The Dangerous Alphabet open in his hands, looking over at the dozen children held hostage on a small rise of stands, each chained together in a manner similar to the shackles still on his wrists. It is on the previous facing page (24) that a television appears, broadcasting an image of the girl's kidnapper disembarking the boat in which he has been sailing with the sack that contains the girl. This scene does not appear in a larger illustrated form, but it is the logical progression 
from page twenty-four to twenty-seven. Page twenty-four depicts the kidnappers sailing into a cave with the girl in tow, and twenty-seven presents an image of the ship docked and empty. The television works with the breakdown between author and audience, as it is broadcasting the very same events that are happening without any indication that these actions are being filmed. Additionally, the television in this form is indicative of the mid-1920s or later, and clearly post-Edwardian. Other post-Edwardian inventions are also present, including an automatic pop-up toaster (24) from 1925 (or later), and a road warning sign graphically depicting a water buffalo (29); such pictorial road signs are characteristic of mid-twentieth century and later signage, as the language and graphical representations indicating warnings for drivers develop. This shift echoes those that occur in Gorey's texts, such as the tennis shoes on the Doubtful Guest. Gaiman and Grimly's text thus takes advantage of the same device as Gorey's: both situate themselves as part of the nineteenth century, but then signal that they are not of it; it is a conscious, metatextual nod to the audience outside of the tale, and the creation and publication of these works in the late twentieth and early twenty-first centuries. Like Gorey's larger oeuvre, The Dangerous Alphabet trades on a general Edwardian air rather than religiously adhering to authenticity of detail.

The Dangerous Alphabet, however, has more in common with Gorey than general aesthetics. Its function as an abecedarium conjures up its predecessor, The Gashlycrumb Tinies, in form and content. Where the pairing of illustrations with couplets is native to many abecedaria, both Gashlycrumb and The Dangerous Alphabet are less concerned with using it as an avenue for basic alphabetical education than as a vehicle of more advanced wordplay. As Philip Nel explains in "Final Word: Gaiman and Grimly's The Dangerous AlphabetDiverting, Deranged, De-Lovely":

The alphabetical parade of dying or dead children in Gorey's The Gashlycrumb Tinies (1963)...is not just a sick joke. It's an evocation of earlier didactic tales for children...where children's carelessness and other misbehavior results in their gruesome deaths, thus warning young readers both to behave better and to prepare their souls for their inevitable demise. Striving to teach both morality and literacy, early alphabets also do not shy away from serious matters...As Gorey does, Gaiman and Grimly mock and partake of these earlier didactic texts. (49)

For The Gashlycrumb Tinies, the couplets present moments of horrific tragedy as if they are 
light entertainment; for The Dangerous Alphabet, the couplets obscure the ways in which Gaiman manipulates the alphabet. Both subvert the basic purpose of an abecedarium while referencing the very traditions from which they draw.

From the very first page of The Dangerous Alphabet, Gaiman warns the reader of the unreliability of the alphabet as presented in the text (1). What this flaw is, however, he does not specify. Instead, the preface presents the reader with the challenge of seeking out and identifying the fault, engaging the audience in a metatextual examination of the narrative similar to the authorial project at work in such Gorey texts as The Other Statue, The Curious Sofa and The Neglected Murderesses. In these works, the reader must engage with the text on an additional level past reading and following the plotline from beginning to end: she or he must also explicitly bring external knowledge to the tale in order to decode and disassemble the narrative. In Gorey's texts, this often requires the reader to untangle the plotline itself; in The Dangerous Alphabet, it means acknowledging fictional artifice and questioning the educational structure laid out in the book.

As with The Gashlycrumb Tinies, The Dangerous Alphabet associates the alphabet with a mix of concrete objects and abstract concepts. The first line, "A is for Always, that's where we embark" (2) presents the reader with the word "always," an abstract notion of time. "Always" here conjures the idea of permanence; the narrative begins already stretched beyond the limits of the text, as it suggests that this adventure is one of many, and thus the telling of this tale is a repetitive action. Yet "Always" is also a concrete marker in The Dangerous Alphabet. The word is a tangible part of the accompanying illustration as it is a signpost that physically marks the children's departure point. The text follows up "A" with an indisputably concrete association of "boat" with "B" (4), but immediately diverges from logistically clear connections with "C", which is "the way that we find and we look" (5). Here, "C" stands in for "see," a clever manipulation of homophones. In fact, the majority of letters are either associated with abstract concepts or subvert the pedagogical process; only ten letters $-\mathrm{B}, \mathrm{D}$, $\mathrm{K}, \mathrm{M}, \mathrm{O}, \mathrm{Q}, \mathrm{R}, \mathrm{S}$, and T - are solely connected to concrete objects or demonstrable states of being. A and $\mathrm{N}$ are the only letters that bridge the gap between concrete and abstract, as $\mathrm{A}$ is the Always signpost, and $\mathrm{N}$ "is for Night, and for Nothing, and Never" (16). While "night" is a demonstrable concept, because $\mathrm{N}$ introduces a series of three words, this string becomes linked together. "Night" therefore is not just the absence of daylight and the conclusion of the day, but it is also a marker of despair. It stands with the concept of nothingness and the 
natural opposite of "always," and as such, its illustration is of a group of captured children, including the main girl character, chained together and lead by a large horned monster. While they do not interact directly with the characters who appear in the "O" illustration (17), the man in this picture clutches a lumpy sack that foreshadows the sack in which the monstrous pirates will stow her. As "O is for Ovens, far under the street" and those ovens are attended by a man with a straight razor and a woman who is producing a significant number of meat pies with obvious bones sticking out of their pastry tops, this illustration directly invokes the Sweeney Todd mythos and Gaiman and Michael Zulli's incomplete Sweeney Todd: The Demon Barber of Fleet Street (1992). The danger for the children is therefore implied to be far greater than the text indicates as they are not just under threat of capture, robbery and death, but in conjunction with "L" (14) - in which four children are in a large cooking pot over a fire, a monster tending to the pot with a large bone ladle - these ovens and pies foreground the potential for dismemberment and cannibalism.

In fact, "L" has the singular function of standing in for a word that does not begin with the letter, nor does it falls under a strict definition of a homophone. Here, "L is, like 'eaven, [the children's] last destination" (14). In order to recognize and decode what "L" stands in for, the reader must first decipher the rest of the sentence. Given the threat of death in this illustration, it follows that "eaven" is a shortened form of "Heaven" - the ' $\mathrm{H}$ ' having been dropped - and the destination to which the line refers. Once the reader makes this connection and applies the same logic to "L," she or he can deduce that "L" is actually "Hell" with the 'H' sound dropped. When Hell and Heaven are thus paired with the illustration, the full meaning becomes clear: the children are experiencing hell at the hands of the monsters before they die and go to "heaven."

Past The Dangerous Alphabet's intent to push past the basic abecedarium function of pairing newly-learned letters with concrete concepts is an even more complex manipulation of language. The reader is first introduced to this linguistic play with the suggested homophone replacement in "C is the way that we find and we look" (5). Yet this manipulation of phonetics moves past sound recognition and associative patterns at "I," where the narrator declares, "I am the author who scratches these rhymes" (11). At this point, the text divorces itself entirely from the basic function of an abecedarium, as it does not attempt to link the letter "I" with a particular word or meaning outside of itself. While "I" is a word on its own, the reader must already understand the complex concept of the individual and 
identification of one's personhood in relation to other people in order to associate the letter with the correct concept. In this case, "I" does not have an explainable object or concept outside of itself; instead, it stands as part of the larger sentence without the pedagogical form that would more correctly fit with an abecedarium. Further, while "C is the way that we find and we look" (5) invites the audience into the text by invoking the collective pronoun "we," "I am the author who scratches these rhymes" (11) reverses this metatextual flow, as it breaks out of the text. In this line, Gaiman acknowledges the artificiality of the tale in a way similar to Gorey's recognition of his role as author in the abecedaria The Chinese Obelisks (1970) and The Glorious Nosebleed (1975).

In The Glorious Nosebleed, the authorial figure appears in the final panel wearing familiar clothing, as he is wearing a full-length fur coat with sneakers, an outfit Gorey himself habitually wore for a significant portion of his life. The author in this panel also has Gorey's features, including his facial hair and glasses, consistent with other self-portraits. Gorey tells us that this figure, "wrote it all down Zealously" (26), where "it" is the events from the previous twenty-five panels. In this illustration, Gorey places himself directly in the narrative, explicitly acknowledging its fictional, created status and his positioning as its creator. The Chinese Obelisks expands this authorial acknowledgement even further, as the entire abecedarium is about "an Author who went for a walk" (1) and all of the alphabeticallyarranged events that happened to him during his sojourn. Once again, he is dressed in Gorey's signature outfit - although this time without his glasses - as he marches through a series of encounters. The artificiality of The Chinese Obelisks is then heightened even further as Gorey kills off his authorial analogue in panel twenty-two, as an urn falls on him; yet the narrative continues. This divide between Gorey the now-deceased character and Gorey the author highlights the fictionalization of the story, as it is impossible for Gorey the author to continue to create post-mortem. In this manner, The Chinese Obelisks is invoking the same metatextual positioning of The Dangerous Alphabet, albeit in a far more gruesome fashion.

Indeed, Gaiman acknowledges the relationship between author and audience in The Dangerous Alphabet once again with "U" (25), where the authorial construct directly addresses both the children held captive in the narrative and the book's reader: "U are the reader who shivers with dread; W's warning went over your head" (25-6). Once again, the author does not just cross into his text, but also looks out from the work at his audience, a technique found in a number of Gorey's works, including The Neglected Murderesses and The 
Curious Sofa. Gaiman revisits the author and audience relationship once more in the penultimate illustration, where "Y's your last question, the end of the ring" (29), as "you" once again invokes the reader outside of the text. Both of these $-\mathrm{U}$ and $\mathrm{Y}-$ rely on homophones just as "C" does; each of these narrative-breaking lines thus to links to each other through an explicit literary figure.

Yet the preface warns the reader to watch for "a dangerous flaw" (1) in the singular. Although the entire narrative is an exercise in manipulation of form and language, it is not homophones or abecedaria rules that the preface warns against. Each of these examples of linguistic play are not, in and of themselves, flaws. The flaw, therefore, is a subtle, simple swap: the letters "W" and "V" are transposed within the narrative, "W" coming before "V." In this manner, the abecedarium form is completely subverted as past the other playful manipulations of language, moving letters out of sequence entirely disrupts the basic pedagogical purpose of the abecedarium: teaching new readers recognition of the alphabet. Although all twenty-six letters remain within the text, this small disruption undermines proper alphabetical order, and with it, the transmission of that order to the student reader. Cleverly, "W" flags its own disruptive break as the line, "W's warnings went over your head" (26) is directly relevant to the in-text narrative - the little boy and his gazelle ignore the warning to "Turn back now!" - and it recalls the warning from the preface. On a literal level, the line is directly above the protagonists' heads, but additionally, the line assumes that the original warning that the alphabet is not trustworthy has been disregarded by the reader.

Past this linguistic play, The Dangerous Alphabet shares a specific visual marker with The Gashlycrumb Tinies. Like the figure of Death that presides over the Tinies, the narrator of The Dangerous Alphabet occupies a similar position. He is a tall figure, cloaked in his own long, floor-length beard, and much like Death, he wears a hat and carries an open umbrella as he stands beside the children who have been forced to listen to his tale (25). Just as Death stands outside of the text of The Gashlycrumb Tinies, only appearing on the frontspiece, the author-character of The Dangerous Alphabet is also a metatextual figure. As Death indicates the boundaries of the Tinies' lives, so does the author delineate the boundaries of the text. He is the figure who most explicitly breaks the fourth wall between the audience and Gaiman and Grimly through the overt references to his authorship and the readers themselves. Yet where the Tinies' Death is an imposing, dark figure, the author-character is its opposite. Death is clothed head to toe in black; the author-character is swathed in his 
white beard, his body reflecting the conditions he lives under: he is thin, boney, hunched over and incredibly pale. He lacks all the imposition of Death, and while he has his own umbrella, it does not cast a shadow nor encompass the twelve children who sit by his side. Likewise, his hat is a sad affair, nothing like the funereal splendour of Death's nineteenth century top hat and veil. He is as bound by and to the narrative as the children, as evidenced by his sad appearance and chains. Where Death represents an end and escape, here the author-character is eternally pinned to his work, chained to his desk (11), and bound to tell his stories (25). Gaiman and Grisly thus remove much of the imminent threat from the narrative as the possibility of a tragic end is usurped instead by a gently tragic figure. The author-character is not menacing in the least; the children's punishment at his hands is to be unwilling listeners rather than individuals doomed to an early grave.

The Dangerous Alphabet undermines its own form as it takes what is a teaching tool and invites the reader to question it. It therefore presents itself as an authority and simultaneously insists the audience question that authority. It is a peculiarly circular pedagogical project, as it both feigns teaching the alphabet and associating linguistic signifiers with real-world concepts and teaches the reader to question teachings. This circularity is a feature of Gaiman and Grimly's approach to the Goreyesque, as they reject Gorey's ambivalence towards his (intended) audiences in favour of a space that invites both children and adults in. Where Gorey's texts linger on his characters' miseries, The Dangerous Alphabet pushes beyond the grimness and black humour of Gorey's works to a brighter, happier outcome.

Where Burton and Gaiman consciously invoke Gorey in their texts, Roman Dirge's graphic novel series Lenore: The Cute Little Dead Girl (1998), which recounts the morbid adventures of a reanimated child, is an unconsciously Goreyesque text. Lenore herself chops, cuts and murders her way through twisted fairy tales, literary retellings and original stories with cheerful aplomb. Published by comic book house Slave Labor Press, Lenore is a traditional black and white comic most obviously taking inspiration from Edgar Allan Poe's "Lenore." Yet, like Gorey, Dirge presents an adulterated, popularized version that cribs from popular culture as much as it takes direct inspiration from Poe's works. Despite discovering 
Gorey late in his career ${ }^{31}$, Dirge's early work reflects the aesthetic sensibilities that populate the artistic subculture Gorey directly influences. As an artist and writer with Slave Labor Graphics, Dirge is part of a larger category of creators for whom Gothically-inspired, black and white comic illustrations facilitate darkly humourous plotlines most often centred on child protagonists faced with macabre situations and settings. Graphic novels such as Johnny the Homicidal Maniac (first publishing circa 1990), Squee! (1997) and I Feel Sick (1999) by Dirge's Slave Labor Press colleague Jhonen Vasquez, advertising logo and graphic novel Emily the Strange (1991; 2005) by Rob Reger, and the illustrated story collection Creepy Susie and 13 Other Tragic Tales for Troubled Children (2004) by Angus Oblong are, like Dirge's Lenore, individual works with a Goreyesque sensibility. Alongside the rise of the goth subculture from the early 1980s onward, such themes and aesthetic choices subsequently experienced a surge in creation and popularity in the late twentieth century and early twentyfirst century. Collaborations between Vasquez and Dirge, as well as Gorey's importance to the goth aesthetic, therefore create an environment in which Dirge may not have been directly influenced by Gorey, but resulted in a general understanding of the aesthetic and thematic choices which can be traced back through the Goreyesque to Gorey himself.

While it is useful within a literary context to consider those creators who are directly inspired by Gorey in order to trace the scope of his direct influence, it is likewise a worthwhile project to account for those who are indirectly influenced. Dirge's participation in a Goreyesque artistic space thus makes him an important example of how Gorey is influential on a far larger literary scale than current standards of popular name recognition and the small critical footprint dedicated to him in literary studies otherwise implies.

Where Gorey's children are subject to the whims of an uncaring world, Lenore's characterization begins at the very point that Gorey's characters meet their ends. Like Gorey's Gashlycrumb Tinies and Charlotte Sophia, Lenore suffers a tragic fate and dies. Yet unlike Gorey's children, Lenore embraces that fate and it becomes the defining force that allows for an outgrowth of characterization and action. Her origin story, "Lenore in The Raven," which appears in the second issue of Lenore (June 1988), begins by directly invoking Edgar Allen

${ }^{31}$ In an interview with Westfield Comics, Dirge denies being directly influenced by Gorey, saying, "I discovered him well into my career, but I wish I had known of him sooner. I might have turned out better." (westfieldcomics.com/wow/frm_int_066.html) 
Poe's poem of the same name, "The Raven" (1845). In this tale, Dirge recounts Lenore's illness and death, her post-mortem resurrection, her estrangement from her living family, the development of her homicidal tendencies, and her new association with monsters (and a tenacious ex-boyfriend whom she tries to kill).

The second panel, which introduces the narrative - the first panel holding the tale's title and a representation of the bird itself - begins with a barely-altered version of Poe's opening line: "Once upon a midnight dreary, as I pondered, weak and weary" (1), where "as" replaces the "while" of the original. The next two panels provide a humourous and condensed but faithful adaptation of the opening stanzas of the poem, with the raven quite literally knocking on the narrator's door. As soon as Lenore opens the door, however, Dirge's tale diverges sharply from the original Poe, as Lenore grabs the raven by its throat and eats it. With this act, the poem comes to an abrupt and early end, the narrator directly engaging with Lenore's actions with an exclamation of dismay - "Hey!!" (1) - and an immediate capitulation to the scenario: "Well... Hmm... O.K. Um, so much for that tale. Would you like to hear another story, Lenore?" (2). This conscious acknowledgement of the relationship between the narrative as a construct and the fictional content is a feature of the Lenore stories, but further to that it marks the break between Lenore's explicit literary ancestry and her subsequent development. It is in this break that Gorey's influence becomes tangible. As the narrator segues into a story about Lenore, the accompanying illustrations provide a visual of a happy girl dressed tidily in a sweet little ruffled dress. In her very first appearance, she stands with her arms outstretched in a welcoming gesture, the panel's perspective adjusted so that the viewer looks down at Lenore as she tilts her head upwards and smiles at her audience. Just like The Hapless Child's Charlotte Sophia, Lenore's eyes are blank white spaces, wide open, but blind to the world around her. Lenore's fate, however, is to die very quickly of an unnamed illness, inhabiting a positioning similar to Gorey's tragic innocents in a highly condensed space. Her downfall takes place over the course of four small panels that occupy less than half of the page: two panels depict her happy, healthy life and the other two display her illness and death. Yet even though the space devoted to her life is very small - or perhaps because it is such a small space - she still follows the trajectory of a Gorey heroine. Her life is pleasant and carefree before she falls to a meaningless fate which is quick and emotionally distant. While the parameters of her fate indicate that this occurrence is deeply sad, Dirge positions the live Lenore at a distance from the reading audience. Not only is Lenore healthy 
for only two short panels, but the narrator presents her death as a matter of fact, devoting only two sentences to it: "But you became very sick. And then you were sick no more" (2), structurally echoing Gorey's brief, emotionally distant textual style.

Additionally, Dirge's artwork is in line with Gorey's aesthetics. Dirge works within similar publishing strictures as Gorey: black and white linework is understandably more economically feasible to print en masse, as it does not require the additional costs of spot and full-colour printing, and the stark lines and high contrasts afforded by pairing black and white without any mitigating or softening shades allows for striking illustrations with a Gothic feel. Just as Gorey makes black and white artwork into a stylistic advantage rather than merely an economic constraint, Dirge uses these boundaries as enhancements to his content. Further, he incorporates the traditional panel layout of comic books and graphic novels, both of which are the successors to the one panel per page format Gorey primarily uses. Even as Lenore lives, Dirge's visuals incorporate unsettling imagery. As soon as she is pictured against the background of her room, the grinning bedposts become evident. The two posts in the foreground display crooked teeth, while the two in the background appear to have mouths that have been stitched closed. The bed's proportions are very slightly off, as the lines of the base and headboard curve slightly upwards and out from the mattress, giving the impression that the bed is far larger than Lenore, and thus looms above her. Dirge's use of shading also intensifies the naturally shadowed areas, so that the base of the bed and the space around and behind Lenore's head and pillow sink into darkness, creeping upward and threatening to engulf the child. As Lenore dies, her previously white eyes become black hollows and the shading intensifies around her face and eyes.

It is at this point that Lenore uses Gorey's fascination with death as a meaningless end as a conduit to new Goreyesque possibilities. Where Gorey's children meet meaningless death and summarily end alongside their narratives, Lenore's death serves as a jumping off point for all of her subsequent characterization and stories. Inexplicably, Lenore reanimates while in the morgue, insisting that she was "[j] ust sleeping" (2), frightening the morgue attendant, who bears a striking resemblance to Dirge's authorial insert. From here, she attends her own funeral, much to the distress of her friends and family (3), and as the memorial service ends, she breaks entirely from her previous life. Dirge signals this break through physical space, as Lenore finds herself on the far left of this page's second panel, her family on the far right, a large bolt of lightning and crack of thunder physically separating them as 
the narrator notes that the attendees "no longer understood [her]. They seemed to not even know who [she was]. They avoided [her]." Part of that lack of recognition is, no doubt, a barrier between realism and fantasy, as for her family, Lenore has died and thus ceases to exist, the funeral marking the end of her narrative; for Lenore, however, her death and funeral are nothing more than a transition to another type of existence where monsters and fantastical events are de rigeur. In the act of dying, Lenore crosses the boundary between life and death, and realism and fantasy. In fact, her physical appearance not only becomes monstrous, with misshapen eyes and thick, ropey strands of hair reminiscent of worms, but her colouring inverts. Her dress, which began as a frilly white outfit, is now an angular black dress, and her hair, previously neatly styled and black, is now a messy, chaotic mass of white ${ }^{32}$. Lenore no longer looks like a child; instead, her proportions become exaggerated, and instead she resembles an otherwordly creature or toy. From this strange rebirth, she embraces her changed state in a way that Burton's monstrous and Gorey's tragic children do not; Lenore's adventures are chaotic and surreal, and they highlight her position within them as the central gleeful protagonist.

Burton, Gaiman and Dirge continue to carry on Gorey's legacy in their own use of the Goreyesque. As with the development of the Dickensian from Charles Dickens' texts, these creators actively contribute to the form of the Goreyesque by taking those tropes Gorey uses in his works and interpreting them through their own lenses, expanding on the themes that reoccur in Gorey's oeuvre. Maria Teresa Chialant, in "Dickensian Resonances in the Contemporary English Novel," says that

Dickens's presence in postmodern fiction can be partly explained by the fact that his novels already articulate, in their own structural features, a parodic use of well-established canonical narrative forms. (43-44)

Just as Gorey examines Dickens' themes and tropes in his play with the Dickensian, the Goreyesque is an aesthetic that allows creators to examine genre play from new and different angles. The Goreyesque clears room for parody, satire and humour, fostering an examination

${ }^{32}$ When pictured on individual issue covers and in subsequent merchandising, Lenore is depicted as having yellow, yarn-like hair, which is notable in that this shift still upholds the diametric opposition between live and dead Lenore - she is a brunette while she is alive, but a blonde once she is dead - but the black and white contrast of the ordinary comic pages underscores this difference even more sharply by virtue of not using spot colour. 
of the foundations of nineteenth century genres, and encouraging a lightness in discourse regarding mortality and morbidity. The Goreyesque embraces the darker places in ourselves, and as it evolves in the hands of Gorey's literary descendants, it becomes a genre through which artists explore the potential for light and hope within that darkness.

Despite the lack of critical attention he has received to date, Gorey's influence on late twentieth and early twenty-first century art and literature is undeniable. Burton's, Gaiman's and Dirge's works retrospectively illuminate Gorey's place in the larger canon as a significant component of the tradition that leads to them. Although Gorey has been dismissed as difficult to categorize, as he does not fit into any singular literary tradition, Gorey's worth is measurable both in his relation to those who have come before him, and his positioning as a dead artist who continues to influence art and artists today. His worth comes from such context, and by considering his generic play and how it informs the aesthetics of artists such as Burton, Gaiman, Dirge, and a host of others, we are able to trace the development of the Goreyesque and better contextualize creators who are directly and indirectly influenced by it. 


\section{Chapter 8: Strangely Overlooked}

At first glance, Gorey's genre play appears to be simply a study in absence. Each foray into generic tropes seems, on the surface, as if Gorey strips away the purpose of each genre for no reason other than to manipulate genre characteristics without the addition of emotional or narrative weight. Yet rather than reducing these genres down to nothing more than their component parts, Gorey's texts highlight the space in which such emotional connections reside and uncover what remains once they are removed. As genres, melodrama, the Dickensian, children's literature, detective and mystery fiction, and Gothic horror all share an indulgence in excess. For melodrama, the Dickensian and Gothic horror, this excess is one of emotion and sentiment. For children's literature, it is the importance of pedagogy, of making sure that texts for children properly equip them with the knowledge they need to proceed in the world as responsible and intelligent citizens. In detective and mystery fiction, it is desire for solvable patterns and decodable secrets, and in Gothic horror, it is an excess of sentimentality and fear. Each of these genres also comes with strong moral statements attached. Each one adheres to a structure in which good is discernable from evil, kindness and suffering are rewarded, and avarice and violence are punished. Gorey's works, however, hold to the narrative outlines but explore what they mean in the face of an amoral worldview.

Gorey uses the characteristics of each genre as signposts through which his audiences are primed for the conventions that elicit certain reactions to each text. His texts assume an informed audience that is familiar with the genres he plays with and is able to evaluate its own expectations. This expectation of some level of literary education mirrors his own engagement with media. Gorey's media knowledge is both broad and deep, as

he could discuss for hours - for entire days - the films of Feuillade or French surrealism or Fanju's Judex or Federico Fellini's Nights of Cabiria or the novels of Ivy Compton-Burnette [ sic] or $19^{\text {th }}$-century book illustration or the paintings of Goya, whom he loved...Gorey was eccentric, there is no question. Who are you acquainted with, for instance, who has read all of Trollope, all 17 of his novels, all 47 books, [sic] but would not miss a single episode of TV's "All My Children" or Andy Griffith in reruns of "Matlock?" Read Lao-tse with understanding but collected true crime magazines and loved "Dr. Who," that improbable science fiction TV series? Cherished Oliver Onions, but 
watched "The Mary Tyler Moore Show" episodes and collected current videos? Could speak with total authority on the novels of Theodore Dreiser or Yukio Mishima and yet was word-perfect on the films of English actress Pamela Franklin and could quote chapter and verse from the 1958 film, Fiend Without a Face, in which a scientist materializes thoughts in the form of invisible brain-shaped creatures which kill people for food? Sat up dutifully by himself to watch movies virtually every night? (Theroux $84-85$ ) These textual preferences highlight his own engagement with a myriad of genres across both "high" and "low" art, including soap operas, social commentaries, fantastical family- and child-friendly tales, true crime and fictional mysteries, and horror stories. These wideranging interests reflect not only the variety of genres within which Gorey writes, but also hint at the ways in which he plays with and manipulates genre, as so many of his works fit comfortably within more than one generic category. For instance, The Gashlycrumb Tinies pairs children's pedagogical literature with Gothic horror, The Deadly Blotter mixes detective fiction and abecedaria, The Retrieved Locket fuses Dickensian melodrama and mystery, and The Hapless Child brings together melodrama, mystery, children's literature, and the Gothic.

Rather than fitting solely in one specific genre category, Gorey's oeuvre is best understood as a metatextual project in which his works engage in dialogue with the conventions of genre fiction. This positioning, as an author consistently writing narratives that maintain a distance between themselves and their readers, gives the appearance of a hard to categorize creator without allegiance to any particular genre. Yet by stepping back from the specifics of genre and examining the form and structure of his texts, his status as a metatextual artist comes into focus. His narratives consistently question what characteristics define each genre he studies, and what happens when important defining features are removed. His texts go further than merely stripping a genre of its meaning and purpose by refreshing audience expectations and providing new views of literary traditions rooted in nineteenth century art.

For Gorey, tragedy is an event from which it is nearly impossible to recover. His melodramas are missing the rewards that come with goodness, kindness and overcoming adversity. Instead, his characters are at the mercy of an unfeeling, cruel world, and they inevitably emerge from their personal trials all the worse. There are no kind or moral endings in a Goreyesque melodrama. Despite being populated by orphans, destitute families, star- 
crossed lovers and pure-hearted children, these tales spare no space for pity. For instance, in The Green Beads, Tancred, his mother and the Baroness come within a hair's breadth of finding the riches that will save them from continued destitution, but ultimately, due to nothing but circumstance and unluckiness, they remain miserably poor. In The Hapless Child, Charlotte Sophia loses everything and is abused and taken advantage of by many horrible people, and just like Tancred, she is almost reunited with her father only to have even that moment taken away by nothing more than circumstance: due to Charlotte Sophia's blindness and how much she has changed, neither she nor her father are able to recognize one another. The Pious Infant concerns a child who dedicates himself to his religion, filling his days with self-denial, self-sacrifice and piety. Unlike Tancred and Charlotte Sophia, Henry's sacrifices are voluntary, but that does not save him from a similar fate. Each of these characters has little control over the course of her or his life, and no matter what they do, none of them are able to escape the inevitability of death.

Embedded in Gorey's works is an appreciation for form over content. While Gorey's melodramas are consumed by tragedy, there is little room for emotion and empathy within them. By virtue of their short form, in-depth characterization is not a priority. Any emotion is muted, as Gorey works to make it difficult for the reader to empathize with the characters or their situation. Instead, their struggles are entertaining diversions which invite laughter. This feature nurtures a detachment from the narrative further cemented by the lack of a moral: rewards and punishments do not align with good and bad behaviour, but instead foster stories of cruelty and brutality driven by random forces rather than any type of universal order. Gorey's characters often experience short, miserable lives in which tragedy is an ordinary occurrence rather than a surprising twist of fate. The lack of morality and emotion do not signal a completely hollow engagement with melodrama, however, as Gorey's narrative and structural choices highlight the importance of emotionality to the genre, foregrounding its purpose by exposing what is left in its absence. The reader is therefore more aware of the workings of melodrama, and beyond that, she or he is able to find moments of pleasure within that structure. While such a reaction is at the expense of the characters within the narrative, given the clear distance between reader and text, Gorey's melodramas invite their audience to find gratification and joy where there would otherwise be sorrow and pity.

As with his melodramas, Gorey's Dickensian texts highlight the importance of sentimentality to the genre. In the Dickensian, sentimentality acts as a mechanism through 
which social problems are delineated. It is paired with an excess of emotion that aims to elicit empathy and concern from its audience, thereby emphasizing the importance of social reform, action or simply sympathy for oppressed classes of people. Gorey's Dickensian narratives, however, avoid serious exploration of social issues and significantly dull any sentimentality or passion that such a narrative might otherwise excite. The Retrieved Locket appears, on the surface, to be a tale of love and loss, in which a little girl is kidnapped and her parents must deal with the agony of her disappearance and the attendant police search. Instead, it is a study in denial: the narrative does not engage in much emotionality, freezing the Fibleys in tableau. Their narrative trajectory is quick and cursory. Within the space of eight panels, their daughter, Amelia Emily, is born; they present her with a locket containing their pictures, the perfect item to identify their lost heir by later; and she is almost immediately kidnapped. Any active emotional engagement they might display stalls at this point, as they transfer all affection to a proxy in the form of a dog. There is no satisfaction or resolution for the Fibleys, as their determination to identify the dog as Amelia Emily blocks any possibility of moving forward with their lives. In both The Haunted Tea-Cosy and The Headless Bust, Gorey's A Christmas Carol homages, this emotional stagnation continues, as Gorey's Scrooge-analogue, Edmund Gravel, fails to learn anything from his paranormal visitors. In fact, these two works are so invested in maintaining emotional distance between Gravel and what should be affecting scenes that the visions he sees have nothing to do with his own life, and therefore have no impact on Gravel as an individual. Without any emotional touchstones to light the way, these stories do not foreground any particular social issues, nor offer up critique of the status quo.

Gorey's Dickensian characters therefore come away from their moral lessons having learned nothing at all, and having failed to change. More than any of Gorey's other genre play, his Dickensian works are studies in stagnancy. His characters actively refuse to move forward (or backward), remaining instead in a narrative stasis. Whereas in his melodramas, tragedy and suffering lead to unkind, unhappy ends, his Dickensian stories are incapable of progressing, even to a miserable, unwelcome conclusions.

Without rewards, punishments, and emotional anchors, Gorey's versions of Dickensian texts invite us to examine the purpose of morality plays. Gorey uses amorality as a tool through which the audience can accept cruel, unfeeling Fate as an inevitability, and then laugh at it. His works obstruct cathartic outpourings of sorrow and triumph in favour of 
the embrace of humour and the absurdities of such plot lines. They underline the artificiality and mundanity of good forever triumphing over evil. For all that Gorey's texts are unrealistic in character, design and content, they do not promise an unrealistic system of rewards for good behaviour and punishment for bad. Instead, as with his melodramas, they invite the reader to find catharsis in humour, and amusement in nihilism.

Following in the same footsteps as his melodrama and Dickensian works, Gorey's play with children's literature concerns itself with the place of sentimentality and emotionality within the genre. He exploits the sentimentality of adults for childhood by using the trappings of children's literature to set up exceptionally distressing and morbid narratives. Instead of narratives in which children's struggles are rewarded with good, full lives, when children are beset by tragedy in Gorey's works, they are treated in the same manner as his adult characters, which, more often than not, means that they die in painful, miserable and unnecessary ways. Often, these deaths happen alongside seemingly pedagogical exercises, as in The Gashlycrumb Tinies, an abecedarium where twenty-six children expire in twenty-six different tragic scenarios. Each child's death marks another letter of the alphabet taught to the reader through rhyme. The Eclectic Abecedarium displays a similar impetus, as it cleaves to its abecedaria roots. In The Eclectic Abecedarium, however, there are no specific named characters to kill off. Despite this lack, threats to children's mortality are built directly into the text as if they are nothing more than tools to aid in teaching the alphabet to students. In contrast, The Utter Zoo casts off any pretence of pedagogy as it is far more concerned with nonsense words and sounds. As there are no children in the story, Gorey shifts the threats to the bodily integrity of the creatures themselves. While they are not explicitly threatened in the text, many are so grotesquely-shaped as to make it difficult for them to move through their environments, or they are unable to fully camouflage themselves, leaving them vulnerable to outside attack. The Wuggly Ump, on the other hand, is an explicit danger to children. Amidst pleasant rhyming couplets, it stalks, terrorizes and swallows them.

Each of these texts revels in language and sound while rejecting the strictly pedagogical role of children's literature, and also the reassurance of safety that comes with mid-twentieth century stories aimed at children. Just as Gorey's Dickensian figures do not change, what lessons there are to find in his children's literature do not stick, nor do they further knowledge. His abecedaria link abstract concepts with the alphabet, circumventing the more concrete language-building of traditional teaching abecedaria. Instead these pseudo- 
pedagogical texts concentrate on presenting a harsh, unfeeling world in which children are punished for no particular reason and death is always around the corner. Learning is a fruitless endeavour for his child characters when life is not particularly long. Yet in Gorey's nonsense works lies simple joy not in pedantic lessons, but in the sounds and forms of things. His nonsense texts highlight rhythm and sound, and in those small, overlooked building blocks are the pieces that make up larger concepts and ideas. Through his nonsense verse, Gorey displays an appreciation of what might be otherwise viewed as unimportant, such as the pleasure of the feel of a syllable shaped on the tongue, or the sound of a word on the air.

In contrast to his direct use of the abecedaria form in much of his children's literature, Gorey removes the essential element of clues from his detective and mystery fiction. These fine details allow the reader to trace the initial crime all the way through the narrative to the criminal's punishment. In Gorey's stories, however, the clues are oblique or nonexistent, rendered extraneous to the narrative. As an abecedarium, The Deadly Blotter stays in step with Gorey's other $\mathrm{ABC}$ texts by maintaining its overall structure and form, but as a detective story, it is vague. The Deadly Blotter provides only the bare minimum of details to suggest that a murder has taken place, preferring instead to shift the reader's gaze from the particulars of the crime to a metatextual view of the elements most necessary to a detective story. The Awdrey-Gore Legacy furthers this examination of the form, as it considers the relationship between author and story. In The Awdrey-Gore Legacy, the true mystery lies not in AwdreyGore's fragmentary notes for an as yet unwritten novel, but rather in her own disappearance and death. As with The Deadly Blotter, these notes deconstruct the elements needed to create a fictional detective story, including the detective figure, an attention to detail, and the possibility of clues. Yet Awdrey-Gore's murder is missing those elements. There is no named detective associated with her case to shepherd the reader through the narrative. What clues there are are jumbled or inconclusive, and the reveal of the murderer is vague, abrupt, and ambiguous. In order to understand, even partially, the circumstances around AwdreyGore's death, the reader must step into the detective role, where she or he must work to decode the order of events, the meaning of oblique text, and the legitimacy of the final confession.

In The Neglected Murderesses and The Loathsome Couple, however, Gorey removes the expected mystery. Both texts present scenarios in which the reader is fully aware of the identity of the criminals and the extent of their crimes, and neither text includes a detective 
figure. There is no need to expend energy searching for clues as those details are already apparent. Yet each tale has an extra-textual mystery. The Neglected Murderesses invites the reader to question what led up to each murder, to speculate what will happen after, and most importantly, to question why these women and their crimes are so easily neglected. The mysteries at the heart of The Loathsome Couple are how Gritch and Snedleigh were able to continue killing for so long without capture, and what motivated them to begin in the first place. As with much of his other genre play, Gorey's detective fiction relies on metatextual engagement, as that is where the process of decoding resides.

The Neglected Murderesses presents tableaux in which crimes are either in progress or concluded: there is no way to intervene, nor is there any punishment forthcoming. The reader stands as witness to these crimes in the position that, in-text, would be occupied by a detective character. Despite also lacking a detective figure, The Loathsome Couple is an outlier in Gorey's detective fiction, as justice is carried out by the end of the narrative. Gritch and Snedleigh are captured through luck, rather than any one character untangling coded clues. As the tale is based on a real event, Gorey's choice to bring punishment and narrative resolution to Gritch and Snedleigh's crimes is both faithful to the truth and delineates the difference between fiction and reality. Gorey's fully-fictional stories are spaces in which justice does not matter, as the creative process and the shaping of a narrative take primacy.

Gorey short-circuits the purpose of detective and mystery fiction, in which an obsession with details leads to working out the larger puzzle at the heart of the plot line. Without a recognizable and trackable pattern of clues, there is no satisfactory progression through the mystery, and no emotional payoff. Gorey's texts cultivate the randomness inherent in crime and criminality, and the fact that such events do not come with patterns which, when followed, will decode, solve and impose order on the world. Just as Gorey's melodrama and Dickensian works do not reward their suffering characters, there is rarely any punishment for the criminals in his detective and mystery fiction. His narratives are ambiguous, leaving the reader to consider what they want to get out of the story rather than merely trace the progression from crime to punishment. Gorey's mysteries lie outside of the text, encouraging his audience to decode the structure of the tale itself.

Gorey's Gothic horror is concerned with the furnishings of the genre. He populates his stories with features that signal Gothic horror, including gloomy, isolated mansions; dark, fertile gardens run rampant; and crumbling ruins. He then places paranormal beings in these 
settings, creating an expectation in his audience that these tales will elicit terror and fear. As with so much of his genre play, however, Gorey continues to enforce the distance between audience and text, blocking the potential for the reader to experience fear. Without a narrative to act as a through-line, this emotional disconnect is most obvious in The West Wing. Despite the Gothic trappings and unexplained phenomena that populate the various panels, The West Wing is the textual equivalent of a museum installation. Each illustration is a new piece of art, presented without commentary or context. The work is a study in atmosphere, as each panel reveals a new corner of the mansion and adds to the overall Gothic furniture, but much like The Retrieved Locket, The West Wing is a series of tableaux. Gorey does not indicate if the events in The West Wing are independent of each other or form a cohesive whole, and as none of the handful of characters appear in more than one panel, there is no sense of the passage of events nor time, and therefore no cause and effect to excite emotion or engender fear.

While The Evil Garden shifts the setting from a semi-private to a public space and supplies a full narrative, the emotional distance remains. The rampant, evil, human-eating garden should elicit fear, but because Gorey does not allot space in the text to characterbuilding, the reader is not encouraged to identify or empathize with the characters. They are merely objects that support the Gothic atmosphere and furnishings on which Gorey focusses, becoming furniture in their own right. Instead of fear, the audience is invited to be amused at the grotesquely absurd situation, finding delight in the demise of the garden's victims. The Doubtful Guest goes even further to undercut any horror in the situation, as Gorey downgrades the threat present in the narrative to a persistent annoyance. As strange and fantastical the guest is, it is incapable of causing real harm to the family; it is only able to disrupt, not destroy, and while it is an unnatural creature, its disruptions are entirely mundane. The Disrespectful Summons also takes away the possibility for large-scale, frightening acts by Miss Squall or her demon familiar, as once the Devil grants her power, she uses it in a manner similar to the guest, engaging in almost exclusively petty actions. Even when the Devil comes to claim her, her emotions are muted, as it is not terror on her face, but surprise and weary acceptance.

Although Gorey's tales often take great glee in excessively grotesque and violent displays, they do not indulge in the gleeful excesses of fear in Gothic horror. Instead of fostering an excitation of terror regarding the monstrous and the supernatural in his 
audiences, Gorey replaces such fears with a sense of mundanity and the normalcy of everyday concerns. He provides no room for excessive emotionality or cathartic experience with which to terrorize the reader. Desire (and emotion in general) in the text is muted or otherwise neutralized, having been dampened down and arrested through Gorey's deprivation of excess emotion. His texts are mannered affairs, unconcerned with creating empathetic links between the reader and the narrative. He pushes forward the mundane and normal over the strange, once again leaving the reader without the cathartic outcome provided by the triumph of good over evil.

All of these genres share the desire for a moral outcome, and Gorey examines each by removing the potential for such an ending. While this lack highlights a world in which there are no surefire ways to impose order or justice on the most miserable of situations, it also makes space in which larger thematic concerns are put aside in order to examine the smallest of things. Gorey's genre play makes the paranormal into the normal, as all fear is stripped away. He folds fantasy and mundanity together, and in doing so, normalizes the supernormal. Gorey's fantasies aren't spectacular or sublime. They take what should be exceptional occurrences, moments of extreme emotion and moral fortitude that act as defining moments of characterization, and demythologize them so that they sink to a more ordinary level. Through this demythologization, Gorey - and by extension, the Goreyesque - prioritizes the ordinary over the extraordinary. Those moments - the underwhelming, the ignored, and the odd - become far more important to each narrative, shifting and recentralizing the reader's gaze to smaller, finer details, including how the story (including artwork and text) has been formed. Gorey invites his audience to enjoy his works from a metatextual standpoint. That distance, the way Gorey puts no stock in the strange and horrifying, in good versus evil, or in reward and punishment underlines the tendency by genre fiction to valorize those same things, and to encourage audiences to look for and prioritize mythological moments over the truly surprising small moments otherwise buried in the mundane. By underplaying the significance of the events in his stories, Gorey represents and refreshes our concepts of the fantastic; he highlights the strangeness in the overlooked.

One point that comes up repeatedly in what little criticism exists regarding Gorey is how his work is "unique" and "indefinable." His multiple influences, encompassing a wide variety of genres, and his play with those genres contribute to the belief that categorizing Gorey's texts is a slippery process at best, and entirely impossible at worst. Despite this 
notion, however, Gorey's oeuvre can be categorized. Gorey's stories are consistently in dialogue with his literary and artistic ancestors. His texts are exceptionally conscious of their roots, and each narrative is an exercise in metatextual discourse. Each work invokes and incorporates the tropes of the genres with which he plays while removing the meaning or central purpose, yet that removal is not about creating an intellectual or emotional void, nor is it about destroying the integrity of the genre. Instead, Gorey removes in order to reveal. His stories invite the reader to consider how each genre works, and what each one requires from its audience in order to succeed as a genre text. In this respect, Gorey makes his audience more conscious of the interaction between reader and text, assuming a knowledgeable viewer conversant with genre conventions. Gorey's stories begin by entertaining his audience, and are sometimes viewed as nothing but shallow fripperies, but each one invites a deeper engagement. Their short formats, made up of quick bursts of text alongside small illustrations and executed within very few panels, allow for swift digestion, but when the reader lingers on the details and slows down to take time to engage with the text, the work opens up before her or him. Gorey's oeuvre is an extended metatextual journey through which appearances cloak actualities.

Approaching Gorey as unclassifiable has the unfortunate effect of creating a selffulfilling prophecy, as those critics branding him as such do not work to position Gorey within the larger literary canon, and new critics thus do not become aware of his texts. It is important, therefore, to explore Gorey's influence on his peers and later creators, and to trace the development of the Goreyesque, as doing so reveals Gorey's influence on the generation of artists and writers that come after him. Specifically, Tim Burton's, Neil Gaiman's and Roman Dirge's works retrospectively reveal Gorey's place in the canon, in the tradition that leads to them. Through their stories, we can see the influence of the Goreyesque. As examples of Goreyesque creators, they point the way to a larger population of artists and writers influenced by Gorey. Where Gorey, while he was writing, was labelled an outlier who did not fit with any tradition, the existence of the Goreyesque aesthetic belies that label.

As the most directly influenced of these three creators, Burton's oeuvre strongly delineates the boundaries of the Goreyesque. In fact, much as Neo-Victorianism is a direct descendant of Victorianism, the "Burtonesque" is a natural outgrowth of the Goreyesque. Burton preserves Gorey's visual aesthetic alongside his preference for morbid themes and overturning genre expectations. Burton then expands on the Goreyesque by bringing a sense 
of hope to his narratives. Where Gorey invites his readers to laugh in the face of hopelessness, Burton finds hope where there appears to be none. Populated by monstrous creatures, The Melancholy Death of Oyster Boy explores their lives (and deaths) and finds that in spite of personal tragedies, most of these characters find happiness in themselves. Where Gorey invites the reader to laugh at despair and death, Burton digs through misfortune to find a more hopeful future.

Gaiman and Gris Grimly's The Dangerous Alphabet takes a similar tack to Burton. As Gaiman is a writer but not an illustrator, most often, he must use text only when describing Goreyesque visuals. His novel, Coraline, is most explicitly acknowledged as his "Edward Gorey book," and its themes of isolation, disconnection and mortality fit neatly into the Goreyesque tradition. It is when Gaiman pairs with an artist that the visual-textual relationship central to the Goreyesque shines. The visual cues, such as muted colour, nineteenth century clothes and settings, and the ever-present threat of mortality invoke Gorey's aesthetic. Gaiman and Grimly also play with the abecedarium form in a manner similar to Gorey. Gorey's ABCs are aimed at an almost exclusively informed adult audience by virtue of their focus on abstract concepts and violent content. Gaiman and Grimly's alphabet is more child-friendly, as far more of their letters are associated with concrete objects and less violent scenes, but their narrative also invites in an adult audience through its introduction. Danger still lurks around every corner, but unlike so many of Gorey's children, the children in The Dangerous Alphabet return safely to their loving parents. Mortal peril is a temporary state, and the desire to laugh at it is less a nihilistic impulse, and more an acknowledgement that safety and security is not far away.

Even as an artist who does not directly encounter Gorey until late in his career, Dirge's early work is Goreyesque in tone. As with The Melancholy Death of Oyster Boy, Lenore showcases black and white line art utilizing heavy crosshatching and unrealistic proportions. Like Gorey, Dirge takes nineteenth century themes and reinterprets them in Lenore. Lenore herself is an interpretation of Edgar Allan Poe's "Lenore," but instead of stopping with her death, in a Goreyesque move, Dirge uses Lenore's demise as the beginning of his story rather than the end. Lenore is transformative in that it asks the reader to consider mortality as something more than a state to be avoided or an ending. The Goreyesque requires its audience to consider mortality, and in Gorey's case, laugh in the face of it while keeping your distance. Just as Burton, Gaiman and Grimly look for more hopeful interpretations of 
mortality, Dirge's interpretation of the Goreyesque frames death as another part of a potentially endless journey. Lenore is transformed in her death, but in that transformation lies a strange sort of happiness and hope.

Much as how Charles Dickens' aesthetic becomes known as the Dickensian once other writers mimic and take inspiration from his style and texts (and similarly, how post-Gorey, Tim Burton's aesthetic becomes known as the Burtonesque), Gorey's genre is self-defined. His works are always conscious of the traditions that shape and inform them, and that quality is what lies at the heart of the Goreyesque. Past the black and white artwork, morbid themes, nineteenth century markers and lack of sentiment and emotionality lies an exceptional understanding of the freedoms and limits of genre. Just as Gorey's narratives showcase the trappings of genre in order to isolate (and remove) the heart, his works employ a specific aesthetic that is ancillary to the metatexual discourse underlying the form. Goreyesque works by later creators utilise Gorey's overall aesthetic, but the works that are most firmly rooted in the Goreyesque are those that transform and interpret genre. These texts pair Goreyesque themes, such as a preoccupation with tragedy and mortality, with deliberate narrative play. They are both self-conscious and encourage their audiences to a similar level of selfconscious engagement with their stories. While some Goreyesque texts preserve their link to nineteenth century genres and some are much more concerned with twentieth and twenty-first century literary conventions, the basic requirement of familiarity with the referenced genres, regardless of type, remains central to the Goreyesque aesthetic. Just as with Gorey's works, the Goreyesque assumes a knowledgeable audience that is able to question the text and their own expectations. Indeed, by enforcing emotional distance between text and reader, and inviting textual interrogation, the Goreyesque opens up space for amusement and humour at the expense of genre expectations. 


\section{WORKS CITED}

Adams, Jeff. "Working Out Comics." Journal of Art \& Design Education, 19.3 (2000): 304-312. Print.

Andersen, Hans Christian. The Complete Fairy Tales and Stories. London: Anchor, 1983. Print.

Archive of Our Own. v0.9.38.4. The Organization for Transformative Works. 2007. Web. 30 December 2014. <http:/archiveofourown.org/>.

Bailey, Katherine R. Appropriations from the 19th Century and the Topic of Death in Modern Gothic Narratives: Edward Gorey, Walt Disney, and Tim Burton. Diss. Florida State University, 2012. Print.

Bainton, Derek. "Urban Legends." Varoom. 15 (Spring 2011): 70-78. Print.

Baker, Keith. Gloom: The Game of Inauspicious Incidents \& Grave Consequences. Austin: Atlas Games, 2004. Card Game.

Baym, Nina and Robert S. Levine, eds. The Norton Anthology of American Literature. New York: W. W. Norton \& Company, 2011. Print.

Bean, Ethelle S. "Technology and Detective Fiction." Clues. 24.1 (Fall 2005): 27-34. Print.

Beaton, Kate. "Gorey Covers." Hark! A Vagrant. 29 January 2010. Web. 26 October 2010. $<\mathrm{http} / /$ harkavagrant.com/index.php?id=242>.

---. "Gorey Covers Part 2." Hark! A Vagrant. 18 February 2010. Web. 26 October 2010. $<$ http $/ /$ harkavagrant.com/index.php?id=247>.

---. "Gorey Covers Part 3." Hark! A Vagrant. 10 March 2010. Web. 26 October 2010. $<\mathrm{http} / /$ harkavagrant.com/index.php?id=252>.

---. "Gorey Covers Part 4." Hark! A Vagrant. 9 July 2010. Web. 26 October 2010. $<$ http $/ /$ harkavagrant.com/index.php?id=272>.

Belasco, Susan and Linck Johnson, eds. The Bedford Anthology of American Literature, Volume Two: 1865 to the Present. New York: Macmillan, 2008. Print.

Bettelheim, Bruno. The Uses of Enchantment: The Meaning and Importance of Fairy Tales. New York: Vintage, 2010. Print.

Bianco, Guillaume. Billy Brouillard: Le don de trouble vue. Toulon: Soleil Productions, 2008. Print.

Biggs, Charles. The Adventures of Harry Franco: A Tale of the Great Panic. Charleston: 
Nabu Press, 2010. Print.

Blue Velvet. Dir. David Lynch. De Laurentiis Entertainment Group, 1986. Film.

Bodmer, George R. "The Post-Modern Alphabet: Extending the Limits of the Contemporary

Alphabet Book, from Seuss to Gorey." Children's Literature Association Quarterly. 14.3 (Fall 1989): 115-117. Print.

Botting, Fred. "Metaphors and Monsters." Journal for Cultural Research. 7:4 (2003): 339365. Print.

Bottum, J. "The Ghost of Christmas Past." The Weekly Standard. 24 December 2001: 29-33. Print.

Boyce, Charlotte and Elodie Rousselot. "The Other Dickens: Neo-Victorian Appropriation and Adaptation." Neo-Victorian Studies. 5.2 (2012): 1-11. Web. 30 December 2014. <http://www.neovictorianstudies.com/>.

Boyde, Melissa. "The Modernist roman à clef and Cultural Secrets, or, I Know that You Know that I Know that You Know." Australian Literary Studies. 24.3-4 (October 2009): 155-166. Print.

Braddon, Mary Elizabeth. Lady Audley's Secret. N.p.: n.p., 1862. Project Gutenberg. Web. 30 December 2014. EPUB file.

Bradford, Edward. "Separate Unity: Edward Gorey's Postcard Sets." Illustration. 31 (Spring 2012): 8-15. Print.

Brentalfloss. The Game Over Tinies. 25 February 2013. Web. 30 December 2014. $<$ http $/ /$ www.ufunk.net/en/jeux-videos/game-over-tinies/>.

Brontë, Emily. Wuthering Heights. Mineola: Dover, 1996. Print.

Brooks, Peter. The Melodramatic Imagination: Balzac, Henry James, Melodrama, and the Mode of Excess. New Haven: Yale University Press, 1976. Print.

Brundige, Ellen. "The Khazad-dûm Tinies: Lord of the Rings Humor." Squidoo. 2004-2005.

Web. 7 December 2010. <http://www.squidoo.com/khazad-dum-tinies>.

Brunetti, Ivan, ed. An Anthology of Graphic Fiction, Cartoons, and True Stories. 2 vols. New Haven: Yale University Press, 2006-2008. Print.

Buckley, Matthew S. "Refugee Theatre: Melodrama and Modernity's Loss." Theatre Journal 61 (2009): 175-190. Print.

Burnett, Frances Hodgson. A Little Princess. London: Puffin, 2014. Print.

---. The Secret Garden. London: Puffin, 2011. Print. 
Burton, Tim. The Melancholy Death of Oyster Boy \& Other Stories. New York: It Books, 1997. Print.

Carroll, Lewis. The Alphabet Cipher. Cambridge: Harvard University, 1868. Print.

---. Through the Looking-Glass. Mineola: Dover, 1999. Print.

Cavallaro, Rosanna. "Solution to Dissolution: Detective Fiction from Wilkie Collins to Gabriel García Márquez." Texas Journal of Women and the Law. 15.1 (Fall 2005): 1-41. Print.

Chialant, Maria Teresa. "Dickensian Resonances in the Contemporary English Novel." Dickens Quarterly. 28.1 (March 2011): 41-51. Print.

Christie, Agatha. The ABC Murders. New York: Harper Collins, 2013. Print.

---. Miss Marple: The Complete Short Stories. New York: William Morrow, 2011. Print.

---. The Mousetrap and Other Plays. New York: Avon, 2012. Print.

---. Murder in the Mews: Four Cases of Hercule Poirot. New York: William Morrow, 2011. Print.

Coats, Karen. "Conventions of Children's Literature: Then and Now." Style. 35.3 (Fall 2001): 389-392. Print.

Collins, Wilkie. The Woman in White. N.p.: n.p., 1859. Project Gutenberg. Web. 30 December 2014. EPUB file.

Corpse Bride. Dirs. Tim Burton and Mike Johnson. Warner Bros., 2005. Film.

Cunningham, Hugh. "Childhood Histories." Journal of Victorian Culture. 9:1 (2004): 9096. Print.

Dahl, Roald. Matilda. London: Puffin, 2013. Print.

Dery, Mark. "Nightshade is Growing Like Weeds." The New York Times. 2 March 2011.

Web. 30 December 2014.

$<$ http $/ /$ www.nytimes.com/2011/03/06/arts/design/06gorey.html $>$

Dickens, Charles. A Christmas Carol: A Ghost Story of Christmas. London: Chapman \& Strand, 1843. Project Gutenberg. Web. 10 November 2013. EPUB file.

---. David Copperfield. N.p.: n.p., 1850. Project Gutenberg. Web. 30 December 2014. EPUB file. 
---. Great Expectations. N.p.: n.p., 1867. Project Gutenberg. Web. 30 December 2014. EPUB file.

---. Nicholas Nickleby. London: Macmillan \& Co., 1916. Project Gutenberg. Web. 30 December 2014. EPUB file.

---. The Old Curiosity Shop. N.p.: n.p., 1840. Project Gutenberg. Web. 30 December 2014. EPUB file.

---. Oliver Twist: The Parish Boy's Progress. N.p.: n.p., 1838. Project Gutenberg. Web. 30 December 2014. EPUB file.

---. A Tale of Two Cities: A Story of the French Revolution. N.p.: n.p., 1859. Project Gutenberg. Web. 30 December 2014. EPUB file.

Dillon, Brian. "Stirrings Still." Modern Painters. 04 (2006): 68-71. Print.

Dirge, Roman. Lenore: Noogies. London: Titan Books, 2009. Print.

"The D'oh-cial Network." The Simpsons. Fox. 15 January 2012. Television.

Doyle, Arthur Conan. The Complete Sherlock Holmes. New York: Race Point Publishing, 2013. Print.

Duplessie, Matt. "The Gashlycrumb Tinies." Vimeo. 2006-2007. Web. 30 December 2014. Music Video. <http://vimeo.com/9541632>.

Eaton, Marcia Muelder. "Laughing at the Death of Little Nell: Sentimental Art and Sentimental People." American Philosophical Quarterly. 26.4 (October 1989): 269-282. Print.

EatToast. The Gallifreycrumb Tinies. DeviantArt. 25 December 2012. Web. 30 December 2014. <http://eattoast.deviantart.com/art/The-Gallifreycrumb-Tinies-344523003>. "Edward Gorey's birthday celebrated with Google Doodle." The Telegraph. 22 February 2013. Web. 30 December 2014. 
$<$ http//www.telegraph.co.uk/technology/google/google-doodle/9887409/Edward-Gor eys-birthday-celebrated-with-Google-Doodle.htm〉.

Eraserhead. Dir. David Lynch. American Film Institute, 1977. Film.

Erikson, Erik H. Childhood and Society. London: Paladin, 1987. Print.

FanFiction.Net. 24 December 2014. Web. 30 December 2014.

$<$ https://www.fanfiction.net/>.

Ford, Paul Leicester, ed. The New England Primer. New York: Dodd, Mead and Company, 1899. Print.

Frankenweenie. Dir. Tim Burton. Walt Disney Pictures, 2012. Film.

Gaiman, Neil. Coraline. New York: Harper Collins, 2012. Print.

Gaiman, Neil and Gris Grimly. The Dangerous Alphabet. New York: Harper Collins, 2008. Print.

Gaiman, Neil and Amanda Palmer. Who Killed Amanda Palmer: A Collection of Photographic Evidence. New York: Eight Foot Books, 2009. Print.

Gaiman, Neil and Michael Zulli. Sweeney Todd: The Demon Barber of Fleet Street. N.p.: n.p., 1992. Print.

Garrity, Shaenon K. "The Trouble with Tribbles: A Television Adaptation By Edward Gorey." LiveJournal. 30 August 2007. Web. 26 October 2010.

$<\mathrm{http} / /$ shaenon. livejournal.com/48834.html .

Gauvin, Edward. "What I'm Working On Right Now." 14 July 2011. Weblog. 30 December 2014. $<$ http://www.edwardgauvin.com/blog/?p=924>.

Gilman, Charlotte Perkins. The Yellow Wallpaper and Other Stories. Mineola: Dover, 1997. Print. 
Goddu, Teresa A. "Vampire Gothic." American Literary History. 11.1 (Spring 1999): 125-141. Print.

Goodsell, Luke. "Tim Burton's Corpse Bride." Empire Magazine Australasia. 7 November 2012. Web. 5 January 2013.

$<$ http//www.empireonline.com.au/reviews/films/2005/11/tim-burton's-corpse-bride/re view/>.

Gorey, Edward. "The Awdrey-Gore Legacy." Amphigorey Also. New York: Berkley Publishing Group, 1983. N. pag. Print.

---. "The Beastly Baby." Amphigorey Too. New York: Berkley Publishing Group, 1975. N. pag. Print.

---. "The Blue Aspic." Amphigorey Also. New York: Berkley Publishing Group, 1983. N. pag. Print.

---. "The Chinese Obelisks: Fourth Alphabet." Amphigorey Too. New York: Berkley Publishing Group, 1975. N. pag. Print.

---. "The Curious Sofa: A Pornographic Work by Ogdred Weary." Amphigorey: Fifteen Books by Edward Gorey. New York: Berkley Publishing Group, 1972. N. pag. Print.

---. "The Deadly Blotter: Thoughtful Alphabet XVII." Amphigorey Again. New York: Berkley Publishing Group, 2007. N. pag. Print.

---. "The Disrespectful Summons." Amphigorey Too. New York: Berkley Publishing Group, 1975. N. pag. Print.

---. "The Doubtful Guest." Amphigorey: Fifteen Books by Edward Gorey. New York: Berkley Publishing Group, 1972. N. pag. Print.

---. "The Eclectic Abecedarium." Amphigorey Also. New York: Berkley Publishing Group, 1983. N. pag. Print. 
---. "The Epileptic Bicycle." Amphigorey Also. New York: Berkley Publishing Group, 1983. N. pag. Print.

---. "The Evil Garden." Amphigorey Too. New York: Berkley Publishing Group, 1975. N. pag. Print.

---. "The Gashlycrumb Tinies." Amphigorey: Fifteen Books by Edward Gorey. New York: Berkley Publishing Group, 1972. N. pag. Print.

---. "The Gilded Bat." Amphigorey Too. New York: Berkley Publishing Group, 1975. N. pag. Print.

---. "The Glorious Nosebleed." Amphigorey Also. New York: Berkley Publishing Group, 1983. N. pag. Print.

---. "The Green Beads." Amphigorey Also. New York: Berkley Publishing Group, 1983. N. pag. Print.

---. "The Hapless Child." Amphigorey: Fifteen Books by Edward Gorey. New York: Berkley Publishing Group, 1972. N. pag. Print.

---. "The Haunted Tea-Cosy: A Dispirited and Distasteful Diversion for Christmas." Amphigorey Again. New York: Berkley Publishing Group, 2007. N. pag. Print.

---. "The Headless Bust: A Melancholy Meditation on the False Millennium." Amphigorey Again. New York: Berkley Publishing Group, 2007. N. pag. Print.

---. "The Loathsome Couple." Amphigorey Also. New York: Berkley Publishing Group, 1983. N. pag. Print.

---. "The Neglected Murderesses." Amphigorey Again. New York: Berkley Publishing Group, 2007. N. pag. Print.

---. "The Other Statue." Amphigorey Again. New York: Berkley Publishing Group, 2007. N. pag. Print. 
---. "The Pious Infant." Amphigorey Too. New York: Berkley Publishing Group, 1975. N. pag. Print.

---. "The Retrieved Locket." Amphigorey Again. New York: Berkley Publishing Group, 2007. N. pag. Print.

---. "Serious Life: A Cruise." Amphigorey Again. New York: Berkley Publishing Group, 2007. N. pag. Print.

---. The Unstrung Harp; or, Mr. Earbrass Writes a Novel. Boston: Houghton Mifflin Harcourt, 1999. Print.

---. "The Utter Zoo." Amphigorey Also. New York: Berkley Publishing Group, 1983. N. pag. Print.

---. "The West Wing." Amphigorey: Fifteen Books by Edward Gorey. New York: Berkley Publishing Group, 1972. N. pag. Print.

---. "The Willowdale Handcar." Amphigorey: Fifteen Books by Edward Gorey. New York: Berkley Publishing Group, 1972. N. pag. Print.

---. "The Wuggly Ump." Amphigorey: Fifteen Books by Edward Gorey. New York: Berkley Publishing Group, 1972. N. pag. Print.

Gorey, Edward and Eugene Federenko. Mystery! PBS. 1980-2014. Television.

Grimm, Jacob and Wilhelm Grimm. The Annotated Brothers Grimm: The Bicentennial Edition. New York: W. W. Norton \& Company, 2012. Print.

Heller, Steven. "Peter Sís, Children's Book Author and Illustrator." Print. 58.3 (05/2004): 30-162. Print.

Hennetier, Pierre Adolph, Louis Alfred Habert and Louis Edmond Cougny. Les Diableries. 1860-1890. Stereoscopic photographs. Web. $<$ http $/ /$ www.londonstereo.com/diableries/index.htmp. 
Hoffman, A. Robin. "G is for Gorey Who Kills Children." Studies in Weird Fiction. 27 (Spring 2005): 23-32. Print.

Hurley, Kelly. "Abject and Grotesque." Routledge Companion to the Gothic. Eds. Catherine Spooner and Emma McEvoy. London: Routledge, 2007. 137-146. Print.

---. The Gothic Body: Sexuality, Materialism, and Degeneration at the Fin de Siècle.

Cambridge: Cambridge University Press, 2004. Print.

The International Conference on the Fantastic in the Arts. Orlando Airport Marriott,

Orlando, Florida. March 2013. Conference. <http://www.fantastic-arts.org/>.

Jackson, Christine A. Myth and Ritual in Women's Detective Fiction. Jefferson: McFarland \& Company, 2002. Print.

Jameson, Fredric. Postmodernism, or The Cultural Logic of Late Capitalism. Durham: Duke University Press, 1991. Print.

Jones, Anna. "A Victim in Search of a Torturer: Reading Masochism in Wilkie Collins's No Name." Novel. 33.2 (Spring 2000): 196-211. Print.

Jones, Cleolinda. "Lemony Snicket: A Series of Unfortunate Events." The Daily Digest. 21 March 2004. Web. 30 December 2014. $<\mathrm{http} / /$ www.dailydigest.net/reviews/revlemonysnicketbooks.htmP.

Kehler, Grace. "Gothic Pedagogy and Victorian Reform Treatises." Victorian Studies. 50.3 (Spring 2008): 437-456. Print.

Kennedy, Victor. "Mystery! Unraveling Edward Gorey's Tangled Web of Visual Metaphor." Metaphor and Symbolic Activity. 8.3 (1993): 181-93. Print.

Kingsley, Charles. The Water-Babies. Oxford: Oxford University Press; 2014. Print. 
Kolbuszewska, Zofia. "A Graphic Story of Writing a Novel: (Pe)R(e)verse Ekphrasis in Edward Gorey's 'The Unstrung Harp'." The Lives of Texts: Exploring the Metaphor. Newcastle upon Tyne: Cambridge Scolars, 2012. 51-60. Print.

Kuskin, Karla. "To Get a Little More of the Picture: Reviewing Picture Books." The Horn Book Magazine. 74.2 (March/April 1998): 159-165. Print.

Lackner, Eden Lee. '"Do You Dream of Heaven? Have You Wanted to Die?': The Perils of Childhood in Tim Burton's and Edward Gorey's Texts." The International Conference on the Fantastic in the Arts. Orlando Airport Marriott, Orlando, Florida. March 2013. Conference Presentation.

---. "A Monstrous Childhood: Edward Gorey's Influence on Tim Burton's The Melancholy Death of Oyster Boy." The Works of Tim Burton: Margins to Mainstream. Ed. Jeffrey Andrew Weinstock. New York: Palgrave Macmillan, 2013: 151-164. Print. Lauter, Paul and Richard Yarborough, eds. The Heath Anthology of American Literature: Volume E. Boston, Cengage Learning, 2013. Print.

Lear, Edward. The Dong with the Luminous Nose. Petaluma: Pomegranate, 2010. Print.

---. The Jumblies. Petaluma: Pomegranate, 2010. Print.

---. The Owl and the Pussycat. London: Puffin, 2014. Print.

Lemony Snicket's A Series of Unfortunate Events. Dir. Brad Silberling. Paramount, 2004. Film.

Lesnick, Silas. "Exclusive Interview: Neil Gaiman on Coraline." Collider.com. 1 February 2009. Web. 30 December 2014.

$<$ http $/ /$ collider.com/movie/article.asp/aid/10734/tcid/1>.

LeVostreGC. Gashelyecrumbe Worthyes. 22 February 2013. Web. 30 December 2014. $<$ https://storify.com/patashoqua/chaucer-s-gashlycrumb-tinies $>$. 
Llewellyn, Mark. "What Is Neo-Victorian Studies?" Neo-Victorian Studies. 1.1 (Autumn 2008): 164-185. Web. 30 December 2014. <http:/www.neovictorianstudies.com/>. Loesberg, Jonathan. "Dickensian Deformed Children and the Hegelian Sublime." Victorian Studies. 40.4 (Summer 1997): 625-654. Print.

Mackay, Catriona. The Hogwarts Tinies or, After the Rowling. N.d. Web. 30 December 2014. <http:/strangehours.com/portfolio/papergashlyindex.htm».

Magliozzi, Ron and Jenny He. Tim Burton. New York: The Museum of Modern Art, 2009. Print.

Manning, Kara M. '"That's the Effect of Living Backwards': Technological Change, Lewis Carroll's Alice Books, and Tim Burton's Alice in Wonderland." Neo-Victorian Studies. 4.2 (2011): 154-179. Web. 30 December 2014. $<$ http $/ /$ www.neovictorianstudies.com/ $>$.

Marciuliano, Francesco. "The Twenty-Seventh Gashlycrumb Tiny." Medium Large: In Honor of Edward Gorey's Birthday. 22 February 2013. Web. 30 December 2014. $<$ https://mediumlarge.wordpress.com/2013/02/22/in-honor-of-edward-goreys-birthday $>$.

Martel, Yann. Life of Pi. Boston: Mariner Books, 2003. Print.

McCloud, Scott. Understanding Comics: The Invisible Art. New York: William Morrow, 1994. Print.

McDermott, Kevin. Elephant House or, The Home of Edward Gorey. Petaluma: Pomegranate, 2003. Print.

McEwen, Neal. Q Signals - 1909: Taken Verbatim from Handbook for Wireless Telegraph Operators Working Installations Licensed by His Majesty's Postmaster-General. The Telegraph Office. 2004. Web. 30 December 2014. 
McGrath, Patrick and Bradford Morrow, eds. The Picador Book of the New Gothic. London: Picador, 1993. Print.

Miles, Robert. Gothic Writing, 1750-1820: A Genealogy. Manchester: Manchester University Press, 2002. Print.

MissingMistcaps. The Gashlycrumb Hobbit. 2012. Enhanced matte paper. Etsy. $<$ https://www.etsy.com/shop/MissingMistcaps/>.

Mnamon: Ancient writing systems in the Mediterranean: A critical guide to electronic resources. Scuola Normale Superiore Laboratorio di Scienze dell'Antichità sezione Informatica per le Lingue Antiche. 2014. Web. 30 December 2014. $<$ http $/ /$ lila.sns.it/mnamon/index.php?page=Esempi\&id=10\&lang=en $>$.

The Moonlight Ball. Animal Rescue League Benefit. Boston, 20 October 2007. Charity. $<$ http $/ /$ www.kambriel.com/moonlightball.htmp.

Moretti, Franco. "The Slaughterhouse of Literature." Modern Language Quarterly. 61.1 (March 2000): 207-227. Print.

Morgan, Jack. "Toward an Organic Theory of the Gothic: Conceptualizing Horror." Journal of Popular Culture. 32.3 (Winter 1998): 59-80. Print.

Nabokov, Vladimir. Lolita. New York: Vintage, 1989. Print.

Nel, Philip. 'Final Word: Gaiman and Grimly's The Dangerous Alphabet-Diverting, Deranged, De-Lovely." First Opinions, Second Reactions. 2.1 (2009): 48-52. Print.

The Nightmare Before Christmas. Dir. Henry Selick. Touchstone, 1993. Film.

Nine Inch Nails. "The Perfect Drug." Dir. Mark Romanek. Sony, 1997. Music Video. $<\mathrm{http} / /$ vimeo.com/3612941>.

Oblong, Angus. Creepy Susie and 13 Other Tragic Tales for Troubled Children. New York: Ballantine, 2004. Print. 
The Oblongs. The WB. Warner Bros., 2001-2002. Television.

Okada, Kazuya and Shuri Okano. "Rhyme Dictionary of Edward Gorey." Acquisition of the Faculty of Education Okayama University. 129 (2005): 103-15. Print.

Oliver, José and Bartolo Torres. El joven Lovecraft. Madrid: Diábolo Ediciones, 2010. Print.

Petzhold, Dieter. "Wish-fulfilment and Subversion: Roald Dahl's Dickensian Fantasy Matilda." Children's Literature in Education. 23.4 (1992): 185-193. Print.

Pietrandrea, David. Grimm: Ride of the Perambulator. Hoboken: ROBOX Studio, 2007. iOS Game.

Playdead. LIMBO. Copenhagen: Microsoft Studios, 2010. Video Game.

Pocock, Isaac. The Miller and his Men: A Melo-Drame, in Two Acts. London: British Library, 2011. Print.

Poe, Edgar Allan. The Complete Tales and Poems of Edgar Allan Poe. New York: Vintage, 1975. Print.

Punter, David. "Pity: Reflections on Algernon Blackwood's Gothic." English Language Notes. 48.1 (2010): 129-138. Print.

---. The Literature of Terror, Volume 2: A History of Gothic Fictions from 1765 to the Present Day. London: Routledge, 2014. Print.

Radcliffe, Ann. The Mysteries of Udolpho. London: Penguin, 2001. Print.

Reiger, Rob. Emily the Strange. Santa Cruz: Cosmic Debris, 1991. Print and Merchandise. Rodach, Michael. The Temperamental Wobble. The Snappy Dance Theater. Cutler Majestic Theatre, Boston. 4-5 June 2004. Performance.

Rose, Natalie. "Flogging and Fascination: Dickens and the Fragile Will." Victorian Studies. 47.4 (Summer 2005): 505-533. Print. 
Ross, Clifford and Karen Wilkin. The World of Edward Gorey. New York: Harry N. Abrams, 2002. Print.

Rusch, Mark T. "The Deranged Episode: Ironic Dissimulation in the Domestic Scenes of Edward Gorey's Short Stories." International Journal of Comic Art. 6.2 (Fall 2004): 445-455. Print.

Sayers, Dorothy L. Strong Poison. London: New English Library, 1968. Print.

Scarry, Richard. Richard Scarry's Find Your ABC's. New York: Sterling, 2009. Print.

Seuss, Dr. Dr. Seuss's ABC: An Amazing Alphabet Book! New York: Random House, 1996. Print.

---. If I Ran the Zoo. New York: Random House, 1950. Print.

Shelley, Mary. Frankenstein; or, The Modern Prometheus. Mineola: Dover, 1994. Print. Shklovsky, Viktor. Theory of Prose. London: Dalkey Archive Press, 2009. Print.

Shonkoff, Jack P. and Deborah A. Phillips, eds. From Neurons to Neighborhoods: The Science of Early Childhood Development. Washington: National Academy Press, 2002. Print.

Shortsleeve, Kevin. "Edward Gorey, Children's Literature, and Nonsense Verse." Children's Literature Association Quarterly. 27.1 (Spring 2002): 27-39. Print.

Smith, Jeff, Jessica Abel and Matt Madden, eds. The Best American Comics 2013. Boston: Houghton Mifflin Harcourt, 2013. Print.

Snicket, Lemony. A Series of Unfortunate Events: The Complete Wreck. New York: Harper Collins, 2006. Print.

Stabile, Susan M. "Still(ed) Lives." American Literary History. 22.2 (Summer 2010): 390-412. Print. 
Stallcup, Jackie E. "Power, Fear, and Children's Picture Books." Children's Literature. 30 (2002): 125-158. Print.

Stevens, Carol. "An American Original." Print. 42.1 (Jan.-Feb. 1988: Jan.-Feb.): N. pag. Print.

Stevenson, Robert Louis. A Child's Garden of Verses. New York: Simon \& Schuster, 1999. Print.

Stoker, Bram. Dracula. Mineola: Dover, 2000. Print.

Strauss, Bob. "Will it be Lemony enough?" The Globe and Mail. 14 December 2004. Web. 30 December 2014. $<$ http:/www.theglobeandmail.com/arts/will-it-be-lemony-enough/article1138790/>.

Stretton, Hesba. Jessica's First Prayer. New York: Lamplighter, 1997. Print.

Theroux, Alexander. The Strange Case of Edward Gorey. Seattle: Fantagraphics Books, 2000. Print.

The Tiger Lillies. The Gorey End. Toronto: EMI, 2003. CD.

Tigges, Wim. "The Limerick: The Sonnet of Nonsense?" Explorations in the Field of Nonsense. 62 (1987): 117-133. Print.

Twain, Mark. Adventures of Huckleberry Finn. New York: Charles L. Webster \& Company, 1885. Project Gutenberg. Web. 30 December 2014. EPUB file.

Twin Peaks. ABC. Lynch/Frost Productions, 1990-1991. Television.

Vasquez, Jhonen. Johnny the Homicidal Maniac: Director's Cut. San Jose: Slave Labor Graphics, 2010. Print.

---. I Feel Sick \#1 (A Book About A Girl). San Jose: Slave Labor Graphics, 2006. Print. ---. Squee's Wonderful Big Giant Book of Unspeakable Horrors. San Jose: Slave Labor Graphics, 1998. Print. 
Verburg, CJ. Edward Gorey On Stage: Playwright, Director, Designer, Performer: A Multimedia Memoir. N.p.: Boom-Books, 2012. Kindle file.

Wallace, David Rains. Beasts of Eden: Walking Whales, Dawn Horses, and Other Enigmas of Mammal Evolution. Oakland: UC Press, 2005. Print.

Walpole, Horace. The Castle of Otranto. Mineola: Dover, 2004. Print.

Weeks, Donald. "Portfolio: Edward Gorey." Maatstaf. 27.2 (1979): 32-48. Print.

Weinstock, Jeffrey Andrew. "Mainstream Outsider: Burton Adapts Burton." The Works of Tim Burton: Margins to Mainstream. New York: Palgrave Macmillan, 2013: 1-29. Print.

Wilde, Oscar. The Picture of Dorian Gray. Mineola: Dover, 1993. Print.

Wilkin, Karen, ed. Ascending Peculiarity: Edward Gorey on Edward Gorey. New York: Harcourt, 2001. Print.

Wilkin, Karen. Elegant Enigmas: The Art of Edward Gorey. Petaluma: Pomegranate, 2009. Print.

Wood, Ellen. East Lynne. Oxford: OUP, 2008. Print.

Wyeth, Andrew. Christina's World. 1948. Tempera on gesso. Museum of Modern Art, New York.

Wyke, Robert. "Dark Star." 21. Autumn 2009: 8-13. Print.

"Yokel Chords." The Simpsons. Fox. 4 March 2007. Television.

Zipes, Jack. "Why Fantasy Matters Too Much." CLCWeb: Comparative Literature and Culture. 10.4 (2008): 2-12. Web. 30 December 2014.

$<$ http $/ /$ docs.lib.purdue.edu/clcweb/vol10/iss $4 / 3>$. 